\title{
Thermal Performance Implications of a Housing Warrant of Fitness in New Zealand
}

Sara Wareing

A thesis submitted to Victoria University of Wellington in fulfilment of the requirements for the degree of Masters of Building Science

Victoria University of Wellington 



\section{Abstract}

A housing Warrant of Fitness (WoF) has been independently proposed by three organisations as a way of improving the quality of rental housing in New Zealand and reducing housing related injuries and health problems.

The New Zealand Green Building Council and the Housing and Health Research Programme (University of Otago, Wellington) have jointly developed a WoF based on Homestar and the Healthy Housing Index (labelled the GH WoF in this document).

Housing New Zealand is in the process of developing a WoF for their properties (HNZ WoF), it has been tested on a number of state houses but the results have not yet been fully released.

Both the GH WoF and the HNZ WoF target thermal and moisture performance amongst other minimum requirements for rental housing. The WoFs specify slightly different housing features as minimum acceptable standards. Both of the WoFs are structured as a checklist, with all items considered mandatory to pass the assessment.

This research investigated the impact of meeting the WoF criteria which impact thermal performance. A thermal model of a villa style house suitable for a family of 4 was modelled in the thermal simulation programme EnergyPlus with a minimum practicable level of thermal performance. A range of New Zealand input values were sought and a number of sensitivity analyses were carried out to validate the model's performance. Combinations of features each meeting the different criteria of the WoFs (such as insulation, ventilation and curtains) were then added to this house.

The results of these models demonstrated that while adding these features will improve thermal performance, a simple pass/fail may be misleading because a house which fails may have equivalent thermal performance to a house which passes.

The pass/fail result does not acknowledge trade-offs between temperature, energy consumption and running cost. Neither WoF accounts for the impact of climate on the ability to achieve comfortable indoor conditions, which has a greater impact than passing or failing a WoF.

The criteria targeted at moisture performance were unable to be analysed as the moisture loads put into EnergyPlus could not be adequately verified.

The research showed that while both WoF could lead to improved thermal comfort in rental housing, meeting the GH WoF requirements would bring about greater thermal performance benefits, the HNZ WoF enables the affordability of heat to be considered when insulating is not feasible. 


\section{Acknowledgements}

This work would not have been possible without the ongoing support of my supervisor Nigel Isaacs, not only throughout this year of research but from the time he first introduced me to 'real' research.

Thanks also to Michael Donn who was always eager to discuss research and new ideas.

In completing this work I have appreciated assistance from the Building Research Association of New Zealand (BRANZ) with financial support from the Building Research Levy.

Finally I would like to thank my family and friends for their support throughout this research, especially Sahib for his continued patience. 


\section{Contents}

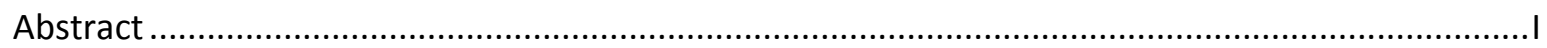

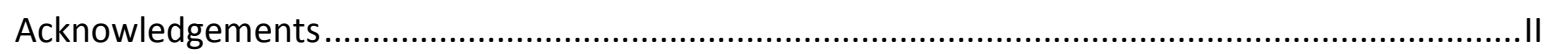

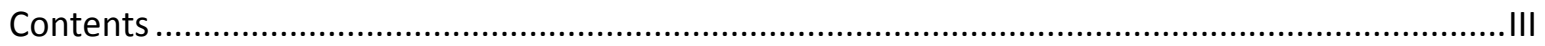

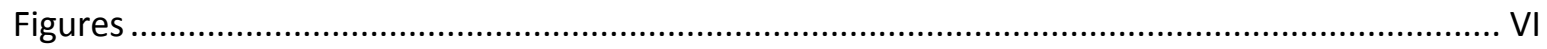

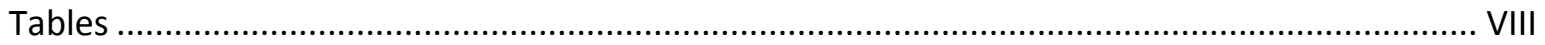

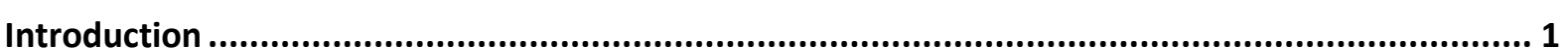

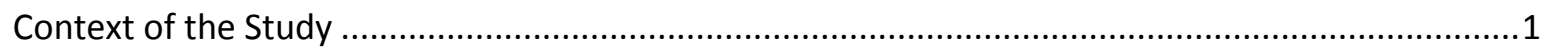

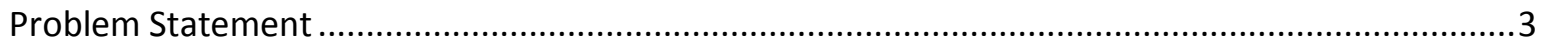

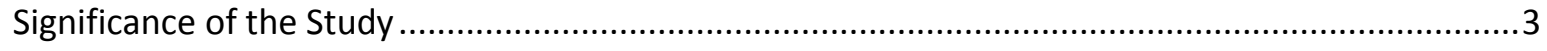

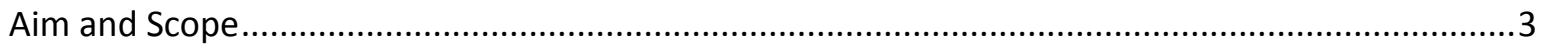

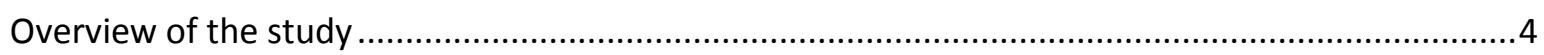

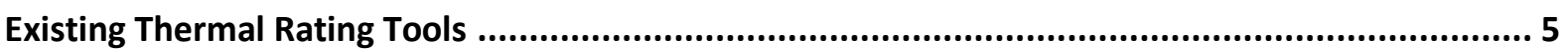

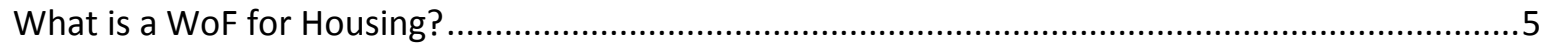

Rating tools available for evaluating the thermal performance and design of dwellings .................8

Evaluation Criteria for Rating Tools................................................................................. 12

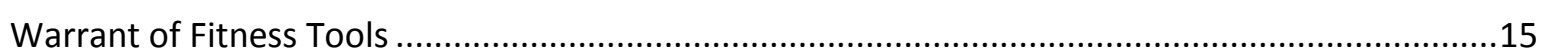

Overview of Tools Proposed for a Housing Warrant of Fitness ................................................ 16

Thermal Performance in the Proposed Warrants of Fitness ................................................. 16

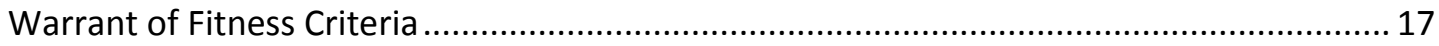

Discussion of the Benefits from a Warrant of Fitness.................................................................19

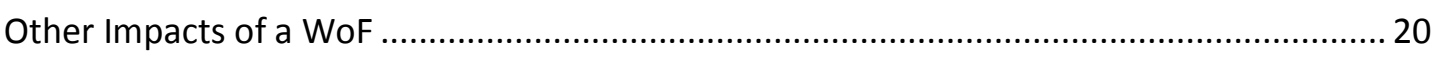

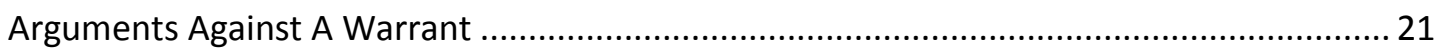

Different Standards for Rental Properties vs New Buildings ................................................ 22

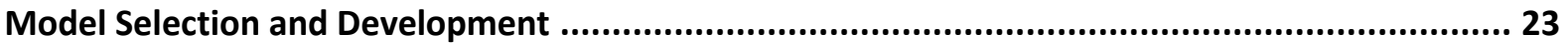

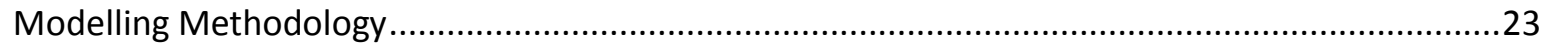

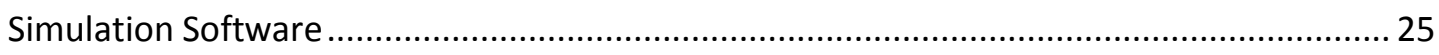

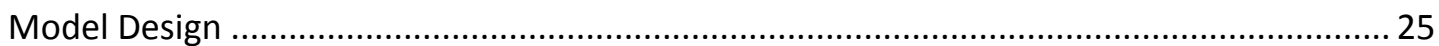

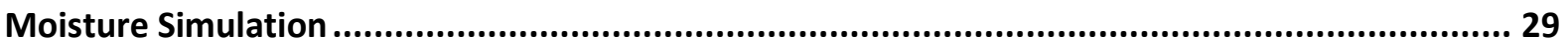

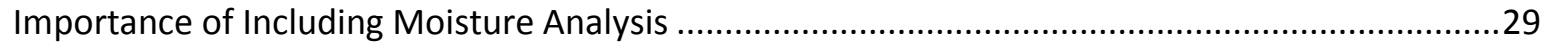

Expected Moisture Loads for Domestic Uses...................................................................... 29

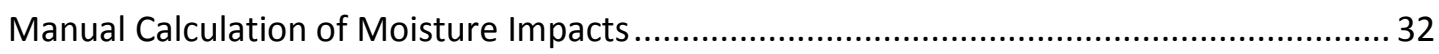

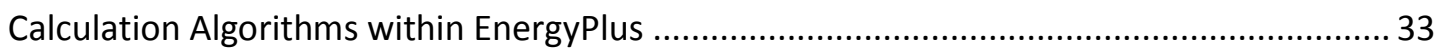

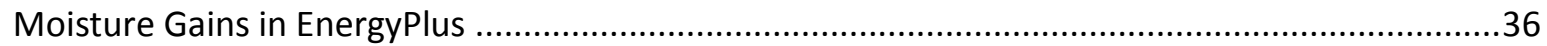

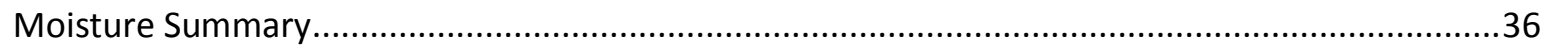

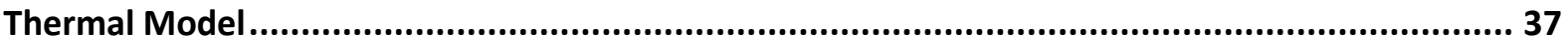

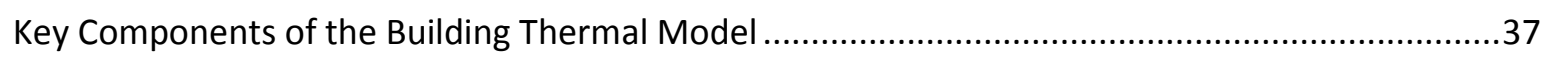

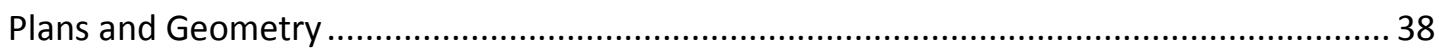


People

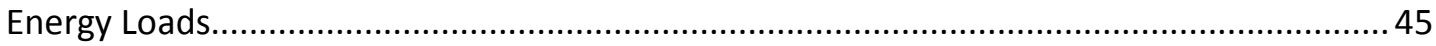

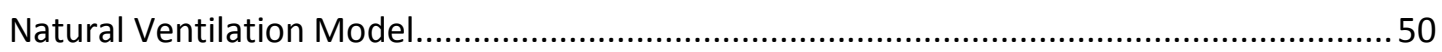

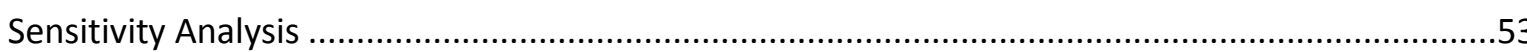

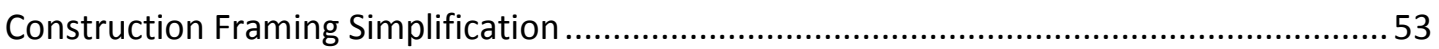

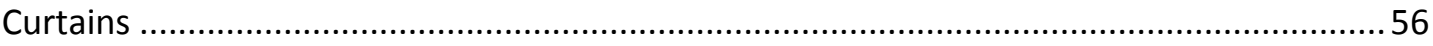

Impact of Load Profiles on Indoor Temperatures ..................................................5

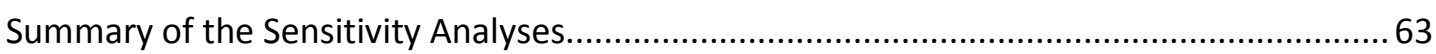

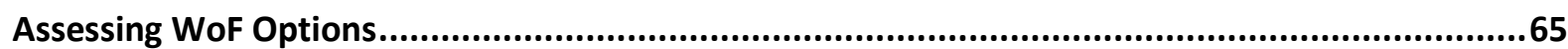

Simulating House Features to Pass/Fail the WoF............................................................65

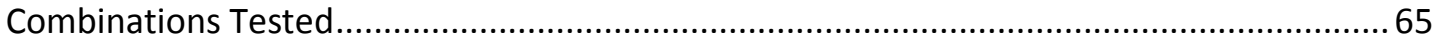

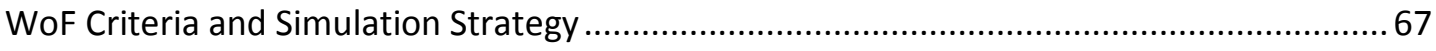

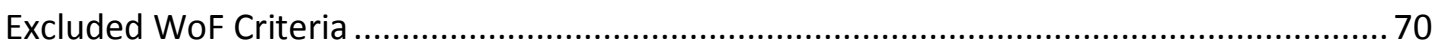

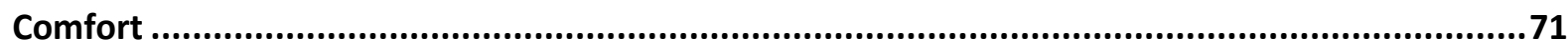

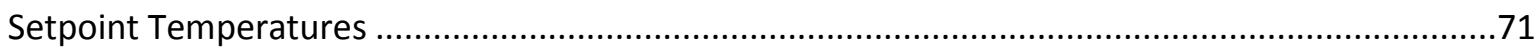

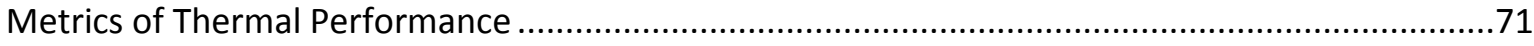

Running a Matrix of Simulations with EnergyPlus .....................................................73

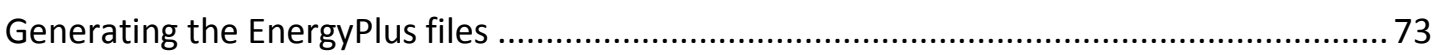

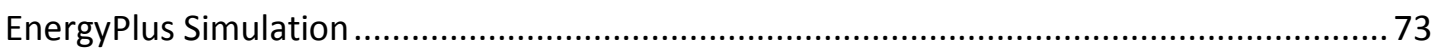

Reading the Results ..................................................................................... 74

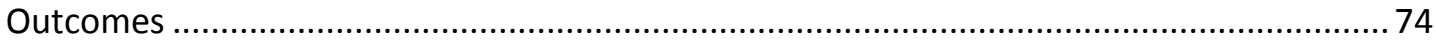

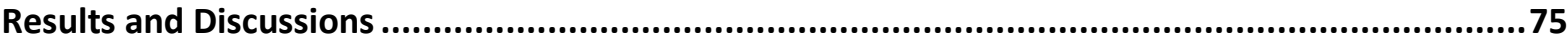

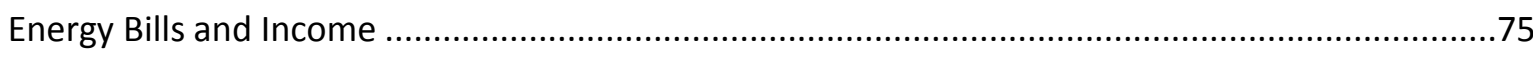

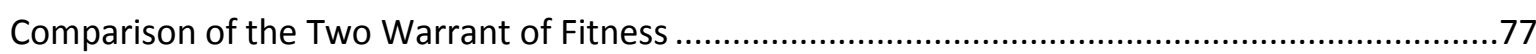

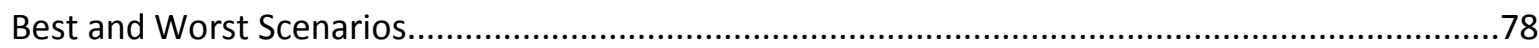

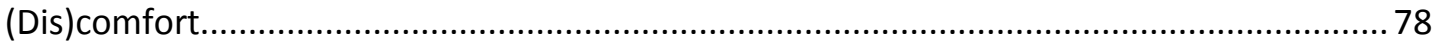

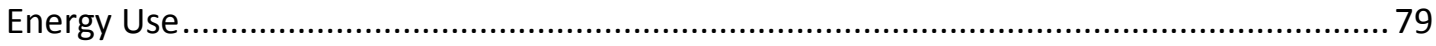

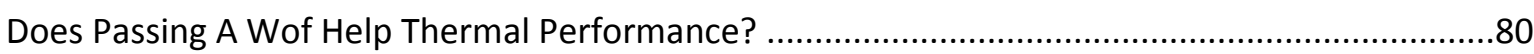

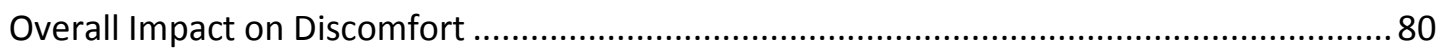

Overall Impact on Potential Energy Consumption ...................................................... 81

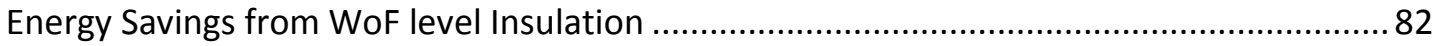

How Does a WoF Compliant House Compare to a New House ...............................................83

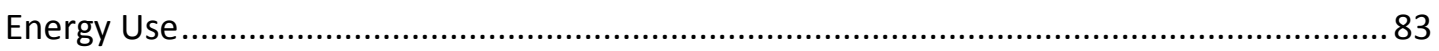

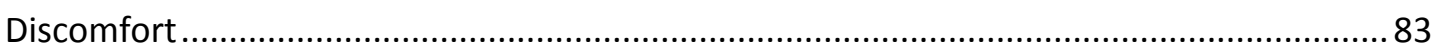

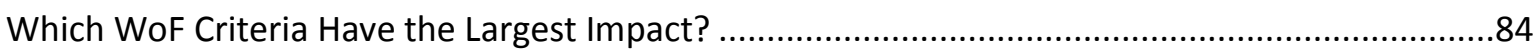

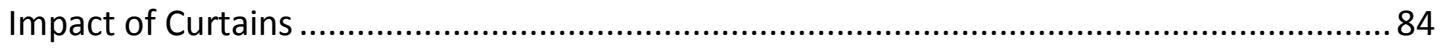

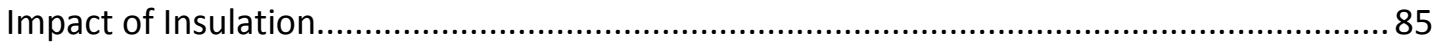

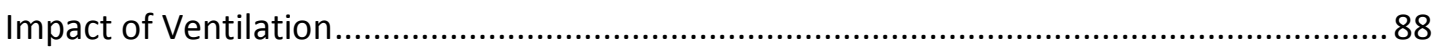




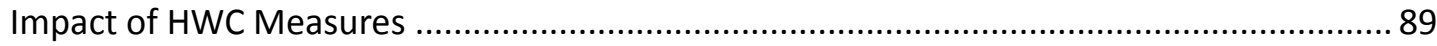

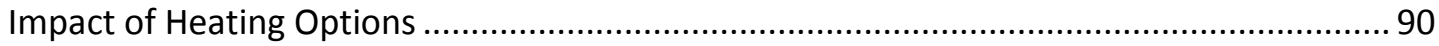

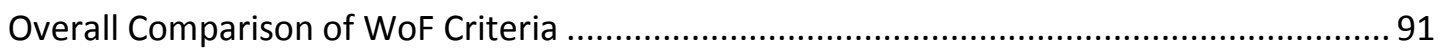

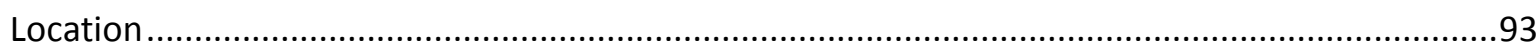

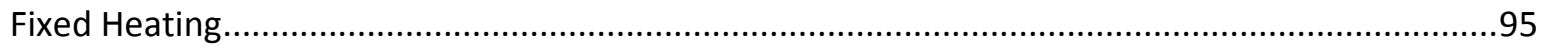

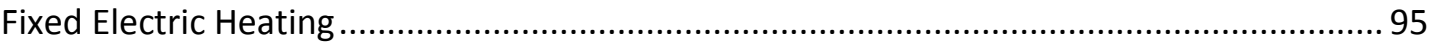

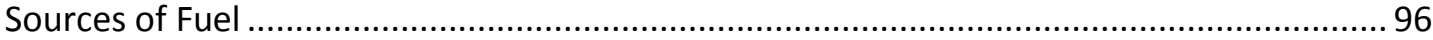

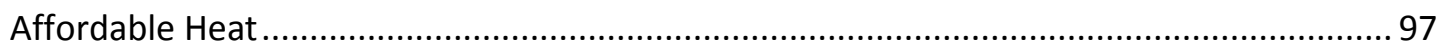

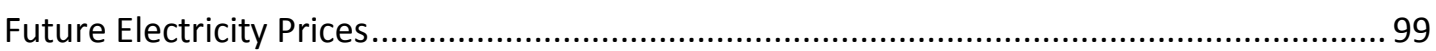

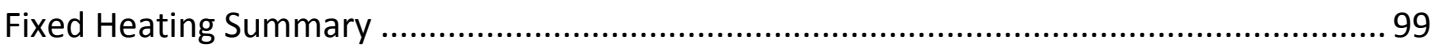

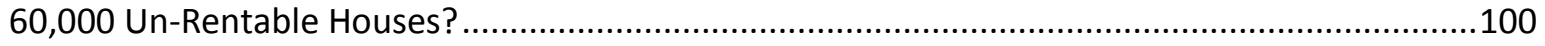

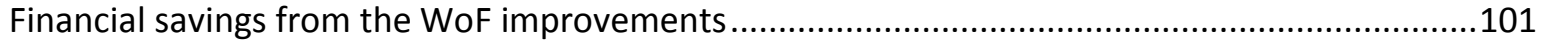

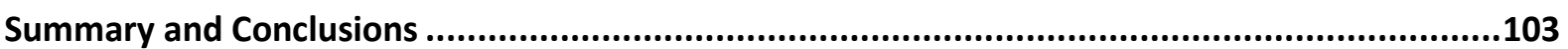

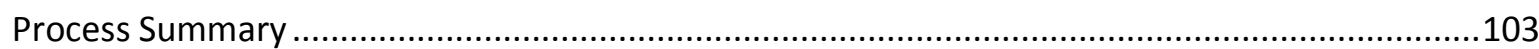

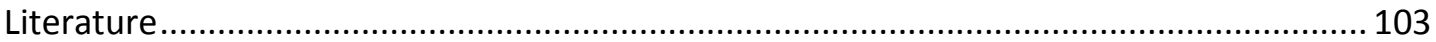

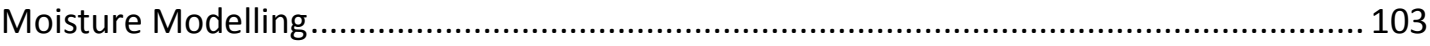

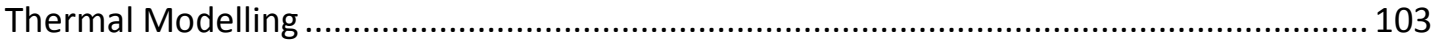

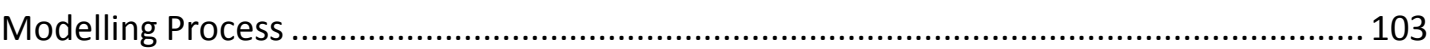

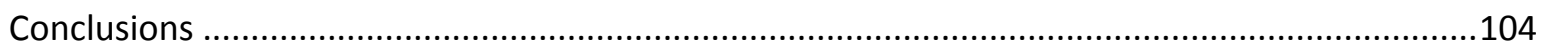

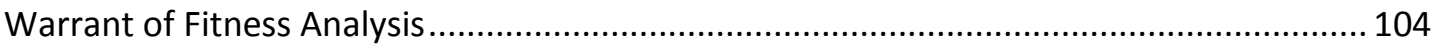

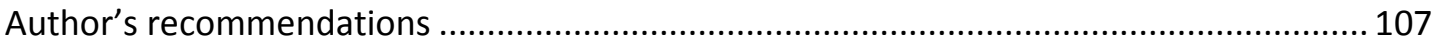

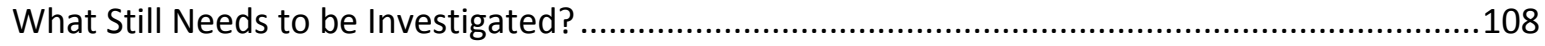

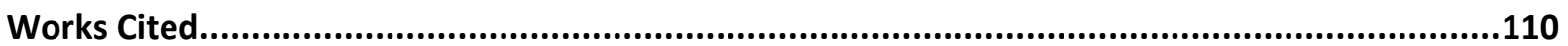

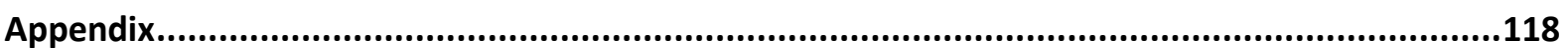

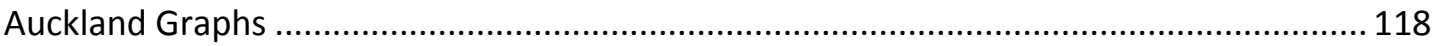

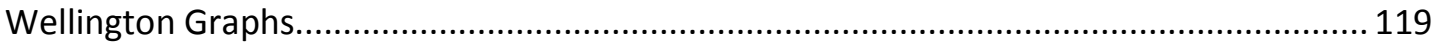

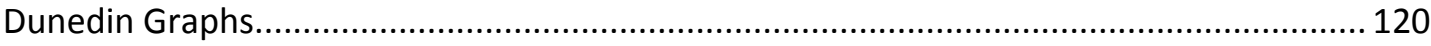

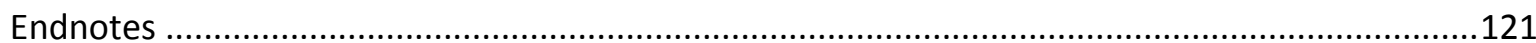




\section{Figures}

Figure 1: Possible changes in rental housing quality as a result of introducing a Mandatory WoF 6

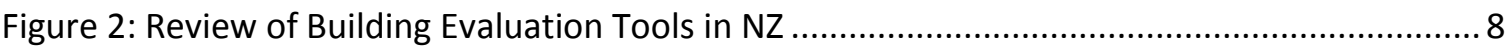

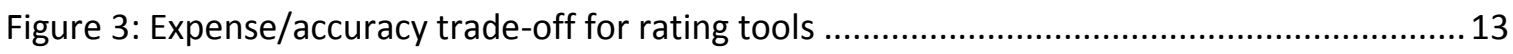

Figure 4: Case study performance compared to performance in rental accommodation .............24

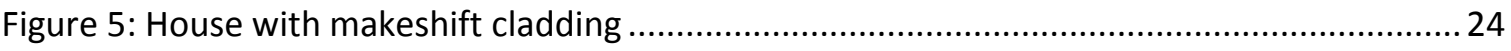

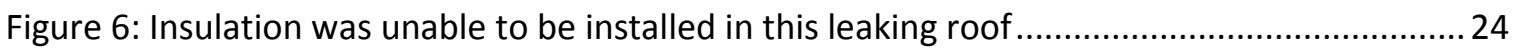

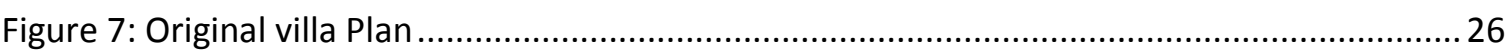

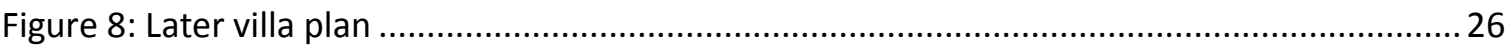

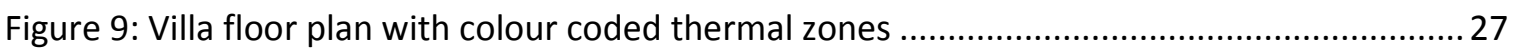

Figure 10: Relative humidity levels and associated micro-organisms/health problems ............... 29

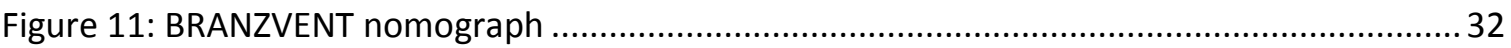

Figure 12: A comparison of the impacts of two calculation algorithms on relative humidity ........34

Figure 13: absolute humidity comparisons between four algorithms …................................... 35

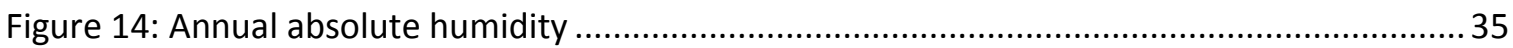

Figure 15: Filled out Other Equipment Object in EnergyPlus................................................... 36

Figure 16: Views of the EnergyPlus model in Sketchup. The orange line indicates North............ 38

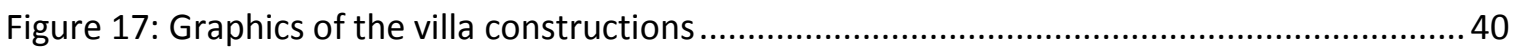

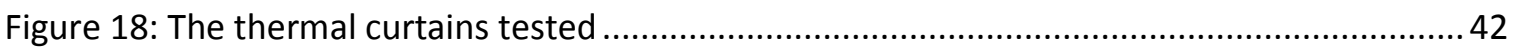

Figure 19: The occupant weekday schedule left and the weekend schedule right ........................4 44

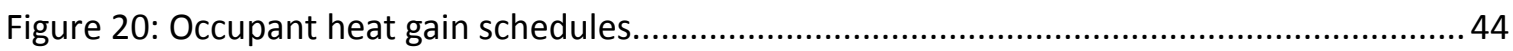

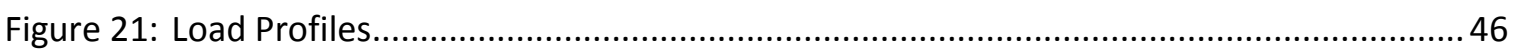

Figure 22: Running costs calculator for a washing machine provided by EECA............................ 46

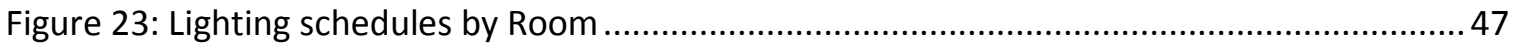

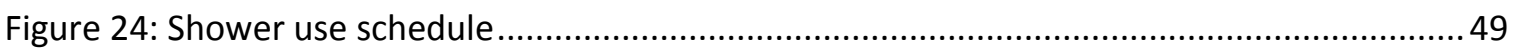

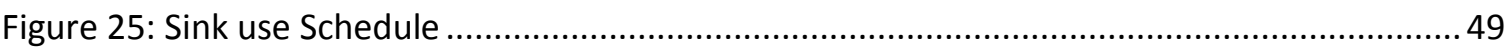

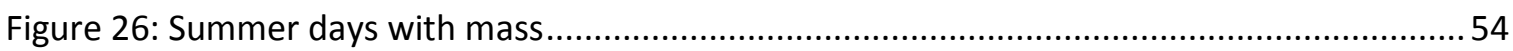

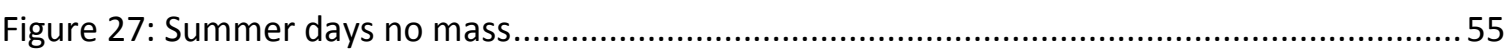

Figure 28: A curtain $80 \mathrm{~mm}$ from the window does little to reduce heat loss (even at R-3)..........56

Figure 29: Even R-0.05 curtains are helpful when hung as close to the window as possible .........57

Figure 30: Curtains provide a smaller reduction in heat loss when there is no heating.................57

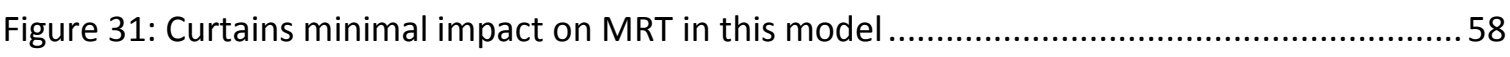

Figure 32: Curtains don't have a noticeable effect on air temperature .....................................58

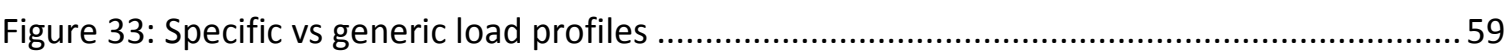

Figure 34: Bathroom operative temperature with and without internal loads .............................61

Figure 35: Comparison of HEEP and Building America single Load Profiles...................................62

Figure 36: Comparison of HEEP, Building America total Load Profiles and Model use .................62

Figure 37: Household Energy Expenditure in 2013 by Income Group ...................................... 75

Figure 38: A comparison of the impact of passing the GH WoF and the HNZ WoF........................ 77

Figure 39: Impact of number of GH WoF criteria failed on discomfort ........................................ 80

Figure 40: The number of GH WoF criteria failed and the impact on energy consumption...........81

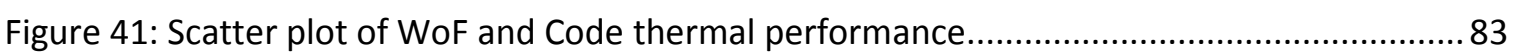

Figure 42: Impact of window treatment on discomfort with different heating options ................84

Figure 43: Impact of window treatment on heating energy with different heating options ........ 84 
Figure 44: Combinations of ceiling and underfloor insulation in Wellington ............................... 86

Figure 45: Combinations of ceiling and underfloor insulation in Wellington ............................... 87

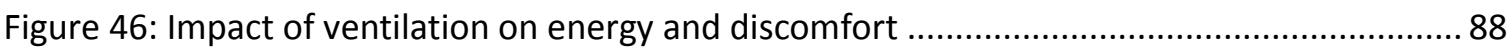

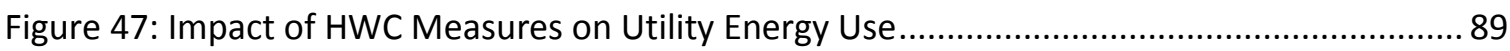

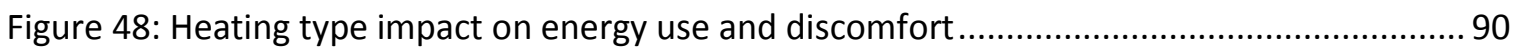

Figure 49: A comparison of the impact of the WoF Criteria across all scenarios .......................... 91

Figure 50: A comparison of thermal performance in Auckland and Dunedin ...............................93

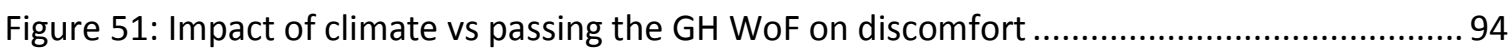



Figure 53: Consumer 2014 comparison of the cost of heating using different heating sources ... 96

Figure 54: Cost of heating with different heating types in Auckland..............................................97

Figure 55: Cost of heating with different heating types in Wellington........................................ 98

Figure 56: Cost of heating with different heating types in Dunedin .......................................... 98

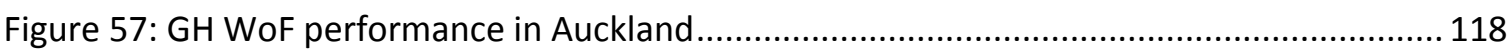

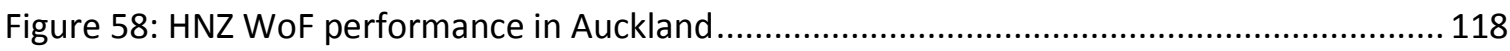

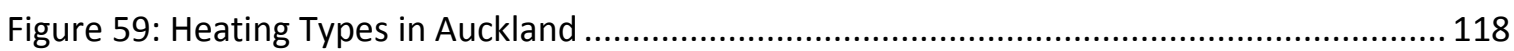

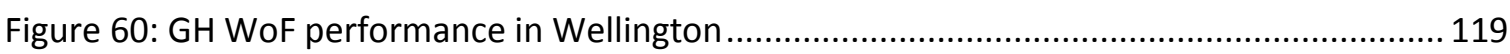

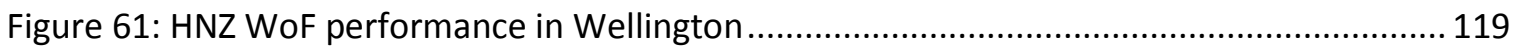

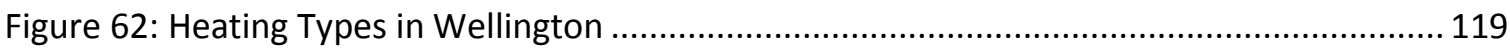

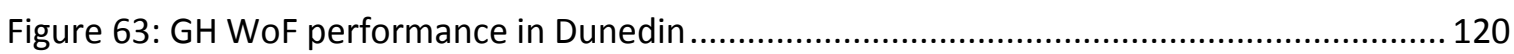

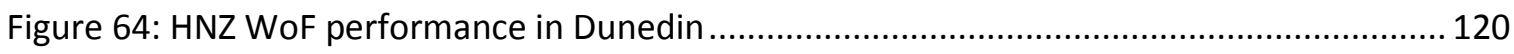

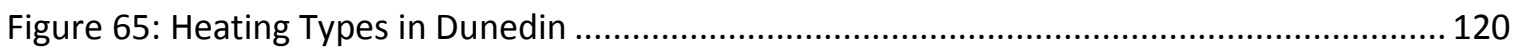




\section{Tables}

Table 1: Comparison of rating tools available for evaluating the performance of dwellings ........ 14

Table 2: Comparison of the two Warrant of Fitness Tools...................................................... 16

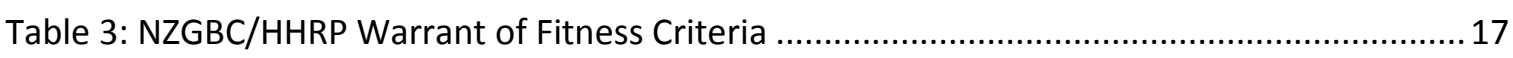

Table 4: Housing New Zealand Warrant of Fitness Criteria ..................................................... 18

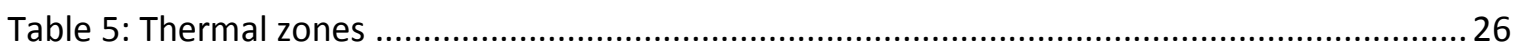

Table 6: A comparison of suggested moisture gains for domestic activities By Source ...............31

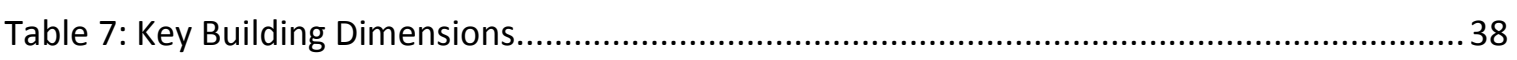

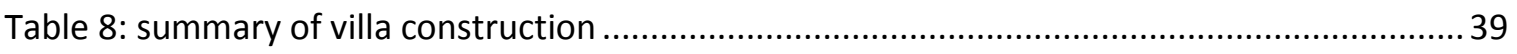

Table 9: Glazing U-Values and Corresponding EnergyPlus Inputs .........................................4 42

Table 10: Tested curtain R-values and corresponding curtain and window performance ............43

Table 11: Heat gains per person for different activities.....................................................4 44

Table 12: HEEP and EnergyPlus model electricity consumption ..............................................45

Table 13: Lighting Wattages for Modelling ...................................................................... 47

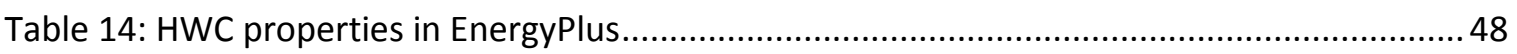

Table 15: Annual average infiltration rates in Wellington for each zone ..................................55

Table 16: Annual average infiltration rates in Christchurch for comparison to measured values 52

Table 17: Comparison of construction framing models .........................................................5.

Table 18: Temperature difference between specific internal loads and generic internal loads ...60

Table 19: Temperature increase through domestic internal loads..........................................6. 61

Table 20: Tested thermal performance criteria from both WoFs ..............................................66

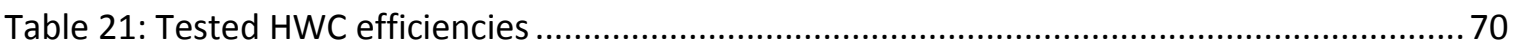

Table 22: WoF criteria targeted at moisture unable to be included ....................................... 70

Table 23: Heat consumption with different heaters and insulation levels ..................................8 82

Table 24: Discomfort score improvements by meeting NZBC requirements .............................83

Table 25: Heating with $2 \mathrm{~kW}$ electric heaters when passing and failing both WoFs .....................96 


\section{INTRODUCTION}

A Warrant of Fitness (WoF) has been proposed as a method of improving the overall quality of housing rented for profit. This thesis investigates the potential impacts a rental Warrant of Fitness could have on the thermal performance of New Zealand's housing.

\section{Context of the Study}

There is a general expert consensus that New Zealand has much substandard/inadequate housing and it is causing negative health and social impacts. The main concerns are coldness, dampness (which frequently results in mould) and poor maintenance.

A wide range of different organisations say New Zealand has a significant number of substandard houses:

- Building Research Association of New Zealand [1]

- Centre for Research, Evaluation and Social Assessment (CRESA) [2]

- Energy Efficiency \& Conservation Authority (EECA) [3]

- Beacon Pathway [4]

- New Zealand Green Building Council [5]

- He Kainga Oranga - Housing and Health Research Programme at Otago University (Wellington) [6]

- Expert Advisory Committee on Solutions to Child Poverty [7]

- New Zealand College of Public Health Medicine [8]

- Canterbury District Health Board [9]

- Auckland Regional Health Board [10]

These include organisations which specialise in health, medicine, energy efficiency, sustainability, construction and child poverty.

The most prominent concern is that substandard housing is associated with a number of health problems. Temperatures below $16^{\circ} \mathrm{C}$, particularly in the presence of high humidity, are associated with adverse health consequences [11].

Direct health effects of cold homes include [4], [12]:

- excess winter mortality from cardiovascular and respiratory disease amongst the elderly;

- increased respiratory problems in children;

- increased communicable illnesses such as colds and flu;

- mental health problems; and

- and the exacerbation of conditions such as arthritis.

Indirect effects include [4]:

- social isolation (e.g. reluctant to invite people around or go out because they do not want to come back to a cold house);

- inactivity (less moving around inside the home, staying in bed/under a blanket);

- lack of privacy within a household (everyone is staying in the 'warm' room);

- absences from school/work (due to illness or caregiver off work);

- increased health care costs; and

- reduced expenditure on food, clothes etc. due to high energy bills.

These health concerns are all linked to the quality of housing and therefore it is expected that improving New Zealand's housing can bring about improved health outcomes. 
The reasons behind our current housing problems have been said to be multifaceted including:

- historically low electricity prices meaning it was previously affordable to heat an uninsulated dwelling [13];

- increasing proportions of households renting with little control over thermal efficiency upgrades or modifications [14];

- split incentives between landlords and tenants for carrying out improvements and receiving the benefits [15];

- a lack of insulation required under previous building codes [16];

- the climate being perceived as mild [17];

- a cultural attitude towards heating primarily only one room [18].

This diversity of causes requires that any tool which aims to improve housing quality has to do so in a variety of ways in order to be successful.

There have already been a number of tools which have attempted to improve the quality of New Zealand's housing stock. The BRANZ Green Home Scheme was the first assessment tool to be launched in New Zealand in 1997 [19]. Since then others have included the Home Energy Rating Scheme (HERS) and Homestar [20], [21]. Even with these assessment tools, there has not been a significant improvement of older housing. The 'Warm Up New Zealand: Heat Smart' scheme provided subsidised insulation has insulated many houses (acting as an incentive rather than an evaluation tool), but these are predominately owner-occupied rather than rentals [22, p. 2].

Public interest in the idea of a 'housing Warrant of Fitness' has been growing since August 2012 when the Children's Commission published their Solutions to Child Poverty in New Zealand which included the recommendation that "every rental property (including state houses) should be subject to a 'Warrant of Fitness'" [7, p. x].

There is both strong interest and strong opposition to introducing some form of minimum standards for rental housing in New Zealand. When the research for this thesis started (May 2014), a parliamentary private member's bill, the "Healthy Homes Guarantee Bill" (sponsored by Labour Party MP Phil Twyford) was due to be debated. Ultimately, it failed to pass its first reading on the $18^{\text {th }}$ March 2015 with a vote of 60 to 60 (a majority of 61 is needed) with both National and ACT opposed [23].

Both MPs and the media were quick to take up the concept of likening the safety of our houses to the safety of our cars and promoting what are essentially minimum design/performance standards for buildings in-use. This concept has been simplified down in the media to a pass/fail idea as would be expected for a vehicle.

As with a car it is not just the owner which is affected by the quality of the dwelling but also tenants, visitors and the general public whose taxes cover publicly funded health and disability services (including ACC and hospital admissions [24]). Media coverage of the proposals has been wide ranging; from newspapers, to current affairs TV shows, to personal blogs. Opinions have been both positive and negative, with debate about the possible benefits and drawbacks such a scheme would bring.

High profile supporters of a Warrant of Fitness included Housing Minister Nick Smith, Social Development Minister Paula Bennett, Metiria Turei of the Green Party, Phil Twyford of Labour Party, Wellington's Mayor Celia Wade-Brown, the Green Building Council, the Housing and Health Research Programme at the University of Otago [25]-[27], [23], [28]-[31]. 


\section{Problem Statement}

When work on this thesis commenced there were two potential avenues for a Housing Warrant of Fitness to be introduced. One was being proposed by Housing New Zealand for state housing and the other was in the Healthy Homes Guarantee Bill which proposed to set minimum standards of heating and insulation for residential premises. Despite the Healthy Housing Guarantee Bill not being passed, a Warrant of Fitness may yet be introduced for social housing in response to Housing New Zealand's trials.

Housing New Zealand carried out a trial on 500 state houses during 2014, although much of the information gathered has not been made public. A spokesperson from the Ministry of Business Innovation and Employment (MBIE) confirmed in May 2015 that this is because the two proposed implementation approaches (a pass/fail rating and a star rating) still "remain under active consideration" [32]. It appears possible that Housing New Zealand may yet introduce one of these proposals as a Warrant of Fitness, and documents released under an Official Information Act request suggest it may be able to be extended further than Housing New Zealand should Cabinet choose to do so [33].

The Auckland, Tauranga, Wellington, Christchurch and Dunedin City Councils also trialled another Warrant of Fitness on 125 dwellings in 2014. This Warrant of fitness was designed by the New Zealand Green Building Council and the Healthy Housing Research Programme (HHRP) [5]. The results from this trial have already been released and well covered by the media [28], [29], [34].

Both of these possible Warrant of Fitness tools are still under development and so far little is known about how these would be able to influence thermal performance.

\section{Significance of the Study}

Some of New Zealand's housing, both rental and private, is considered by many people to be in poor condition [1]. A Warrant of Fitness for rental housing is currently being proposed as a means of improving the housing stock and alleviating housing related health problems and injuries.

If a Housing Warrant of Fitness (WoF) is introduced, it is critical that the assessment criteria bring about the intended benefits. This thesis aims to support the preliminary investigations by investigating the proposed WoF criteria relating to thermal performance (both directly and indirectly) through thermal simulation of a case study dwelling. This will make it possible to analyse the benefits to thermal performance through meeting the proposed WoF criteria.

\section{Aim and Scope}

Aim: To test whether the two proposed Housing WoF tools are an effective way of measuring the thermal performance of New Zealand housing.

The scope has been constrained to the thermal performance aspects to enable the research to be carried out within the time constraints of a Master of Building Science thesis. The full WoF criteria cover a wide range of issues including safety, thermal performance, moisture sources, maintenance and essential amenities. 


\section{Overview of the study}

This thesis is divided into nine sections, as listed below:

\section{LITERATURE REVIEW}

This section provides an overview of the tools available and previously used in New Zealand for assessing the thermal performance of residential properties. It evaluates these tools against five criteria, illustrating the varying levels of suitability for assessing minimum performance standards for residential dwellings.

The two Warrant of Fitness tools are introduced and compared to these evaluation criteria. Some background on the development of these tools is provided and the thermal criteria are compared.

\section{MODEL SELECTION AND DEVELOPMENT}

The selection of the house design to be used to test the impact of the thermal WoF criteria is described, along with the selected house plan, basic features and the selection of the simulation tool.

\section{MOISTURE MODELLING}

This section investigates the possibility of combining moisture and thermal modelling to measure the broader benefits of the proposed WoF criteria. It investigates the benefits of adding this analysis to thermal simulations and the data available on moisture loads from domestic activities. Two methods of moisture analysis are investigated, the hand calculation method from BRANZVENT and moisture calculation models combined with thermal simulation.

\section{THERMAL MODEL DESIGN}

The design of the initial thermal house model, representing the lower end of New Zealand housing thermal performance is covered along with the model features, sources for simulation inputs and modelling tips for modellers wishing to explore similar issues.

\section{THERMAL MODEL SENSITIVITY ANALYSIS AND VALIDATION}

A number of sensitivity analyses were carried out to test the impact of the features of the house model and simulation assumptions on thermal performance. This was an iterative process carried out alongside the thermal model design.

\section{SIMULATION APPROACH}

This section covers the design and simulation of a matrix of house models to test a wide range of possible combinations of building features.

\section{RESULTS AND DISCUSSION}

This section looks at results from across the range of thermal models and uses these to provide insight into what impacts a WoF may have on thermal performance. It also contains discussions on the benefits and impacts a Housing Warrant of Fitness may cause.

\section{CONCLUSIONS}

The key findings and lessons learned about the housing WoFs and their impacts on thermal performance are provided. 


\section{EXISTING THERMAL RATING TOOLS}

This section investigates the tools already available for assessing thermal performance and compares these to the requirements of a WoF style tool.

\section{What is a WoF for Housing?}

The New Zealand Transport Agency defines a (vehicle) Warrant of Fitness as "a regular check that your vehicle meets required safety standards, at the time of inspection" [35]. When this definition is applied to housing, it suggests a pass/fail assessment that determines whether or not a home meets key safety standards. In a vehicle WoF there is no flexibility in the outcome of the assessment. You either receive a WoF or have to fix any safety related problems before receiving it.

A housing Warrant of Fitness would have to take a somewhat more flexible approach, as houses are not built to such standardised designs as vehicles, nor are subjected to such a range of mandatory minimum safety standards, nor to formal performance testing. Possible assessment criteria, such as the presence of insulation, can be difficult to determine depending on the construction types. A housing Warrant of Fitness would not be the same type of tool as a vehicle Warrant of Fitness, but it would perform a similar function, setting minimum performance requirements that have to be reviewed regularly to ensure the safety of both the users and general public.

A housing Warrant of Fitness would have to assess the presence/absence of features rather than run tests to ensure the house was functioning as intended. These would indicate the dwelling can be lived in, in a safe and healthy manner, but it must be recognised that occupant(s) operation could have a significant effect [36], [37].

The fundamental idea behind a WoF style house assessment is to increase the range and coverage of the minimum standards a rental dwelling must meet. Currently the local council is only required to intervene and insist on remediation when a building is considered dangerous, earthquake-prone or insanitary. The threshold for a building meeting these criteria is very high, "likely to cause injury or death" in the ordinary course of events [38]. A mandatory Warrant of Fitness would also prevent a dwelling deemed sub-standard by a council from being rented again to new tennants until the required issues are resolved. Currently, if a tenancy is terminated because of the inadequate quality of the dwelling, there is no requirement for the landlord to remediate the property before putting it up for rent again [15, p. 10]. Indicators of how energy efficient a home will be (such as insulation, efficient heating and water efficient appliances) are not always visible in pre-rental inspections or advertising photos. Mandatory publishing of this information would also help with market recognition for these features.

Figure 1 illustrates how the overall quality of rental housing could change if new minimum performance standards above a threshold were introduced. By introducing a new minimum mandatory performance standard above the point when the council classifies the house as dangerous or insanitary, dwellings will either be upgraded or fall out of the rental market. Depending on where this new threshold is placed, it is expected the majority of dwellings below 
the threshold would be upgraded to meet the new minimum performance required, while the very worst would no-longer be rented due to the cost of upgrading.

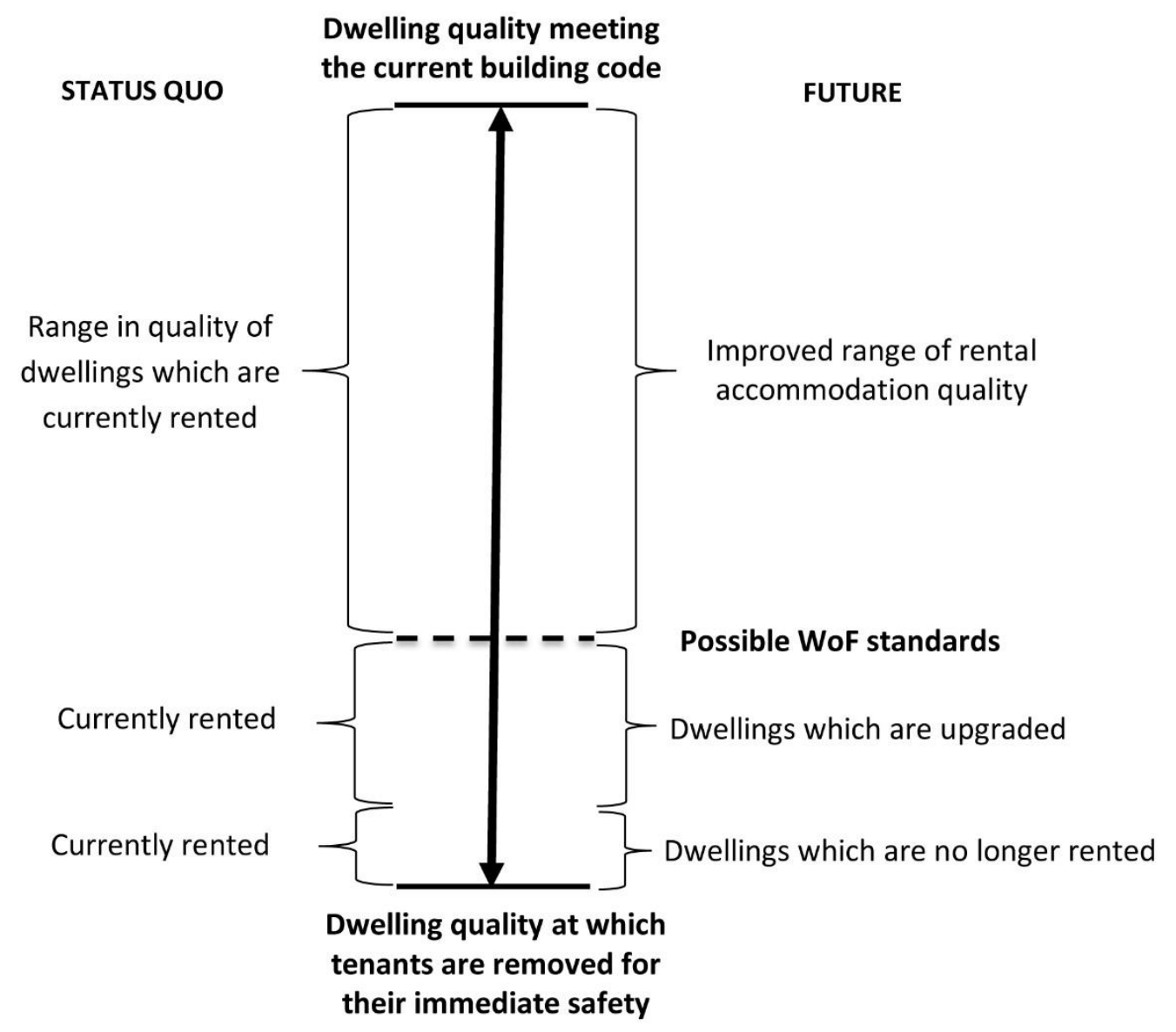

FIGURE 1: POSSIBLE CHANGES IN RENTAL HOUSING QUALITY AS A RESULT OF INTRODUCING A MANDATORY WOF

The reasons for proposing minimum standards for rental properties are primarily public health benefits with some expected energy savings. The focus is on rental properties because a growing proportion of New Zealanders are renting rather than buying their own home [39, p. 37], [40]. Additionally low-income households are more likely to live in rental housing [41, p. 132]. There is currently little incentive for either landlords or tenants to upgrade the performance of a rental property because one does not see the reduced operating costs and the other does not have the security to see energy efficiencies beyond the end of the rental agreement.

The public health benefits are expected to be reduced mortality and reduced hospitalisation for housing related illness (including circulatory illnesses and respiratory illness, such as asthma) [42, p. 8]. Households which currently don't heat to temperatures they find comfortable may not see any energy savings as they may achieve higher temperatures and hence greater comfort and consequently health savings. Households which already heat to temperatures they find comfortable would be expected to make energy savings with the introduction of insulation.

Financial benefits to the country are expected in the form of reduced hospitalisation costs, reduced pharmaceutical costs and the value of increased life-years from an overall reduction in mortality. These expected benefits are based on analysis of the impact of the Warm Up NZ: Heat 
Smart programme which shows they were due to primarily the retrofitting of insulation with a small contribution from clean efficient heat sources $[42$, p. 9].

A WoF also works towards addressing the issue of social equity. Low-income tenants who rent the cheapest, poorly insulated dwellings have to pay more to achieve the same amount of warmth as someone who is able to afford to rent a more expensive and more energy efficient dwelling. A WoF requiring minimum levels of thermal performance would theoretically reduce this gap. Addressing inadequate housing is also part of the proposed solution to the social problem of child poverty [7], [43].

However opponents to the use of a Warrant of Fitness point out that it may cause problems with the availability of affordable housing [34], [44]-[46]. A compulsory WoF could pose a threat to these tenants only able to afford housing at the lowest end of the quality spectrum. If these dwellings are no longer rented because the cost of remediating them is too high or the rent rises to cover upgrades, then it is argued that the most vulnerable may be unable to find rental accommodation.

Thermal performance is obviously a key part of any list of minimum standards due to the expected benefits. Existing research indicates these benefits are most likely to come from adequate insulation levels rather than increasing the efficiency of a dwelling's heating source [42]. However, thermal performance is only one aspect of what makes a 'good' dwelling and there are many more criteria which could require more urgent attention to make housing safe and healthy.

Internationally the risks to occupants caused by living in a particular dwelling have been measured across a wide range of criteria. The UK Housing Health and Safety Rating System (HHSRS) evaluates 29 criteria across four key areas; physiological requirements, psychological requirements, protection against infection and protection against accidents [47]. The USA Housing-based Hazard Index (also abbreviated to HHI but different from the NZ tool) evaluates dwellings on 71 criteria across eight key areas; structure, moisture/mould, electrical, ventilation \& combustion appliances, pests, pets, fire and lifestyle factors [48].

HHSRS appears to be the only tool which sets limits to unacceptable performance. If any category 1 hazards are present (i.e. any hazard likely to cause death, permanent paralysis below the neck, malignant lung tumour, regular severe pneumonia, permanent loss of consciousness, or $80 \%$ burn injuries), then the dwelling fails. If this happens local authorities have multiple options to carry out repairs, with increasing levels of intervention depending on the nature of the hazard. Removing tenants is not the first level of response [49].

New Zealand research indicates a significant financial benefit to the nation from the reduction in injuries caused by safety hazards in the home, similar to the types of injuries targeted by the HHSRS [50]. The number of deaths from home injuries is higher than the road toll, further reinforcing the idea that our houses need to have minimum standards in the same way that our cars do.

Considering all the above issues, the question then arises of what criteria should be assessed to ensure a dwelling achieves suitable minimum standards (limited to thermal performance for the scope of this thesis) across a wide range of possible housing designs, and what tool can be used to assess these? 


\section{Rating tools available for evaluating the thermal performance and design of dwellings}

A literature review has been carried out of the existing New Zealand residential dwelling rating tools to evaluate their suitability for a WoF type assessment. Figure 2 illustrates how these were identified. The use of these building rating tools has always been voluntary while a Warrant of Fitness is mandatory, so a degree of adaptation for any selected tool WoF would be required. Any selected rating tool would have to be applicable to residential buildings of all possible forms, e.g. detached houses, town houses, apartments etc.

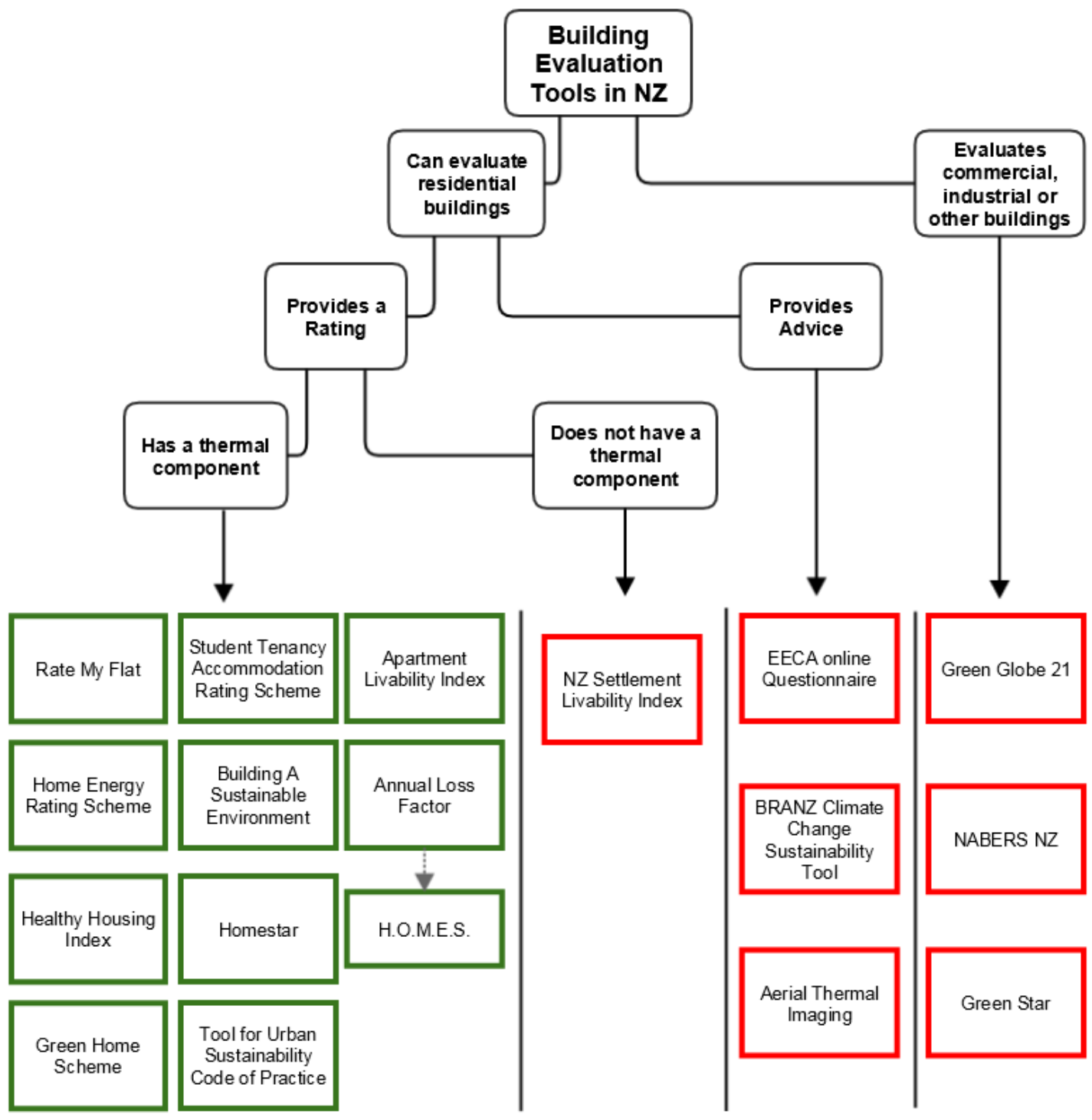

FIGURE 2: REVIEW OF BUILDING EVALUATION TOOLS IN NZ

The follow sections examine these various rating tools. Each section covers who developed the tool, key features of the tool, what the tool measures and whether or not it is still in active use. 


\section{BRANZ Green Home Scheme}

The Green Home Scheme (GHS) was launched by BRANZ in 1997 and was New Zealand's first residential building rating tool (and also the first formal building rating tool). The assessment covered a number of categories including energy use, lighting systems, indoor pollutants, use of recycled materials, waste disposal methods and storage of hazardous materials. These categories were weighted to provide the final score which was presented as Fair, Good, Very Good or Excellent. To get a rating an accredited assessor was required to examine the plans submitted for building consent. Credits were calculated manually, either by determining the presence of items or hand calculation of the thermal performance of the building based on element areas and construction R-values. [51]

The GHS was retired to coincide with the launch of Homestar in November 2010. A lack of marketing and finding hand calculations too laborious seem to be two reasons for the low uptake of the tool, and Homestar was seen to provide better international alignment [19].

\section{Home Energy Rating Scheme}

The Home Energy Rating Scheme (HERS) was an attempt to implement the Australian tool NatHERS in New Zealand. NatHERS has been successfully implemented in Australia, with a rating mandatory for new domestic dwellings. The star rating is gained by achieving a particular energy consumption per floor area which is normalised by the severity of the climate [52]. This allows comparisons across Australia's wide variety of climates. In Australian Capital Territory a rating is also required to be displayed when a dwelling is sold or leased [52]. HERS (and NatHERS) use the simulation tool AccuRate to model a household's likely energy consumption based on the building fabric, heating types (space heating and water heating), climate and occupancy. A whole-house rating (1-10 stars) is then calculated from this information. Individual heating and hot water ratings are also provided. HERS does not appear to consider any other energy uses such as lighting or appliances beyond the basic internal energy loads for a pre-set use. A HERS rating was required to be provided by a trained assessor due to the complexity of the tool. The use of HERS was discontinued in New Zealand in November 2010 [53]-[56].

\section{Homestar}

Homestar was launched in November 2010 and in some ways can be thought of as an improved amalgamation of the Green Home Scheme and HERS. It provides a more automated form of calculation than GHS and less complexity and less time required for assessment than HERS. It was intended to overcome shortcomings of both tools.

Homestar uses 52 questions to measure the performance of a dwelling in terms of health \& comfort, site, management, energy, water and waste. It awards the home a rating from 1 to 10 stars [20]. Homestar provides an online assessment tool where anyone can enter information about their home to get an indicative rating but a certified rating can only be obtained by using a Homestar Assessor. The scheme is run by the New Zealand Green Building Council (NZGBC).

\section{Healthy Housing Index}

The Healthy Housing Index (HHI) is a currently primarily academic tool, developed by researchers at the University of Otago and the Building Research Association of New Zealand (BRANZ), to measure the performance of a dwelling in terms of health and safety. The HHI was first trailed in 2002 and has been in its current format since 2007 [57]. It includes criteria related to structural soundness, adequate services, warmth and dryness, safety and protection from external hazards. 
Assessment must be carried out by a trained building professional [57]. There does not currently appear to be a definite final output such as the other tools provide, however a rating style assessment and a pass/fail style assessment are reportedly under development [58, p. 5]. Currently the main benefits of the tool appear to be identifying problems and bringing them to the notice of the occupants/owners through informal communication. The HHI has been used to undertake a number of studies identifying trends based on risk factors and demographics.

\section{Building a Sustainable Environment}

Building a Sustainable Environment (BASE) is a green building assessment tool specifically for Christchurch, initially proposed in September 2011. It is intended to help lift the quality of buildings above the New Zealand Building Code (NZBC) when much of the city is being rebuilt following the September 2011 earthquake. It only applies to new buildings and is targeted at larger scale buildings with mechanical services including commercial office space, multi-storey residential spaces, retail spaces and mixed-use buildings.

The assessment of a BASE rating appears to rely entirely on signed statements and reports from senior project members with professional qualifications known as "BASE Declarations". There does not appear to be a requirement for the NZGBC (as the developers and operators of BASE) to view the constructed building or even the plans. [59]

\section{Apartment Liveability Index}

The Apartment Liveability Index is a rating tool developed as part of a Master of Building Science thesis (Bennett 2010) to evaluate the living conditions in apartments. The goal of the tool is to ensure the importance of health and liveability issues (including the thermal and acoustic environment) do not go unnoticed by prospective apartment occupants. It was designed to evaluate and compare apartment liveability over a wide range of indicators, not just those which are easily visible.

There are six assessment criteria which evaluate thermal comfort, which contribute up to $7.51 \%$ of the overall apartment weighted score. There is one question each on moisture/mould/dampness, humidity, sunlight/orientation, cooling control, heating control and R-values of constructions. [60], [61]

\section{Student Tenancy Accommodation Rating Scheme}

The Student Tenancy Accommodation Rating Scheme (STARS) is a rating scheme for Dunedin student accommodation, managed by the Otago University Accommodation Office. The private landlord completes an online questionnaire covering building features which affect fire safety, security, insulation, and heating and ventilation. There are a total of 32 questions across these areas with yes/no responses for all but the insulation levels, which have 4-5 graduated responses. Results rely on the honesty of the landlord but a selection of properties are independently audited by the STARS team annually. The site is for the use of students from the University of Otago and Otago Polytechnic. [62]

\section{Rate My Flat}

Rate My Flat is another online Dunedin student accommodation rating tool. It is a direct response to the landlord driven nature of the STARS rating tool. Rate My Flat gives the tenants an opportunity to also rate the accommodation they live in. The tenants are able to rate their flat from 1 to 5 on 13 criteria, including the price of the flat, landlord responsiveness, warmth, 
amount of sun, mould, draughts, acoustic performance and shower pressure. There are also comment boxes provided for general information which is published with the overall ratings. The site was launched in September 2014 and quickly received 1,000 ratings from past and present student flats. The ratings are available online for use when students are considering a prospective flat, and landlords can advertise a property is available for rent directly on the site. [63]

\section{Tool for Urban Sustainability Code of Practice}

The Tool for Urban Sustainability Code of Practice (TUSC) is a web based sustainability assessment and education tool which was implemented by Waitakere City Council with support from the Ministry for the Environment. TUSC appears to have been retired after the amalgamation of the Auckland Regional Council and the district councils including Waitakere City Council.

TUSC was available for use for free online so prospective developers could explore its features and the impact of design decisions on sustainability. The main driver behind the uptake of TUSC was that the property owners were able to get a rates remission. This was based on the sustainability of their development and was awarded when they completed a TUSC assessment with their building or resource consent application.

TUSC measured sustainability in terms of improvement over an average 2004 dwelling. The categories were energy, water, stormwater, wastewater, transport efficiency and ecology diversity. The rating tool is a questionnaire with responses either as yes/no checkboxes or multiple choice. The webpage was still available in July 2014, but appears to have since been taken down.

TUSC was primarily intended for new developments, however existing homeowners could still use the tool to evaluate the sustainability of their home as options below current NZBC were included in the multiple choice questions. [64], [65]

\section{Annual Loss Factor}

The Annual Loss Factor Tool (ALF, currently version 3.2) has been developed by BRANZ to aid in the thermal design of houses. It can also calculate the Building Performance Index which can be used to demonstrate compliance with the energy efficiency clause of the New Zealand Building Code.

A high level of information about the building is required to use this tool. Users must enter information on climate (location); heating; thermal mass; ventilation as well as wall, roof, floor and window areas, perimeters and constructions. With this information ALF then provides an estimate of the heat loss through each element of the building envelope, the heat losses through ventilation, the gains from internal loads and the windows and therefore how much heating would be required for your chosen heating schedule and temperature. As well as the pass/fail building performance index, ALF provides information on house energy consumption which reflects both the efficiencies and demands. [66] 


\section{Evaluation Criteria for Rating Tools}

While reviewing literature available on housing rating tools, a number of key categories became apparent which differentiate the current rating tools. By identifying these, it was also possible to identify what combination of responses would be required from a Warrant of Fitness. The following sections provide a brief overview of the categories/classifications. Table 1 at the end of this section summarises how the tools align with the rating criteria.

Although not available at the start of this thesis indicated, later information showed this was the approach taken by Housing New Zealand (HNZ), although their analysis has not yet been made public. Housing New Zealand also analysed a range of options including their own Property Quality Index (not publicly available), Lifetime Design (a concept rather than a specific tool) and The Housing Improvement Regulations 1947.

\section{Dwelling types}

This category covers the types of housing that are able to be assessed. For a Warrant of Fitness to be able to be widely used it is important that all types of dwellings can be assessed, not just the most common detached house. The Green Home Scheme was notable for only really being applicable to detached houses, which would be partly explained by the housing market when the tool was developed, but also in rating houses a green section was seen as a key component.

This is an area where the current WoF tools do not work well. Because of their pass/fail approach to ceiling and underfloor insulation, many do not include an additional response for multi storey buildings e.g. only STARS has an option for another storey above or below.

\section{Energy/Health/Sustainability}

This category is for the main intent of the tool. Three categories have been developed based on the reviewed New Zealand and international literature. These categories can and do overlap (particularly in the case of sustainability), and other categories may be required for other rating tools not covered here. However, many of the tools studied tend towards one focus:

Energy = building skin and services used.

Health ( $\&$ safety) = people who will use the building.

Sustainability = includes a wide range of criteria, including categories which are for the good of the environment (e.g. water use, recycling, planting native plants) rather than directly for the benefit of the occupants.

\section{Pass/Fail vs Scale}

This category covers the type of rating each tool provides. The key idea behind a Warrant of Fitness is that there is a minimum pass standard required of a dwelling. Energy rating tools generally use a scalar rating, where all from the very worst to the very best are rated in a way which reflects their performance, while green building rating tools usually have some kind of rating to show how good a building is but don't award any certification below a certain level of performance.

Health and safety focussed tools tend to present their results as an index of risk to the occupants in different areas, with some setting a threshold for when that risk becomes unacceptable. 
Generally scoring ranges from a low score represents low risk to a high score representing high risk.

\section{New/Existing}

This covers whether the tool can rate new buildings (i.e. design tool) or existing buildings (i.e. performance evaluation tool) or whether it evaluates both. A Warrant of Fitness has to be applicable to existing buildings but may also indicate if a new building will comply even if it does not have to be certified e.g. not built for rental. Many green building rating tools focus on new buildings, because that is where larger impacts can be made. Energy rating tools tend to be applicable to both new and existing, while health based tools tend to be focused on existing dwellings because that is where they can achieve their greatest impact.

\section{Assessment Method}

This field covers what method of assessment each tool uses. The methods of assessing buildings for rating tools fall into 5 main categories (modified from [48, p. 5243]).

1. Questionnaire or self audit

2. Visual Inspection by trained assessor

3. Environmental measurements

4. Simulation or complex calculation

5. Collection of biological samples from occupants or dwelling

They each experience a trade-off between increasing expense and increasing accuracy (

figure 3). Current rating tools available in New Zealand only cover the first 4 approaches.

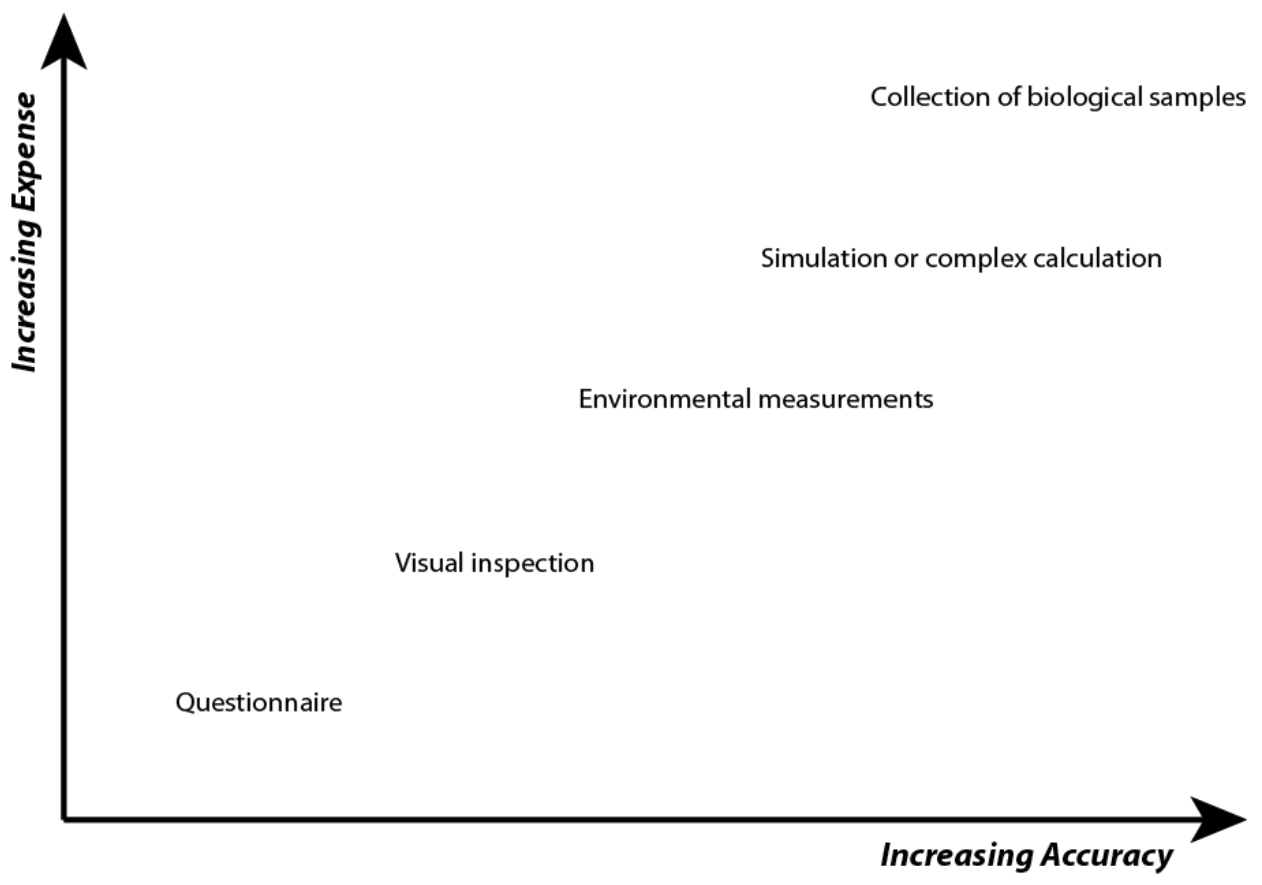

FIGURE 3: EXPENSE/ACCURACY TRADE-OFF FOR RATING TOOLS

Table 1 summarises how each of the investigated rating tools meet these evaluation criteria. 


\begin{tabular}{|c|c|c|c|c|c|c|}
\hline Tool & Publisher & $\begin{array}{l}\text { Dwelling } \\
\text { Types }\end{array}$ & $\begin{array}{l}\text { Pass/Fail vs } \\
\text { Scale }\end{array}$ & $\begin{array}{l}\text { New/ } \\
\text { Existing }\end{array}$ & $\begin{array}{l}\text { Energy/Health } \\
\text { / } \\
\text { Sustainability }\end{array}$ & $\begin{array}{l}\text { Assessment } \\
\text { Method }\end{array}$ \\
\hline Homestar & $\begin{array}{l}\text { Green } \\
\text { Building } \\
\text { Council }\end{array}$ & $\begin{array}{l}\text { Primarily targeted } \\
\text { at houses but no } \\
\text { limitations for } \\
\text { other dwellings }\end{array}$ & 1-10 Scale & Both & Sustainability & $\begin{array}{l}\text { Questionnaire. Visual } \\
\text { Inspection for } \\
\text { certified rating }\end{array}$ \\
\hline $\mathrm{HHI}$ & $\begin{array}{l}\text { University of } \\
\text { Otago. In } \\
\text { development }\end{array}$ & $\begin{array}{l}\text { All residential } \\
\text { dwellings }\end{array}$ & Not yet developed & Existing & Health & $\begin{array}{l}\text { Visual inspection + } \\
\text { Environmental } \\
\text { measurements }\end{array}$ \\
\hline BASE & $\begin{array}{l}\text { Green } \\
\text { Building } \\
\text { Council }\end{array}$ & $\begin{array}{l}\text { Apartment } \\
\text { buildings (multi } \\
\text { storey residential } \\
\text { buildings) }\end{array}$ & $\begin{array}{l}\text { Appears to be Pass } \\
\text { Fail }\end{array}$ & New & Sustainability & $\begin{array}{l}\text { Signed statements of } \\
\text { compliance }\end{array}$ \\
\hline HERS & $\begin{array}{l}\text { EECA } \\
\text { Obsolete }\end{array}$ & Any dwellings & $0.5-6$ scale & Both & Energy & Simulation \\
\hline STARS & $\begin{array}{l}\text { University of } \\
\text { Otago, Otago } \\
\text { Polytech and } \\
\text { Dunedin City } \\
\text { Council }\end{array}$ & $\begin{array}{l}\text { Student } \\
\text { accommodation }\end{array}$ & 1-5 for 3 categories & Existing & Health \& Safety & Questionnaire \\
\hline Rate My Flat & Liveable & $\begin{array}{l}\text { Student } \\
\text { accommodation in } \\
\text { Dunedin }\end{array}$ & $\begin{array}{l}1-5 \text { scale for } 4 \\
\text { categories }\end{array}$ & Existing & $\begin{array}{l}\text { Health \& level of } \\
\text { amenity }\end{array}$ & Questionnaire \\
\hline TUSC & $\begin{array}{l}\text { Waitakere } \\
\text { Council } \\
\text { Retired }\end{array}$ & $\begin{array}{l}\text { Residential } \\
\text { buildings }\end{array}$ & $\begin{array}{l}\text { \% improvement over } \\
\text { an average } 2004 \\
\text { dwelling for } 6 \\
\text { categories }\end{array}$ & $\begin{array}{l}\text { New } \\
\text { (can } \\
\text { informally } \\
\text { rate } \\
\text { existing) }\end{array}$ & Sustainability & $\begin{array}{l}\text { Questionnaire. Visual } \\
\text { Inspection for } \\
\text { certified rating }\end{array}$ \\
\hline $\begin{array}{l}\text { Green Home } \\
\text { Scheme }\end{array}$ & $\begin{array}{l}\text { BRANZ } \\
\text { Obsolete }\end{array}$ & $\begin{array}{l}\text { New residential } \\
\text { dwellings } \\
\text { (Detached and } \\
\text { semi-detached } \\
\text { dwellings only) }\end{array}$ & $\begin{array}{l}\text { Weighted credits. } \\
\text { Fair, Good, Very } \\
\text { Good and Excellent } \\
\text { overall rating }\end{array}$ & $\begin{array}{l}\text { New (or } \\
\text { recently } \\
\text { completed) }\end{array}$ & $\begin{array}{l}\text { Sustainability and } \\
\text { safety }\end{array}$ & $\begin{array}{l}\text { Questionnaire. Visual } \\
\text { Inspection and } \\
\text { calculation for } \\
\text { certified rating }\end{array}$ \\
\hline $\begin{array}{l}\text { Apartment } \\
\text { Liveability } \\
\text { Index }\end{array}$ & $\begin{array}{l}\text { Jessica } \\
\text { Bennett } \\
\text { Thesis only }\end{array}$ & Apartments & $\begin{array}{l}\text { Total weighted \% } \\
\text { rating and weighted } \\
\% \text { ratings for } 5 \\
\text { categories }\end{array}$ & Existing & Liveability & Questionnaire \\
\hline ALF & BRANZ & Detached houses & $\begin{array}{l}\text { Building } \\
\text { performance index } \\
\text { score and pass/fail } \\
\text { for NZBC min. } \\
\text { requirements }\end{array}$ & Both & Energy & $\begin{array}{l}\text { Questionnaire which } \\
\text { determines } \\
\text { mathematical inputs } \\
\text { for calculations }\end{array}$ \\
\hline
\end{tabular}

None of these existing rating tools would appear to be suitable for use as a Warrant of Fitness as they currently are structured:

BASE is only applicable to a very small proportion of residential constructions, multi-dwelling residential buildings over 3 storeys. Because its assessment criteria target mechanical heating, ventilation and air-conditioning systems it is not applicable to most of New Zealand's housing stock. 
Rate My Flat targets its questions at subjectively rating consequences (Is there mould? Is it cold?) rather the than causes. It is expected that a WoF will go beyond identifying negative impacts of housing quality to identifying whether there are features which would cause these negative impacts. It could be argued that shower pressure is also not a critical area for minimum performance standards.

The standards set by TUSC are well beyond even the current NZBC, the majority of its criteria are aimed at encouraging superior quality dwellings. Issues relating to minimum performance of a dwelling would require some scales (such as levels of insulation) to have significantly more resolution at the lower performing end of the scale.

Apartment Liveability Index targets many apartment specific issues rather than issues relevant to all kinds of housing.

HERS and Green Home Scheme have been retired due to a lack of success, presumably caused by the calculations being too complex and the difficulties of a manual rating tool. The successful components of each tool have been incorporated into Homestar.

Annual Loss Factor tool provides a good understanding of the thermal performance of a detached dwelling but it requires a high level of knowledge about the building's construction(s) and also some knowledge about how the occupants operate it. It provides a key metric of performance in the Building Performance Index and translates that to a pass/fail rating, however currently the standards are set to meet the NZBC. ALF only assesses thermal and moisture performance. It does not consider other aspects such as safety and amenity which appear equally important for minimum standards in rental housing. In order to adapt ALF into a Warrant of Fitness assessment, a minimum permissible Building Performance Index would need to be established.

It would therefore appear that Homestar, the Healthy Housing Index or STARS have the most potential to be adapted to become a WoF. STARS has a number of criteria which are specifically targeted at a student lifestyle although it does a good job of highlighting whether a building has key design features ranging from essential (e.g. smoke alarms) to desirable (e.g. solar panels).

\section{Warrant of Fitness Tools}

Initially it was expected that a WoF tool would be based primarily on tools already in use ('no new tools approach' [67]) so there would be no need for the difficult process of researching, developing, testing and educating people on a new tool. As the research into these tools demonstrates, none of the pre-existing tools were completely suitable for a WoF. Housing New Zealand also found the current range of publically available tools inadequate for a WoF style assessment, causing them to begin development of a tool for their properties. [33]

In 2013, the NZGBC proposed to use Homestar, with the pass threshold set at a three star rating [67]. This was intended to convey the idea that the WoF standards were low and left much room for improvement. This would have removed the need for developing a new tool. The HHI was also proposed as a WoF [58], [68], although in its original format it has numerous assessment criteria (37 pages) making it complex to assess. In 2014 Homestar and HHI were combined and refined to form a new tool, simply presented as the Housing Warrant of Fitness [69]. 


\section{Overview of Tools Proposed for a Housing Warrant of Fitness}

Currently there are two draft proposals for a Warrant of Fitness, one by Housing New Zealand (HNZ) [70], [71] and the other a joint effort between the New Zealand Green Building Council and He Kainga Oranga/Housing and Health Research Programme (HHRP) [6]. For clarity these will be referred to as the HNZ WoF and the GH WoF (Green-Housing).

Both of these WoFs have the same intent of establishing minimum acceptable standards for housing, but the items in a building they assess (and the way they measure them) differ. The HNZ WoF is longer with 48 questions compared to 31 in the GH WoF. The extra questions in the HNZ WoF focus on whether adequate power points are provided around the house, the presence of vermin, presence of doors, whether the building Warrant of Fitness ${ }^{1}$ is current and whether stoves are prevented from tipping.

The main difference in the thermal criteria between the tools is that the GH WoF requires a fixed form of heating for every dwelling while the HNZ WoF considers a power point for a heater in the living room adequate, unless insulation is unable to be installed in both the ceiling and under the floor.

Table 2 compares the proposed warrant tools using the same evaluation criteria as table 1 . Based on these criteria, both these tools meet the key requirements for being able to assess a WoF across all housing types. Both chose to do the assessment in a checklist manner to reduce time and cost. (A checklist falls somewhere between a questionnaire and a visual inspection in terms of expense and accuracy (figure 3)).

\begin{tabular}{|l|l|l|l|l|l|l|}
\hline \multicolumn{2}{|l|}{ TABLE 2: COMPARISON OF THE TWO WARRANT OF FITNESS TOoLS } \\
\hline Tool & Publisher & Dwelling Types & $\begin{array}{l}\text { Pass/Fail vs } \\
\text { Scale }\end{array}$ & $\begin{array}{l}\text { New/ } \\
\text { Existing }\end{array}$ & $\begin{array}{l}\text { Energy/Health/ } \\
\text { Sustainability }\end{array}$ & $\begin{array}{l}\text { Assessment } \\
\text { Method }\end{array}$ \\
\hline GH WoF & $\begin{array}{l}\text { NZGBC } \\
\text { HHRP }\end{array}$ & $\begin{array}{l}\text { All residential } \\
\text { dwellings }\end{array}$ & $\begin{array}{l}\text { Pass/fail for each } \\
\text { criteria and the } \\
\text { WoF overall } \\
\text { Or a star rating }\end{array}$ & Existing & Health \& Safety & Checklist \\
\hline HNZ WoF & HNZ & $\begin{array}{l}\text { Specifically for state } \\
\text { housing but designed } \\
\text { to be applicable to all } \\
\text { residential dwellings }\end{array}$ & $\begin{array}{l}\text { Pass/fail for each } \\
\text { criteria and the } \\
\text { WoF overall } \\
\text { Or a star rating }\end{array}$ & Existing & Health \& Safety & Checklist \\
\hline
\end{tabular}

\section{Thermal Performance in the Proposed Warrants of Fitness}

There are 5 criteria in the GH WoF and 5 in the HNZ WoF that evaluate thermal performance. However, when considering all criteria that would indirectly be involved in a thermal simulation

\footnotetext{
${ }^{1} \mathrm{~A}$ building Warrant of Fitness (required under the NZBC) is not to be confused with the new proposals for a housing Warrant of Fitness. "A building Warrant of Fitness is a statement supplied by a building owner, confirming that the systems specified in the compliance schedule for their building have been maintained and checked in accordance with the compliance schedule for the previous 12 months, and that they will continue to perform as required." [72]
} 
there are 8-11 and 11-15 criteria in each tool respectively. (The variation is due to the range of complexity possible in a model, as some simulation tools allow more complexity than others.)

Both of these New Zealand developed WoF tools use a checklist indicating whether or not items and conditions are present in a dwelling. By meeting all of the items on the checklist it is expected that the dwelling will be reasonably fit for human habitation and will therefore pass its Warrant of Fitness. However currently there is no identified relationship between meeting the specific criteria of a warrant and adequate thermal performance.

\section{Warrant of Fitness Criteria}

The sections below outline all of the proposed criteria in the GH WoF [6, pp. 86-104] and the HNZ WoF [71] respectively. The tables are colour coded to indicate which criteria are able to be analysed through thermal simulation (green) or inform a simulation (grey).

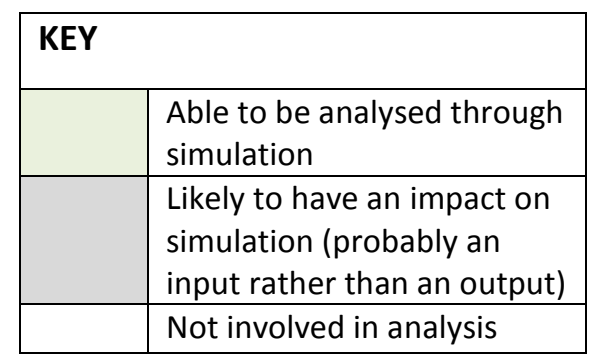

\begin{tabular}{|c|c|}
\hline 1 & Is there a functional, safe stove-top and oven? \\
\hline 2 & Is there adequate space for food preparation and storage? \\
\hline 3 & Is there an adequate supply of hot and cold potable water? \\
\hline 4 & Is the hot-water at the $\operatorname{tap} 55^{\circ} \mathrm{C}\left( \pm 5^{\circ} \mathrm{C} ?\right)$ \\
\hline 5 & Is there a functional toilet, which does not have a cracked or broken seat, cistern or bowl? (Yes/no) \\
\hline 6 & Is there a suitably located bath or shower in good working order? \\
\hline 7 & $\begin{array}{l}\text { Are there secure or high level cupboards or shelves for storing hazardous or toxic substances out of } \\
\text { children's reach? }\end{array}$ \\
\hline 8 & Is there a fixed form of safe and effective space heating? \\
\hline 9 & Do the bathroom, kitchen and all bedrooms have some form of ventilation to outside? \\
\hline 10 & $\begin{array}{l}\text { Is the house reasonably free of visible mould, i.e. the total area of mould is less than an A4 sheet of } \\
\text { paper? }\end{array}$ \\
\hline 11 & Are the power outlets and light switches safe and in good working order? \\
\hline 12 & Is there adequate indoor lighting? \\
\hline 13 & Does the house have adequate working smoke alarms? \\
\hline 14 & Have the windows got effective latches \\
\hline 15 & Have high windows got security stays? \\
\hline 16 & Are there curtains or blinds in the bedrooms and living area? \\
\hline 17 & Do glass doors have safety visibility strips? \\
\hline 18 & Does the house have thermoplastic insulated cabling? \\
\hline 19 & Does the house have ceiling insulation to WoF standards? \\
\hline 20 & Does the house have underfloor insulation to WoF standards? \\
\hline 21 & Is the house weathertight with no evident leaks, or moisture stains on the walls or ceiling? \\
\hline 22 & Is a ground vapour barrier installed under the ground floor? \\
\hline 23 & Is the house in a reasonable state of repair? \\
\hline 24 & Is the storm and waste water drainage being adequately discharged? \\
\hline 25 & Is there any water ponding under the house? \\
\hline 26 & Is there adequate outdoor lighting near entrance ways? \\
\hline 27 & Does the house appear to be structurally sound? \\
\hline 28 & $\begin{array}{l}\text { Are there handrails for all internal stairs and all outdoor steps that access the house, and do } \\
\text { balconies/decks have balustrades to the current Building Code? }\end{array}$ \\
\hline 29 & Is there fire egress to the current Building Code? \\
\hline 30 & Is the address clearly labelled and identifiable? \\
\hline 31 & Are there securely locking doors? \\
\hline
\end{tabular}




\begin{tabular}{|c|c|}
\hline \multicolumn{2}{|c|}{ TABLE 4: Housing NeW ZEALAND WARRANT OF FITNESS CRITERIA } \\
\hline & Insulated and Dry \\
\hline $1-4$ & $\begin{array}{l}\text { Living Room, bedrooms, kitchens \& laundries can be ventilated by accessible opening } \\
\text { window/s, door/s or mechanical ventilation. (There is at least one form of ventilation present) }\end{array}$ \\
\hline 5-6 & $\begin{array}{l}\text { Bathrooms, toilets can be ventilated by accessible external opening window/s or mechanical } \\
\text { ventilation. (There is at least one form of ventilation present) }\end{array}$ \\
\hline 7 & $\begin{array}{l}\text { Lounges have minimum of two fixed wired power points } \\
\text { Power points present and working, with one in an appropriate location for a heater }\end{array}$ \\
\hline 8 & The roof is intact and not leaking \\
\hline 9 & The building exterior is intact and not leaking \\
\hline $10-11$ & $\begin{array}{l}\text { Ceiling and underfloor insulation is present. Where not practicable to install (eg. no ceiling } \\
\text { cavity/no access), appropriate heating must be installed }\end{array}$ \\
\hline 12 & Accessible subfloor spaces are dry and have adequate air vents \\
\hline 13 & $\begin{array}{l}\text { Property has no or limited mould } \\
\text { Internal surfaces are free of "uncontrollable" mould and property is free of (dampness and } \\
\text { musty smells) }\end{array}$ \\
\hline 14 & Landlord-provided driers are vented to the building exterior \\
\hline & Safe and Secure \\
\hline 15 & The Building Warrant of Fitness is current, where required \\
\hline 16 & Hot water temperature controls are present and working (Hot water is at a safe temperature) \\
\hline 17 & Windows to be structurally sound, functional and not leak \\
\hline 18 & $\begin{array}{l}\text { Security stays on some ground floor windows allow for secure ventilation while tenants are } \\
\text { out; security stays protect against falls from windows }\end{array}$ \\
\hline 19 & External glass doors and low level glazing have safety visibility strip \\
\hline $20-21$ & $\begin{array}{l}\text { Access to the front door is safe } \& \text { well lit. (Access needs to be free of trip hazards; steps and } \\
\text { ramps to meet acceptable standards.) }\end{array}$ \\
\hline 22 & $\begin{array}{l}\text { Secure storage for hazardous/toxic substances out of children's reach. (Property to provide a } \\
\text { source of secure/lockable storage or storage at least } 1200 \mathrm{~mm} \text { above floor level) }\end{array}$ \\
\hline 23 & Exterior doors are functional and fit for purpose \\
\hline 24 & $\begin{array}{l}\text { Internal / external stairs, landings \& decks have balustrades and handrails } \\
\text { (All stairs, ramps, landings, decks meet minimum fall from height standards.) }\end{array}$ \\
\hline 25 & No visible electrical hazards \\
\hline 26 & Smoke alarms are present and working \\
\hline & Essential Amenities \\
\hline 27 & Bedrooms to have at least two functional and safe fixed power points \\
\hline $28-29$ & Bedroom, bathroom \& toilet doors are present, secure and functioning \\
\hline 30 & Property must have a functioning kitchen sink and taps, and potable hot and cold water. \\
\hline 31 & Dedicated water and waste services for a washing machine \\
\hline 32 & Bathroom to have functioning hand wash services and potable hot and cold water \\
\hline 33 & Bathroom to have bath or shower services \\
\hline 34 & Property to provide functioning toilet facilities \\
\hline 35 & Kitchens must provide food storage facility. \\
\hline 36 & Waste water and sewerage services to be present and functional \\
\hline 37 & Storm water systems (where provided by local authorities) to be present and functional \\
\hline 38 & Floor linings are intact, can be kept hygienic and do not present trip hazards \\
\hline 39 & Ceiling \& wall linings are intact and can be kept hygienic \\
\hline 40 & All freestanding stoves are protected from tipping \\
\hline 41 & The property number is clearly visible to emergency services from the street \\
\hline 42 & No obvious signs of vermin infestation at the time of letting \\
\hline 43 & Habitable spaces (bedroom, living, kitchen, dining area) have electrical lighting \\
\hline 44 & Habitable spaces (bedroom, living, kitchen, dining area) have natural light \\
\hline 45 & Properties to provide a means of hot cooking \\
\hline 46 & Properties to provide hygienic surface for food preparation \\
\hline 47 & Kitchen to have at least two fixed power points \\
\hline 48 & Laundry to have at least one fixed power point \\
\hline
\end{tabular}




\section{Discussion of the Benefits from a Warrant of Fitness}

Ultimately the desired outcome for a WoF is for tenants to be able to live a healthy and safe lifestyle in their homes. Housing New Zealand suggests that a WoF "will help ensure healthier and safer living environments for people living in properties, particularly those on lower incomes" [73, p. 1]. The HHRP suggests that a WoF tool "will assist in improving the quality of the rental housing stock, which would result in improved health outcomes and a reduction in household injuries" [6, p. 9].

International literature recommends a range of indoor conditions as being conducive to good health. There are suggested ranges for both indoor temperatures and moisture levels which are documented in sections "Heating and Comfort Temperatures", p.71 and "Importance of Including Moisture Analysis", p.29. If tenants are able to heat the dwelling to healthy temperatures, ventilate excess moisture and have adequate hot water for hygiene then it is expected that health problems such as asthma, circulatory problems and infectious diseases caused by overcrowding will be reduced [42, p. 11].

The Expert Advisory Group on Solutions to Child Poverty appear to support a warrant primarily because it could reduce the cost of running a dwelling, as well as potentially reduce functional overcrowding [7, p. 26]. Their report generalised that "poor housing is a cause of many health issues for children, including infectious diseases, respiratory illnesses and preventable injuries" [7, p. 26]. Overcrowding however is linked to more specific health outcomes including "the spread of infectious diseases including respiratory infections, such as childhood pneumonia, rheumatic fever and meningococcal virus." [7, p. 26]. Unfortunately there does not appear to be a clear definition of what constitutes "poor housing" so it is difficult to determine what would remediate this. The report states that some rental housing is currently 'bad' without explicitly stating why, and suggests that a WoF could address this. A further workshop focus group then suggested that the Healthy Housing Index can determine what is 'good' and 'bad' housing. [74, p. 1]

Functional overcrowding (too many people spending their time in only one room) may follow from New Zealand trends of heating only one room. To combat this, the room (expected to be the living room) would have to be larger (such as in a modern open plan design or an older cellular building with walls removed) or multiple heat sources would have to be introduced. It is unlikely these would be able to be included in a warrant targeted at providing minimum standards. BRANZ's Household Energy End Use Project (HEEP) completed in 2005 found that the majority of occupants ( $85 \%$ ) heated their living room but only $49 \%$ heated bedrooms and comparatively few heated utility rooms (32\%). It will be difficult to argue that multiple sources of heat are needed as a minimum to prevent health complications in renting households when this is not common practice in 'average' households.

It is unclear that a WoF would provide any restrictions on absolute overcrowding (too many people living in the one house) beyond current tenancy agreements which specify the maximum number of occupants permitted.

The 2011 assessment of the Warm up NZ: Heat Smart programme by Telfar-Bernard et al. indicated that there should be overall financial benefits from installing insulation [42], [75], [76]. The study was unable to identify whether there would be financial benefits from installing heating. The addition of insulation would be expected to result in small temperatures rises of $0.5-$ 
$1.4^{\circ} \mathrm{C}$ in an unheated dwelling [77]. Even with this temperature increase a source of heating is still required if houses are to maintain comfort temperatures throughout winter. The heating capacity required to maintain comfort varies according to the severity of the climate, with more heating needed in Otago and less in Auckland.

If safety related concerns are addressed then it is expected that there will be fewer ACC claims for accidents at home such as falls and burns. This is somewhat mitigated by behaviour modification in visibly unsafe situations, meaning the reduction in accidents is unlikely to be directly proportional to the reduction in home hazards. [50]

\section{Other Impacts of a WoF}

Housing defects are not always visible in photos or easily identifiable in a short inspection of a prospective rental property. Disclosure of a dwelling's condition could be a first step to improving the market. Landlord comments so far have shown that they are wary of the cost of upgrades to their properties. Would they be more agreeable to simply declare the condition of their property rather than fix it?

The BRANZ House Condition Survey indicates that tenants and owners are likely to be overly optimistic about the quality of their house $[1, p .10]$. This can be because they don't have the construction education required to identify some defects or due inherent biases towards over valuing things we own relative to other's belongings. Either way an educated and impartial person is needed to carry out the housing assessment. This of course carries with it a cost, even if there are no upgrades immediately required.

Rental property owners are in a service industry. 'Mum and Dad investors' who own one or two rental properties as a supplementary source of income make up a large proportion of the total rental property markets. They frequently don't have a budget for repairs, maintenance and improvements and operate on a low yield [78, p. 7]. Other service industries are subject to regulation and assessment, such as proving they meet food hygiene standards, yet there is currently no requirement that a leased house is able to be lived in [15].

It seems that while the use of a WoF has the potential to lift the overall condition of rental housing, it is unlikely that it would resolve child poverty related health conditions. A number of these are related to overcrowding and fuel poverty. The current WoFs do not address absolute overcrowding (too many people in one house) or functional overcrowding (too many people inhabiting one room because all the other rooms are too cold).

Replacing unflued gas heaters with clean heating (in most cases heat pumps) has been shown to reduce symptoms of asthma in children [76]. A WoF could help by reducing the appeal of an unflued gas heater if a source of heating is provided with the house and tenants can afford to run this heating. If a fixed form of heating is already provided then it is likely it would be used rather than buy a new heater. If electric resistance heaters are provided this may not be the case. These can be expensive to run, and if permanently wired the tenants cannot determine how much electricity they are using and therefore how much the heating is costing them. The difficulty with eliminating unflued gas heaters is that they facilitate budgeting for heating. The cost of a bottle of gas is known exactly and it is clear when this is exceeded, the gas runs out. 
Conversely there may be an increased risk from portable gas heaters including the risk of fire and indoor pollutants. If a living room is fitted with a clean heat source then the portable gas heater may be relocated to another room, likely a bedroom (the $2^{\text {nd }}$ most common room type to be heated according to the HEEP study), where the unflued gas heater could pose more danger. If the WoF inspection is carried out before tenants move in then there is no way of addressing the dangers of unflued gas heaters.

Solid fuel burners (wood, coal or pellet fuelled) could potentially be a way of displacing unflued gas heaters used by very low-income tenants. They would allow the tenant to continue the same rationing behaviours for budgeting but they would provide more heat for the same budget. Solid fuel burners provide visible evidence of how much fuel has been consumed and therefore how much of the heating budget. This type of feedback is not readily available from portable electric heaters (extra power metering appliances would have to be purchased and understood) and isn't available at all from fixed heating wired into the wall including heat-pumps. The cost of the appliance and the installation remains an issue. Local council requirements around air pollution may also make this more difficult.

\section{Arguments Against A Warrant}

Blog posts and comments on published articles provide no shortage of opinions on introducing a WoF for housing. Some are supportive but many have arguments as to why a WoF should not be introduced. Many of these relate to tenant behaviour, suggesting that low-income tenants will not use the systems provided [79]. Landlords commonly comment that the cost of rent will have to go up as a result of a WoF which will further disadvantage low-income tenants. There is even the argument "why should renters be entitled to better housing than property owners" which reflects on the overall quality of the housing stock, not just rental properties [80].

A WoF has been presented as helping reduce child poverty related illness [7], but counter arguments state that it is the behaviour of the tenants that cause these illnesses not the houses themselves [81].

Judging by the variety of opinions voiced online, the onus appears strongly on the tenant to modify their behaviour to accommodate the house. These include: it is the tenant's responsibility to enquire about heating and insulation; if the house isn't good enough they should move elsewhere; the tenant should not be able to complain about mould unless they have kept windows open in all weather conditions regardless of security concerns; a power point means the tenant can plug in their own heater; the tenant should use pot lids and avoid taking long hot showers to prevent generating too much steam; and washing should never be dried inside, no matter the weather.

It would seem that there is a strong burden on tenants to live 'correctly' and that they should suffer any consequences from not doing so, regardless of the house design. Some house design features provide more tolerance for 'imperfect' occupant behaviours. An extract fan in the bathroom can make all the difference between ventilating when it is wintery outside and opening the window would let in freezing air. Window stays help an occupant securely leave windows open during the day. Efficient HWCs mean less money required to keep water hot and make it more affordable to keep the water at a safe temperature. Efficient hot water fixtures mean less hot water overall is needed, and can reduce the need to increase the temperature of the hot 
water to ensure they don't run out. The tenant should be able to remove some mould and wipe away condensation, but again this is made easier or more difficult by the materials used to construct the house and means of reducing moisture.

A power plug in every room means that it is possible for the tenant to go out and buy a number of portable electric heaters, however if they do not have a sizeable heating budget then they will be unable to heat the house to acceptable temperatures.

'Correct' occupant behaviours are still possible much of the time in a house which fails the WoF but they are made more difficult [82]. Preventing moisture build up and keeping the house warm may require contradictory actions, such as running a heater while a window is open.

On one side there is an argument that if these people pay less rent, then they should put more time and effort into living 'correctly' to avoid health problems. 'We shouldn't have to pay money because you don't live the right way' seems to be the theme of the argument. Relative poverty is a sum of many small disadvantages, such as those caused by housing. On the other side there appears to be a forceful push for a WoF to 'fix child poverty' and yet tenuous connections determining how this will help.

\section{Different Standards for Rental Properties vs New Buildings}

The criteria in table 3 and table 4, suggested as mandatory minimum requirements for rental properties, present some interesting issues. Firstly a number of the criteria are not explicitly required by the NZBC. The NZBC does not prescribe requirements such as curtains, window stays and clearly labelling the address of a property, because it is deemed an unnecessary high level of regulation. The NZBC view is that the market influences what buyers of new houses expect as a minimum.

The Building Act explicitly states that "a person who carries out any building work is not required by this Act to achieve performance criteria that are additional to, or more restrictive than, the performance criteria prescribed in the building code" [15, p. 12]. New legislation would have to be developed to support the introduction of a new way of assessing minimum existing building standards with care to ensure that they align with the standards required of new buildings. 


\section{MODEL SELECTION AND DEVELOPMENT}

This section explores the selection of the house model used to evaluate the selected WoF components and the selection of the analysis tools.

\section{Modelling Methodology}

As noted in the previous chapter, the proposed Warrant of Fitness aims to improve housing thermal performance because this has the ability to bring about 'improved health outcomes'. Two proposed WoF methods have been described along with the questions that related to the thermal performance. The next stage of work is to quantify the consequences of passing (or failing) the required thermal components of either WoF on the dwelling's thermal performance.

A case study has been used to evaluate the impact of the proposed criteria on the lower end of the rental housing stock in terms of thermal performance. This requires a model which represents the lowest practical end of the housing stock in terms of thermal quality. This targeted level of performance is illustrated on the continuum of housing quality illustrated in figure 4, where a base model would sit at the dashed red line and upgrading different components of the house would bring it progressively closer to the dashed black line.

The simulations will analyse the physical ability of the house to be maintained at comfortable conditions with different features required to pass either WoF. This is limited by the physical properties of the house, primarily size, insulation level and the amount of heating available. The economic ability of tenants to maintain these comfortable conditions is partially influenced by the physical properties of the house (what fuel source heating and other appliances require) but it is equally a function of the tenants' income. Tenants renting their home are more likely to have a lower income than those who own their own home [41, p. 132], making the economic ability to heat important. The economic impact of the WoF criteria on running the house will be discussed, but this is not wholly able to be assessed using thermal and energy simulation.

The results from this case study represent the largest likely changes in performance from a WoF. Dwellings which are already partially insulated would see some benefit by adding more, but these benefits would not be as significant as those experienced by insulating an uninsulated house.

To keep the scope of the project within a suitable range for a Master's thesis, only one house design will be analysed. A detached house has been chosen because as of 2006 (the latest available data) $65 \%$ of renting households lived in detached houses [83]. The basic construction type of the dwelling is light timber framing, suspended timber flooring and sheet metal roofing.

These are common construction types in older houses and also have the possibility to retrofit insulation [84]. This construction type has a low level of thermal mass which is important because it stores heat and releases it slowly. Therefore the results from this model will only be applicable to dwellings with lightweight construction, i.e. not buildings with a concrete floor, brick cladding or concrete roofing tiles. 


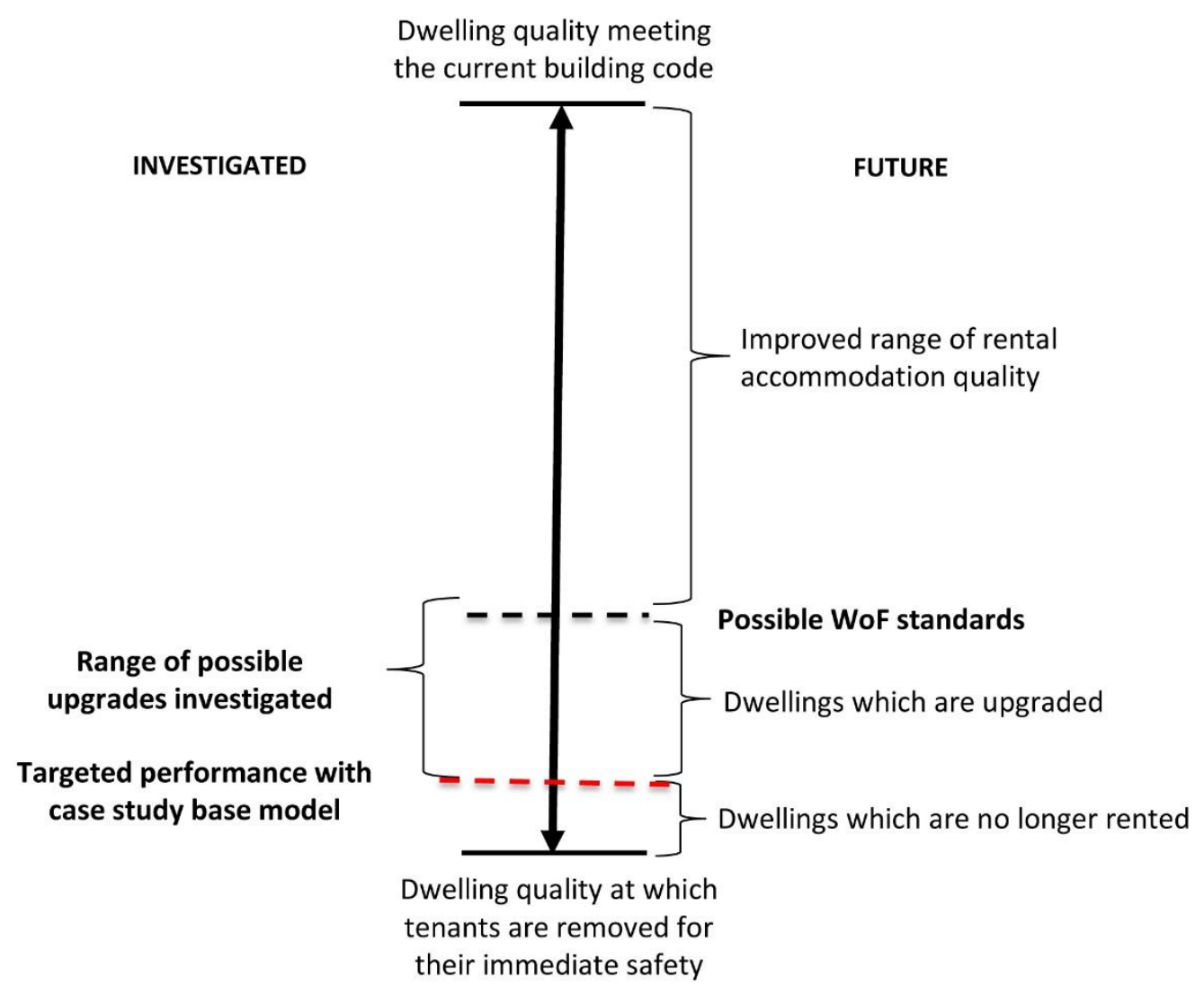

FIgURE 4: CASE STUdY PERFORMANCE COMPARED TO THE RANGE OF PERFORMANCE IN RENTAL ACCOMMODATION

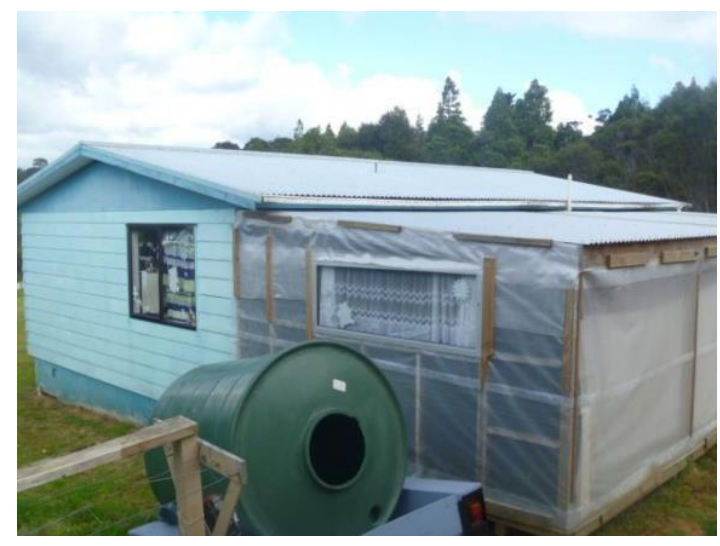

FIGURE 5: HOUSE WITH MAKESHIFT CLADDING

[85]

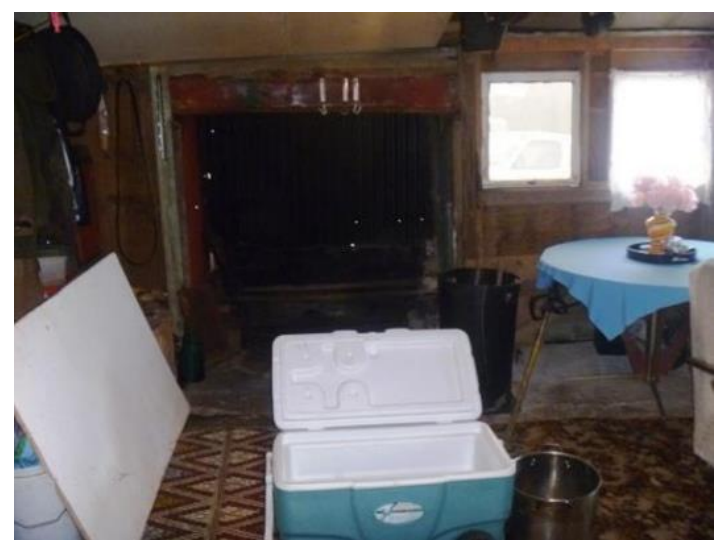

FIGURE 6: INSULATION WAS UNABLE TO BE INSTALLED IN THIS LEAKING ROOF [85]

The modelled house has been chosen to describe the lowest rung of performance to be investigated. It is recognised that there is housing with inferior thermal performance e.g. some housing applying for insulation retrofits under the Warm Up NZ: Heat Smart program has been in such poor condition it was not possible to install the insulation (pictured in figure 5 and figure 6 above) [85]. Modelling is not required to predict that dwellings with large holes in the walls and no interior linings are going to have poor thermal performance.

Importantly for thermal modelling, substandard performance can occur in a multitude of different ways. Figure 5 and figure 6 illustrate two real life examples which would be impractical 
to analyse through simulation. Houses of such poor quality are usually visibly substandard, whereas the WoF aims to mitigate less visible problems. Seriously substandard housing would also be very difficult to upgrade to warrant criteria, suggesting other approaches are required.

\section{Simulation Software}

Modelling was carried out using EnergyPlus ${ }^{2}$ version 8.1. Geometry was drawn using Open Studio $^{3}$ version 1.2.0 and Sketchup ${ }^{4}$ version 13.0. The model was initially simulated using the Wellington NIWA weather file available from the EnergyPlus website. Technical EnergyPlus specific tips to aid future modellers are provided as endnotes (page 121).

EnergyPlus version 8.1 was selected for a range of reasons:

- EnergyPlus is tested to international standards for each new version of the programme [86],

- EnergyPlus is freely available for anyone wishing to replicate this type of analysis,

- the ability to write inputs as plain text files,

- the author's previous experience with the software,

- expertise available within the School of Architecture and Design using and researching with this software.

\section{Model Design}

The villa is an older house typology which has been acknowledged to underperform thermally [87]. Based on the summary of the most likely villa constructions [88] and cross comparison with the WoF criteria; a villa in its un-modified state would fail all thermal components of both WoFs but it is still possible to retrofit measures to achieve a pass.

The villa typology has been well documented in "Old New Zealand Houses" [89, p. 155] and in the BRANZ Renovate series [88]. It is an example of an older construction type built without insulation. The cottage house type $[89$, p. 155] also meets these criteria, but the floor plate is not necessarily large enough to accommodate the types of spaces the current housing market expects (internal kitchen, bathroom and laundry). The villa is a type of house which is being rented with varying levels of upgrades. By assuming the model is as close to the original design, the intent is to capture the worst probable performance. It has been assumed that the dwelling lighting, plumbing and utilities have been suitably upgraded.

A plan was obtained from Wellington City Archives for a three bedroom suburban villa built in 1910 (figure 7) and extended sometime before 1960 (figure 8), although still in keeping with the villa typology. The plan information was combined with physical measurements taken when renovations were carried out in 2013 . The house has since undergone significant renovations and repairs making it no longer recognisable as a villa, but the earlier plans match well with the common villa typology [89, p. 155].

Figure 9 shows the floor plan with colour coded thermal zones (also listed in table 5) used in the simulation modelling.

\footnotetext{
${ }^{2}$ http://apps1.eere.energy.gov/buildings/energyplus/energyplus_about.cfm

${ }^{3}$ https://www.openstudio.net/

${ }^{4} \mathrm{http}: / /$ www.sketchup.com/
} 


\begin{tabular}{|l|}
\hline TABLE 5: THERMAL ZONES \\
\hline Living \\
\hline Dining \\
\hline Kitchen/laundry \\
\hline Hallway \\
\hline Bathroom \\
\hline Bedroom 1 \\
\hline Bedroom 2 \\
\hline Bedroom 3 \\
\hline Attic \& subfloor - uninhabited zones \\
\hline
\end{tabular}

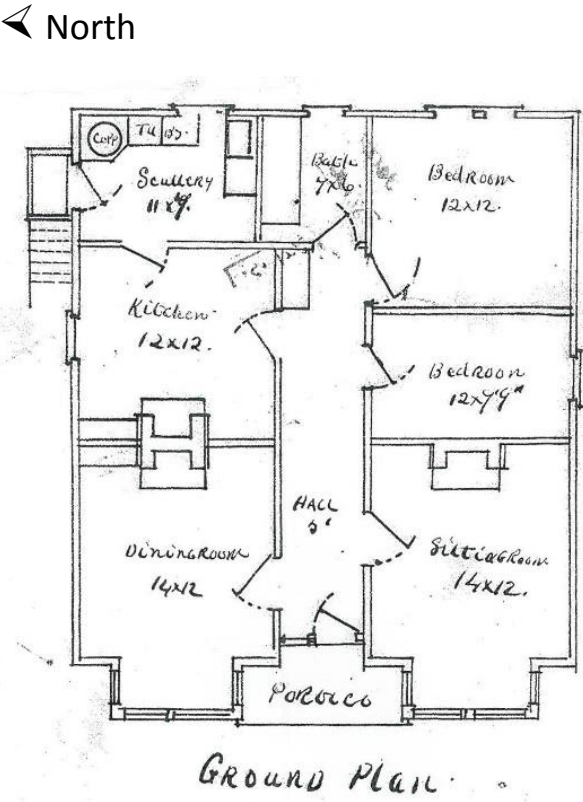

Figure 7: ORIGINAL VILLA PLAN (1910)

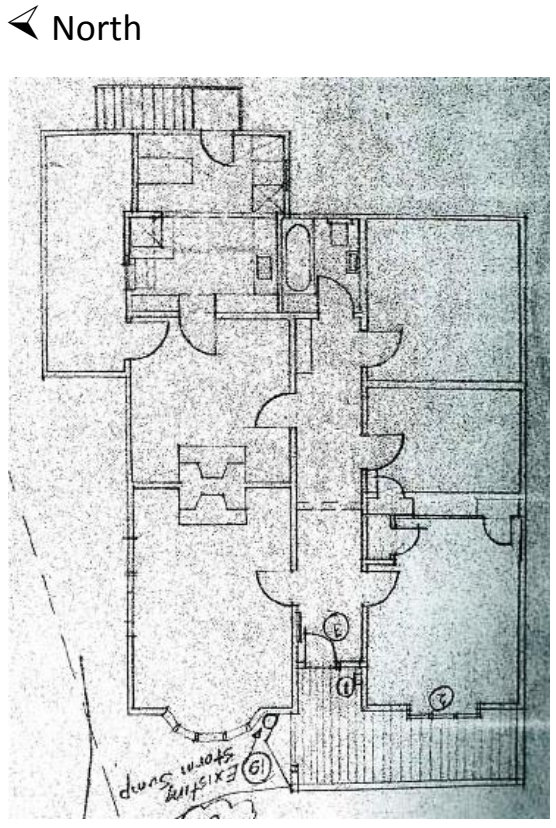

FIGURE 8: LATER VILLA PLAN (1960S) 


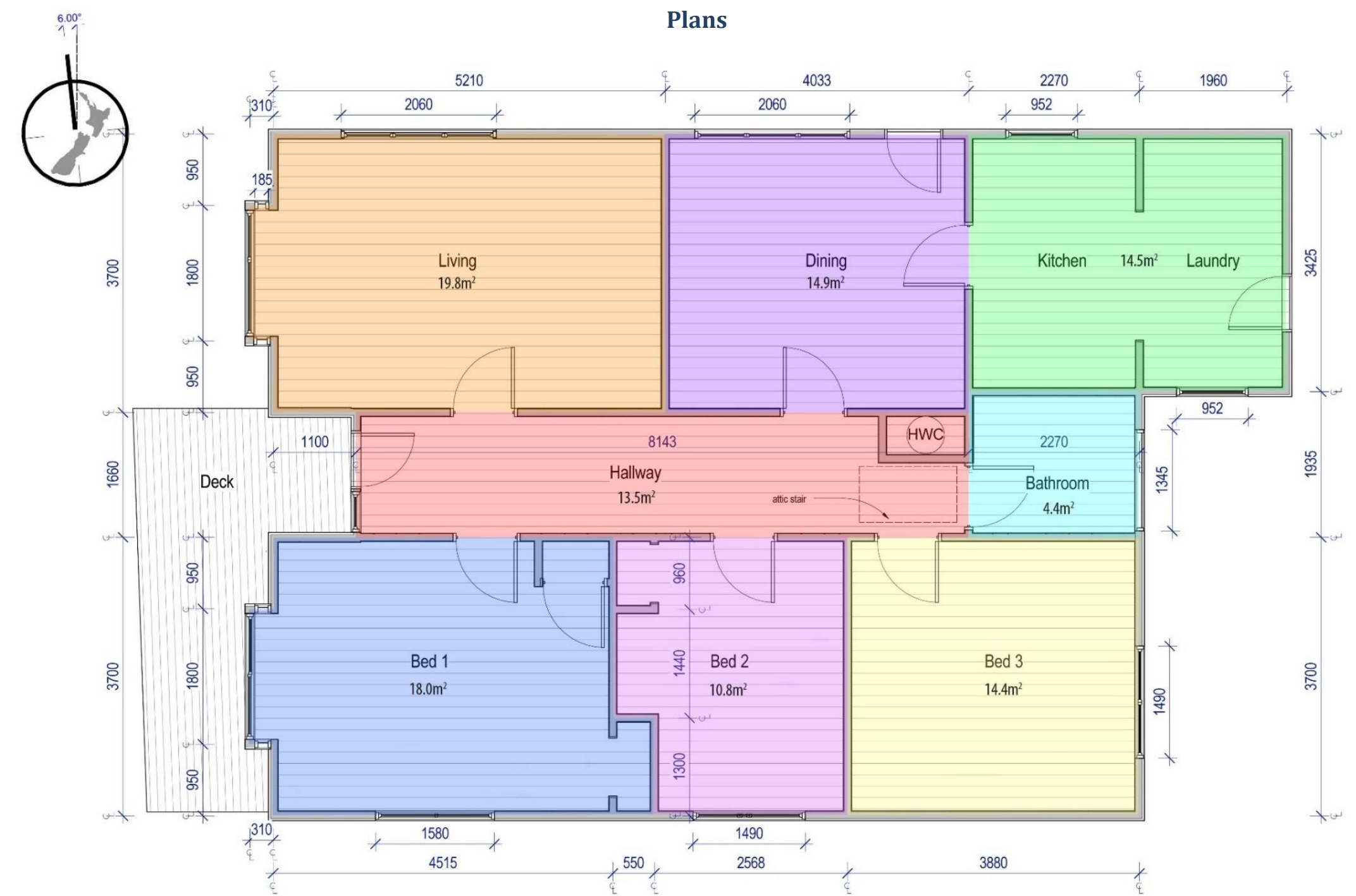




\section{MOISTURE SIMULATION}

This section covers different approaches for the analysis of moisture impacts and loads which cause these.

\section{Importance of Including Moisture Analysis}

Thermal simulation alone will not quantify the benefits of a number of the WoF criteria.

The WoF questions concerned with moisture issues include: the condition of the subfloor including adequate ventilation and a ground vapour barrier; adequate discharge of stormwater; weathertight envelope; extract fans or suitable ventilation in kitchens, bathrooms and bedrooms; and externally vented clothes drying. These are criteria 9, 10, 21, 22, 24 and 25 in the GH WoF (table 3) and criteria 1-6, 8, 9, 12, 13, 14 and 36 in the HNZ WoF (table 4).

Most commonly moisture issues manifest as condensation (on windows or in more severe cases on walls) and over time as mould growth. Condensation itself is not a health hazard but a building which experiences severe condensation is likely to later experience mould growth [90]. Repeated occurrences of condensation may cause moisture damage to construction materials.

High relative humidity (high absolute moisture levels and/or low indoor temperatures) can also promote the growth of a number of organisims which lead to health problems, as illustrated in figure 10. High relative humidity allows bacteria, viruses, fungi (mould) and mites to grow while also causing allergic rhinitis, asthma and chemical interactions. Excessively high $\mathrm{RH}$ levels are both a frequent occurance in New Zealand homes and a cause of many health problems. [91]

\section{Optimim Relative Humidity Ranges for Health}

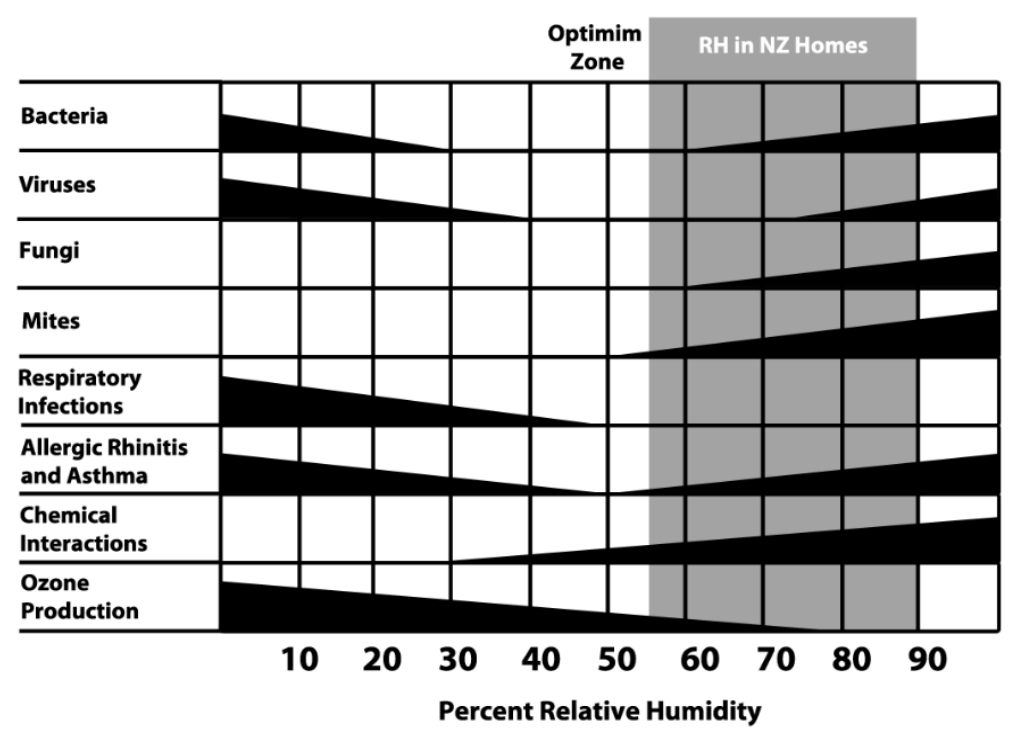

FIGURE 10: RELATIVE HUMIDITY LEVELS AND ASSOCIATED MICROORGANISMS/HEALTH PROBLEMS [91]

\section{Expected Moisture Loads for Domestic Uses}

To examine moisture related issues it is necessary to firstly quantify how much moisture is likely to be added through domestic uses (e.g. showers, cooking) as well as common maintenance problems (e.g. leaky gutters, no subfloor damp-proof membrane). The next stage is to identify when these loads may become problematic. How much added moisture can be tolerated with/without insulation or ventilation? Does the local climate impact on this? Is it possible to 
trade-off removing some moisture sources and allowing others to remain? Can common moisture sources be ranked in order of importance to fix or remove?

There are a number of sources available detailing the amount of moisture generated by typical domestic activities [11], [92]-[98]. However, comparison of these sources reveals a wide variation in expected moisture load for the same activities. The various sources are summarised in table 6 (p.31).

Analysis of the estimated moisture loads from unvented washing suggests these values are a high estimate. A home experiment was carried out weighing three loads of washing when dry and after a wash and assuming the difference in weight to be water retained by the washed clothes. This found between $0.8 \mathrm{~L}$ to $1.4 \mathrm{~L}$ of water per load of washing, compared to the reported $5 \mathrm{~L}$. The loads were from 2 and $4 \mathrm{~kg}$ (a full load and a half load in a front and top loader respectively). There are likely to be some additional moisture gains from a top-loading washing machine, however front-loading washing machines are by necessity watertight so there is unlikely to be any moisture gains from these.

Websites targeted to provide sustainable/green building advice (the first column in table 6) also significantly over represent the amount of moisture generated by showers or baths, apparently due to an incorrect unit conversion at some stage (a British standard initially published figures of 0.2 litres per person: then a BRANZ Bulletin published a figure of 1.5 litres per household: finally sustainability websites published 1.5 litres per person).

This research has found a lack of documented moisture loads due to modern technology under New Zealand conditions and habits. This would benefit from additional research, as without measurements on the moisture sources there is no certainty of the benefits from interventions.

\section{Subfloor Moisture}

Houses with suspended floors may also have significant subfloor moisture gains. BRANZ measurements in multiple climates in New Zealand suggest these are in the order of 0.3 to 0.55 litres of water per day per $\mathrm{m}^{2}$ of exposed soil [99]. This translates to 33 to 61 litres of water a day entering the subfloor space for the test villa. The use of a ground vapour barrier (e.g. a layer of polythene covering the earth) is estimated to reduce this by $70 \%$ to $90 \%$ [100]. Depending on the extent of transmission through the floor construction, this could be the largest house moisture source. 
TABLE 6: A COMPARISON OF SUGGESTED MOISTURE GAINS FOR DOMESTIC ACTIVITIES BY SOURCE

\begin{tabular}{|c|c|c|c|c|c|c|c|c|c|c|c|c|}
\hline & \multicolumn{2}{|c|}{$\begin{array}{l}\text { ConsumerBuild/Smarter } \\
\text { Homes/Eco Design } \\
\text { Advisors (as at 2014) } \\
\text { [94], [95], [97] }\end{array}$} & \multicolumn{2}{|c|}{$\begin{array}{l}\text { BRANZ Bulletin } \\
4602005 \\
{[92]}\end{array}$} & \multicolumn{2}{|c|}{$\begin{array}{l}\text { British Standard } \\
5250: 2002 \\
{[93]}\end{array}$} & \multicolumn{2}{|c|}{$\begin{array}{l}\text { BRANZ Conference } \\
\text { Paper [96] } \\
\text { Referencing: British } \\
\text { Standard 5925:1991 }\end{array}$} & \multicolumn{2}{|c|}{$\begin{array}{l}\text { WHO Health Impact of } \\
\text { Low Indoor } \\
\text { Temperatures } 1985 \text { [98] } \\
\text { Referencing British } \\
\text { Standard 5250:1975 }\end{array}$} & \multicolumn{2}{|c|}{$\begin{array}{l}\text { WHO Guidelines for } \\
\text { Healthy Housing } 1988 \\
\text { [11] } \\
\text { Referencing The } \\
\text { Weather Conditioned } \\
\text { House } 1958\end{array}$} \\
\hline & $\mathrm{L}$ & per & $\mathrm{L}$ & per & $\mathrm{L}$ & per & $\mathrm{L}$ & per & $\mathrm{L}$ & $\begin{array}{l}\text { per }(5 \text { person } \\
\text { household) }\end{array}$ & $\mathrm{L}$ & per \\
\hline Cooking - gas & 3.0 & Day & 3.0 & day & 3.0 & Day & 3 & day & 3 & day & 2.1 & \\
\hline $\begin{array}{l}\text { Cooking - } \\
\text { electric }\end{array}$ & & & & & 2.0 & Day & 2 & day & & & & \\
\hline $\begin{array}{l}\text { Clothes } \\
\text { washing }\end{array}$ & 0.5 & Day & 0.5 & day & 0.5 & Day & & & 0.5 & day & 2.0 & Not specified \\
\hline $\begin{array}{l}\text { Showers and } \\
\text { baths }\end{array}$ & 1.5 & day (/person) & 1.5 & day & 0.2 & person/day & 0.2 & day/person & 1.0 & day & 0.3 & Not specified \\
\hline Dishes & 1.0 & Day & 1.0 & day & 0.4 & Day & & & & & 0.5 & day (totalled) \\
\hline $\begin{array}{l}\text { Clothes drying } \\
\text { (unvented) }\end{array}$ & 5.0 & Load & 5.0 & load & 1.5 & person/day & $1-1.5$ & person/day & 5.0 & day & 12 & Not specified \\
\hline $\begin{array}{l}\text { Gas heater } \\
\text { (unflued) }\end{array}$ & 1.0 & Hour & 0.2 & kW/hour & 0.15 & $\mathrm{~kW} / \mathrm{hr}$ & $0.3-0.6$ & $\mathrm{hr}$ & 0.15 & $\mathrm{~h} / \mathrm{kW}$ & & \\
\hline $\begin{array}{l}\text { Breathing, } \\
\text { active }\end{array}$ & 0.2 & $\mathrm{hr} /$ person & 0.2 & $\mathrm{hr} /$ person & 0.055 & $\mathrm{hr} /$ person & 0.055 & $\mathrm{hr}$ & 1.7 & 2 people/16hours & & \\
\hline $\begin{array}{l}\text { Breathing, } \\
\text { asleep }\end{array}$ & 0.02 & $\mathrm{hr} /$ person & 0.02 & $\mathrm{hr} /$ person & 0.040 & $\mathrm{hr} /$ person & 0.040 & $\mathrm{hr}$ & 1.5 & 5 people/8 hours & & \\
\hline Perspiration & 0.03 & Hour & 0.03 & hour & & & & & & & & \\
\hline Pot plants & as muc & you give & & & & & 0 to a lot & & & & & \\
\hline Floor mopping & & & & & & & & & & & 1.1 & Not specified \\
\hline
\end{tabular}

Rows where the values vary noticeably across sources are highlighted in grey. Values are reported to the same number of decimal places as the original source. 


\section{Manual Calculation of Moisture Impacts}

The BRANZVENT calculation process is built into Annual Loss Factor (ALF) [66]. It can also be carried out as a hand calculation. The documentation for the hand calculation is currently unpublished [101], but is provided as low resolution charts in [102].

The BRANZVENT calculation methodology is designed to help minimise condensation on the external walls of bathrooms and kitchens that are not heated specifically to control moisture [101]. Figure 11 illustrates the difference between the uninsulated villa (black line) and the villa with WoF level insulation in the ceiling and subfloor (green line).

Adding high levels of ceiling and underfloor insulation (R3.01 in the ceiling and R1.77 underfloor) makes a moderate difference to the whole building conductance (reducing it from $\sim 880 \mathrm{~W} /{ }^{\circ} \mathrm{C}$ to $\sim 550 \mathrm{~W} /{ }^{\circ} \mathrm{C}$ ). However, when keeping all the other inputs (internal heat gains, thermal bridge Rvalue, location and room configuration) the same, the difference between readings on the graph is only the thickness of a pen line.

Digitally plotting the performance on a graph allowed a higher level of resolution, making small changes visible. This revealed the effect of adding insulation was to reduce the minimum required air change rate by $0.07 \mathrm{ACH}$ (Air Changes per Hour) for the kitchen and $0.22 \mathrm{ACH}$ for the bathroom. The larger difference for the bathroom was due to its small size $\left(\sim 14 \mathrm{~m}^{3}\right)$. The nomograph, reproduced in figure 11 , shows the infiltration is more than adequate for the kitchen, while the bathroom would need additional ventilation with either level of insulation.

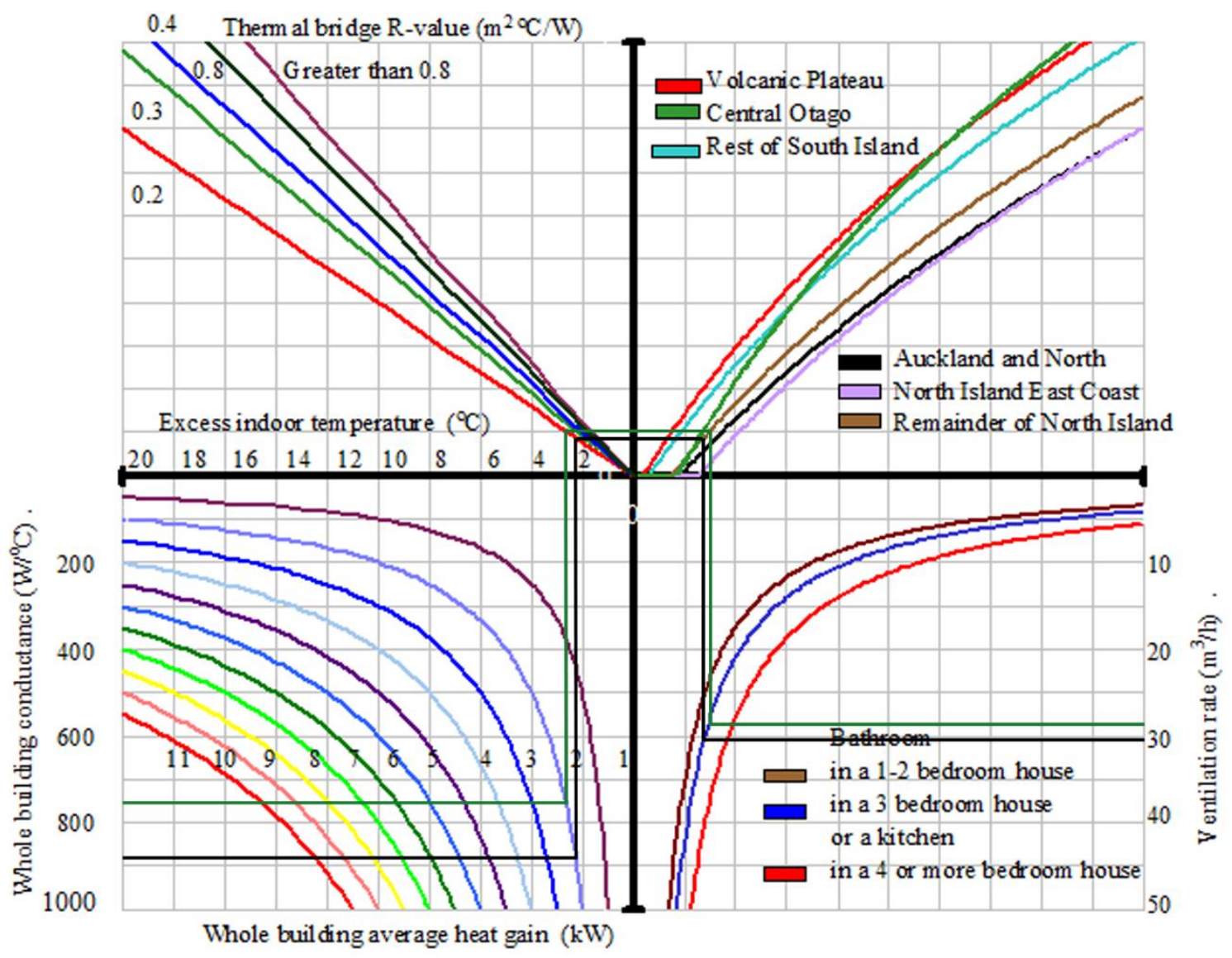

FIGURE 11: BRANZVENT NOMOGRAPH 
It is also difficult to use BRANZVENT to identify when mould would occur. It is not clear how far below the ventilation requirements the house would have to be before mould is possible or likely. BRANZVENT is designed to be used to provide a general indication whether a house is likely to suffer moisture problems, rather than testing the impact of small changes in design, as would be the case for testing the WoF.

The BRANZVENT tool has also been designed to be simple to use and to provide general guidance, is therefore unsuitable for WoF use.

\section{Calculation Algorithms within EnergyPlus}

Possible alternatives for analysing moisture impacts are highly detailed calculation algorithms, including those in EnergyPlus. EnergyPlus has some capacity for moisture analysis which is usually used for commercial mechanical conditioning systems. Dedicated moisture modelling programmes provide greater sophistication.

EnergyPlus is primarily targeted at heat and energy use simulations. The default heat balance algorithm (method of calculating building loads and losses) is the 'Conduction Transfer Function', a "a sensible [dry] heat only solution and does not take into account moisture storage or diffusion in the construction elements" [103]. EnergyPlus has three other heat balance algorithms available for use:

1. 'Moisture penetration depth conduction transfer function' otherwise termed as an effective moisture penetration depth model (EMPD)

2. 'Combined heat and moisture finite element' which is a coupled heat and moisture transfer and storage solution (HAMT).

3. 'Conduction finite difference' which is also a sensible heat only model but with the ability to represent phase change materials.

Further developments of EnergyPlus moisture modelling methods are to include a 2 layer EMPD model [104], [105]. It is not clear when this modification will be released.

The single layer EMPD model assumes that a thin layer of the interior surfaces perform the majority of the moisture buffering [106, p. 54]. The HAMT model calculates the moisture performance of the whole wall including influences from the outside climate [106, p. 49]. The conduction finite difference model does not analyse moisture loads.

The single layer EMPD model is suitable for evaluating moisture fluctuations over hours but cannot be used reliably for results over months or years [104, p. 6]. This is because at longer time periods the buffering capabilities of the core layers of the wall become important.

The HAMT model requires detailed material properties (sorption isotherms, suction, redistribution, diffusion and thermal conductivity) for all the construction materials in addition to the thermal properties. The EMPD model only requires the effective moisture penetration depth to be calculated and four coefficients to be provided for the moisture equation. The formula is provided in the EnergyPlus engineering reference document [106, p. 54] and an alternative formula is provided in [104, p. 6]. Example materials for both moisture calculation methods are available in the example files provided with EnergyPlusi. 
It does not appear possible to simplify the building constructions when using the HAMT model. One strategy for simplified thermal modelling is to model timber framing and insulation or an air gap as a single material with an equivalent $\mathrm{R}$-value of the two materials combined (while accounting for thermal bridging)

Modelling the framing and the insulation materials separately in EnergyPlus is a complex exercise. Walls have to be manually divided into areas based on the proportions of framing and insulation, requiring much trial and error experimentation. Adding this level of complexity to the model is time consuming and limited by not knowing the exact proportion of wall framing.

The EMPD model will not reliably represent moisture transfer from the subfloor to the living spaces through the constructions. Some transfer can be estimated by defining effective leakage areas, making the assumption the floor is not tightly constructed, but moisture transfer through the flooring materials will not be accounted for.

\section{Impact of Moisture Calculation Algorithms}

To test this, the EMPD calculation algorithm was used on a simple EnergyPlus box model with no internal loads, a single zone and a constant ventilation rate of $0.5 \mathrm{ACH}$. The impacts on the relative humidity are shown in figure 12 . The heat transfer mode (green) has a larger variation than the EMPD model (blue).

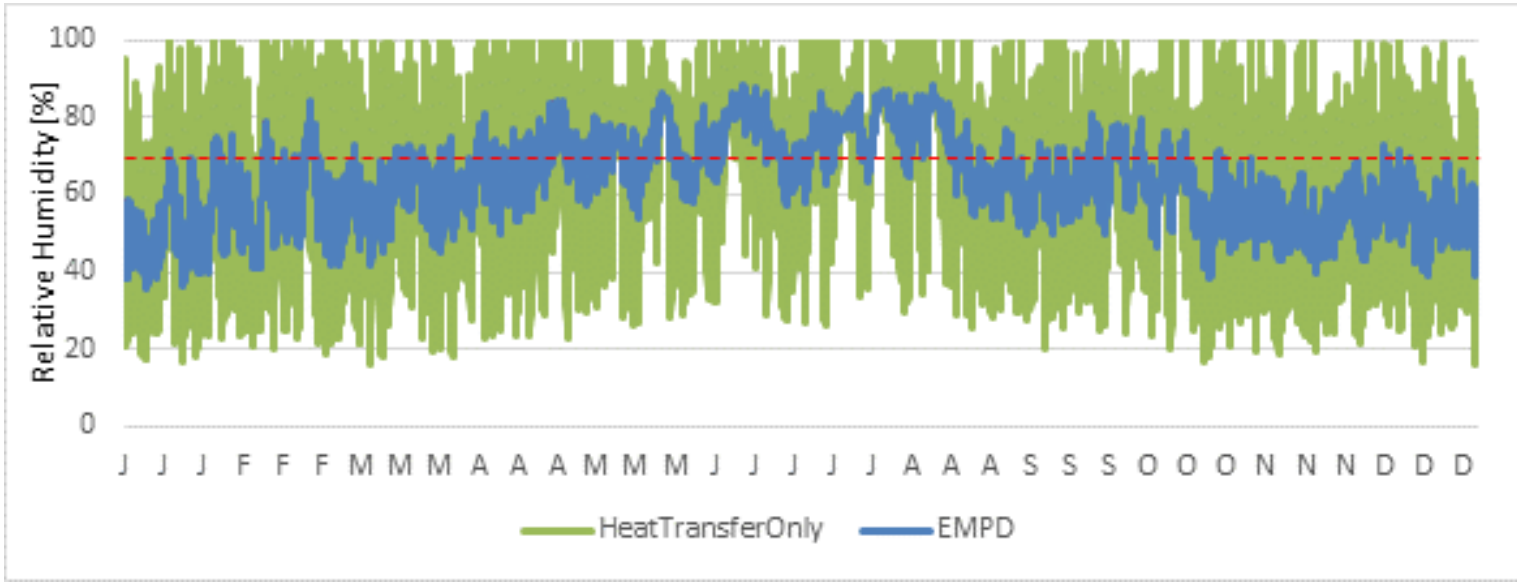

FIGURE 12: A COMPARISON OF THE IMPACTS OF TWO CALCULATION ALGORITHMS ON RELATIVE HUMIDITY

From a performance perspective, the heat transfer only model indicates the building has a large number of hours where the humidity is over $70 \%$ (dotted red horizontal line in figure 12) and therefore is more likely to experience mould problems. The EMPD model suggests that episodes with greater than $70 \% \mathrm{RH}$ are far fewer and occur predominately in winter, which better aligns with the nature of moisture problems experienced in New Zealand houses.

It is evident from figure 12 that the EMPD algorithm which allows for moisture transfer has a significant impact on the RH fluctuation. From this analysis, it appears not useful to report RH as a performance metric unless a validated moisture capable calculation model is implemented.

\section{Moisture Model Evaluation}

The EnergyPlus HAMT model has been shown to have good agreement with WUFI, the widely accepted 2D moisture modelling program used by BRANZ [107]. 


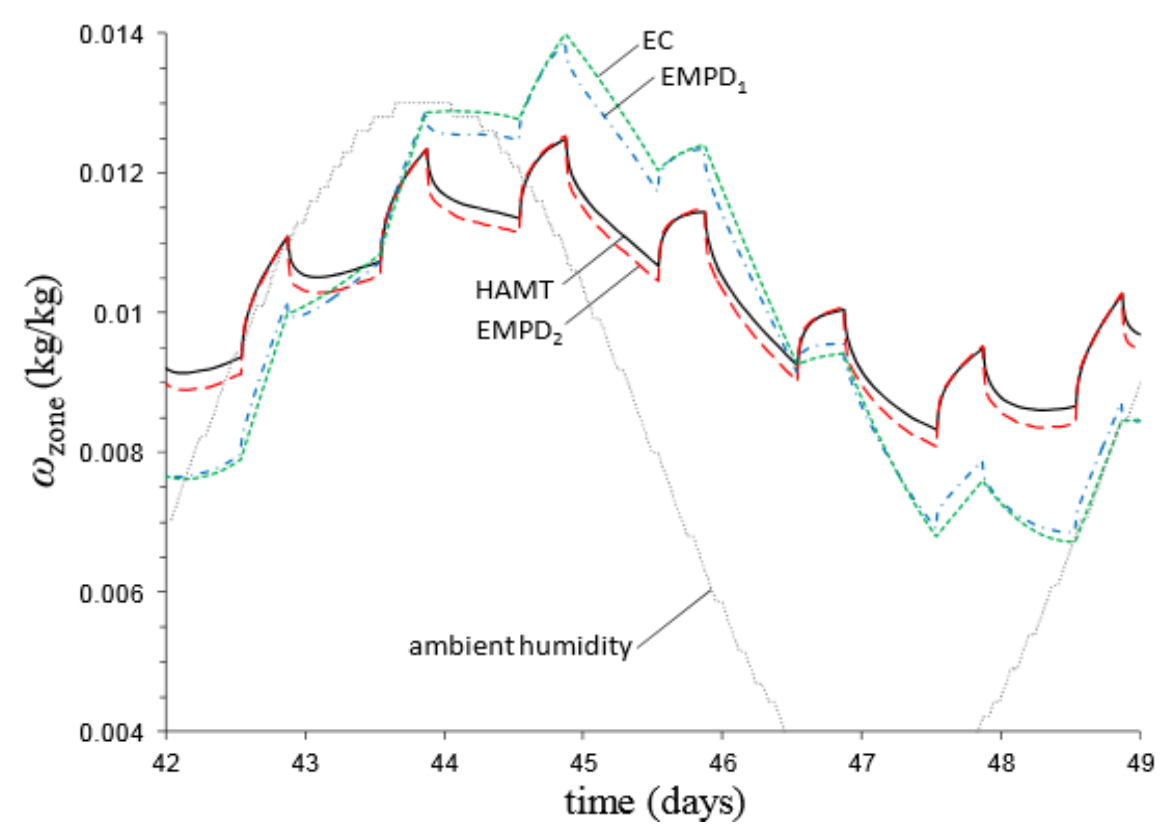

FIGURE 13: ABSOLUTE HUMIDITY COMPARISONS BETWEEN FOUR DIFFERENT MOISTURE MODELLING ALGORITHMS

Woods et al. published a comparison between four different moisture modelling algorithms, analysing the performance of a single zone model with concrete construction [104]. An Effective Capacitance (EC) approach was also used, although this is not a moisture calculation algorithm but a multiplier on the room air volume to approximate added moisture capacity due to walls and furnishings.

The HAMT, EC and EMPD 1 models were all simulated in EnergyPlus. The EMPD 2 model was simulated in a customised version of EnergyPlus. It uses two effective moisture penetration layers, one shallow and one deep to better represent short and longer term fluctuations. The results in figure 13 indicate that the EMPD model moderates the swings in ambient humidity somewhat while the HAMT model moderates the swings in absolute humidity even further [104, p. 14].

The author's own simulations in figure 14 (using the test box) show a different pattern. The EMPD model predicted greater increases in absolute humidity above the outdoor conditions, while the heat transfer only model matched the outdoor conditions.

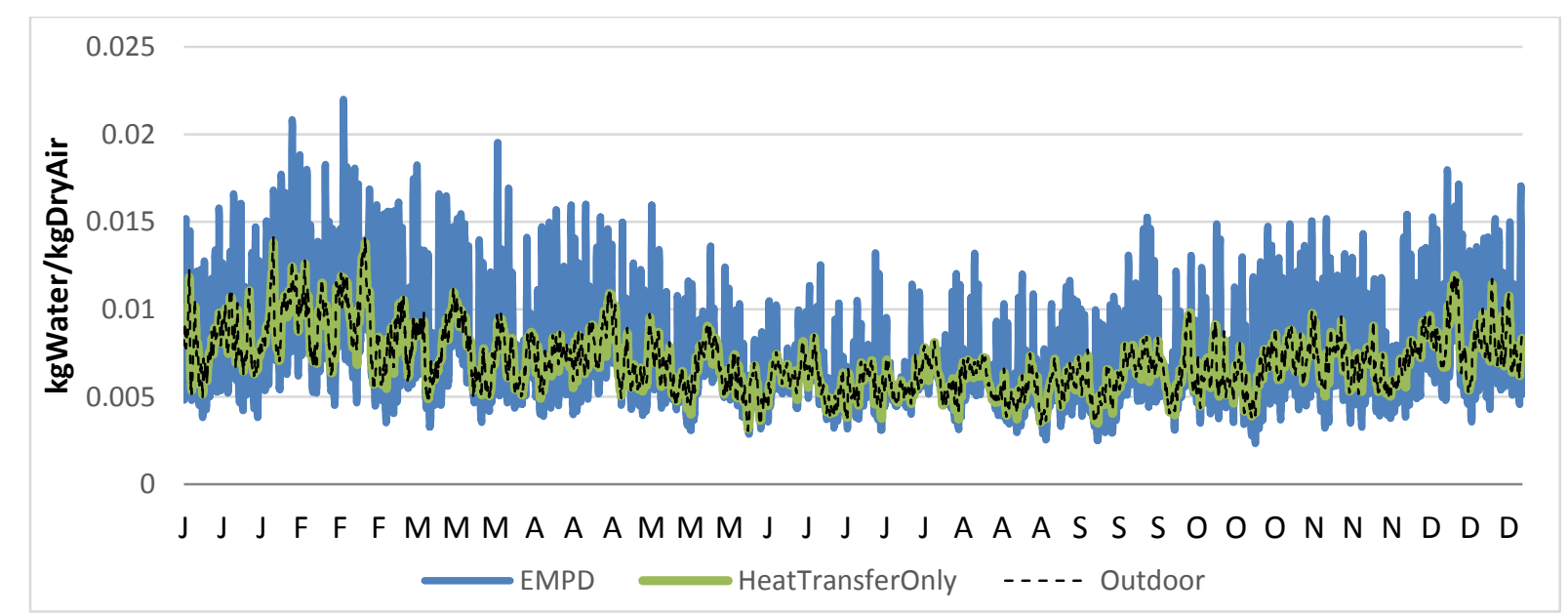

FiguRE 14: ANNUAL ABSOLUTE HUMIDITY 


\section{Moisture Gains in EnergyPlus}

The guidance for incorporating moisture loads using EnergyPlus is limited. After an e-mail request, the EnergyPlus Helpdesk provided the method for adding moisture gains using the "Internal Gains - Other Equipment" object. This object is set up for heat loads in Watts, but moisture loads are measured in litres (or kg) per hour.

\begin{tabular}{|l|l|l|}
\hline Field & Units & Obj1 \\
\hline Name & & $15 L /$ day \\
\hline Zone or ZoneList Name & & $\begin{array}{l}\text { Room } \\
\text { Always On Discrete }\end{array}$ \\
\hline Schedule Name & & $\begin{array}{l}\text { EquipmentLevel } \\
\text { Design Level Calculation Method }\end{array}$ \\
\hline Design Level & W & \\
\hline Power per Zone Floor Area & W/m2 & \\
\hline Power per Person & W/person & \\
\hline Fraction Latent & & 1 \\
\hline Fraction Radiant & & 0 \\
\hline Fraction Lost & & 0 \\
\hline
\end{tabular}

Figure 15: Filled OUt Other EquipMent OBJeCt IN ENERGYPLUS

The conversion from $\mathrm{kg} / \mathrm{hr}$ moisture load is: Emission rate $[\mathrm{kg} / \mathrm{hr}] *$ latent heat vaporisation of water $[2,260,000 \mathrm{~J} / \mathrm{kg}] * 1 / 3600$ seconds per hour $=$ moisture load in Watts $[\mathrm{J} / \mathrm{s}]$

The load is set in EnergyPlus as $100 \%$ latent, so moisture emissions of $0.5 \mathrm{~kg} / \mathrm{hr}$ are equivalent to a load of 314W.

Other researchers have documented adding a scheduled latent load to represent additional moisture loads [104, p. 7], converting $0.5 \mathrm{~kg} / \mathrm{hr}$ to $347 \mathrm{~W}$. This does not match with the process provided by the EnergyPlus Helpdesk.

Attempts were also made to verify in EnergyPlus that the added load in Watts produced the desired moisture load within the zone. This was not practical due to the buffering effect of internal surfaces. It is also not possible to run a moisture simulation in EnergyPlus without some form of ventilation, as the model produces a constant increase/decrease in moisture levels over the year depending on the selected calculation algorithm. The increases in absolute humidity $(\mathrm{kg}$ of water per kg of air) did not match the daily added zone loads. The absolute humidity may be well above or below that of an identical model with no loads. The annual moisture load patterns appear plausible, but could not be compared or verified.

\section{Moisture Summary}

While important to include moisture analysis to analyse the true benefit of the housing WoF criteria, EnergyPlus does not deal appropriately with household moisture loads, as they are included by specifying a fraction of the latent load. Calculating or finding values for these inputs is difficult as they are unable to be verified through EnergyPlus outputs alone. The moisture loads may be able to be verified through comparison with validated moisture modelling software but this falls outside the scope of this thesis.

Using the EMPD algorithm would ensure that the RH does not fluctuate excessively, however the validity of the reported absolute humidity from this model is unknown. It does not appear possible to firstly add believable moisture loads representing modern appliance use and behaviour. Secondly the quality of the results are unknown due to the inability to validate moisture loads in EnergyPlus. As a result, it was decided not to analyse varying moisture loads. 


\section{THERMAL MODEL}

This section covers the key components of the thermal model, sources for these inputs and sensitivity analyses of the impact these features have on performance.

\section{Key Components of the Building Thermal Model}

The key components of the thermal model are those aspects which are expected to have significant impact on the performance. These can be summarised as:

- Building plan

- Construction
- Wall, roof \& floor constructions
- Thermal mass
- Subfloor design
- Attic design
- Curtains

- Occupants and their behaviour

- Internal Loads

- Electrical loads

- Lighting (input separately to electrical loads)

- Domestic Hot Water

- Natural ventilation (including infiltration)

- Effective Moisture Penetration Depth (EMPD) properties

Main values for these components of the model, their sources and strategies used to implement them are documented in the following sections. A number of sensitivity analyses are then documented, exploring their importance and the potential impact of inaccurate values.

Numerous other objects are required in an EnergyPlus simulation. These allow the programme to run without errors and generate the desired outputs. These are not documented here as they are considered to have a minimal impact on the thermal performance of the model. Examples of these objects include the simulation control object, timestep object and output objects. A copy of the base model file is appended on CD. 


\section{Plans and Geometry}

As discussed on page 25, this is a 3 bedroom, 1 bathroom villa with a separate kitchen, living room and dining room. The window configuration is a mixture of the original villa design and later alterations. This is due to the lack of elevations for the original building and the number of renovations the house has undergone making measurement of the original window size impossible. Key dimensions describing the villa plan are provided in table 7. The window-to-wall ratio is $13.9 \%$, well below the threshold of $30 \%$ where the NZBC verification method requires specific analysis [108, p. 19]. Figure 16 is a 3D perspective of the villa design with a transparent view showing the internal rooms.

A generalised overview of the model is presented in the following sections, followed by detailed information on the key components.

\begin{tabular}{|c|c|}
\hline Floor Area & $110.3 \mathrm{~m}^{2}$ \\
\hline Wall Height & $3.05 \mathrm{~m}$ \\
\hline Conditioned Wall Area & $153 \mathrm{~m}^{2}$ \\
\hline Window Area & $26.6 \mathrm{~m}^{2}$ \\
\hline $\begin{array}{l}\text { Window-to-wall Ratio } \\
\text { (glazed area } \div \\
\text { conditioned wall area) }\end{array}$ & $13.9 \%$ \\
\hline Conditioned Volume & $350 \mathrm{~m}^{3}$ \\
\hline $\begin{array}{l}\text { Unconditioned Volume } \\
\text { (attic \& subfloor) }\end{array}$ & $1634 \mathrm{~m}^{3}$ \\
\hline Eave Depth & $0.18 \mathrm{~m}$ \\
\hline
\end{tabular}

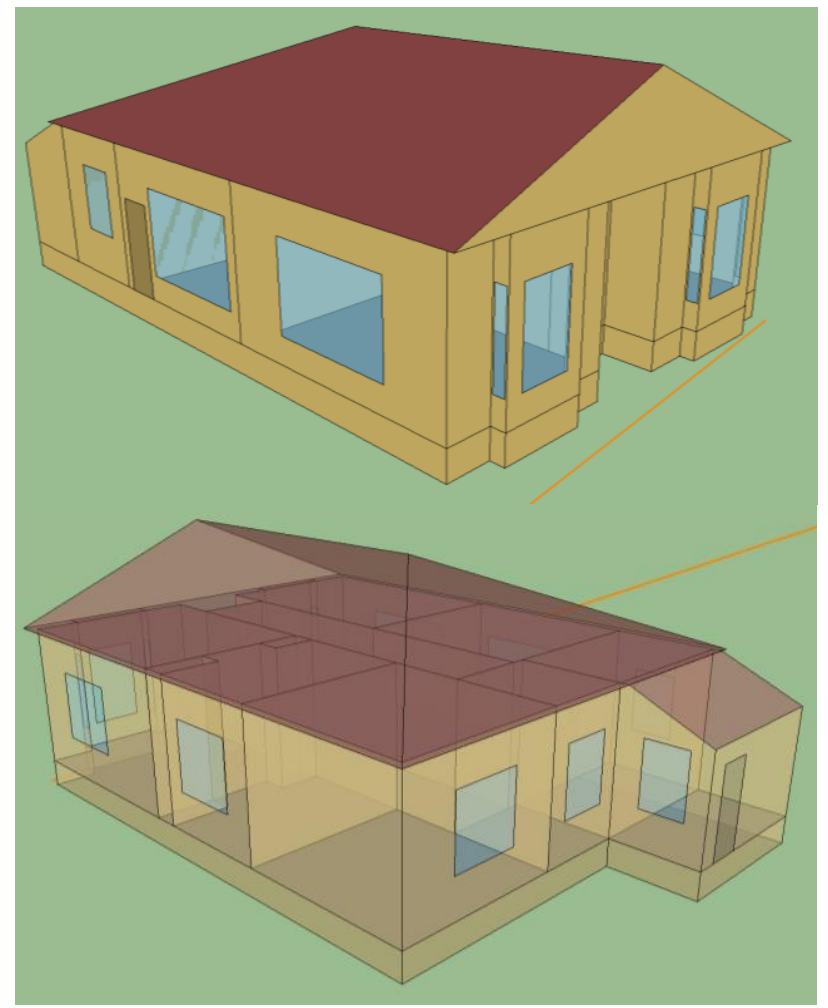

Figure 16: VIEWS OF THE ENERGyPLUS MOdel IN SKETCHUP. THE ORANGE LINE INDICATES NORTH 


\section{Construction}

The building construction has a significant impact on how much heat is gained and lost through the skin of the building. The test villa constructions are based on the summaries of construction methods provided in [88].

Villa walls were originally constructed with scrim (a rough, loosely woven hessian fabric applied over timber sarking) but this has generally been replaced, so the test villa uses $12 \mathrm{~mm}$ plasterboard.

The three bedrooms each have carpet over the floorboards as this is common practice. The modelling found that carpet has a small impact on the operative temperature (an average of the radiant and air temperature), increasing it on average by $0.14^{\circ} \mathrm{C}$.

The ceiling is plasterboard beneath timber framing, again using plasterboard in place of original construction materials. Insulation is laid around the ceiling framing rather than between rafters. This places the attic outside the thermal envelope, meaning it is not heated. The roof remains as $4 \mathrm{~m}$ corrugated steel. ${ }^{\mathrm{ii}}$

TABLE 8: SUMMARY OF VILLA CONSTRUCTION

\begin{tabular}{|l|l|l|}
\hline Component & Uninsulated & Insulated \\
\hline \multirow{2}{*}{ Wall } & $12 \mathrm{~mm}$ plasterboard & \\
\hline \multirow{2}{*}{ Ceiling } & R-0.12 airgap & \\
\cline { 2 - 3 } & $25 \mathrm{~mm}$ weatherboard & \\
\hline \multirow{2}{*}{ Floor } & $12 \mathrm{~mm}$ plasterboard & $12 \mathrm{~mm}$ plasterboard \\
\hline & (no material) & Up to R-3.01 material \\
\hline Roof & $18 \mathrm{~mm}$ floorboards & $18 \mathrm{~mm}$ floorboards \\
\hline Internal Wall & (no material) & Up to R-1.77 material \\
\hline & $1 \mathrm{~mm}$ corrugated steel & \\
\hline Foundation wall & $12 \mathrm{~mm}$ plasterboard & \\
\hline Subfloor base & R-0.12 airgap & \\
\hline & $12 \mathrm{~mm}$ plasterboard & \\
\hline
\end{tabular}




\section{External Wall}

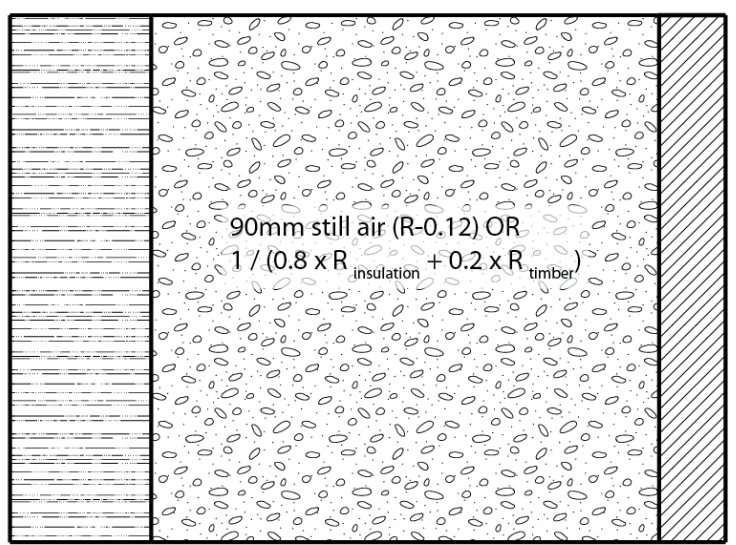

$25 \mathrm{~mm}$ weatherboards
$12 \mathrm{~mm}$ plasterboard
Internal Wall

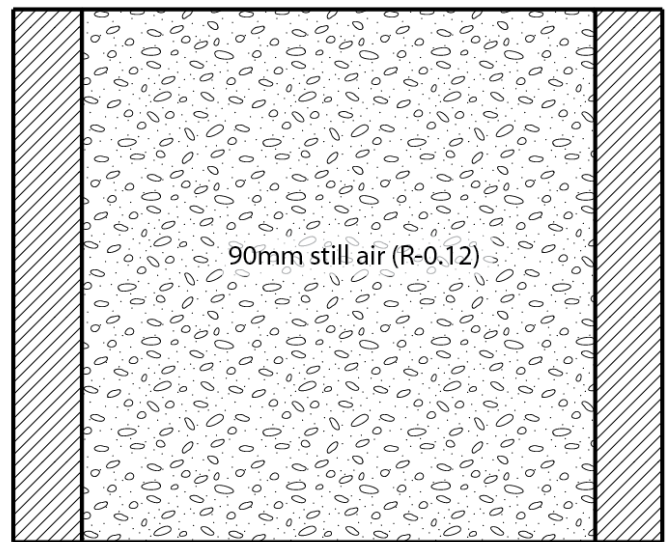

$12 \mathrm{~mm}$ plasterboard

$12 \mathrm{~mm}$ plasterboard
Ceiling

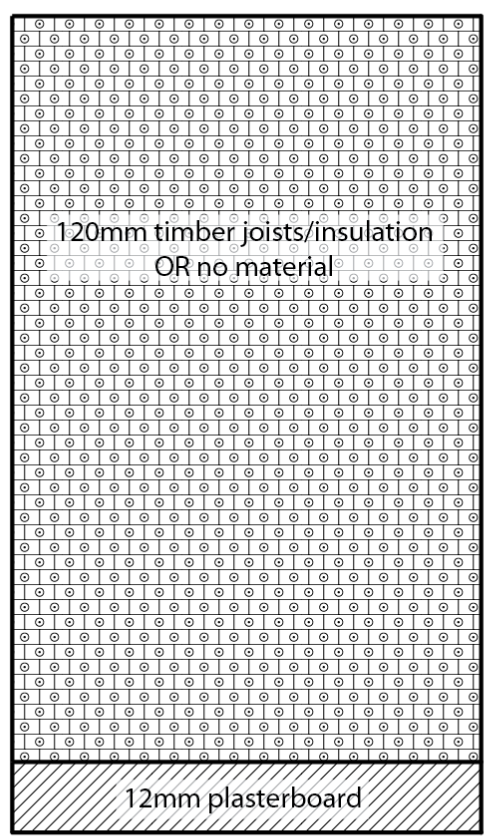

Floor

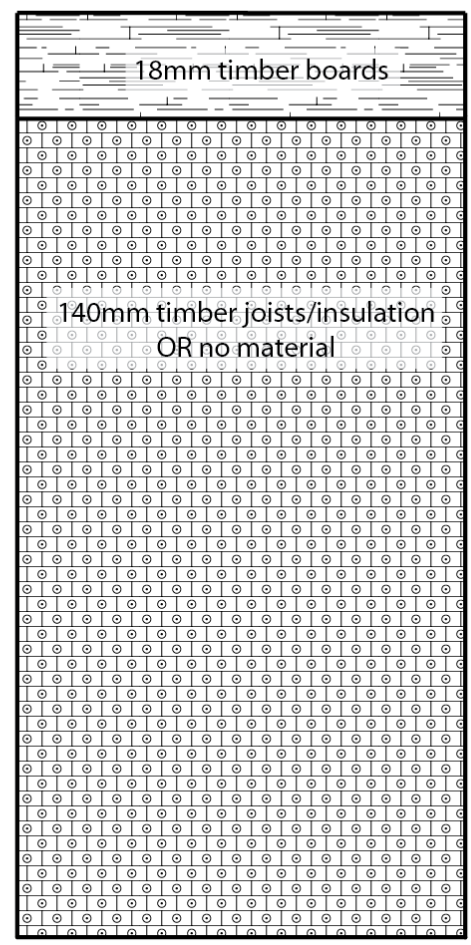




\section{Thermal Mass}

Thermal mass has an impact on thermal performance by storing heat when the sun is shining on it or when the surrounding air temperature is warmer than the material. The high thermal mass material then releases this heat when the surrounding air is cooler. A building with no thermal mass both heats up and cools down very quickly, causing sharp swings in temperatures. In reality there is no material without some thermal mass, but in EnergyPlus it is possible to model a material with no mass. Materials with low thermal mass include glass, timber and plasterboard, while high thermal mass materials include stone, brick and concrete.

The materials modelled with thermal mass are plasterboard, floorboards, weatherboards, carpet, metal roofing and soil in the subfloor zone. The timber framing and insulation are modelled without mass because they have been simplified into one homogenous material.

Other than the soil material in the subfloor (which is not in contact with any habitable zone) there are no high-mass materials in this model. High thermal mass would be expected to influence how much heating a building needs and how comfortable it is able to be kept without heating. It is also likely to reduce instance of overheating in the Auckland climate [109, p. 20].

\section{Subfloor Modelling Strategy}

The subfloor zone functions as a form of insulation, separating the house from the cold earth beneath. The properties of this zone will impact how well it insulates the house from outside temperatures, before even adding subfloor insulation.

The ground temperatures, which were available, were the undisturbed soil temperatures, measured at a $0.5 \mathrm{~m}$ depth. EnergyPlus specifically warns that these are likely to be too extreme for the ground under a conditioned building. For commercial buildings it is suggested that the ground temperature is related to the heating/cooling set point. As this building model often has no set point; the methods suggested within EnergyPlus are unsuitable. EnergyPlus also provides auxiliary programs 'slab' and 'basement' for calculating ground temperatures under a concrete slab or basement but these were found to be unsuitable

The chosen compromise was to model the subfloor zone with a 'floor' of $0.5 \mathrm{~m}$ thick soil to moderate the ground temperatures.

Subfloor ventilation modelling was as documented in the section 'Infiltration Modelling' p.51.

\section{Attic Modelling Strategy}

The attic was modelled as a thermal zone (as opposed to using a material of equivalent thermal performance) in order to allow for later inclusion of thermal insulation. This also allowed attic ventilation (and the corresponding reduction in thermal resistance) to be accounted for.

\section{Curtains}

Curtains have the potential to reduce overnight window heat loss, provided they are drawn when the sun sets, have a suitable thickness (R-value) and they seal around the window to stop cold air convection currents.

EnergyPlus has objects with parameters specifically designed for modelling window coverings, including curtains. The object 'WindowMaterial:Shade' is demonstrated in the example files to represent a curtain. 
The curtain construction is able to be scheduled on or off, representing the curtains being open or closed. EnergyPlus has a number of pre-defined schedules relevant to window coverings. The 'On Night If Low Outside Temp And Off Day' schedule was chosen as applicable to curtain use. The low temperature outside was specified as $18^{\circ} \mathrm{C}$ i.e. the curtains are drawn when the night time external temperature is below $18^{\circ} \mathrm{C}$.

It is possibly to significantly alter the performance of a simulated curtain with assumptions independent of the R-value of the curtain, as will be demonstrated in the following tests.

Tested U-Values for single glazed windows in a timber frame with a variety of thermal window treatments were obtained from the Technical Conservation Group document on Thermal performance of traditional windows [110]. These figures were provided as U-values including an allowance for the effective thermal resistance of a still air layer on either side of the pane of glass. Equation 1 in the document indicates this still air layer had a performance of R-0.17. EnergyPlus requires 'WindowMaterial' objects to be entered without these surface resistance values [106, $p$. 222]. To obtain inputs for EnergyPlus the measured U-value [110, p. 12] was converted to an Rvalue; the allowance for surface resistance was removed; and the R-value was converted back to a U-value.

\begin{tabular}{|c|c|c|c|c|}
\hline & $\begin{array}{l}\text { U-Value } \\
\text { (W/m² } \mathrm{K})\end{array}$ & $\begin{array}{l}\text { R-Value } \\
\left(K \cdot \mathrm{m}^{2} / \mathrm{W}\right)\end{array}$ & $\begin{array}{l}\text { R-Value } \\
\text { less } \\
\text { surface } \\
\text { resistance }\end{array}$ & U-Value \\
\hline Single glazing & 5.4 & 0.185 & 0.0152 & 65.9 \\
\hline $\begin{array}{l}\text { Single glazing } \\
\text { with thermal } \\
\text { curtains } \\
\text { illustrated in } \\
\text { figure } 18\end{array}$ & 3.2 & 0.313 & 0.143 & 7.0 \\
\hline $\begin{array}{l}\text { Single glazing } \\
\text { with modern } \\
\text { roller blind* }\end{array}$ & 3.0 & 0.455 & 0.285 & 3.5 \\
\hline Double glazing & 1.9 & 0.526 & 0.356 & 2.8 \\
\hline
\end{tabular}

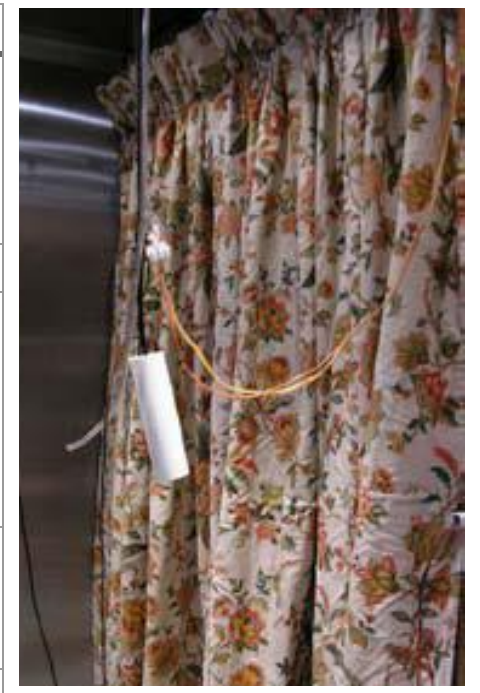

FIGURE 18: THE THERMAL CURTAINS TESTED [110]

* Not used in final simulations to reduce excessive comparisons

There are two possible methods for describing windows in EnergyPlus; the 'SimpleGlazingSystem' which requires few inputs; and standard 'WindowMaterial:Glazing' objects which require complete optical and thermal properties rather than simple heat loss values. Since the surface resistance coefficients were removed to enter the curtain performance into EnergyPlus, it was necessary to use the 'WindowMaterial:Glazing' object to describe the single glazing behind the curtain.

The WindowMaterial:Glazing object was used for single glazing while the simple glazing system was used for the double glazing. To model single glazing using the window material glazing objects, it was necessary to find a range of optical and thermal properties. The program Window 7.2 was used to obtain data for generic types of glass for $3 \mathrm{~mm}$ and a $6 \mathrm{~mm}$ options. Window 7.2 calculates performance $\mathrm{U}$-values for panes of glass based on the glass properties, pane size and 
exterior conditions. With the same dimensions as the window tested in [110], the $3 \mathrm{~mm}$ glass had a U-value of 5.6 (measured U-5.4) and the $6 \mathrm{~mm}$ glass $\mathrm{U}-5.5$ (measured U-5.4). It was decided to use the properties for the $6 \mathrm{~mm}$ glass for the single glazing option.

To reverse engineer curtains to match validated performance in [110], the opening multipliers and porosity were maintained at default values, the distance between the curtain and the glass was set to $0.001 \mathrm{~m}$ (the closest possible) and the curtain R-value varied to produce a performance of U-7.0.

The R-value was calculated from the window heat loss rate, the outside surface temperature, the inside surface temperature (on the surface of the curtain) for the hours of the year when the curtain is covering the window for the whole hour.

TABLE 10: TESTED CURTAIN R-VALUES AND CORRESPONDING CURTAIN AND WINDOW THERMAL PERFORMANCE

\begin{tabular}{|l|l|l|l|l|l|}
\hline Curtain R-value & Curtain U-value & $\begin{array}{l}\text { Conductivity } \\
\text { for } \mathbf{0 . 0 0 3 m} \\
\text { thick curtain }\end{array}$ & $\begin{array}{l}\text { Performance } \\
\text { R-value }\end{array}$ & $\begin{array}{l}\text { Performance } \\
\text { U-value }\end{array}$ & $\begin{array}{l}\text { Difference } \\
\text { from } \\
\text { target }\end{array}$ \\
\hline $\mathbf{0 . 0 7}$ & 14.3 & 0.043 & 0.11 & 8.8 & -1.74 \\
\hline $\mathbf{0 . 0 9}$ & 11.1 & 0.033 & 0.14 & 7.4 & -0.36 \\
\hline $\mathbf{0 . 0 9 5}$ & 10.5 & 0.032 & 0.14 & 7.2 & -0.21 \\
\hline $\mathbf{0 . 0 9 7}$ & $\mathbf{1 0 . 3}$ & $\mathbf{0 . 0 3 1}$ & $\mathbf{0 . 1 4}$ & $\mathbf{7 . 1}$ & $-\mathbf{0 . 0 5}$ \\
\hline $\mathbf{0 . 1 0}$ & 10.0 & 0.030 & 0.14 & 6.9 & 0.11 \\
\hline $\mathbf{0 . 2 5}$ & 4.00 & 0.012 & 0.30 & 3.4 & 3.65 \\
\hline $\mathbf{0 . 5 0}$ & 2.00 & 0.006 & 0.55 & 1.8 & 5.20 \\
\hline $\mathbf{A c u}$ & & &
\end{tabular}

A curtain in EnergyPlus with an R-value of 0.097 over $6 \mathrm{~mm}$ single glazing produced comparable results to those measured in [110] (shown by a grey shading in table 10).

\section{People}

People contribute to the thermal performance of a house by acting as mini-heaters. Each person gives off from 72 to 180 Watts of heat depending on activity (see table 11). This gain reduces the need for winter heating but increases the need for summer cooling. People also contribute to moisture loads (by breathing), however this is not included in the model.

The household is based on a stereotypical two parents and two children. The occupants are out on weekdays and at home in the weekend. This was chosen as a realistic number of people to inhabit a 3 bedroom house and result in a suitable level of water consumption, power consumption, internal heat gains and heating need for the simulation loads. The occupants' locations have been scheduled based on the test villa room layout to ensure they spend some time in every room. This is not based on any 'typical' schedule. 


\begin{tabular}{|c|c|c|c|c|c|c|c|c|c|c|c|c|c|c|c|c|c|}
\hline & Living & Bed 1 & Bath & Bed 3 & Hall & Bed 2 & Dining & Kit. & & Living & Bed 1 & Bath & Bed 3 & Hall & Bed 2 & Dining & Kit. \\
\hline 1:00 & - & 2 & - & 1 & - & 1 & - & - & $1: 00$ & - & 2 & - & 1 & - & 1 & - & - \\
\hline $2: 00$ & - & 2 & - & 1 & - & 1 & - & - & $2: 00$ & - & 2 & - & 1 & - & 1 & - & - \\
\hline $3: 00$ & - & 2 & - & 1 & - & 1 & - & - & $3: 00$ & - & 2 & - & 1 & - & 1 & - & - \\
\hline $4: 00$ & - & 2 & - & 1 & - & 1 & - & - & $4: 00$ & - & 2 & - & 1 & - & 1 & - & - \\
\hline $5: 00$ & - & 2 & - & 1 & - & 1 & - & - & $5: 00$ & - & 2 & - & 1 & - & 1 & - & - \\
\hline $6: 00$ & - & 2 & - & 1 & - & 1 & - & - & $6: 00$ & - & 2 & - & 1 & - & 1 & - & - \\
\hline $7: 00$ & - & 2 & - & 1 & - & 1 & - & - & $7: 00$ & - & 2 & - & 1 & - & 1 & - & - \\
\hline $8: 00$ & - & - & 2 & - & 2 & - & - & - & $8: 00$ & - & - & 2 & - & 2 & - & - & - \\
\hline 9:00 & - & - & - & - & - & - & 2 & 2 & 9:00 & - & - & - & - & - & - & 2 & 2 \\
\hline $10: 00$ & - & - & - & - & - & - & - & - & $10: 00$ & 4 & - & - & - & - & - & - & - \\
\hline $11: 00$ & - & - & - & - & - & - & - & - & $11: 00$ & 2 & - & - & - & - & - & - & 2 \\
\hline $12: 00$ & - & - & - & - & - & - & - & - & $12: 00$ & - & - & - & - & - & - & 4 & - \\
\hline $13: 00$ & - & - & - & - & - & - & - & - & $13: 00$ & 3 & - & - & - & - & - & - & 1 \\
\hline $14: 00$ & - & - & - & - & - & - & - & - & $14: 00$ & 2 & - & - & 1 & - & 1 & - & - \\
\hline $15: 00$ & - & - & - & - & - & - & - & - & $15: 00$ & 2 & - & - & 1 & - & 1 & - & - \\
\hline $16: 00$ & - & - & - & - & - & - & - & - & $16: 00$ & 2 & - & - & 1 & - & 1 & - & - \\
\hline $17: 00$ & - & - & - & 1 & - & 1 & - & 1 & $17: 00$ & 1 & - & - & 1 & - & 1 & - & 1 \\
\hline $18: 00$ & - & - & - & 1 & - & 1 & - & 1 & $18: 00$ & 3 & - & - & - & - & - & - & 1 \\
\hline $19: 00$ & - & - & - & - & - & - & 4 & - & $19: 00$ & - & - & - & - & - & - & 4 & - \\
\hline $20: 00$ & 3 & - & - & - & - & - & - & 1 & $20: 00$ & 3 & - & - & - & - & - & - & 1 \\
\hline $21: 00$ & 4 & - & - & - & - & - & - & - & $21: 00$ & 4 & - & - & - & - & - & - & - \\
\hline $22: 00$ & 3 & - & 1 & - & - & - & - & - & $22: 00$ & 3 & - & 1 & - & - & - & - & - \\
\hline $23: 00$ & - & - & 2 & 1 & - & 1 & - & - & $23: 00$ & - & - & 2 & 1 & - & 1 & - & - \\
\hline $0: 00$ & - & 2 & - & 1 & - & 1 & - & - & $0: 00$ & - & 2 & - & 1 & - & 1 & - & - \\
\hline
\end{tabular}

FIGURE 19: THE OCCUPANT WEEKDAY SCHEDULE LEFT AND THE WEEKEND SCHEDULE RIGHT

The numbers in figure 19 indicate how many people are in that room for that hour of the day.

Note the time refers to when the hour ends.

\begin{tabular}{|c|c|c|c|c|c|c|c|c|c|c|c|c|c|c|c|c|c|}
\hline & Living & Bed1 & Bath & Bed3 & Hall & Bed2 & Dining & Kit. & & Living & Bed1 & Bath & Bed3 & Hall & Bed2 & Dining & Kit. \\
\hline $01: 00$ & & 72 & & 72 & & 72 & & & 01:00 & & 72 & & 72 & & 72 & & \\
\hline $02: 00$ & & 72 & & 72 & & 72 & & & $02: 00$ & & 72 & & 72 & & 72 & & \\
\hline 03:00 & & 72 & & 72 & & 72 & & & 03:00 & & 72 & & 72 & & 72 & & \\
\hline 04:00 & & 72 & & 72 & & 72 & & & 04:00 & & 72 & & 72 & & 72 & & \\
\hline $05: 00$ & & 72 & & 72 & & 72 & & & $05: 00$ & & 72 & & 72 & & 72 & & \\
\hline $06: 00$ & & 72 & & 72 & & 72 & & & 06:00 & & 72 & & 72 & & 72 & & \\
\hline 07:00 & & 72 & & 72 & & 72 & & & 07:00 & & 72 & & 72 & & 72 & & \\
\hline $08: 00$ & & & 126 & & 126 & & & & $08: 00$ & & & 126 & & 126 & & & \\
\hline 09:00 & & & & & & & 108 & 171 & 09:00 & & & & & & & 108 & 171 \\
\hline $10: 00$ & & & & & & & & & $10: 00$ & 126 & & & & & & & \\
\hline $11: 00$ & & & & & & & & & 11:00 & 126 & & & & & & & 171 \\
\hline $12: 00$ & & & & & & & & & $12: 00$ & & & & & & & 108 & \\
\hline $13: 00$ & & & & & & & & & $13: 00$ & 108 & & & & & & & 171 \\
\hline $14: 00$ & & & & & & & & & $14: 00$ & 180 & & & 180 & & 180 & & \\
\hline $15: 00$ & & & & & & & & & $15: 00$ & 180 & & & 180 & & 180 & & \\
\hline $16: 00$ & & & & & & & & & $16: 00$ & 180 & & & 180 & & 180 & & \\
\hline $17: 00$ & & & & 171 & & 171 & & 171 & $17: 00$ & 126 & & & 171 & & 171 & & 171 \\
\hline $18: 00$ & & & & 126 & & 126 & & 171 & $18: 00$ & 126 & & & & & & & 171 \\
\hline 19:00 & & & & & & & 108 & & \begin{tabular}{|c|}
$19: 00$ \\
\end{tabular} & & & & & & & 108 & \\
\hline $20: 00$ & 108 & & & & & & & 171 & $20: 00$ & 108 & & & & & & & 171 \\
\hline $21: 00$ & 108 & & & & & & & & $21: 00$ & 108 & & & & & & & \\
\hline $22: 00$ & 108 & & 108 & & & & & & $22: 00$ & 108 & & 108 & & & & & \\
\hline $23: 00$ & & & 126 & 126 & & 126 & & & $23: 00$ & & & 126 & 126 & & 126 & & \\
\hline $00: 00$ & & 72 & & 72 & & 72 & & & 00:00 & & 72 & & 72 & & 72 & & \\
\hline
\end{tabular}

FIGURE 20: OCCUPANT HEAT GAIN SCHEDULES. THE WEEKDAY IS ON THE LEFT AND THE WEEKEND ON THE RIGHT.

Occupant heat gain schedules are shown above. Table 11 gives the heat gain in Watts per occupant based on different kinds of activities [103, p. 349]

\begin{tabular}{|r|l|}
\hline \multicolumn{2}{|l|}{ TABLE 11: HEAT GAINS PER PERSON } \\
FOR DIFFERENT ACTIVITIES \\
\hline $72 \mathrm{~W}$ & Sleeping \\
\hline $108 \mathrm{~W}$ & Seated, quiet \\
\hline $126 \mathrm{~W}$ & Standing, relaxed \\
\hline $171 \mathrm{~W}$ & Cooking \\
\hline $180 \mathrm{~W}$ & Walking \\
\hline
\end{tabular}




\section{Energy Loads}

Energy loads impact the thermal performance of a house because they are an indirect form of heating. Some of the energy used to run appliance such as TVs, lights and ovens is converted to heat by the appliance and then transferred into the air to heat the room. This heat has a sensible (dry) and in some cases a latent (wet) component. Sensible heat causes the temperature to change while latent heat is the energy taken for moisture to evaporate, adding a moisture load to a zone.

Energy loads for this model were, when possible, based on New Zealand data. Where this was not possible international data was used, and EnergyPlus default values used as a last resort.

\section{Electricity Consumption}

The electricity consumption for the villa was based primarily on the results from HEEP found the average annual household energy consumption was $11,410 \mathrm{kWh}$, including hot water, space heating and lighting which can be modelled in EnergyPlus. The HEEP values for these loads are included in table 12 below for reference, but the model calculated consumption for these through the more detailed inputs. The table below sets out all the different end uses of electricity in the model. Dark values are provided by HEEP and light values indicate how all the end-uses would produce the total consumption found by HEEP.

The data for cooking range and refrigeration can be found in table 66 in HEEP [18, p. 118]. The figures for New Zealand overall were used.

TABLE 12: HEEP AND ENERGYPLUS MODEL ELECTRICITY CONSUMPTION

\begin{tabular}{|c|c|c|c|c|c|c|}
\hline & All Fuels & Electricity & $\begin{array}{l}\text { kWh per } \\
\text { day }\end{array}$ & $\begin{array}{l}\text { Wh per } \\
\text { day }\end{array}$ & $\begin{array}{l}\text { Fraction } \\
\text { Sensible }\end{array}$ & $\begin{array}{l}\text { Fraction } \\
\text { Latent }\end{array}$ \\
\hline Average Total Energy Use & 11,410 & 7,800 & 31.26 & 31,260 & & \\
\hline $\begin{array}{l}\text { Hot Water (modelled } \\
\text { specifically) }\end{array}$ & 3,260 & 2,440 & 8.932 & 8,932 & & \\
\hline $\begin{array}{l}\text { Space Heating (modelled } \\
\text { specifically) }\end{array}$ & 3,820 & 920 & 10.47 & 10,466 & & \\
\hline All Cooking & 900 & & 2.466 & 2,466 & 0.40 & 0.30 \\
\hline $\begin{array}{l}\text { Lighting (modelled } \\
\text { specifically) }\end{array}$ & 910 & & 2.493 & 2,493 & 1.00 & 0.00 \\
\hline Refrigeration & 1,120 & & 3.068 & 3,068 & 1.00 & 0.00 \\
\hline Clothes Washer & 334.0 & & 0.915 & 915 & 0.80 & 0.00 \\
\hline Clothes Dryer (optional) & 245.0 & & 0.671 & 671 & 0.15 & 0.05 \\
\hline Miscellaneous & 1,066 & & 1.362 & 2921 & 0.66 & 0.02 \\
\hline Total & 11,410 & & & 31,260 & & \\
\hline
\end{tabular}




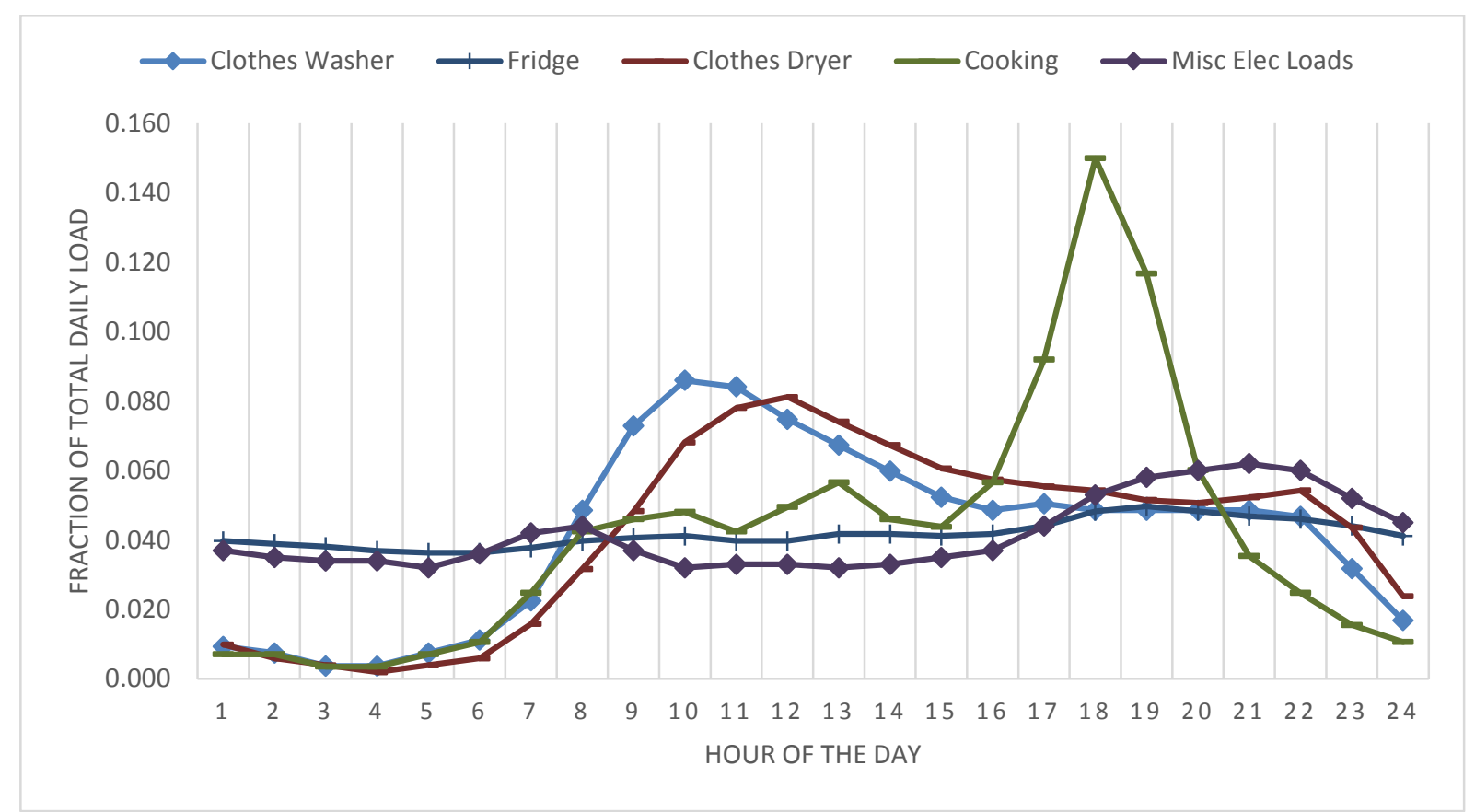

FIgURE 21: LOAD PROFILES

Clothes washer \& clothes dryer

The consumption for these is based on the EECA running costs calculator, illustrated in figure 22 [113].

The washing machine is assumed to be $7 \mathrm{~kg}$ capacity with 6 washes a week ( $50 \%$ warm/cold) for a washing machine with a $1 \frac{1}{2}$ star rating. The corresponding consumption for this is $334 \mathrm{kWh}$ p.a.

\section{Washing Machine}

\section{STEP TWO}

Select your usage details

Wash setting

Cold $v$

Capacity $[\mathrm{kg}]$

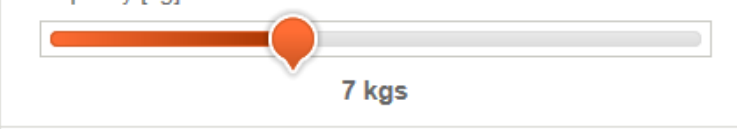

Average number of uses per week

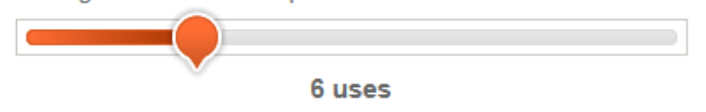

Percentage of washes using cold water cycle

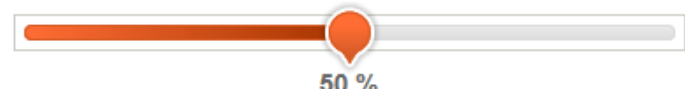

\section{STEP THREE}

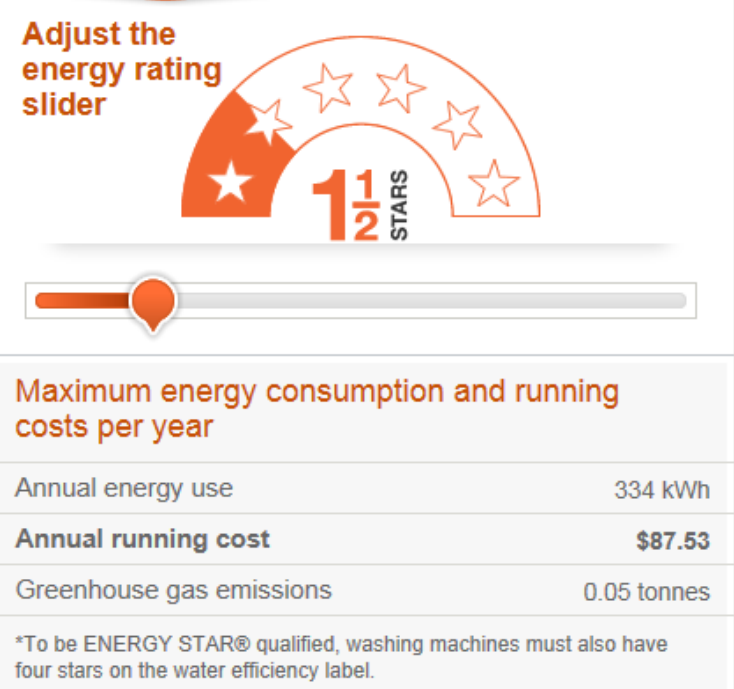

FIGURE 22: RUNNING COSTS CALCULATOR FOR A WASHING MACHINE PROVIDED BY EECA

Initially, a separate, unvented clothes dryer was going to be used to investigate the impact of moisture but as moisture modelling was not possible, it was not necessary to add this to the model. The dryer energy was assigned to miscellaneous equipment and is distributed around the house. 


\section{Miscellaneous equipment}

These are other electrical uses not already accounted for; including TV(s), computer(s), charger(s) or other plug-in electrical device(s). This miscellaneous equipment is assumed to use the difference between the overall HEEP household consumption and the sum of the individual energy uses already accounted for in the simulation.

\section{Lighting Consumption}

For comparability with the criteria in the WoFs (one working light in each room) the lighting wattage is much lower than the consumption recorded in HEEP. The kitchen and the living room were each given 2 lights due to their size and layout to produce acceptable levels of light.

Lighting wattage is set out in table 13 and Schedules are illustrated in figure 23.

TABLE 13: LIGHTING WATTAGES FOR MODELLING

\begin{tabular}{|l|l|l|}
\hline Room & Bulbs & $\begin{array}{l}\text { Total } \\
\text { Wattage }\end{array}$ \\
\hline Lights Living & $2 \times 23$ W CFL bulb & $46 \mathrm{~W}$ \\
\hline Lights Bed1 & $1 \times 23$ W CFL bulb & $23 \mathrm{~W}$ \\
\hline Lights Bath & $1 \times 23$ W CFL bulb & $23 \mathrm{~W}$ \\
\hline Lights Bed3 & $1 \times 23$ W CFL bulb & $23 \mathrm{~W}$ \\
\hline Lights Hall & $2 \times 18$ W CFL bulb & $36 \mathrm{~W}$ \\
\hline Lights Bed2 & $1 \times 23$ W CFL bulb & $23 \mathrm{~W}$ \\
\hline Lights Dining & $1 \times 23$ W CFL bulb & $23 \mathrm{~W}$ \\
\hline Lights Kitchen & $2 \times 23$ W CFL bulb & $46 \mathrm{~W}$ \\
\hline
\end{tabular}

\begin{tabular}{|c|c|c|c|c|c|c|c|c|c|c|c|c|c|c|c|c|c|}
\hline & Living & Bed 1 & Bath & Bed 3 & Hall & Bed 2 & Dining & Kit. & & Living & Bed 1 & Bath & Bed 3 & Hall & Bed 2 & Dining & Kit. \\
\hline $1: 00$ & - & - & - & - & - & - & - & - & $1: 00$ & - & - & - & - & - & - & - & - \\
\hline $2: 00$ & - & - & - & - & - & - & - & - & $2: 00$ & - & - & - & - & - & - & - & - \\
\hline $3: 00$ & - & - & - & - & - & - & - & - & $3: 00$ & - & - & - & - & - & - & - & - \\
\hline $4: 00$ & - & - & - & - & - & - & - & - & $4: 00$ & - & - & - & - & - & - & - & - \\
\hline $5: 00$ & - & - & - & - & - & - & - & - & $5: 00$ & - & - & - & - & - & - & - & - \\
\hline $6: 00$ & - & - & - & - & - & - & - & - & $6: 00$ & - & - & - & - & - & - & - & - \\
\hline $7: 00$ & - & - & - & - & - & - & - & - & $7: 00$ & - & - & - & - & - & - & - & - \\
\hline $8: 00$ & - & 1 & 1 & 1 & 1 & 1 & - & - & $8: 00$ & - & 1 & 1 & 1 & 1 & 1 & - & - \\
\hline 9:00 & - & 1 & - & 1 & 1 & 1 & 1 & 1 & 9:00 & 1 & 1 & - & 1 & 1 & 1 & 1 & 1 \\
\hline $10: 00$ & - & - & - & - & - & - & - & - & $10: 00$ & 1 & - & - & - & - & - & - & - \\
\hline $11: 00$ & - & - & - & - & - & - & - & - & $11: 00$ & - & - & - & - & - & - & - & - \\
\hline $12: 00$ & - & - & - & - & - & - & - & - & $12: 00$ & - & - & - & - & - & - & - & - \\
\hline $13: 00$ & - & - & - & - & - & - & - & - & $13: 00$ & - & - & - & - & - & - & - & - \\
\hline $14: 00$ & - & - & - & - & - & - & - & - & $14: 00$ & - & - & - & - & - & - & - & - \\
\hline $15: 00$ & - & - & - & - & - & - & - & - & $15: 00$ & - & - & - & - & - & - & - & - \\
\hline $16: 00$ & - & - & - & - & - & - & - & - & $16: 00$ & 1 & - & 1 & - & - & - & - & - \\
\hline $17: 00$ & - & - & - & 1 & - & 1 & - & 1 & $17: 00$ & 1 & - & 1 & 1 & - & 1 & - & 1 \\
\hline $18: 00$ & - & - & - & 1 & 1 & 1 & - & 1 & $18: 00$ & 1 & - & - & - & 1 & - & - & 1 \\
\hline 19:00 & - & - & - & - & - & - & 1 & - & $19: 00$ & 1 & - & - & 1 & - & 1 & 1 & - \\
\hline $20: 00$ & 1 & - & - & - & 1 & - & - & 1 & $20: 00$ & 1 & - & - & - & 1 & - & - & 1 \\
\hline $21: 00$ & 1 & - & - & - & - & - & - & - & $21: 00$ & 1 & - & 1 & - & - & - & - & - \\
\hline $22: 00$ & 1 & - & 1 & - & - & - & - & - & $22: 00$ & 1 & - & - & - & - & - & - & - \\
\hline $23: 00$ & 1 & - & 1 & 1 & 1 & 1 & - & - & $23: 00$ & 1 & - & 1 & 1 & 1 & 1 & - & - \\
\hline $0: 00$ & - & 1 & - & - & - & - & - & - & $0: 00$ & - & 1 & - & 1 & - & 1 & - & - \\
\hline
\end{tabular}

FIGURE 23: LIGHTING SCHEDULES BY ROOM (WEEKDAY ON LEFT, WEEKEND ON RIGHT) RED = OFF \& GREEN = ON

\section{Hot Water System}

The model contains a detailed plumbing system with electric water heating. This is used to analyse the impact of the heat gains from the HWC (HWC) as well as the heat and moisture gains from hot water consumption. The detailed hot water system also permits including the efficiency of the HWC in the analysis.

Cold water temperatures (using the site:WaterMainsTemperature object) were initially calculated based on the Wellington ground temperatures [106, p. 1240]. However, a transcription error resulted in the default value of $10^{\circ} \mathrm{C}$ year round being used, removing some free heating for hot water in summer. The consequences of this are discussed in the "Results and Discussion" section. 
The system uses a HWC modelled on the Rheem 312250 (specified as suitable for a family of 4) [114]. The distribution pipes are simplified to be adiabatic and do not contribute to heat loss. Key parameters for modelling the HWC are set out in table 14. As required by the NZBC, water is stored at $60^{\circ} \mathrm{C}$ and delivered at $55^{\circ} \mathrm{C}$ at the tap. Not all of the necessary data was available from the manufacturer's website, some figures had to be obtained through correspondence with a product representative.

TABLE 14: HWC PROPERTIES IN ENERGYPLUS

\begin{tabular}{|l|l|l|}
\hline Field & Value & Source/Comments \\
\hline Tank volume & $0.25 \mathrm{~m}^{3}$ & {$[114]$} \\
\hline Setpoint temp schedule & $60^{\circ} \mathrm{C}$ & $\begin{array}{l}\text { Set at } 60^{\circ} \mathrm{C} \text { based on recommendations by Rheem and } \\
\text { requirements in NZBC Clause G12, 6.14.3. }\end{array}$ \\
\hline $\begin{array}{l}\text { Deadband temperature } \\
\text { difference }\end{array}$ & $8^{\circ} \mathrm{C}$ & Email from the product representative \\
\hline Maximum temperature limit & $70^{\circ} \mathrm{C}$ & {$[114]$ Set as the maximum thermostat setting } \\
\hline Heater fuel type & Electricity & {$[114]$} \\
\hline $\begin{array}{l}\text { Heater thermal efficiency } \\
\text { Ambient temperature zone } \\
\text { name }\end{array}$ & 0.98 & $\begin{array}{l}\text { Based on WaterHeaterDHWPlantLoop.idf (an example file } \\
\text { provided with EnergyPlus) }\end{array}$ \\
\hline $\begin{array}{l}\text { Loss coefficient to ambient } \\
\text { HWC is located in the hallway in an uninsulated cupboard }\end{array}$ & $1.4088 \mathrm{~W} / \mathrm{K}$ & $\begin{array}{l}\text { Email from product representative. This is a conversion } \\
\text { from the standing heat loss, more detail is provided below. }\end{array}$ \\
\hline $\begin{array}{l}\text { Loss fraction to zone } \\
\text { Indirect water heating } \\
\text { recovery time }\end{array}$ & 1 & Left as default. All heat lost warms the hallway zone. \\
\hline
\end{tabular}

Standing heat loss is reported in $\mathrm{kWh}$ per day. A formula for conversion to Watts/Kelvin is provided below. The $55.6^{\circ} \mathrm{C}$ temperature differential was originally specified as $100^{\circ} \mathrm{F}$ in NZS 4602:1976.

Loss coefficient to ambient $[\mathrm{W} / \mathrm{K}]=\frac{\text { standing heat loss }[\mathrm{kW}] \times 1000}{\text { temperature differential } \times \text { hours }}=\frac{1.88 \times 1000}{55.6 \times 24}$

$$
=1.409 \mathrm{~W} / \mathrm{K}
$$

The hot water loop has two water uses attached, a sink and a shower. The flow rates for these $(8 \mathrm{~L} / \mathrm{m}$ for a shower and $4.5 \mathrm{~L} / \mathrm{m}$ for a sink) are based on the 2008 Auckland Water Use Study [115, p. 66]. Schedules were then created to match the flow rate with the recorded total consumption of heated wateriii $[115$, p. 66]. Shower usage was set at $4 \times 7$ minute showers per day $(7$ minutes was the average recorded shower length), as shown in figure 24 . This resulted in an annual consumption of $78,840 \mathrm{~L}$ of hot water for showering by the household. This is slightly higher than the average recorded consumption $(73,584 \mathrm{~L}$ ) because each study participant took on average only 0.9 (not 1) showers per day.

It was impractical in EnergyPlus to have 0.9 showers a day (it requires schedules accurate to sub 1 minute intervals or varying schedules across the year) and the variation caused by the scheduled loads would make analysis more difficult. Bathtub consumption is not included in the simulation, which in the BRANZ study measured to be approximately $3,880 \mathrm{~L}$ p.a., narrowing the difference between measured and simulated results. 


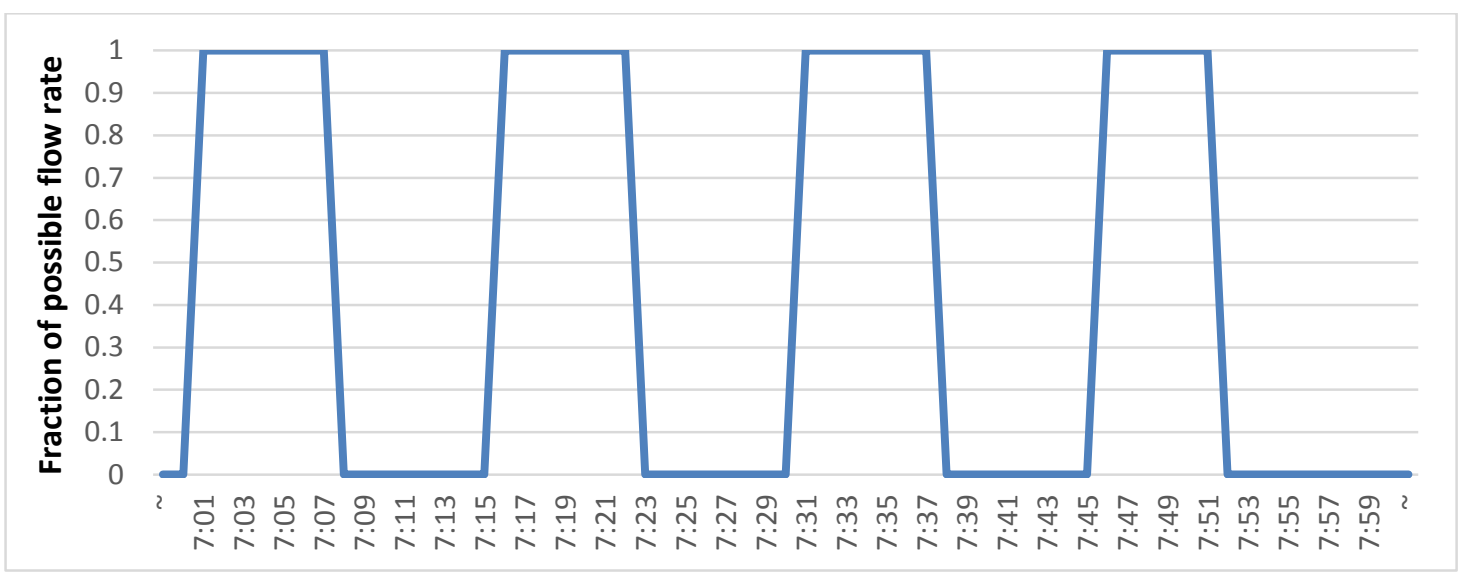

FIGURE 24: SHOWER USE SCHEDULE

The sink consumption in the model includes water use recorded by sinks in the BRANZ study as well as by dishwashers which only accounted for an average of $2 \%$ of the total indoor water use (5,168L p.a.). The sink use is scheduled in the morning and evenings (shown in figure 25). The sink is either running at $100 \%$ of its flow rate or it is off. More detailed use schedules are available (for example from Building America [112]). These schedules however are not necessarily more accurate for this scenario, because they distribute consumption throughout the day when the occupants of this test villa have been specified not to be home. These schedules may also hide issues related to peak heat and moisture generation.

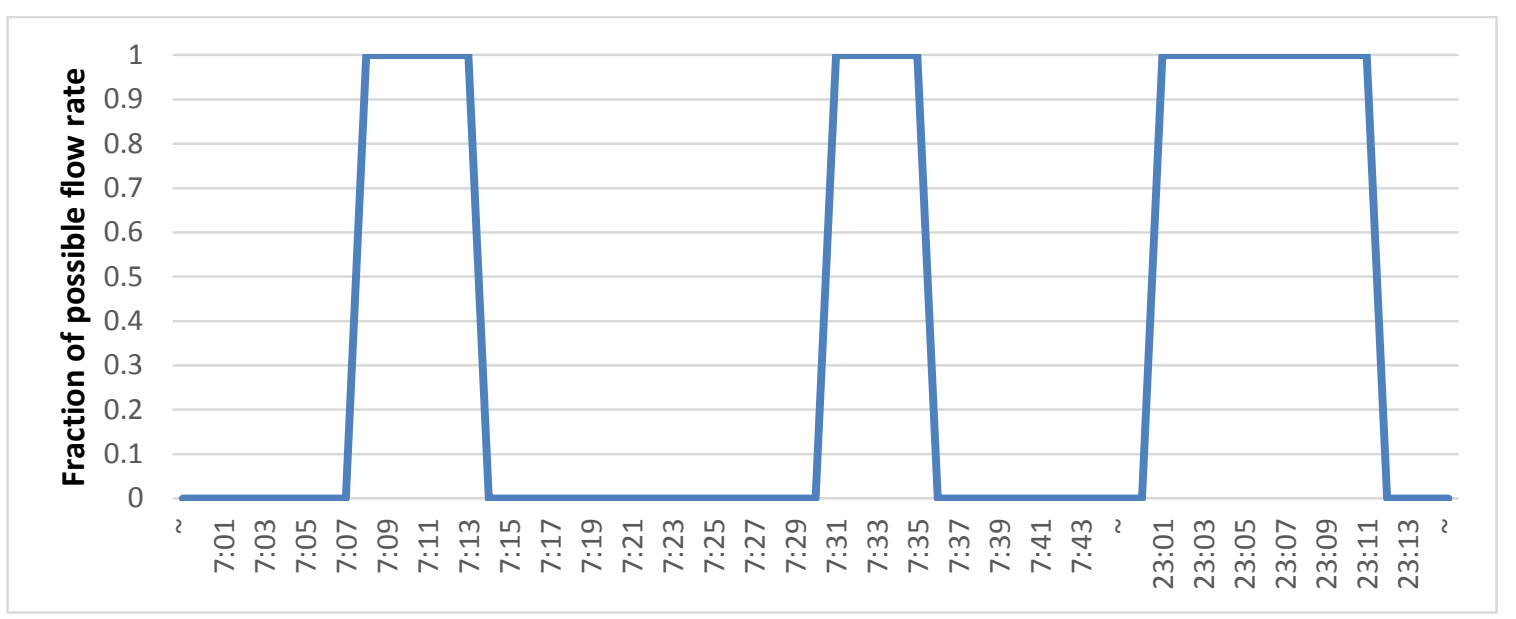

FIGURE 25: SINK USE SCHEDULE

The temperatures at the tap/shower are lower than the $55^{\circ} \mathrm{C}$ delivered water temperature as specified in the WoF. This is because Clause G1 6.14.1 of the NZBC states the temperature for children must be below $45^{\circ} \mathrm{C}$ but as comfortable showering temperatures range from $38-45^{\circ} \mathrm{C}$ [116]. $41^{\circ} \mathrm{C}$ was picked as a middle-point. This is achieved by a tempering valve mixing cold water with the stored hot water at $60^{\circ} \mathrm{C}$.

Hot water consumption by the washing machine was not modelled because energy consumption figures available from EECA already take into account the hot water [113]. The power consumption object also describes the amount of sensible heat (temperature rise) and latent heat (moisture gain) from the washing machine. The fractions of sensible and latent load come from the Building America house simulation protocols [111, p. 46] 


\section{Natural Ventilation Model}

Ventilation is used for the removal of heat and pollutants from the building. The ventilation is controlled based on the internal temperature (occupants open the windows if it gets too warm) but it would also have an effect on internal moisture levels and other pollutants such as carbon dioxide. Only the impact on temperature will be directly measured. Ventilation will also have an indirect impact on relative humidity.

There are two methods of modelling natural ventilation in EnergyPlus. The 'simple' method using the 'Zone Airflow' objects permits the addition of a constant ventilation rate as a simple flow rate $\left[\mathrm{m}^{3} / \mathrm{s}\right]$, flow per floor area $\left[\mathrm{m}^{3} / \mathrm{s} . \mathrm{m}^{2}\right]$, flow per exterior surface area $\left[\mathrm{m}^{3} / \mathrm{s} . \mathrm{m}^{2}\right]$ or Air Changes per Hour. This option was considered too simple for natural ventilation in a domestic situation when the ventilation also serves as cooling.

The 'AirflowNetwork' model allows for more detailed representation of natural ventilation (although not nearing the complexity of a computational fluid dynamics model). The airflow network model calculates temperatures for a single node in each zone, under the assumption that the air is evenly mixed and the temperature in the zone is uniform.

To model natural ventilation for the test villa the following objects were used:

'Component:SimpleOpening': A window and a door were defined based on the AirflowNetwork example files provided with EnergyPlus. The maximum opening factor of 0.5 (fraction of the surface that opens) for the door was based on the example file's value of 0.5. The maximum opening factor for the windows of 0.25 is a default value due to the lack of information on the original windows. For sash windows the opening factor could be as high as 0.5 but not all the windows appeared to be sash windows.

'Surface:EffectiveLeakageArea': More detail is provided on this in the following section. One leakage object was provided for every external wall in the building.

'Surface': This is where every external wall, window and internal and external door was matched with an opening object or a leakage area. The leakage objects are always on and the ventilation objects are always available.

'Zone': The ventilation control is set to 'temperature' and ventilation is scheduled to be available when the internal temperature reaches $24^{\circ} \mathrm{C}$. The ventilation temperature is based on NZS 4218:2009, clause G4.1.1. The lower limit for maximum venting is set to $2^{\circ} \mathrm{C}$ and the upper limit is set to $30^{\circ} \mathrm{C}$. In practice, the simulation in Wellington does not approach a $30^{\circ} \mathrm{C}$ difference between the indoor and outdoor temperature.

These ventilation objects are then managed using the 'Energy Management Sensor' objects. These comprise of the 'Sensor', 'Actuator', 'ProgramCallingManager' and 'Program'. There is a Sensor for each zone to determine the zone operative temperature, an actuator which is able to control the opening of the windows based on a schedule, a Program Calling Manager which sets the order of the calculations and the Program which sets out additional rules for when the actuator can and can't open the windows. The function of the program is to open the windows when the zone reaches a specified temperature and when it is hot indoors prevent the windows from remaining open if it is hotter outside. Note that the temperature difference specified by the 'Zone' object takes precedence over the absolute temperature specified in the 'Program' object. 
These objects have a free form data entry field which will not be automatically highlighted if there are errors or conflicts, so care must be taken with these objects. These Energy Management System objects were adapted from files by Cory, documented in his thesis [117, p. 426].

\section{Infiltration Modelling}

Infiltration is essentially uncontrolled ventilation. It causes varying levels of heat loss depending on the outside temperatures and strength of the wind.

Initially ventilation rates for different types of New Zealand housing constructions were obtained from work by McNeil et al. [118]. This reports the average air changes per hour for a pre 1960s dwelling with strip floors and unsealed timber windows as 19AC/H under a pressure of 50 Pascals.

From this an effective leakage area (ELA) was calculated for the whole building using two formulas. First the building volume is converted to $\mathrm{ft}^{3}$. Second, the $\mathrm{ACH}_{50}$ (for the whole building) is converted into cubic feet per minute at 50 pascals ( CFM $_{50}$ ) based on the following equation $[119$, p. 10]:

$$
C F M_{50}=A C H_{50} \times \frac{\text { Volume }\left[f^{3}\right]}{60}=19 \times \frac{12348}{60}=3910.2
$$

Second, the following equation from Lawrence Berkeley Laboratory [119, p. 10] converts the $\mathrm{CFM}_{50}$ into a house ELA of $0.134 \mathrm{~m}^{2}\left(1345 \mathrm{~cm}^{2}\right)$.

$$
E L A=\frac{C F M_{50}}{2700}=\frac{3910.2}{2700}=1.4482 f t^{2}=0.1345 m^{2}
$$

This ELA was then distributed pro-rata across all the external walls of the living zones (excluding the subfloor or attic).

The ELA for the subfloor space was set according to the NZBC requirement of $3,500 \mathrm{~mm}^{2}$ of net open area for every $1 \mathrm{~m}^{2}$ of floor area. This equates to a requirement of $0.3861 \mathrm{~m}^{2}$ of vent area for the subfloor. This was assigned proportionally to the subfloor walls.

The ELA for the attic was set to $0.08 \mathrm{~m}^{2}$, based on published measurements for a house of comparable construction (timber weatherboards with a galvanised steel roof) [120].

The achieved ventilation rates were then checked to ensure the model was producing reasonable rates using the airflow network to represent natural ventilation.

To analyse the building with the windows 'closed' the opening factor was set to a negligible amount (0.00001). Removing the windows entirely was not possible because the simulation requires multiple openings for each zone to calculate the infiltration rate. When simulating the model in Wellington's climate the subfloor achieved an average of $13.2 \mathrm{ACH}$ over the year while the whole house achieved an average total of $8.7 \mathrm{ACH}$. Further detail for each zone is provided in table 15. 
Table 15: Annual aVerage infiltration rates in Wellington (Air Changes Per Hour) for each zone

\begin{tabular}{|c|c|c|c|c|c|c|c|c|c|c|}
\hline \multicolumn{10}{|c|}{ House } \\
\hline Bath & Bed1 & Bed2 & Bed3 & Dining & Hall & Kitchen & Living & Total & Subfloor & Attic \\
\hline 0.05 & 1.7 & 0.03 & 1.8 & 0.16 & 0.10 & 3.2 & 1.7 & $\mathbf{8 . 7}$ & 13.2 & 4.0 \\
\hline
\end{tabular}

The zones with the smallest infiltration rates are those with the smallest external wall area. The subfloor has very high ventilation rates. These are likely higher than would be seen in real homes because the house is assumed to have no obstructions around the subfloor. Additionally BRANZ House Condition Surveys have repeatedly found insufficient ventilation under timber-framed floors i.e. the opening areas are not as large as the NZBC requirements [87].

Wellington has a notoriously windy climate so the villa was also tested using the Christchurch weather file which resulted in 5.1 ACH for the living spaces and 6.4 ACH for the subfloor (table 16).

TABLE 16: ANNUAL AVERAge INFILTRATION RATES IN CHRISTCHURCH FOR COMPARISON TO MEASURED VALUES

\begin{tabular}{|c|r|r|r|r|r|r|r|r|r|r|}
\hline \multicolumn{1}{|c|}{ House } \\
\hline Bath & Bed1 & Bed2 & Bed3 & Dining & Hall & Kitchen & Living & Total & Subfloor & Attic \\
\hline 0.04 & 0.94 & 0.03 & 1.5 & 0.09 & 0.07 & 1.5 & 0.86 & $\mathbf{5 . 1}$ & 6.4 & 1.7 \\
\hline
\end{tabular}

When located in Christchurch the test villa has a slightly lower infiltration rate, however it is still well above the suggested rate of $0.5 \mathrm{ACH}$ to remove contaminants [121]. 


\section{Sensitivity Analysis}

Tests were carried out to identify the impact/significance of adding different components to the model. One key issue was the lack of documentation on the importance of different 'features' for a domestic, naturally ventilated, thermal model. It was impossible to know if adding different things into the model would have a noticeable effect on thermal performance until the work was completed. Once features were included in the model it was easy to parametrically change values to test the model's sensitivity. A summary of these sensitivity analyses is provided on $p .63$

For ease of troubleshooting these sensitivity analyses were carried out on a simple square 'box' model with three zones: (1) a subfloor, (2) an attic and (3) a habitable room.

\section{Construction Framing Simplification}

Multiple methods of modelling walls, ceilings and floors with framing were trialled. An uninsulated construction which would normally contain timber framing and airspace was simplified in three different ways.

1. The middle layer of the wall was assumed to be a $90 \mathrm{~mm}$ airgap because thermal bridging would render the insulating effects of the timber negligible.

2. The middle layer was modelled as a no-mass construction with an R-value determined by calculating the R-values for timber (20\%) and a 90mm airgap (80\%)

3. Two constructions were created, one with a middle layer of timber and one with a middle layer as an airgap then dividing each wall, ceiling and floor into $80 \% / 20 \%$ areas

Two insulated constructions were also tested.

4. The middle layer modelled as a single no-mass material representing $20 \%$ timber $80 \%$ insulation

5. Two different constructions: one with a middle layer of timber and the other with a middle layer of insulation. The walls, ceiling and floor were again divided $80 \% / 20 \%$.

As given in table 17, each wall had an outer layer of $25 \mathrm{~mm}$ weatherboard and an inner layer of $12 \mathrm{~mm}$ plasterboard with the middle layer being varied. The ceiling and floor had either $12 \mathrm{~mm}$ plasterboard or $18 \mathrm{~mm}$ hardwood timber floorboards on the inside and the varying construction on the outside. The insulation achieved the maximum overall R-value intended to be used in the analyses. 
TABLE 17: COMPARISON OF CONSTRUCTION FRAMING MODELS

\begin{tabular}{|c|c|c|c|c|}
\hline & & Wall & Ceiling & Floor \\
\hline \multirow[t]{4}{*}{ Uninsulated } & 1 & $\begin{array}{l}12 \mathrm{~mm} \text { plasterboard } \\
\mathrm{R}-0.12 \text { airgap } \\
25 \mathrm{~mm} \text { weatherboard }\end{array}$ & $\begin{array}{l}12 \mathrm{~mm} \text { plasterboard } \\
\text { (no material) }\end{array}$ & $\begin{array}{l}18 \mathrm{~mm} \text { floorboards } \\
\text { (no material) }\end{array}$ \\
\hline & 2 & $\begin{array}{l}12 \mathrm{~mm} \text { plasterboard } \\
\mathrm{R}-0.19 \text { material } \\
25 \mathrm{~mm} \text { weatherboard }\end{array}$ & $\begin{array}{l}12 \mathrm{~mm} \text { plasterboard } \\
\mathrm{R}-0.18 \text { material }\end{array}$ & $\begin{array}{l}18 \mathrm{~mm} \text { floorboards } \\
\mathrm{R}-0.23 \text { material }\end{array}$ \\
\hline & $\begin{array}{l}3 \\
80 \%\end{array}$ & $\begin{array}{l}12 \mathrm{~mm} \text { plasterboard } \\
\mathrm{R}-0.12 \text { airgap } \\
25 \mathrm{~mm} \text { weatherboard }\end{array}$ & $\begin{array}{l}12 \mathrm{~mm} \text { plasterboard } \\
\text { (no material) }\end{array}$ & $\begin{array}{l}18 \mathrm{~mm} \text { floorboards } \\
\text { (no material) }\end{array}$ \\
\hline & $20 \%$ & $\begin{array}{l}12 \mathrm{~mm} \text { plasterboard } \\
\mathrm{R}-0.75 \text { timber } \\
25 \mathrm{~mm} \text { weatherboard }\end{array}$ & $\begin{array}{l}12 \mathrm{~mm} \text { plasterboard } \\
\mathrm{R}-1.2 \text { timber }\end{array}$ & $\begin{array}{l}18 \mathrm{~mm} \text { floorboards } \\
\mathrm{R}-1.2 \text { timber }\end{array}$ \\
\hline \multirow[t]{3}{*}{ Insulated } & 4 & $\begin{array}{l}12 \mathrm{~mm} \text { plasterboard } \\
\mathrm{R}-2.7 \text { material } \\
25 \mathrm{~mm} \text { weatherboard }\end{array}$ & $\begin{array}{l}12 \mathrm{~mm} \text { plasterboard } \\
\mathrm{R}-2.7 \text { material }\end{array}$ & $\begin{array}{l}18 \mathrm{~mm} \text { floorboards } \\
\mathrm{R}-2.7 \text { material }\end{array}$ \\
\hline & $\begin{array}{l}5 \\
80 \%\end{array}$ & $\begin{array}{l}12 \mathrm{~mm} \text { plasterboard } \\
\mathrm{R}-2.8 \text { insulation } \\
25 \mathrm{~mm} \text { weatherboard }\end{array}$ & $\begin{array}{l}12 \mathrm{~mm} \text { plasterboard } \\
\mathrm{R}-2.7 \text { insulation }\end{array}$ & $\begin{array}{l}18 \mathrm{~mm} \text { floorboards } \\
\mathrm{R}-2.6 \text { insulation }\end{array}$ \\
\hline & $20 \%$ & $\begin{array}{l}12 \mathrm{~mm} \text { plasterboard } \\
\mathrm{R}-0.75 \text { timber } \\
25 \mathrm{~mm} \text { weatherboard }\end{array}$ & $\begin{array}{l}12 \mathrm{~mm} \text { plasterboard } \\
\mathrm{R}-1.2 \text { timber }\end{array}$ & $\begin{array}{l}\text { 18mm floorboards } \\
\mathrm{R}-1.2 \text { timber }\end{array}$ \\
\hline
\end{tabular}

Results for 4 summer days are graphed below. Initially the $80 \% / 20 \%$ constructions used timber with mass. The analysis was then repeated using a timber material without mass to check whether the differences were due to the inclusion of mass or the separation of insulation from the framing.

Dividing each surface up into $80 \% / 20 \%$ portions is a very time consuming way to model. It doubles the number of materials required and increases the chance of error when inputting the information because of the increased options. When using OpenStudio to create the model geometry, neither SketchUp nor OpenStudio have a tool to easily divide surfaces into specified areas. This has to be done manually, with much trial and error in the case of irregular shapes.

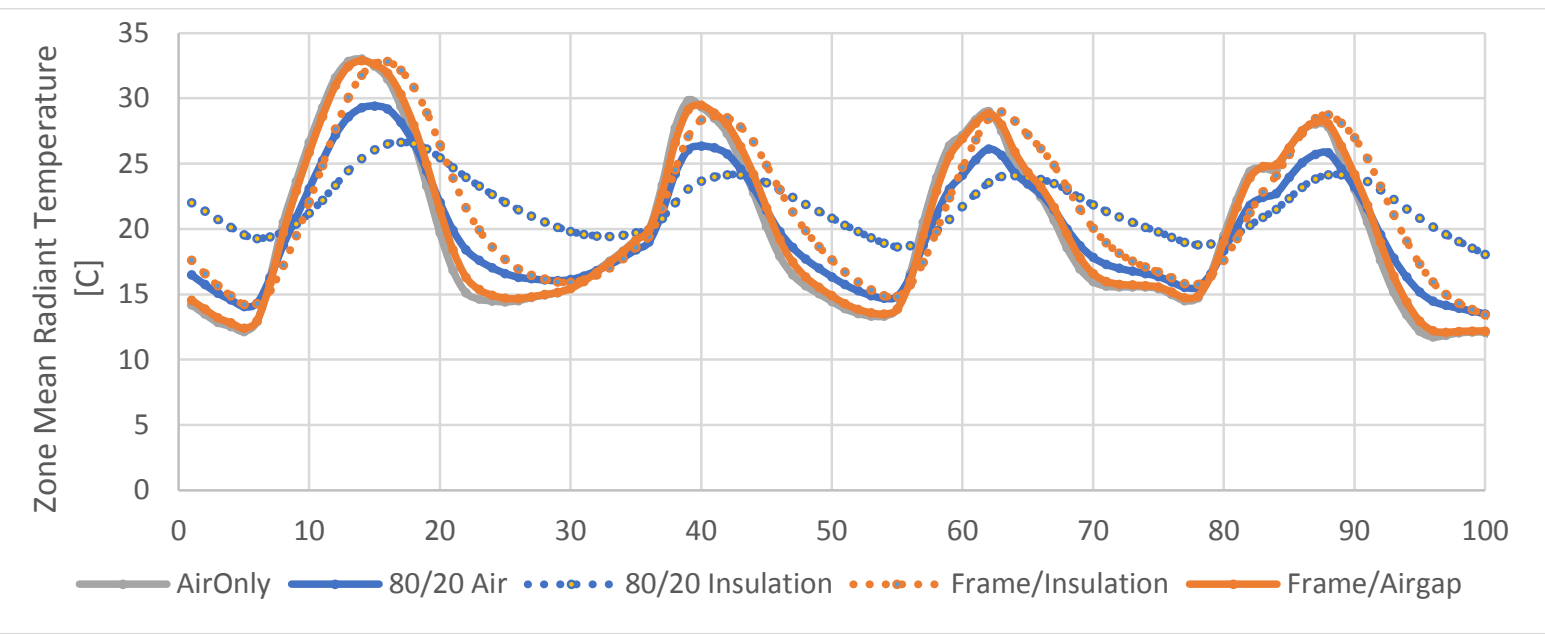

FIGURE 26: SUMMER DAYS WITH MASS 
The main benefit of dividing every wall into two pieces is the ability to account for the effects of the mass of the timber framing. The $80 \% / 20 \%$ insulation line shows moderated peaks and troughs in the daily temperature swings in figure 26. Minimal effects from mass are evident in the air temperatures (not graphed) where the peaks are slightly reduced when compared to the other methods.

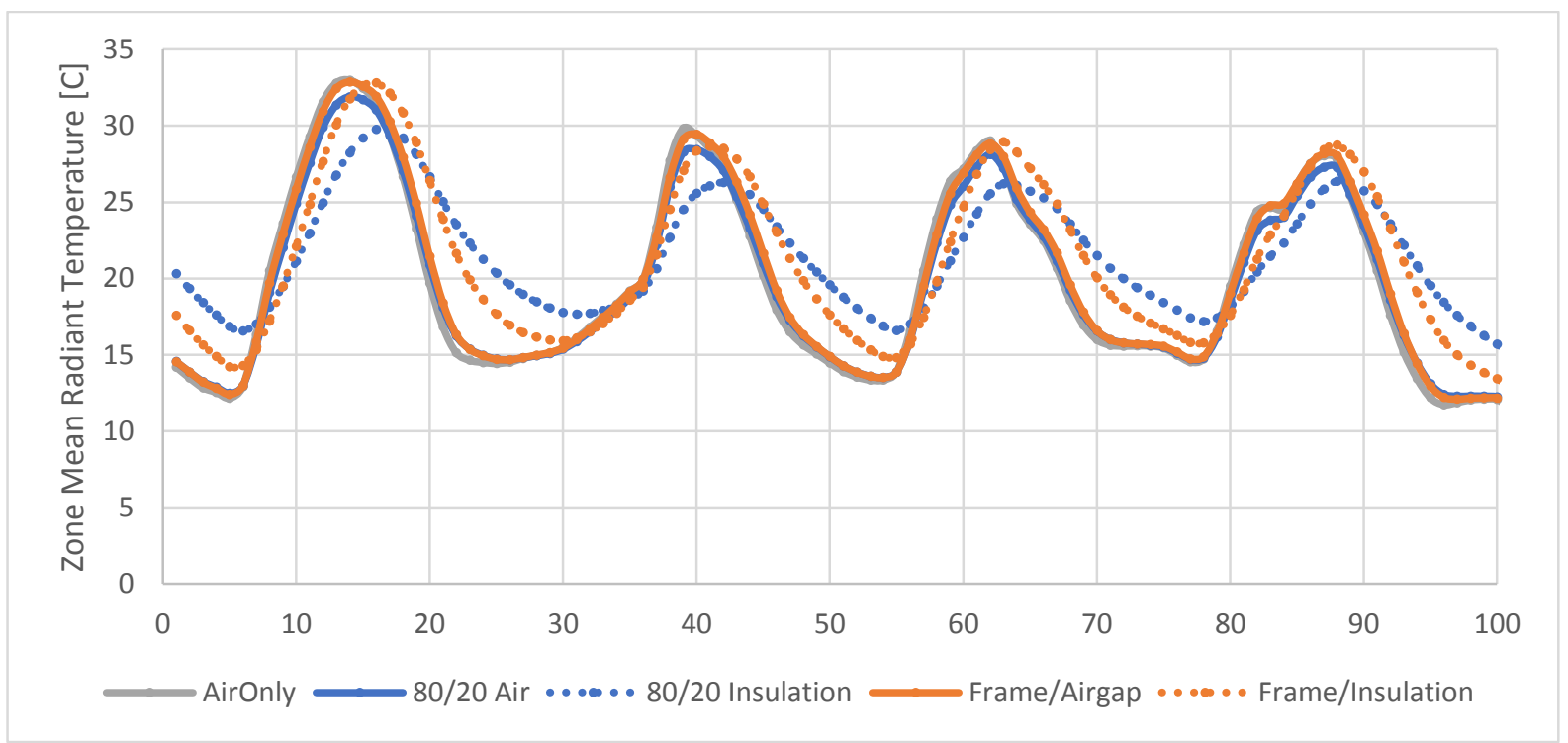

FIGURE 27: SUMMER DAYS NO MASS

Figure 27 shows the same constructions modelled using a no-mass material for the timber framing. The peak temperatures are all much closer for each modelling method, indicating that it was the thermal mass affecting this aspect of performance. The $80 \% / 20 \%$ insulation still predicts warmer temperatures overnight than the combined frame/insulation modelling method, indicating that this is a function of the separated construction materials.

\section{Justification for homogenous core walls}

Drawing the geometry for the test villa, splitting each wall into $80 \% / 20 \%$ proportions on both surfaces would be time consuming. Drawing the geometry and then trouble-shooting simulation errors which are much more likely to arise from complex geometry (particularly with surface matching) would take much longer. It also makes it much more time consuming to analyse changes to the villa's construction such as adding varying levels of insulation.

The internal framing of any rental property and the test villa is an unknown quantity. The $80 \%$ $20 \%$ split is a rounded assumption. Framing proportions from Design Navigator indicate that the framing could vary anywhere between $15 \%$ and $24 \%$, for studs $300-400 \mathrm{~mm}$ apart with and without dwangs [122]. Complexity around window and door opening would add more variability to this.

Splitting every wall into proportional parts for framed and non-framed areas is a precise modelling strategy, however it lacks the underlying information of what the constructions are in reality. This strategy adds complexity to the model but it does not necessarily add value because the model is more precise than the supporting information. 


\section{Curtains}

To test the impact of curtains on a model, an alteration was made to the 'box' model. Every wall was given a window, $3 \mathrm{~m}$ long by $1 \mathrm{~m}$ high. Previously only the North and South walls had windows.

Curtains were modelled with the WindowMaterial:Shade object.

Initially two parameters were tested to examine the model sensitivity: (1) curtain insulation performance (entered as a conductivity); and (2) the distance of the curtain from the window. The zone was heated to $18^{\circ} \mathrm{C}$ continuously. A selection of days in winter was graphed to show differences with and without curtains

After testing the two initial parameters it became evident that there were more ways to influence the thermal performance of curtains. The curtain opening multipliers and airflow permeability also have significant effects on the performance of a curtain. A curtain with the opening multipliers and airflow permeability all set to 0 will have performance comparable to a curtain $0.001 \mathrm{~m}$ from the glass.

\section{Curtain Distance}

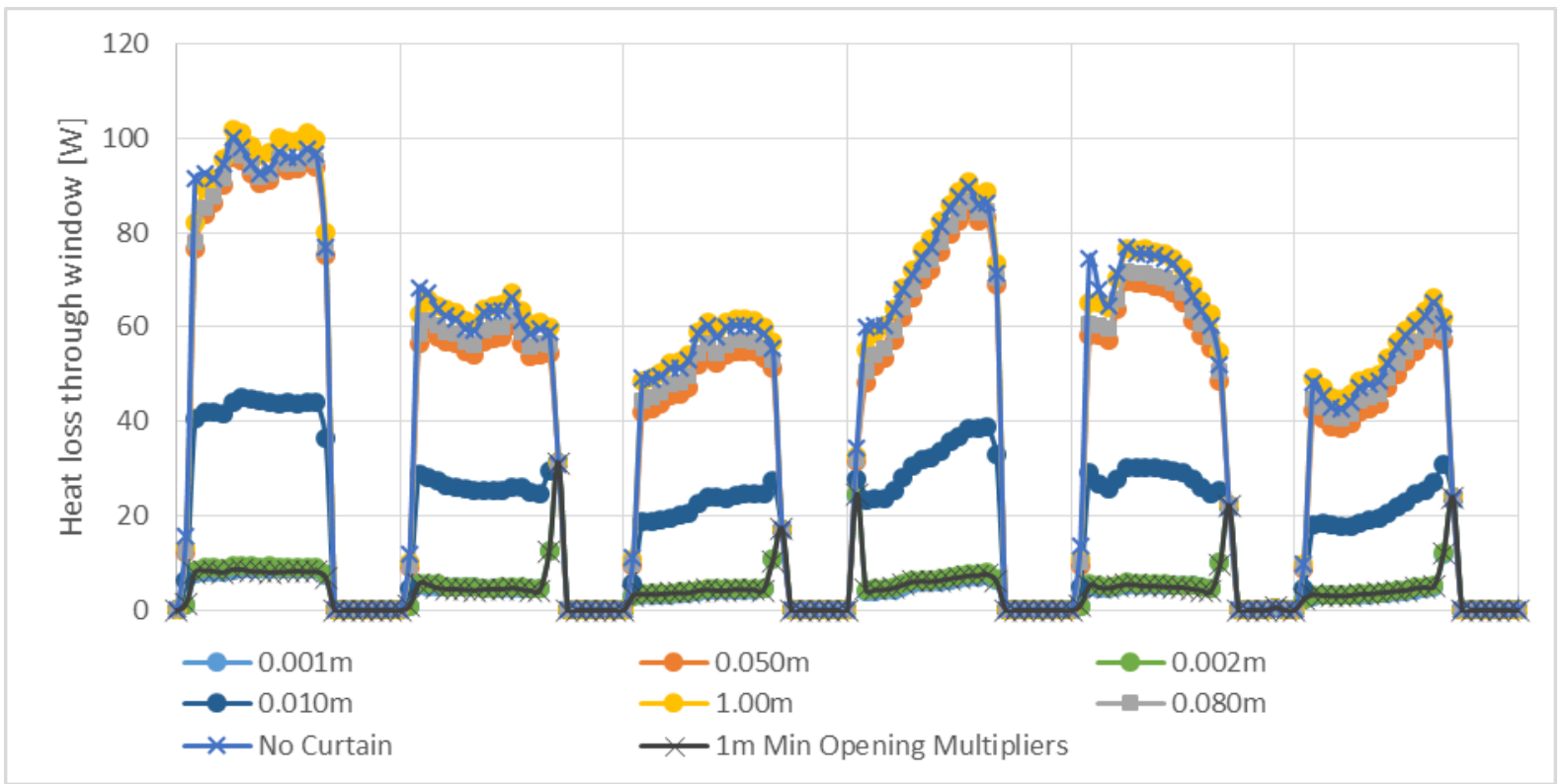

FIGURE 28: A CURTAIN 80MM FROM THE WINDOW DOES LITTLE TO REDUCE HEAT LOSS (EVEN AT R-3)

This analysis was carried out using an R-3 curtain. The graph above shows the curtain provides an excellent reduction in window heat loss when it is only 1 or $2 \mathrm{~mm}$ from the window. Once the curtain is $10 \mathrm{~mm}$ from the window the heat loss increases significantly. At $50 \mathrm{~mm}$ and beyond the modelling suggests the curtain only provides minor advantages over plain single glazing even with a very high insulation value. 


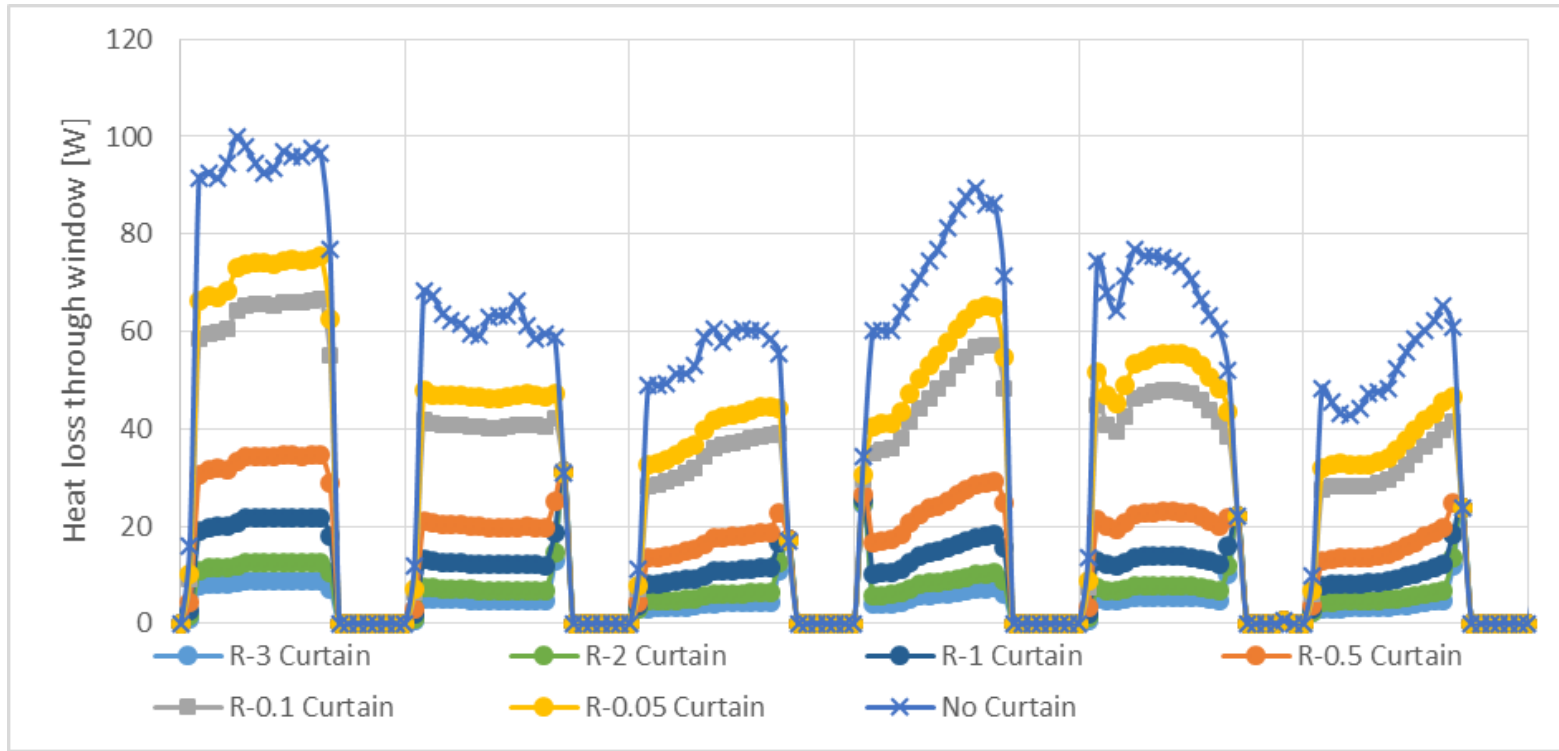

FIGURE 29: EVEN R-0.05 CURTAINS ARE HELPFUL WHEN HUNG AS CLOSE TO THE WINDOW AS POSSIBLE

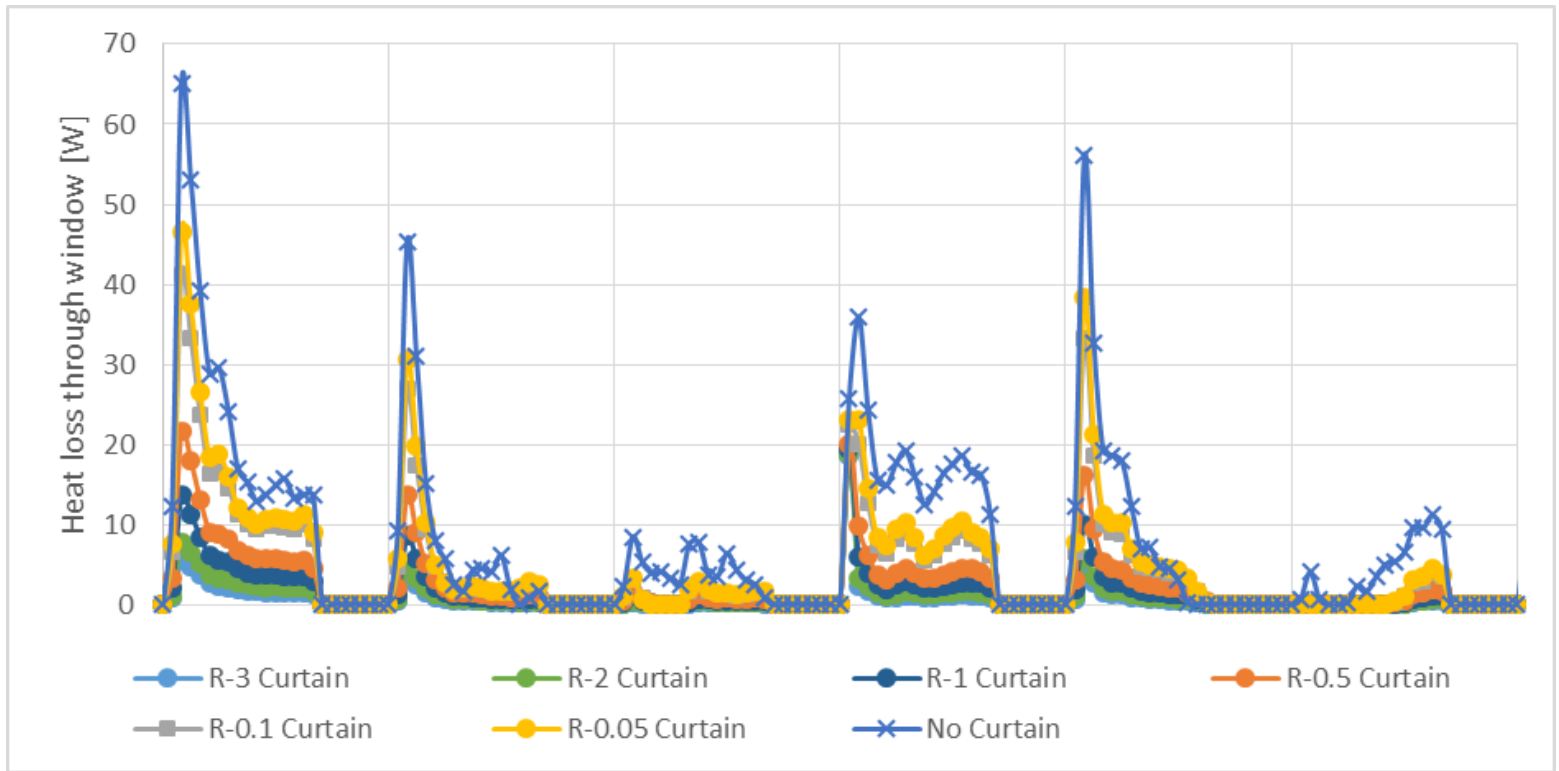

FIGURE 30: CURTAINS PROVIDE A SMALLER REDUCTION IN HEAT LOSS WHEN THERE IS NO HEATING

This analysis was carried out with the curtain $0.001 \mathrm{~m}$ from the window to observe the maximum possible benefit of the change in R-values. The R-3 curtains predictably resulted in a significant reduction in heat loss through the windows. However, the R-0.05 and R-0.1 curtains still provide a distinct benefit over uncovered windows.

These analyses indicate it would be easy to produce a simulation which shows curtains have a minimal effect on window heat loss by manipulating the distance of the curtain from the window, the airflow permeability and side opening multipliers. Keeping the curtain as close as possible would provide a best case scenario but one that is probably unlikely to be achieved in New Zealand houses. Placing the curtain $80 \mathrm{~mm}$ away from the window (approximately the wall framing and plaster board thickness) results in the curtains providing little benefit, despite their Rvalue. Little documentation is available on how to determine values for these inputs or values linked to real world examples. This then necessitated the reverse engineering of the curtain $\mathrm{R}$ values documented in the earlier section on curtains, p.41. 
Curtains have a very small impact on mean radiant temperature (MRT) when the zone is heated and with no heating have no noticeable impact on MRT (figure 31). Even R-3 curtains with no air leakage appear to have no impact on air temperature without heating (figure 32). This may be because as the windows are no-longer the weakest element in the thermal envelope, more heat is lost through the uninsulated walls. It may also be due to the window-to-wall ratio in the test box.

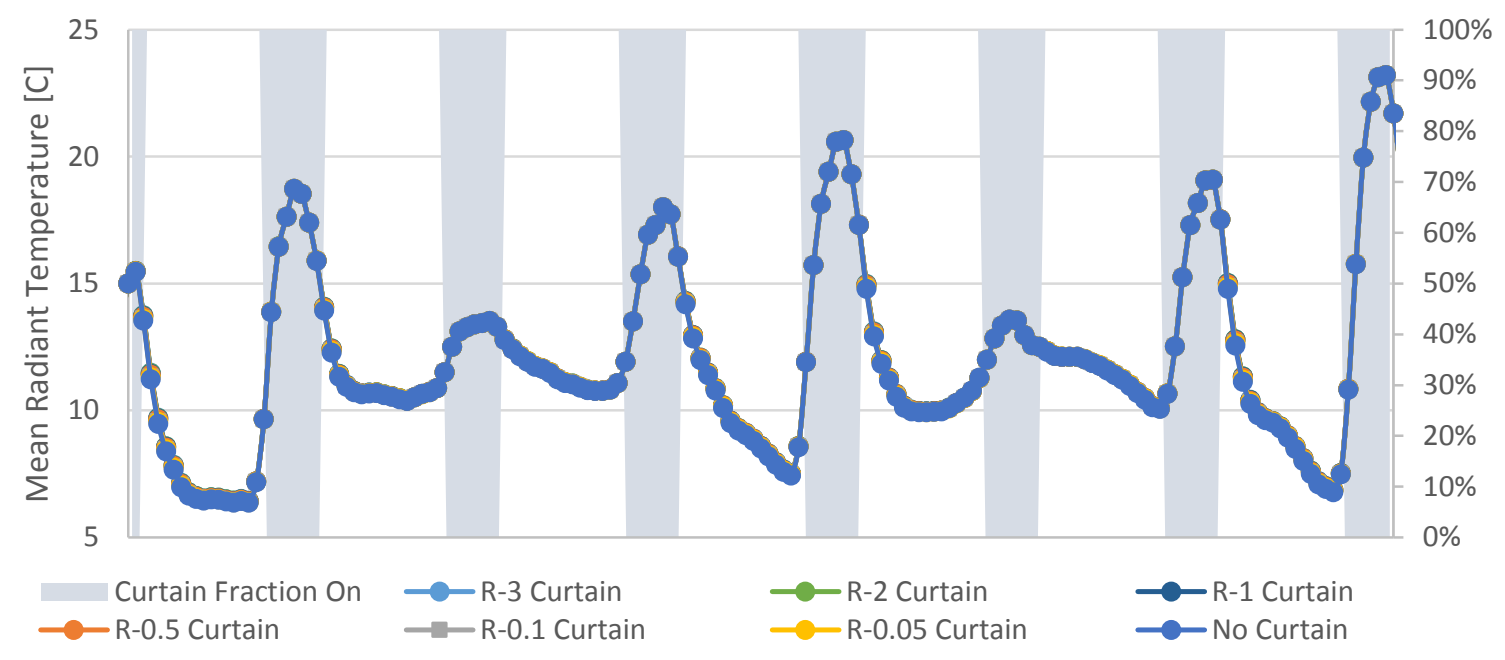

FIgURE 31: CURTAINS MINIMAL IMPACT ON MRT IN THIS MODEL

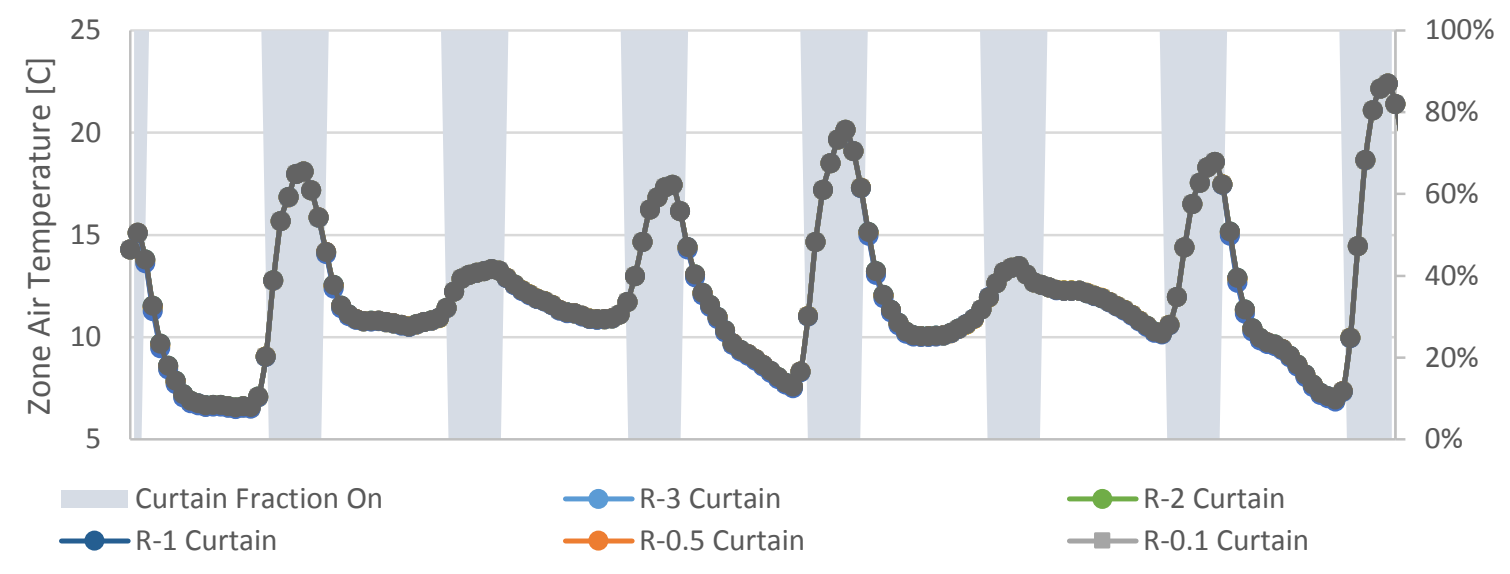

FIGURE 32: CURTAINS DON'T HAVE A NOTICEABLE EFFECT ON AIR TEMPERATURE

Figure 32 suggest that curtains will not have a significant impact on thermal performance if air temperature is used as the main measure of performance. EnergyPlus summary tables provide air temperature, not MRT or operative temperature.

\section{Impact of Load Profiles on Indoor Temperatures}

This analysis was intended to test the impact of the household occupancy patterns on room temperatures and energy use. Equipment load profiles are shaped to represent average living patterns with peaks in the morning and evening and lower loads at other times. What difference would there be if all the loads were constant and evenly distributed across the building? This is a scenario which could be appropriate for rental housing where occupancy patterns are unknown and unpredictable. This type of simplification would mean that the simulation provides average 
conditions which do not represent any type of household but do not discriminate against different living patterns such as night or shift workers.

\section{Simulation Uncertainty Due to Assumed Occupancy Patterns}

The load profiles for each type of equipment and the dwelling overall are summarised in figure 33. Total loads for the specific load profiles and the generic simulation with evenly distributed loads are shown as dotted lines while the specific profiles for each type of equipment are shown as solid lines.

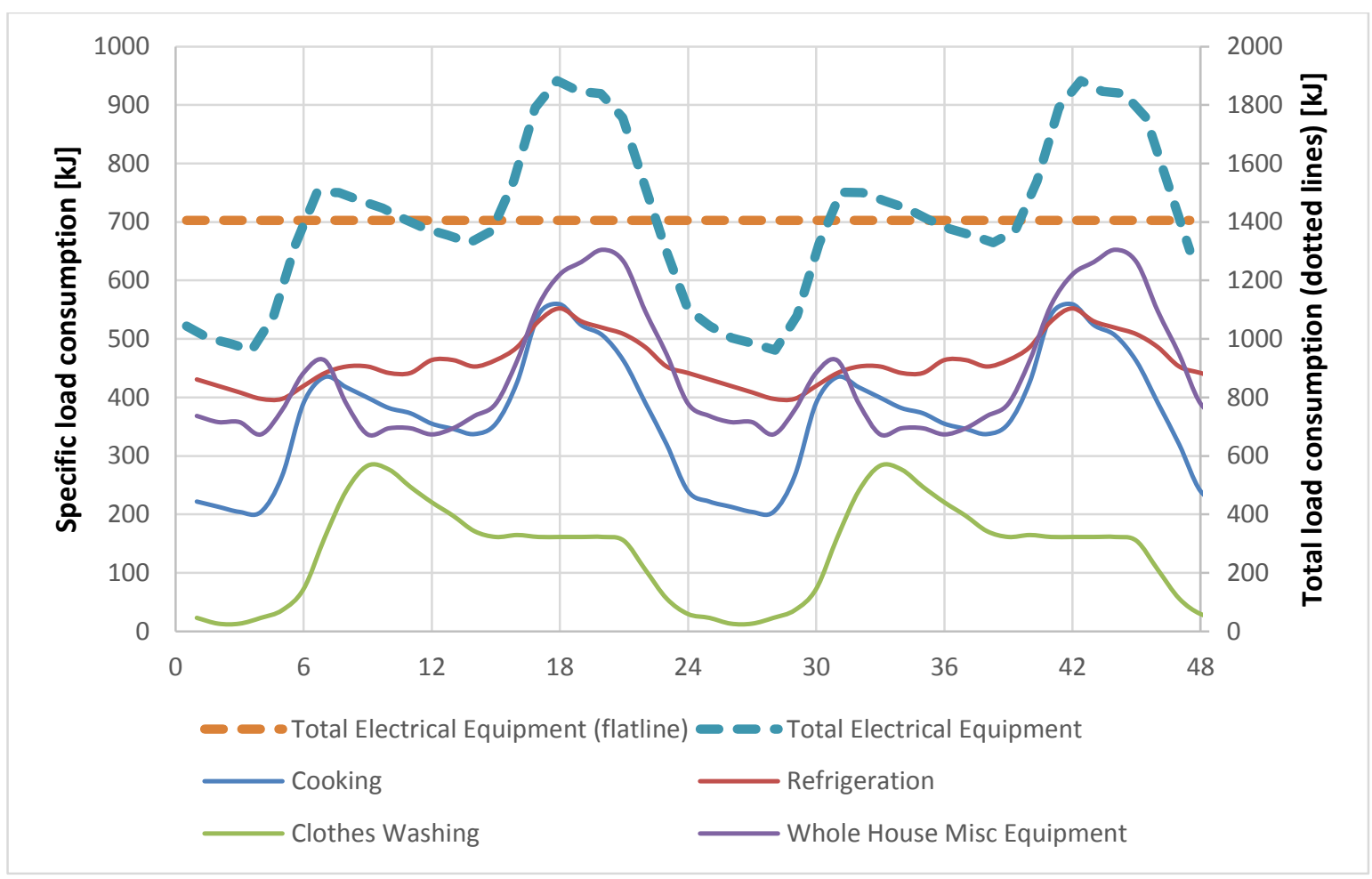

FIGURE 33: SPECIFIC VS GENERIC LOAD PROFILES

The specific load profiles are based on an 'average' household. In this average household it is assumed that most occupants are out of the house from 9am-5pm, but not all, hence the loads never drop to zero. In comparison to the flat line of the generic approach, the specific loads are higher in the evening and morning while being lower overnight and during the middle of the day.

In each case the loads are also distributed differently across the building. The specific loads are comparatively concentrated in the kitchen and laundry zone, while being lower in the other living zones where there is only miscellaneous equipment. Lighting loads have been left constant at 1 or 2 lightbulbs per room. Domestic lighting power densities could be much higher if many lights and/or inefficient lighting was used.

Thermal simulations are able to report temperatures to many decimal places, however it is unlikely that an occupant will notice a $0.001^{\circ} \mathrm{C}$ change in temperature. Literature on adaptive thermal comfort provides some insights into what level of temperature change an occupant will notice. Nichol et al state that "[daily] temperature drifts within $\pm 1 \mathrm{~K}$ of the customary temperature would attract little or no notice" [123, p. 37]. Hensen summarises that "it may be concluded that slow temperature changes up to about $0.5 \mathrm{~K} / \mathrm{h}$ have no influence on the width of the comfort zone as established under steady-state conditions" [124, p. 8]. While these research 
results may not be directly applicable to simulation results which compare two theoretical results side by side, rather than a single person experiencing changing conditions, they indicate that small temperature changes are unlikely to be noticed by occupants.

TABLE 18: TEMPERATURE DIFFERENCE BETWEEN SPECIFIC INTERNAL LOADS AND GENERIC INTERNAL LOADS

\begin{tabular}{|l|l|l|l|l|l|l|l|l|}
\hline & BATH & BED1 & BED2 & BED3 & DINING & HALL & KITCHEN & LIVING \\
\hline Min & $-0.6^{\circ} \mathrm{C}$ & $-0.6^{\circ} \mathrm{C}$ & $-0.5^{\circ} \mathrm{C}$ & $-0.4^{\circ} \mathrm{C}$ & $-0.4^{\circ} \mathrm{C}$ & $-0.4^{\circ} \mathrm{C}$ & $0.3^{\circ} \mathrm{C}$ & $-0.8^{\circ} \mathrm{C}$ \\
\hline Max & $0.4^{\circ} \mathrm{C}$ & $-0.1^{\circ} \mathrm{C}$ & $-0.2^{\circ} \mathrm{C}$ & $-0.1^{\circ} \mathrm{C}$ & $0.0^{\circ} \mathrm{C}$ & $-0.1^{\circ} \mathrm{C}$ & $1.9^{\circ} \mathrm{C}$ & $-0.1^{\circ} \mathrm{C}$ \\
\hline Average & $-0.1^{\circ} \mathrm{C}$ & $-0.2^{\circ} \mathrm{C}$ & $-0.3^{\circ} \mathrm{C}$ & $-0.3^{\circ} \mathrm{C}$ & $-0.2^{\circ} \mathrm{C}$ & $-0.3^{\circ} \mathrm{C}$ & $1.0^{\circ} \mathrm{C}$ & $-0.2^{\circ} \mathrm{C}$ \\
\hline
\end{tabular}

White indicates the temperature change is not likely to be noticeable, light grey indicates the temperature change might be noticeable and dark grey indicates the temperature change is probably noticeable.

Table 18 shows the difference in air temperatures in the test villa with the specific loads and generic loads. By using the specific load profiles instead of constant average loads, the kitchen experiences an operative temperature increase of up to $1.9^{\circ} \mathrm{C}$ while the living room experiences a decrease of up to $0.8^{\circ} \mathrm{C}$. On average the kitchen is $1.0^{\circ} \mathrm{C}$ warmer and the living room $0.2^{\circ} \mathrm{C}$ cooler than the generic simulation. The maximum impacts of the specific loads on temperature are shown in the kitchen in the evening and the living room (the largest of the living zones) overnight.

Hourly analysis shows the simulation with specific loads is more likely to show the dwelling is comfortable when the occupants are actively occupied (i.e. at home and awake). The specific loads produce a higher temperature in the kitchen with a slightly cooler temperature elsewhere (except the bathroom). The specific loads profiles for this 'average' household working 9am-5pm are up to $08^{\circ} \mathrm{C}$ lower in the living room than in the average model. It also shows a perceptible rise in the kitchen temperature at around $6 \mathrm{pm}$ which may not reflect all lifestyles, although this rise would be timed with occupancy of the kitchen in most living situations.

\section{Impact of Bathroom Equipment}

Bathroom equipment was omitted from the specific vs generic load analysis (but not the removal of all loads) as it could not realistically be distributed across the whole of the dwelling.

The impact of the hot water equipment on bathroom temperature in July is presented in figure 34 below. The use of the shower and sink give morning and evening temperature spikes. These reach up to $8^{\circ} \mathrm{C}$ and could easily mean the difference between the bathroom being at a comfortable temperature or being far too cold, although they will be accompanied by high levels of humidity. 


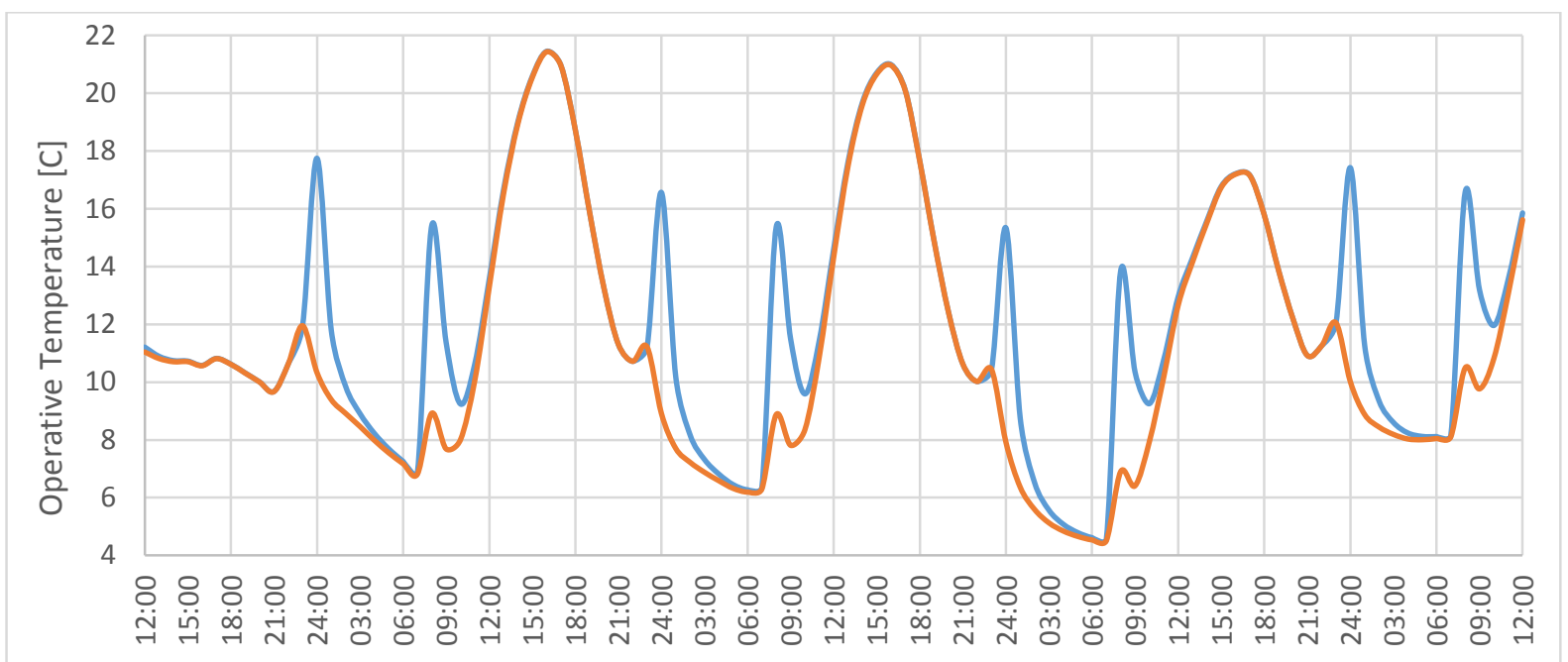

FIGURE 34: BATHROOM OPERATIVE TEMPERATURE WITH (BLUE LINE) AND WITHOUT (ORANGE LINE) INTERNAL LOADS

Simulation Uncertainty Due to Assumed Occupant Power Consumption

The power consumption has been based on average values found by the HEEP study. In severe cases of poverty, occupants may turn off household appliances because they can't afford the running cost. To explore the impact of this kind of lifestyle on the performance of the villa, all electrical equipment was removed. The only internal gains were from the occupants themselves. Table 19 shows the difference between the temperatures in the house with and the same house without appliances. The shading pattern is the same as for table 18.

TABLE 19: TEMPERATURE INCREASE THROUGH DOMESTIC INTERNAL LOADS

\begin{tabular}{|l|l|l|l|l|l|l|l|l|}
\hline & BATH & BED1 & BED2 & BED3 & DINING & HALL & KITCHEN & LIVING \\
\hline Min & $0.3^{\circ} \mathrm{C}$ & $0.1^{\circ} \mathrm{C}$ & $0.2^{\circ} \mathrm{C}$ & $0.1^{\circ} \mathrm{C}$ & $0.2^{\circ} \mathrm{C}$ & $0.5^{\circ} \mathrm{C}$ & $0.5^{\circ} \mathrm{C}$ & $0.1^{\circ} \mathrm{C}$ \\
\hline Max & $8.5^{\circ} \mathrm{C}$ & $0.6^{\circ} \mathrm{C}$ & $0.6^{\circ} \mathrm{C}$ & $0.9^{\circ} \mathrm{C}$ & $0.8^{\circ} \mathrm{C}$ & $1.3^{\circ} \mathrm{C}$ & $2.9^{\circ} \mathrm{C}$ & $0.6^{\circ} \mathrm{C}$ \\
\hline Average & $1.3^{\circ} \mathrm{C}$ & $0.2^{\circ} \mathrm{C}$ & $0.3^{\circ} \mathrm{C}$ & $0.3^{\circ} \mathrm{C}$ & $0.4^{\circ} \mathrm{C}$ & $0.8^{\circ} \mathrm{C}$ & $1.5^{\circ} \mathrm{C}$ & $0.2^{\circ} \mathrm{C}$ \\
\hline
\end{tabular}

The temperature increase in the hall is because this is where the HWC is located. The bathroom and the kitchen have increased temperatures due to appliance and hot water use. The other rooms have very small temperature gains from lighting and miscellaneous electrical equipment.

Assuming how energy services are used will have an impact on temperatures in rooms with large appliances and hot water use. It may also have an impact on how warm other rooms are, although not at all times of the day.

\section{Load Profile and Indoor Temperature Results}

The results suggest that using broad assumptions about how a household uses their house (where the loads are located and when they are used) are unlikely to have a noticeable impact on thermal comfort except in utility rooms (kitchen/laundry/bathroom) and where the HWC is located. Assuming the house has internal loads (the occupants have not turned off appliances to save expenses) may have an impact on thermal comfort in general spaces and is likely to have a noticeable impact in utility rooms.

Specific load profiles would have the most impact if the occupants' exposure to internal temperatures is considered. This is because occupants tend to make rooms warmer with their presence and their use of energy services. When measuring air temperatures across the whole house, specific load profiles may or may not make a difference to expected comfort. 
Building America Load Profiles vs HEEP Load Profiles

Building America is a research program sponsored by the U.S. Department of Energy (who also publish EnergyPlus). Their House Simulation Protocol provides 'standard user profiles' to represent average occupant behaviour. These are a valuable source of EnergyPlus specific values based on field and laboratory experiments.

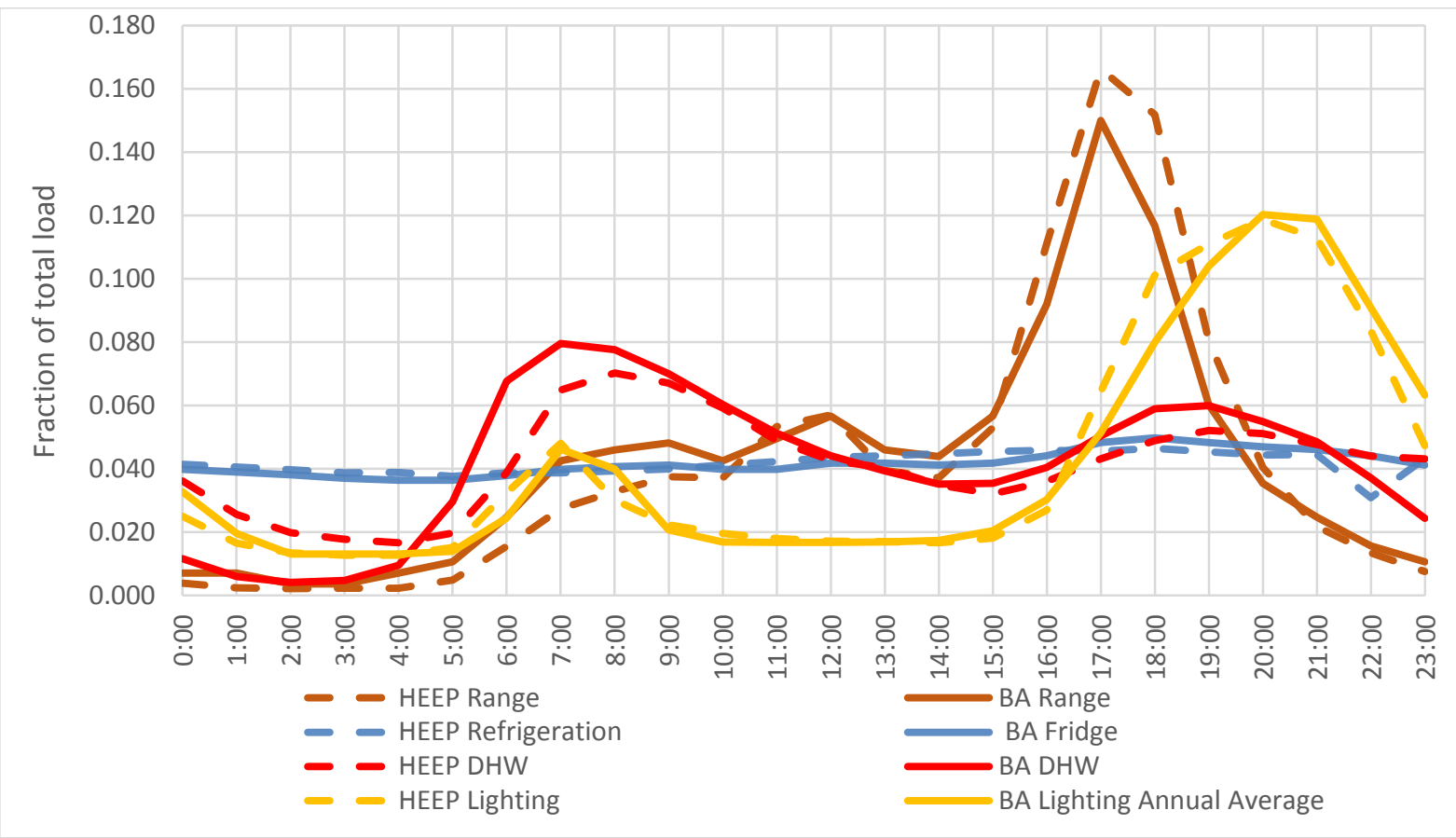

Figure 35: Comparison of HeEP and BUILding America single LoAd Profiles

To ensure the use of international figures hasn't produced implausible results, figure 35 compares the Building America model load profiles (the fraction of the total daily load used each hour) were compared to HEEP measured data [125]. The HEEP data is published as half-hourly results for summer and winter, which were averaged to hourly values for the whole year, comparable to those entered into EnergyPlus. The Building America range and fridge profiles were added to the EnergyPlus model along with a miscellaneous profile. Figure 36 below shows the EnergyPlus modelled electricity consumption compared to the Building America totals for electric appliances and the HEEP total electricity consumption profile.

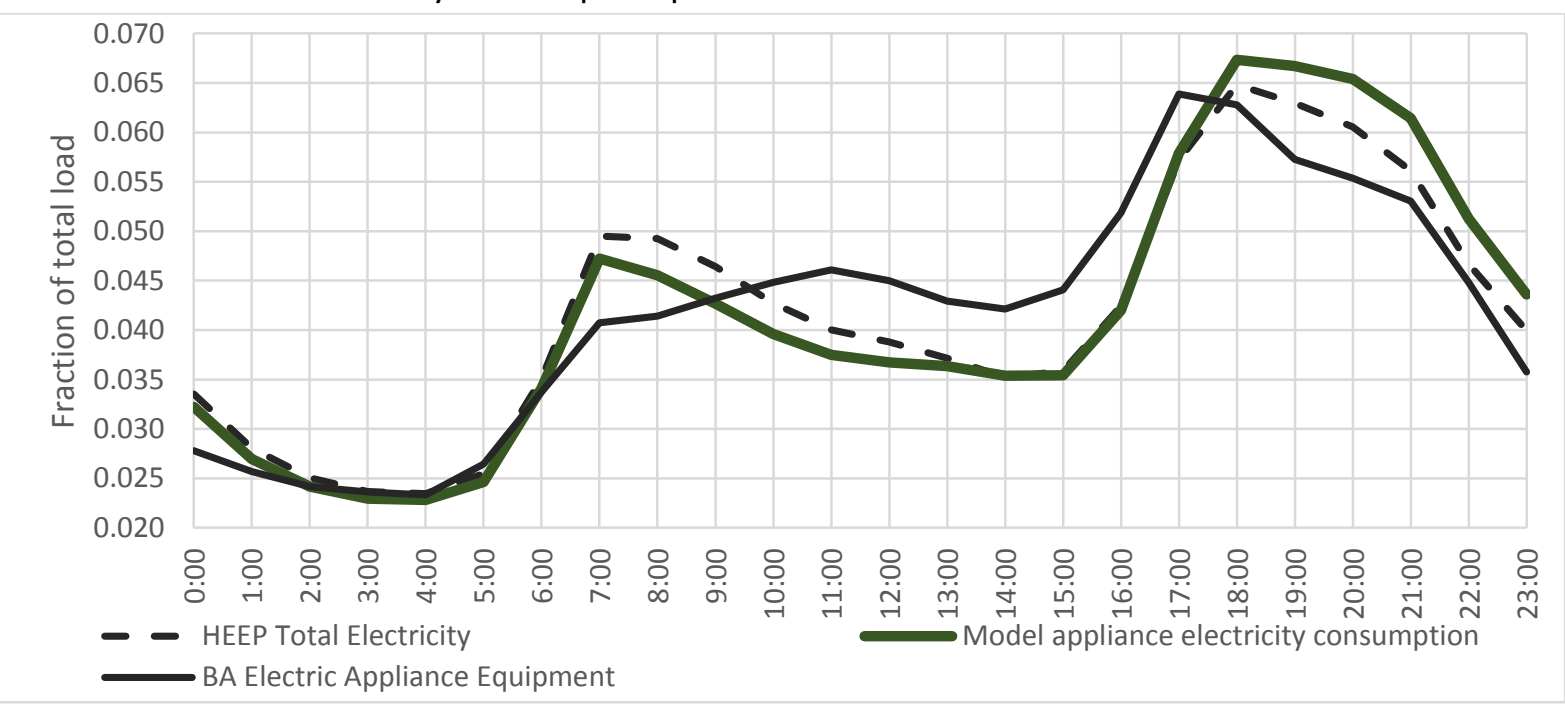

Figure 36: Comparison of HeEP, Building America total LoAd Profiles ANd Model use 
The appliance electricity use profile as generated by the EnergyPlus simulations (excluding lighting and domestic hot water) most closely matched the HEEP total electricity consumption profile rather than the Building America appliance use profile. This would appear to be due to the Building America profile including lighting and hot water. The hot water has a peak in the morning while the lighting has a peak in the evening and both are low during the middle of the day (shown in figure 35). Including this data would make the Building America load profile more closely resemble the HEEP and model appliance electricity consumption.

\section{Summary of the Sensitivity Analyses}

This sub-section provides a summary of the various sensitivity analyses.

Using two unique materials to model the frame and the insulation/airgap within a wall instead of using a single homogenous material with a comparable R-value may be desirable if specific information on the framing is available. This modelling method enables the model to consider the effect of the thermal mass of the framing. It was not used for the test villa as the proportion of framing has been assumed and precisely modelling an assumption will not provide more meaningful results.

Curtains produce a notable change to the heat loss through windows, but their effect on the zone temperature is limited unless heating is used. Once heating is used they increase the radiant temperature of the window surface allowing the mean radiant temperature to further increase. The performance of curtains can be significantly altered by assumptions made about the opening multipliers. It is however possible to produce believable performance by reverse engineering the curtain object to match measured R-values.

The inclusion of internal loads in the test villa had a noticeable effect on comfort temperatures, however the distribution of these loads was not a significant factor except in the kitchen, bathroom and hallway. The temperature in these utility rooms benefits noticeably from the internal gains. In the case of the bathroom the temperature is raised by up to $8^{\circ} \mathrm{C}$ in the mornings when the occupants are using the room, although accompanied by increased humidity.

Load profiles published by Building America, which are designed to be input into simulations, match the New Zealand measured usage patterns and accordingly are used to provide a valuable resource for some obscure input values. 



\section{ASSESSING WOF OPTIONS}

This section documents the different house features, designed to pass and fail the WoF criteria in a variety of ways, how they were described in EnergyPlus and combined into a matrix of options to be investigated.

\section{Simulating House Features to Pass/Fail the WoF}

A number of scenarios were selected to test the impact of the proposed Warrant of Fitness criteria. These scenarios are listed in table 20, numbered from 1 to 31. EnergyPlus files with each of these scenarios are provided on the appended CD. These different options were chosen to cover the different ways a house could pass the warrant (e.g. using different kinds of insulation with different implicit levels of performance), alongside options that failed the warrant. While the blanket insulation case failed the warrant due to the way the criteria are designed to be measured, it exceeded the thermal performance of the other options.

HWC (HWC) performance has been included to assess its impacts on performance compared to the other criteria. Work by Beacon Pathway suggests that this should be a key component of any energy retrofit measures [126]. The HWC is not currently included in either of the warrant tools, as it is assumed that appliance failure will eventually cause all households to replace their cylinder with a current model with higher performance.

\section{Combinations Tested}

A matrix of possible combinations of the following warrant criteria has been tested to identify how performance is related to whether a scenario passes or fails the WoF. To generate this matrix a possible method of complying or not complying with each of the 8 thermal components of the WoF (Rows $\mathrm{A}$ to $\mathrm{H}$ in the table above) are combined together. This leads to 16,200 possible combinations ( $4 \mathrm{~A} \times 2 \mathrm{~B} \times 6 \mathrm{C} \times 2 \mathrm{D} \times 6 \mathrm{E} \times 5 \mathrm{~F} \times 6 \mathrm{G} \times 3 \mathrm{H}$ ).

It became necessary to omit some possible combinations to reduce calculation time. Categories $A$ and $B$ were combined to reduce the overall number of simulations as it was not important to test the impact of changing the hot water setpoint when there was no shower. Only one combination of HWC efficiencies and heating only in the living room were tested as preliminary runs suggested these extra combinations were not expected to produce useful results. The heat losses from the HWC will have no impact on heating in the living room and these heat losses are able to be seen in options 7, 8, 9 and 10. Double glazing with no roof/wall/floor insulation was also not tested as it is an unlikely combination.

This left 7,656 scenarios to be tested, which covered the majority of possible combinations of the following criteria. 


\begin{tabular}{|c|c|c|c|c|}
\hline CRITERIA & $\begin{array}{l}\text { 'CHECK BOX' IN WARRANT OF } \\
\text { FITNESS TOOL }\end{array}$ & $\begin{array}{l}\text { CHANGE } \\
\text { NO. }\end{array}$ & CHANGE DESCRIPTION & PASS/FAIL \\
\hline A & $\begin{array}{l}\text { Is the hot water at the tap } \\
55^{\circ} \mathrm{C} \pm 5^{\circ} \mathrm{C} \text { ? } \\
\mathrm{HNZ} \text { temp not stated but } \\
\text { likely the same } \\
\text { Is there a suitably located } \\
\text { bath or shower in good } \\
\text { working order? }\end{array}$ & $\begin{array}{l}1 \\
2 \\
3 \\
4\end{array}$ & $\begin{array}{l}50^{\circ} \mathrm{C} \text { (with showers) } \\
55^{\circ} \mathrm{C} \text { (with showers) } \\
60^{\circ} \mathrm{C} \text { (with showers) } \\
\mathrm{HWC} \text { turned off (with showers) } \\
\text { No showers } \mathrm{HWC} \text { at } 55^{\circ} \mathrm{C}\end{array}$ & $\begin{array}{l}\text { Pass } \\
\text { Pass } \\
\text { Pass (To Code) } \\
\text { Fail } \\
\text { Fail }\end{array}$ \\
\hline C & $\begin{array}{l}\text { Is there a fixed form of safe } \\
\text { effective heating? }\end{array}$ & $\begin{array}{l}7 \\
8 \\
9 \\
10 \\
11 \\
12\end{array}$ & $\begin{array}{l}\text { No heating } \\
\text { Whole house maintained at } 18 \mathrm{C} \\
\text { 'Economic' heater in living and bedrooms } \\
(400 \mathrm{~W} / 260 \mathrm{~W}) \\
2 \mathrm{~kW} \text { electric heater in living \& bedrooms } \\
\text { Fireplace in living room }(15 \mathrm{~kW}) \\
\text { Heat-pump in living room }(5.5 \mathrm{~kW})\end{array}$ & $\begin{array}{l}\text { Fail (To Code) } \\
\text { Presumed to pass } \\
\text { Pass } \\
\text { Fail } \\
\text { Pass } \\
\text { Pass }\end{array}$ \\
\hline D & $\begin{array}{l}\text { Do the bathroom, kitchen and } \\
\text { bedrooms all have some form } \\
\text { of ventilation to the outside? }\end{array}$ & $\begin{array}{l}13 \\
14\end{array}$ & $\begin{array}{l}\text { Ventilation available } \\
\text { No ventilation }\end{array}$ & $\begin{array}{l}\text { Pass (To Code) } \\
\text { Fail }\end{array}$ \\
\hline E & $\begin{array}{l}\text { Are there curtains or blinds in } \\
\text { the bedrooms and living } \\
\text { area? }\end{array}$ & $\begin{array}{l}15 \\
16 \\
17\end{array}$ & $\begin{array}{l}\text { Single glazing no window coverings } \\
\text { (conductivity of } 1 \mathrm{~W} / \mathrm{m} \cdot \mathrm{K} \text { ) } \\
\text { Single glazing with curtains (R-0.14) } \\
\text { Double glazing with no curtains (R-0.36) }\end{array}$ & $\begin{array}{l}\text { Fail } \\
\text { Pass } \\
\text { Pass (To Code) }\end{array}$ \\
\hline $\mathbf{F}$ & $\begin{array}{l}\text { Does the house have ceiling } \\
\text { insulation at least } 120 \mathrm{~mm} \\
\text { thick? }\end{array}$ & $\begin{array}{l}18 \\
19 \\
20 \\
21 \\
22\end{array}$ & $\begin{array}{l}\text { No insulation ( R-0.15) } \\
\text { Code level insulation (R-2.90) } \\
120 \mathrm{~mm} \text { min possible R-value (R-1.43) } \\
120 \mathrm{~mm} \text { max possible R-value }(\mathrm{R}-1.81) \\
115 \mathrm{~mm} \text { blanket insulation }(\mathrm{R}-3.01)\end{array}$ & $\begin{array}{l}\text { Fail } \\
\text { Presumed to Pass } \\
\text { Pass } \\
\text { Pass } \\
\text { Fail (To Code) }\end{array}$ \\
\hline G & $\begin{array}{l}\text { Does the house have } \\
\text { underfloor insulation? }\end{array}$ & $\begin{array}{l}23 \\
24 \\
25 \\
26 \\
27 \\
28\end{array}$ & $\begin{array}{l}\text { No insulation ( R-0.20) } \\
\text { Code level insulation ( } R-1.30) \\
\text { Draped foil insulation ( } R-1.10) \\
90 \mathrm{~mm} \text { bulk insulation min ( } \mathrm{R}-1.27) \\
90 \mathrm{~mm} \text { bulk insulation max R-value (R-1.77) } \\
\text { Any R-value of polystyrene allowed (not } \\
\text { simulated) }\end{array}$ & $\begin{array}{l}\text { Fail } \\
\text { Presumed to pass } \\
\text { Pass } \\
\text { Pass } \\
\text { Pass (To Code) } \\
\text { Pass }\end{array}$ \\
\hline H & $\begin{array}{l}\text { Is the HWC post } 2004 \text { or } \\
\text { otherwise wrapped with } \\
\text { insulation? }\end{array}$ & $\begin{array}{l}29 \\
30 \\
31\end{array}$ & $\begin{array}{l}2004 \text { min performance cylinder (loss } \\
\text { coefficient } 1.4088 \text { ) } \\
\text { Wrapped D-grade cylinder (loss coefficient } \\
2.2482 \text { ) } \\
\text { D-grade cylinder (loss coefficient } 2.9976 \text { ) }\end{array}$ & $\begin{array}{l}\text { (To Code) } \\
\text { N/A } \\
\text { N/A }\end{array}$ \\
\hline $\mathbf{I}$ & $\begin{array}{l}\text { Ceiling insulation is present. } \\
\text { Otherwise appropriate } \\
\text { heating must be installed }\end{array}$ & & $\begin{array}{l}\text { Covered by the combinations } 10,11 \text { or } 12 \\
\text { with } 18 .\end{array}$ & \\
\hline J & $\begin{array}{l}\text { Underfloor insulation is } \\
\text { present. Otherwise } \\
\text { appropriate heating must be } \\
\text { installed. }\end{array}$ & & $\begin{array}{l}\text { Covered by the combinations } 10,11 \text { or } 12 \\
\text { with } 23 \text {. }\end{array}$ & \\
\hline K & $\begin{array}{l}\text { Lounge has a minimum of two } \\
\text { fixed wired power points. } \\
\text { One suitable for a heater. }\end{array}$ & & $\begin{array}{l}\text { Suggests the } 2 \mathrm{~kW} \text { electric heater or } \\
\text { 'economic' heater in the living (options } 9 \\
\text { or } 10 \text { with ceiling and subfloor insulation) }\end{array}$ & \\
\hline
\end{tabular}




\section{WoF Criteria and Simulation Strategy}

The coding of the categories examined in the following sub-sections match the criteria labelling in table 20.

Criteria A: Is the hot water at the tap $55^{\circ} \mathrm{C} \pm 5^{\circ} \mathrm{C}$ ?

This criteria is intended to evaluate the risk of legionella (increased risk when a HWC stores water below $60^{\circ} \mathrm{C}$ ) and the risk of burns (increased risk when the water delivered at the tap is above $\left.55^{\circ} \mathrm{C}\right)[6$, p. 87]. Higher setpoints are associated with higher standing losses, and increased energy use.

The scenarios tested are changes in the setpoint of the HWC which could plausibly produce 50 $60^{\circ} \mathrm{C}$ water at the nearest tap to the cylinder (thermostat setting between $50^{\circ} \mathrm{C}$ and $60^{\circ} \mathrm{C}$ ). The setpoints are: (1) $50^{\circ} \mathrm{C},(2) 55^{\circ} \mathrm{C},(3) 60^{\circ} \mathrm{C}$ and (4) the HWC turned off. The EnergyPlus model automatically mixes the hot water with cold to produce $41^{\circ} \mathrm{C}$ water at the tap/shower. Adjusting a thermostatic mixing valve would have the same impact on water temperature at the tap as using a mix-tap. However the mix-tap would have less impact on the thermal performance of the hot water system. Turning off the HWC has been observed in some HNZ housing as an extreme form of tenant budgeting, so has been included in the analysis.

Criteria B: Is there a suitably located bath or shower in good working order?

This criteria has an impact on the thermal performance of the house because of the role a shower has on the bathroom air temperature and humidity. A bath would have a lesser impact as it generates less steam and releases less heat to the room through the smaller exposed surface area. Two extremes have been tested: (1) 4 people showering in succession in the morning with the variety of HWC setpoints and (2) no showers (or baths) assuming there is no shower or bath supplied but the hot water ( $\mathrm{HWC}$ setpoint $55^{\circ} \mathrm{C}$ ) is still functioning. For the scenario with no showers, hot water continues to be used in the bathroom sink.

Criteria C: Is there a fixed form of safe effective heating?

The GH WoF Assessment Manual specifies safe heating as anything other than an un-flued gas heater. There is no definition of what an effective heater is, only what it is not. The criteria is assessed by visually confirming there is a heater in "the main living area" and then recording the wattage if possible. A minimum heating wattage is not required to pass the GH WoF. [6, p. 89]

The test villa has partitioned rooms rather than the modern open plan style living areas, resulting in a smaller proportion of the house heated by a single living room heater. In this worst case situation, passing the WoF would mean less comfortable temperatures are able to be achieved across the house than would be the case in a house with open plan rooms. The EnergyPlus model assumes that the doors between rooms are shut, although there is some heat transfer due to airflow around the door. This reflects the 'conserve the heat' mentality found in many households.

The forms of heating simulated are: (1) no heating at all; (2) the house maintained at $18^{\circ} \mathrm{C}$ by a heating system with infinite capacity; (3) 'economic' low wattage heaters $400 \mathrm{~W}$ in the living room, $260 \mathrm{~W}$ in each of the dining room, kitchen and bedrooms; (4) a $2 \mathrm{~kW}$ electric heaters in each of the living room, dining room, kitchen and bedrooms; (5) a 15kW fireplace only heating the living room; and (6) a $5.5 \mathrm{~kW}$ heat-pump only heating the living room. 
The infinite capacity heating provides an upper estimate of how much heat the house would need in order to be comfortable. The 'economic' low wattage heaters are a $400 \mathrm{~W}$ heater in the living room and 260W heaters in each of the bedrooms, dining room and kitchen [127]. While they would technically pass the WoF criteria, they only provide minimal amounts of heat for each room, totalling $1.7 \mathrm{~kW}$ for the whole house. The $2 \mathrm{~kW}$ electric heater is just below the maximum plug load $(2.4 \mathrm{~kW})$. The fireplace is assumed to be on a mid-sized burner capable of generating $15 \mathrm{~kW}$ output to the room, although HEEP measurements showed that fireplaces are rarely operated at their maximum capacity [36, p. 160]. The heat-pump with a $5.5 \mathrm{~kW}$ output is the median output of the range of heat-pumps listed on the EnergyStar website [128].

Criteria D: Do the bathroom, kitchen and bedrooms all have some form of outside ventilation?

Natural ventilation is provided by openable windows, the easiest and cheapest option. As there are no internal rooms, it was not considered necessary to have an electric fan. While only (1) full ventilation and (2) no ventilation options were tested, a lack of ventilation in any one of the bathroom, kitchen or bedroom(s) would cause a house to fail the WoF. To model the no ventilation option, the opening fraction of the window is reduced to $0.01 \%$ (effectively closed) but the passive ventilation (infiltration) remains.

EnergyPlus models airflow with a single node (calculation point) in the middle of each zone and assumes that the temperature and humidity of the zone are even across the entire zone, so it only provides limited representation of target or source extract ventilation (e.g. range hoods or shower extract). A small fan intended for target extraction would be modelled as having an even effect across the whole zone. The apparent benefits of such a system would be heavily weighted by the volume of the zone, so an extract fan would misleadingly appear more beneficial in a smaller zone. Target extract systems have not been simulated.

Criteria E: Are there curtains or blinds in the bedrooms and living area?

Three options were simulated for this scenario; (1) uncovered single glazing; (2) single glazing with curtains; and (3) double glazing. There was data available for a fourth option, a thermal blind but it was not expected to provide noticeably different performance as it has a similar R-value.

Although the Housing Warrant of Fitness Assessment Manual recognises venetian or slat blinds, it is for their contribution to privacy and reduction of overheating [6, p. 95]. No data was found on the thermal performance of these blinds, so they were not modelled.

Criteria F: Does the house have ceiling insulation at least $120 \mathrm{~mm}$ thick?

By setting the requirements for insulation based on depth, a wide variety of performance is possible from different products. From the range of insulation products provided with the Design Navigator Construction R-Value Calculator, WoF compliant ceiling insulation can range between R-1.8 and R-6.4 [122]. Alongside (1) no insulation, three specific insulation products were selected to be tested: (2) the minimum R-value possible with $120 \mathrm{~mm}$ of fibre insulation between the framing (product R-value of 1.8, performance of R-1.43); (3) the maximum R-value possible with $120 \mathrm{~mm}$ of fibre insulation between the framing (product R-2.7, performance R-1.81); and (4) blanket insulation over the framing. This preceding case would not pass the WoF as it is only $119 \mathrm{~mm}$ deep, however it has a product R-value of 2.9 and performance of R-3.01. 
Code level insulation (5) was also tested for reference ( $R$-2.9 performance for Wellington in Zone 2 as per NZS4218:2009) and is presumed to pass the WoF, although in practice there are products available which may meet the NZBC required R-value but are less than $120 \mathrm{~mm}$ deep .

Criteria G: Does the house have underfloor insulation?

WoF requirements can be met by a range of options for underfloor insulation. While bulk insulation must be over $90 \mathrm{~mm}$ thick, no thickness is specified if rigid polystyrene is used. Intact foil insulation is acceptable, as is "any other form deemed appropriate by the assessor" [6, p. 97].

The underfloor insulation products from the Design Navigator Construction R-Value Calculator give a range of R-values for WoF compliant insulation between R-0.29 and R-3.5 [122].

Alongside (1) no insulation, the options tested were the (2) maximum ( $R-1.5)$ and ( 3 ) minimum ( $R$ 2.6) product $R$-values for $90 \mathrm{~mm}$ bulk insulation. This gives a floor $R$-value of $R-1.27$ and $R-1.77$ respectively. The minimum R-value for (4) rigid polystyrene insulation is $\mathrm{R}-0.36$ for $10 \mathrm{~mm}$ of Goldfoam, while the maximum is R-3.38 for $105 \mathrm{~mm}$ of Koolfoam BlackPearl [122]. This is a very wide range of performance for acceptable insulation so it was not possible to test a single representative value. Foil insulation (5) floor performance is based on The BRANZ House Insulation Guide [129, p. 85] for foil draped over joists with a $100 \mathrm{~mm}$ sag. No additional benefit has been added to allow for the perimeter foundation wall, as EnergyPlus accounts for this.

Code level insulation (6) for Zone 2 with R-1.3 performance was also tested for reference as it is presumed to pass WoF requirements.

Criteria H: Is the HWC post 2004 or otherwise wrapped with insulation?

Tested energy efficiency upgrades by Beacon Pathway have suggested that addressing the HWC is an important part of energy efficiency/sustainability upgrades [126]. Three potential options were tested for the HWC heat losses; (1) an option which meets the current NZBC; (2) an old inefficient cylinder; and (3) the old inefficient cylinder wrapped with thermal insulation.

The NZBC, which calls up NZS 4305, requires a modern 250 litre HWC to have a maximum standing heat loss of $1.88 \mathrm{kWh} /$ day, as documented in table 14.

The standing heat loss of a D-grade cylinder (the lowest possible rating) under the discontinued WaterMark labelling system was $3.6 \mathrm{kWh} /$ day for a $180 \mathrm{~L}$ cylinder and $4.6 \mathrm{kWh} /$ day for a $270 \mathrm{~L}$ cylinder [130, p. 164]. Adjusting these figures proportionally for a $250 \mathrm{~L}$ D-grade cylinder, the standing losses are estimated to be $4.3 \mathrm{kWh} /$ day

The EECA Energy Saver Fund provides a table of standing losses for wrapped and unwrapped HWCs [131]. The range of efficiencies relates to the discontinued Watermark labelling system with grades A-C and "other" presumably being for a D-grade cylinder. The standing losses of the $180 \mathrm{~L}$ and $270 \mathrm{~L}$ "other" cylinders covered with an R-1.1 wrap are given as $1.8 \mathrm{kWh} /$ day and $2.3 \mathrm{kWh} /$ day respectively. Again these values were adjusted proportionally to indicate a standing loss of $\mathbf{2 . 1} \mathbf{k W h} /$ day for a wrapped $250 \mathrm{~L}$ D-grade cylinder. HWC wraps have evidently advanced since this EECA research in 1996 and HWC wraps of up to R-1.3 are now available [132], so this performance could be exceeded.

Beacon Pathway also investigated the impact of HWC insulation retrofits in their Papakowhai Renovation project. The measured benefit of an insulation wrap was a reduction of standing 
losses between $11 \%$ and 30\% [126], giving a standing heat loss between $\mathbf{2 . 8}$ to $\mathbf{3 . 6} \mathbf{k W h} /$ day for a 250L wrapped D-grade cylinder.

The average of these 3 values $(2.1,2.8$ and $3.6 \mathrm{kWh} /$ day) of $2.8 \mathrm{kWh} /$ day was used in the EnergyPlus model, as it provides a performance more towards the measured performance (where installation may not be perfect) rather than theoretical ideal performance. The standing heat losses and respective loss coefficients, as used in EnergyPlus, are set out in the table below.

TABLE 21: TESTED HWC EFFICIENCIES

\begin{tabular}{|l|l|l|}
\hline & $\begin{array}{l}\text { Standing Heat Loss } \\
\text { (kWh/day) }\end{array}$ & $\begin{array}{l}\text { Loss Coefficient to Ambient } \\
\text { (W/K) }\end{array}$ \\
\hline (1) Current Code & 1.88 & 1.409 \\
\hline (2) Wrapped D-Grade Cylinder & 2.84 & 2.098 \\
\hline (3) D-Grade Cylinder & 4.25 & 3.189 \\
\hline
\end{tabular}

\section{Excluded WoF Criteria}

As it was not feasible to analyse the impact of the WoF criteria targeting moisture, table 22 summarises the omitted moisture problem criteria.

TABLE 22: WOF CRITERIA TARGETED AT MOISTURE UNABLE TO BE INCLUDED

\begin{tabular}{|l|l|l|l|}
\hline & 'CHECK BOX' IN WARRANT OF FITNESS TOOL & $\begin{array}{l}\text { WoF } \\
\text { TOOL }\end{array}$ & \\
\hline 9 & $\begin{array}{l}\text { Is the house weathertight with no evident leaks or moisture } \\
\text { stains? } \\
\text { HNZ separates this into 2 categories, roof and building exterior. }\end{array}$ & $\begin{array}{l}\text { GH } \\
\text { HNZ }\end{array}$ & Not Included \\
\hline 10 & Is a ground vapour barrier installed? & GH & Not Included \\
\hline 11 & $\begin{array}{l}\text { Is there any water ponding under the house? } \\
\text { Accessible subfloor spaces are dry and have adequate air vents. }\end{array}$ & $\begin{array}{l}\text { GH } \\
\text { HNZ }\end{array}$ & Not Included \\
\hline 12 & Is the storm and waste water being adequately discharged? & GH & Not Included \\
\hline 16 & Property has no or limited (less than A4 sheet) mould & GH & Not Included \\
\hline
\end{tabular}




\section{COMFORT}

This section examines issues of comfort and discomfort in the house. It starts by considering the minimum and maximum acceptable temperatures, and then explores different ways of providing discomfort information.

\section{Setpoint Temperatures}

When heating is used in the model it heats to a setpoint of $18^{\circ} \mathrm{C}$. However the discomfort score is calculated for the number of hours when the test villa is below $16^{\circ} \mathrm{C}$ or above $25^{\circ} \mathrm{C}$.

There is a general consensus in New Zealand literature that temperatures below $16^{\circ} \mathrm{C}$, particularly in the presence of high humidity, should be avoided [133], [134] and are associated with adverse health consequences [4]. These often refer back to guidelines provided by the World Health Organisation's publication Damp and Mould [135] which suggests the lower air temperature limit of $16^{\circ} \mathrm{C}$

For this research, $18^{\circ} \mathrm{C}$ has been chosen as the bottom of the comfort range [136]. The top has been suggested as $22^{\circ} \mathrm{C}$ in the living room and up to $20^{\circ} \mathrm{C}$ in bedrooms for winter heating [135]. However, HEEP reported average living room temperatures are close to $16^{\circ} \mathrm{C}[18, \mathrm{p}$. 70]. This indicates that selecting a heating temperature that is too high would not match occupant behaviour. When the HEEP households had fixed heating however they heated to around $18^{\circ} \mathrm{C}$ $\left[18\right.$, p. 84] indicating that households do desire warmer temperatures than $16^{\circ} \mathrm{C}$ but they must have the heating capacity and/or ability to do so.

Cooling is not often perceived as an issue, but modelling requires a higher limit temperature threshold. Overheating is more likely to be an issue in the northern North Island. Based on the HEEP research, $25^{\circ} \mathrm{C}$ has been selected as the top of the comfort range. HEEP found that most houses are between $20^{\circ} \mathrm{C}$ and $25^{\circ} \mathrm{C}$ for most of the time during summer. Over all the houses, the majority spend less than two hours per day at temperatures over $25^{\circ} \mathrm{C}[18, \mathrm{p} .92]$. Temperatures immediately above this threshold are unlikely to cause serious health impacts (indoor temperatures with associated negative health impacts are above $\left.32^{\circ} \mathrm{C}[137]\right)$ but they are likely to be considered too warm for occupants of a temperate climate [138, p. 14].

\section{Metrics of Thermal Performance}

One of the intended results of the Warrant of Fitness schemes is to encourage improved thermal performance in rental housing. This may be seen as reduced heating requirements (energy efficiency) or increased indoor temperatures ('take-back' or 'rebound effect' [22, p. 4]). For this research, two key measures of performance have been used to analyse the models: energy use and a discomfort score.

The energy use (kWh) totals utility energy for household services and space heat requirements. Thermal performance was examined at a house level rather than an occupant level. This is because looking at the thermal comfort of the simulated occupants is heavily biased by assumptions about how many occupants there are, what room they are in and what activity they 
are carrying out. In reality occupants modify their behaviour by being more (or less) active or moving to a warmer (or cooler) room.

EnergyPlus provides a summary of the number of hours the heating and cooling setpoints are not met for the whole 'facility' in the summary tables, so these were examined It became apparent that whole facility 'time setpoint not met' hours were not suitable for analysing houses with New Zealand's heating patterns. This metric counts an hour as uncomfortable if any one zone is outside the temperature threshold. As most of the models only have heating in some rooms but not all (Criteria $C$ in table 20 and p.67), those with just large heaters in the living room appeared to be performing badly.

To address this limitation a discomfort score was created, which ensures models are not excessively penalised for the location of the heating while leaving opportunity for improvement by heating additional rooms. This discomfort score is calculated by taking the discomfort hours (hours below $16^{\circ} \mathrm{C}$ or above $25^{\circ} \mathrm{C}$ ) for each zone (see table 5), multiplying them by the floor area of that zone and then totalling these up for the whole house. This is then normalised to a percentage value for the year ( 8760 hours). This whole house, whole year figure makes it easy to compare different combinations of WoF criteria.

EnergyPlus reports energy use as a single annual figure for all uses by fuel type or end use category. Reporting energy use by fuel type provided a practical balance between investigating thermal performance in enough detail and analysing thousands of models. EnergyPlus provides the building summary as a csv-file, making it easy to extract key indicators.

The two end uses are electricity energy (plug loads, lighting and hot water) and district heating. District heating is effectively the heat output by a heater when the fuel type or efficiency is not specified. The heat energy used and not the energy required to run the heater is reported because heat-pumps and solid fuel burners can have a range of efficiencies depending on the model, the temperature outside for the heat-pump and how the solid fuel burner is operated. Both the Consumers' Institute and EECA provide costs per kWh of heat allowing the cost of heating to be calculated [139], [140]. 


\section{RUNNING A MATRIX OF SIMULATIONS WITH ENERGYPLUS}

Analysing a matrix of possible combinations (see table 20) can be separated into three components:

1. Generating model files;

2. Running each file through the EnergyPlus simulation; and

3. Extracting results.

\section{Generating the EnergyPlus files}

Generating the files was the most complicated of the three components, requiring a number of steps:

- Creating a base model in the EnergyPlus IDF Editor

- Creating IDF files with each of the proposed changes.

- Pasting the base model into Excel (from the text editor).

- Pasting the relevant lines of text for each of the proposed changes into another tab in the same document, along with reference codes. (This frequently required lines of text from many places in the document.)

- Writing a macro to automate the process of copying and pasting lines of text into the base model tab for each combination.

Note this was structured to be a direct copy and paste exercise so the file stayed the same length and lines of text could be copied into the same cell in Excel each time. This meant reducing numbers to be effectively zero instead of removing features entirely.

- Getting the Excel macro to save this changed file as a formatted text (space delimited) or .prn file using the syntax "filename.idf" including quotes, which saved a file directly usable in EnergyPlus.

- Repeating this process for every combination of changes to be tested. Running this macro took approximately 4-5 hours.

\section{EnergyPlus Simulation}

This was carried out using four computers to reduce simulation times $(1,918$ files were run on each computer). The IDF files were manually sorted into a folder on each of the computers and was set up to run using the group of input files feature available in the IDF Editor.

Each batch of files was simulated with three TMY weather files produced by the New Zealand National Institute of Water \& Atmospheric Research to provide performance across the country. The locations selected were Auckland, Wellington and Dunedin to demonstrate the impacts of a wide range of climatic conditions on house performance.

On 4 computers running four files at a time (the maximum recommended), it initially took approximately 29 hours. This was reduced to 5.7 hours by running 24 files simultaneously on each of the 4 computersiv . 


\section{Reading the Results}

The EnergyPlus files were set up to write out a table of summary reports as a .csv filev

From this output file four annual summary values were used; the number of hours the heating setpoint wasn't met; the number of hours the cooling setpoint wasn't met; total electricity use (for appliances, lighting and hot water); and the total district heating used (the default source of heat when no fuel is specified). These are consistently reported in the same 4 cells in the .csv file so it was possible to write another Excel macro to automate the process of reading these values from every output file and calculating the discomfort score from these values (detailed p.71). This macro ran in approximately 2-3 hours for each location (three macro runs were required in total).

These values were then exported to IBM SPSS Statistics 22 for further analysis.

\section{Outcomes}

Overall the process of writing 7,672 model files, simulating them three times each and processing the outputs was surprisingly easy. By automating the time consuming components with an Excel macro, the hands-on time required for this analysis was cut dramatically. ${ }^{\text {vi }}$ 


\section{RESULTS AND DISCUSSIONS}

The energy requirements and discomfort levels of the range of house upgrades investigated will be presented in the following sections. However, first it is useful to look at what New Zealand households currently spend on energy services to provide a frame of reference for the results.

\section{Energy Bills and Income}

To maintain indoor conditions considered to have minimal risks to health it is necessary to use both heating and ventilation. Hot water (for hygiene) and suitable appliances (for food safety) will also presumably assist preventing adverse health effects. To obtain these improved health outcomes, tenants must have these systems available and be able to afford the running costs. New Zealand household expenditure on energy services has been used to provide a reference for affordability [141], with the data broken down by income rather than fuel type.

The Statistics NZ Household Economic Survey found the average weekly expenditure on household energy services to be $\$ 46$ for 2012/2013 (the latest available data), or approximately $\$ 2,390$ per year. The lowest income households spend as little as $\$ 1,695$ p.a. while the highest income households spend $\$ 3,214$ p.a. (figure 37). Household income and size are related, with more single person households having a low-income and higher income households are more likely to have more occupants. Household size would be expected to have an impact on the level of energy services required.

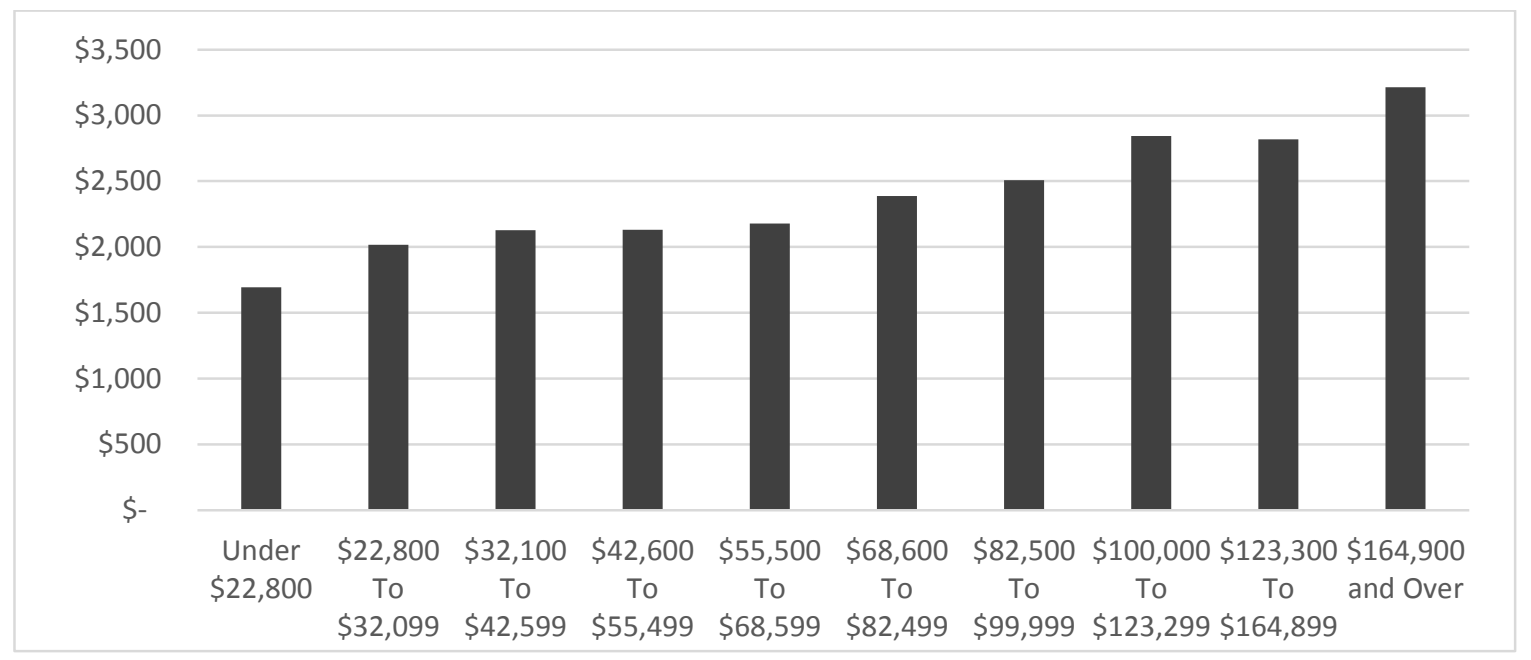

FIgURE 37: HOUSEHOLD ENERGY EXPENDITURE P.A. IN 2013 BY INCOME GROUP

The test villa (assumed to have 4 occupants) uses 3,960kWh of electricity for appliances. On a prepay low-user plan this would cost around \$1,090p.a.

The hot water heating requirements for the test villa may be slightly overstated due to cold water temperatures not fluctuating seasonally (see "Hot Water System" p.47). The modelled hot water energy requirements range from $1,713 \mathrm{kWh}$ for a code compliant HWC with no showers to $5,380 \mathrm{kWh}$ for a D-grade HWC at maintained at $60^{\circ} \mathrm{C}$. For comparison, HEEP measured hot water heating requirements averaging $3,260 \mathrm{kWh}$.

The total 7,220 kWh $(3,260 \mathrm{kWh}$ for hot water plus 3,960kWh for household appliances) on a prepay low user plan would cost $\$ 1,880$ p.a., which is already approximately $\$ 185$ above the average 
low-income household expenditure. Depending on the occupancy of these households, they may already struggle to afford adequate hot water and household appliance services alongside space heating.

Households with incomes of up to $\$ 55,499$ spend slightly more on energy services at $\$ 2,132$ p.a. This is the upper income group which would qualify for community service card power prices with a family of 4 [142]. This household may have around $\$ 250$ to spend on heating for the year.

High-income households may spend as much as $\$ 1,150$ p.a. on space heating if they paid average prices for electricity and maintained the same household appliance and hot water consumption as measured by HEEP.

'Average' households may have $\$ 410$ to spend on space heating with the same expenditure on other energy requirements. If it is presumed that the average household in the HES is comparable to the average household in HEEP then this provides a starting point for determining how much energy services the household would require and whether this is affordable.

These figures suggest that providing affordable space heating even for average households will be a challenge. $\$ 410$ is unlikely to provide whole house heating using an expensive heating source (such as plug in electric heaters) or in a cold climate. This would provide an economic motive for households to only heating the living room on winter evenings, as observed by HEEP.

The electricity prices for following analyses will be calculated at the rate of $27.38 \mathrm{c} / \mathrm{kWh}$ which is the average price (including GST) paid by households in 2013 [143]. This allows for comparison with actual 2013 household expenditure and does not require assumptions about which electricity plan the household would be on. 


\section{Comparison of the Two Warrant of Fitness}

The two proposed WoFs take different approaches to minimum thermal requirements. The GH WoF requires both heating and insulation. The HNZ WoF requires heating or insulation. The following graphs investigate what impact these two different approaches have.

Of the 7,672 model variations 729 pass the GH WoF and 1,272 pass the HNZ WoF. The difference is due to the HNZ WoF's permitted substitution of heating for insulation as all the heating options tested were considered to be "appropriate heating".

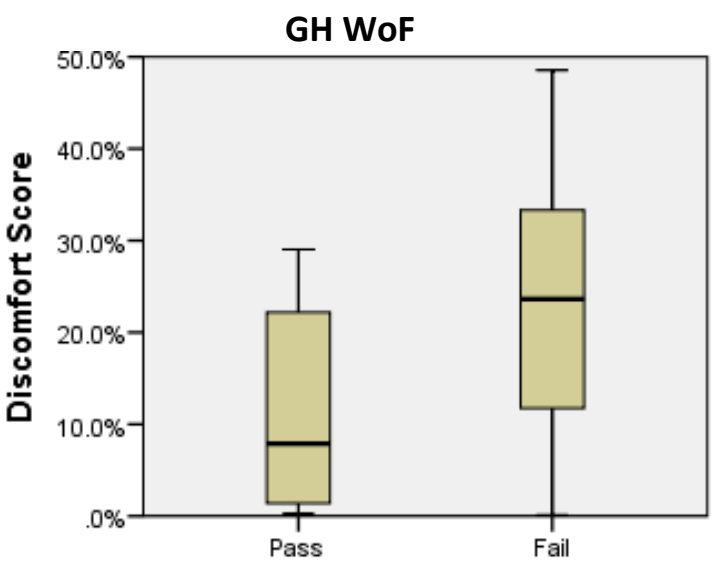

GH WoF Overall

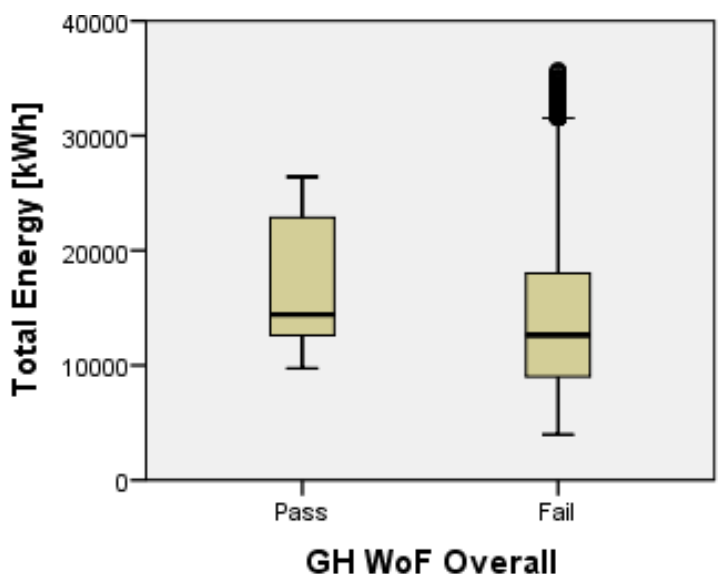

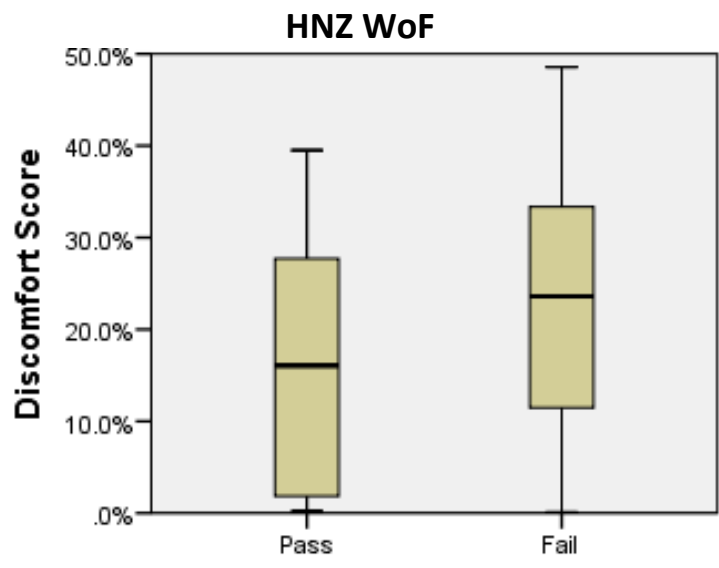

HNZ WoF Overall

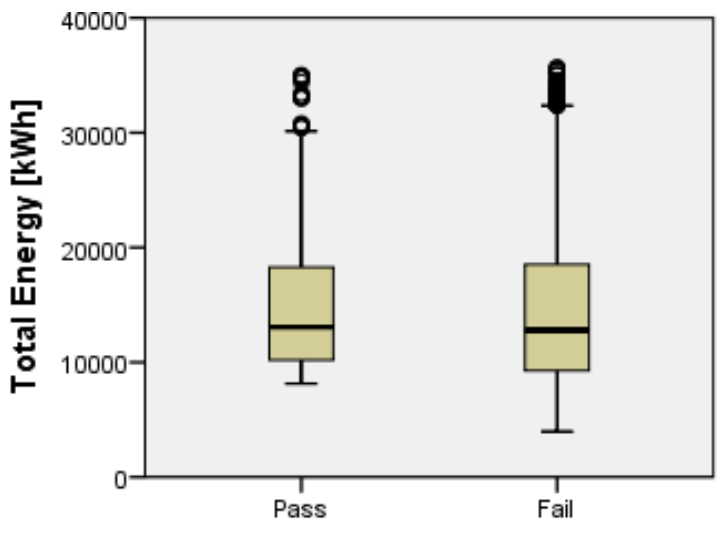

HNZ WoF Overall

FIGURE 38: A COMPARISON OF THE IMPACT OF PASSING THE GH WOF AND THE HNZ WOF ON DISCOMFORT AND ENERGY CONSUMPTION

Key:

Whiskers $=$ range

Box $=$ upper \& lower quartiles and median

Circles $=$ outliers

While passing the GH WoF appears to reduce the extremes of bad performance (too uncomfortable or high energy use) it does not guarantee better thermal performance than a building which fails.

Meeting the requirements of the HNZ WoF does not seem to be a reliable indicator of lower energy use or of lower levels of discomfort. This results from its substitution approach to heating 
and insulation. A house can pass if it has either insulation or "appropriate" heating (which is currently undefined). This can lead to high levels of discomfort when there is no heating used, and high levels of heating required when there is no insulation.

The analysis suggests that the GH WoF would have a greater positive impact on the thermal performance of the housing stock overall by requiring insulation and heating. Conversely the benefits of the HNZ WoF may be seen in the economic performance of the dwelling provided cheaper heat sources were available, rather than in the amount of heat required. Merely knowing a house passes or fails either of the WoFs does not present a reliable indicator of expected comfort or energy consumption. There is opportunity for overlapping performance between a house which passes and another which fails. The following sections provide the analysis behind these results.

\section{Best and Worst Scenarios}

This section presents a summary of the best and worst possible combinations of the house features presented in table 20 , Tested thermal performance criteria from both WoFs.

\section{(Dis)comfort}

The most uncomfortable house model:

- is located in Dunedin;

- had the HWC turned off;

- has no heating;

- has no ventilation;

- is single glazed with no curtains;

- has no ceiling insulation; and

- has bulk underfloor insulation with the maximum R-value.

This model received a discomfort score of $48.6 \%$ and does not pass either of the WoFs. The only attribute which is surprising is the presence of underfloor insulation. This may be due to the underfloor insulation not reducing heat loss as much as it contributes to overheating. The equivalent model with no underfloor insulation is marginally less uncomfortable with a score of $47.0 \%$. The model with underfloor insulation has more hours with temperatures over $24^{\circ} \mathrm{C}$ than the model without underfloor insulation has hours below $16^{\circ} \mathrm{C}$.

The least uncomfortable of the models:

- is located in Wellington;

- has the HWC turned off;

- has central heating;

- has full ventilation;

- is single glazed;

- has code level insulation in the ceiling; and

- no subfloor insulation.

This model received a discomfort score of $0.1 \%$. These are somewhat distorted results because the heating system is able to provide all the warmth needed so the other criteria have been optimised to reduce overheating. There are no unnecessary gains from the HWC and excess heat is able to be lost through the windows and floor. The Wellington climate is cooler than the 
Auckland climate meaning it is able to provide adequate summer cooling and the unlimited central heating is able to provide adequate warmth in winter. However, this house model does not pass either of the WoFs.

The least uncomfortable of the models with a realistic heating system (i.e. any of the options other than the infinite capacity central heating):

- uses the $2 \mathrm{~kW}$ electric heaters;

- has a D-grade HWC set to $60^{\circ} \mathrm{C}$;

- has full ventilation;

- is double glazed;

- has blanket ceiling insulation; and

- R-1.1 underfloor insulation meets the requirements of NZS4218 for all climates.

It appears that the heat losses from the inefficient HWC are acting as supplementary space heating in this model. This does not pass the GH WoF as the blanket insulation is not deep enough (only $195 \mathrm{~mm}$ thick when $200 \mathrm{~mm}$ is required), but it does pass the HNZ WoF which places no requirements on the thickness of insulation.

\section{Energy Use}

The lowest energy use model:

- is located in Auckland;

- has the HWC turned off;

- has no heating but full ventilation;

- is double glazed;

- has blanket ceiling insulation; and

- bulk underfloor insulation with the minimum R-value.

This model uses $3,962 \mathrm{kWh}$ a year $(\$ 1,084$ per year or $\sim \$ 90$ per month since this is all electricity and no heating). This would not pass either of the WoFs because firstly the HWC has been turned off and secondly there is no heating.

The highest energy use model (excluding the infinite central heating models):

- is located in Dunedin;

- has a D-grade HWC set to $60^{\circ} \mathrm{C}$;

- uses $2 \mathrm{~kW}$ electric heaters;

- has full ventilation;

- is single glazed; and

- is uninsulated.

This house model uses $34,065 \mathrm{kWh}$ p.a. (costing up to $\$ 9,327$ per year or $\sim \$ 777$ per month). The HES reports high-income households spend around $\$ 3,214$ on energy a year so this house design costs almost 3 times more to run. Again this house would not pass either of the WoFs even though this combination of features is not unheard of in New Zealand housing.

This model only uses $1,620 \mathrm{kWh}$ p.a. less than the highest energy use model with the infinite capacity central heating. $12 \mathrm{~kW}$ of heating, distributed across the house, appears mostly adequate to keep this house warm. The fuel cost however will limit heating with this type of heaters more so than their physical heat output. 


\section{Does Passing A Wof Help Thermal Performance?}

The analysis has shown that improving thermal performance will reduce discomfort (measured by the discomfort score) or reduce energy requirements (mostly for heating). Ideally both will be reduced indicating a warmer house at lower cost.

The scenarios described earlier in table 20 are designed to capture performance which just meets the requirements of a WoF (e.g. insulation which is $200 \mathrm{~mm}$ thick not any thicker) and performance which completely fails the requirements of a WoF (e.g. no insulation at all, no ventilation at all). This is reflected in the performance as failing a criteria can cause a substantial decrease in performance. Failing a criteria less severely (e.g. having $100 \mathrm{~mm}$ of insulation instead of the required $200 \mathrm{~mm}$ or lacking ventilation in only one room) would have a less substantial impact on the discomfort score.

\section{Overall Impact on Discomfort}

Figure 39 shows the discomfort levels in models which meet all of the thermal requirements of the GH WoF (left of graph) compared to scenarios which meet progressively less of the thermal requirements (right).

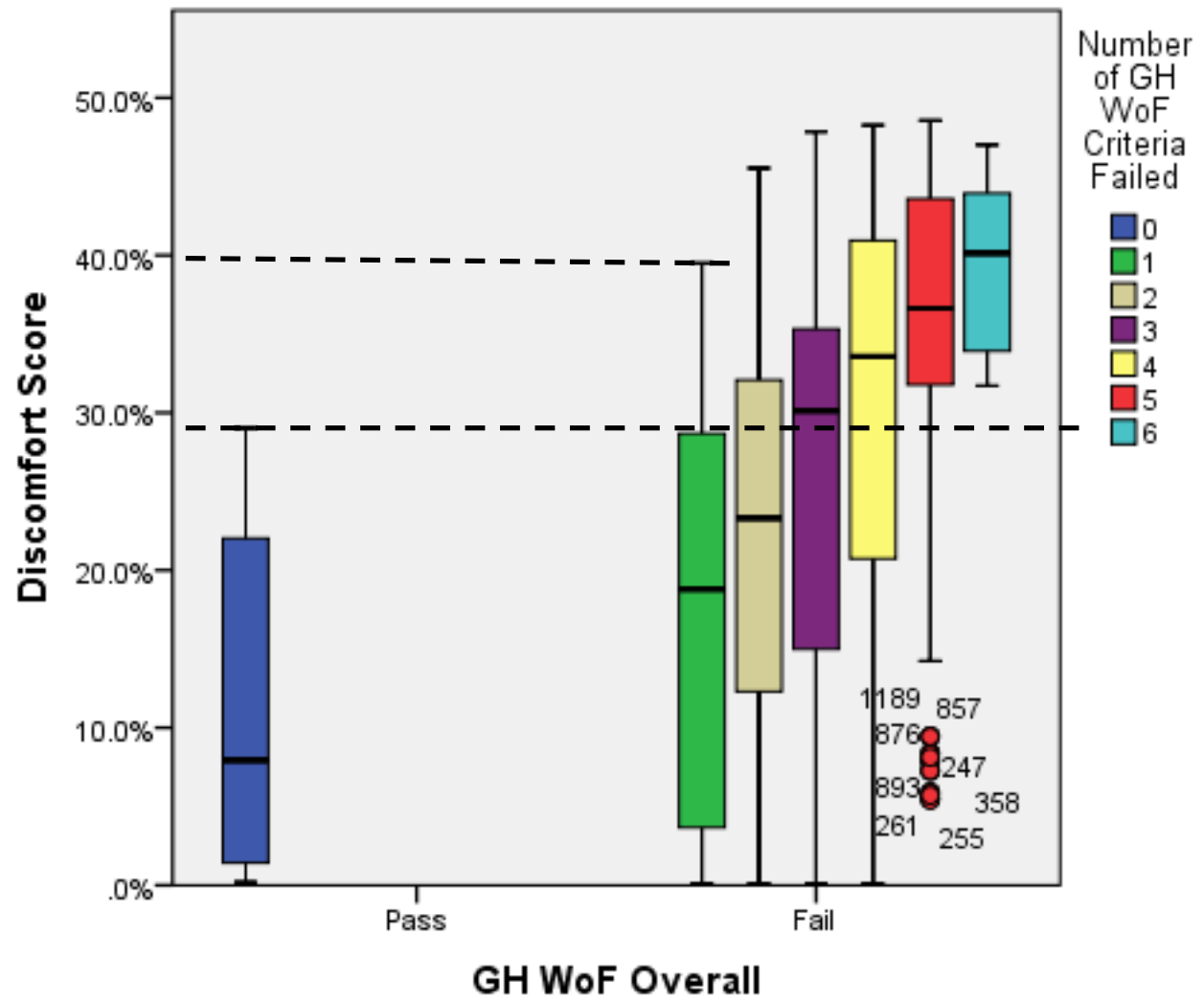

FIGURE 39: IMPACT OF NUMBER OF GH WOF CRITERIA FAILED ON DISCOMFORT

The models which pass the GH WoF (the dark blue bar) have a lower maximum discomfort score. As soon as the model fails one WoF criteria (any of the options tested from the HWC setpoint to the heating type) it is still possible to achieve a low discomfort score but it now becomes likely to achieve a higher discomfort score. The mean, upper quartile and maximum are all shifted upwards. 
Figure 39 shows there is a significant increase in the potential for discomfort between the models which fail no criteria and those which fail any one criteria. This inter-quartile range of potential discomfort is increased by $10 \%$. Having no features which would contribute towards passing the WoF (all 6 criteria failed) is a guarantee of substandard performance with a high discomfort score. The best case scenario is less comfortable than any model which passes the WoF. With each criteria in the WoF checklist which is passed, the potential for high levels of discomfort are reduced.

\section{Overall Impact on Potential Energy Consumption}

Figure 40 provides a view of the energy consequences of failing GH WoF criteria. As the number of criteria failed increases, the median energy use decreases but the range remains high, until with 6 criteria failed the house has no heating, or hot water services remaining therefore severely limiting energy consumption.

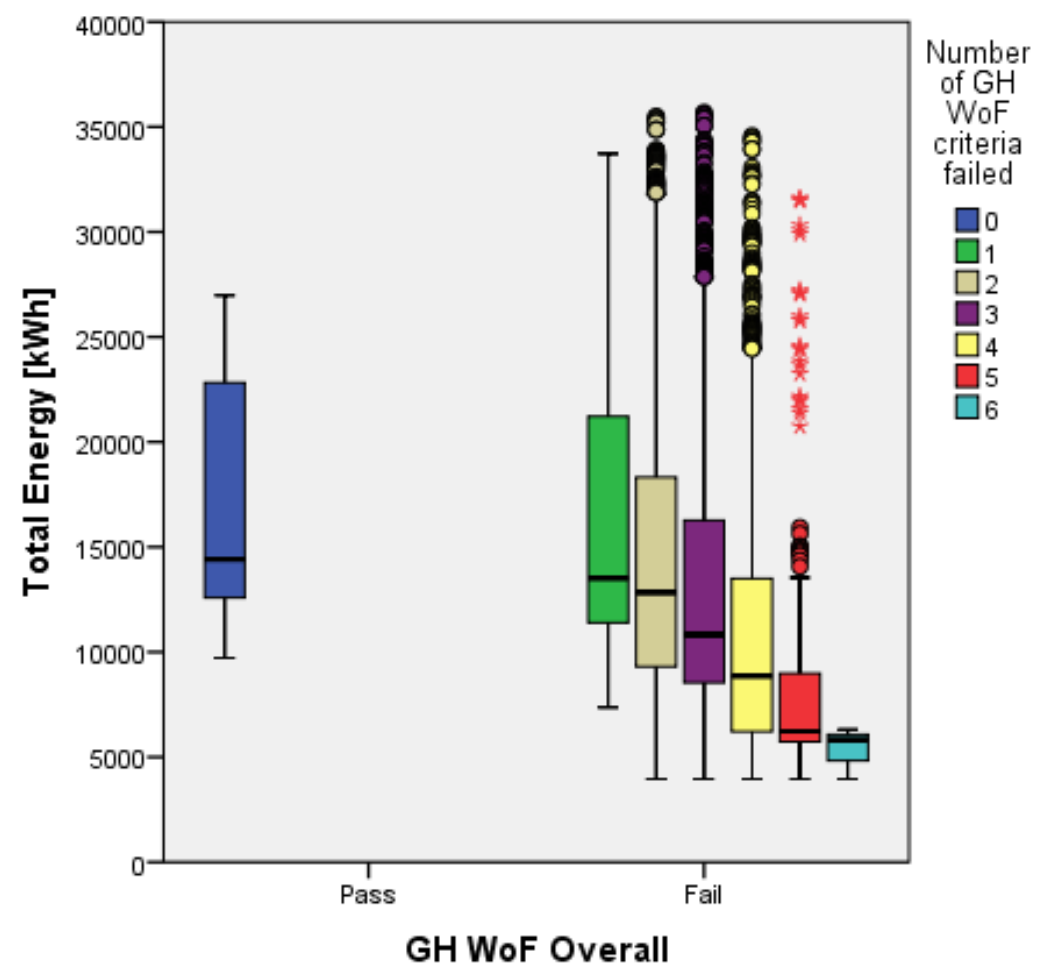

FIGURE 40: THE NUMBER OF GH WOF CRITERIA FAILED AND THE IMPACT ON POTENTIAL ENERGY CONSUMPTION

When a house fails any one of the thermal criteria of the GH Warrant of Fitness, there is the potential for energy use to either increase or decrease. Energy use will increase when there is no insulation, more so when there is no ceiling insulation than no underfloor insulation. Energy use will decrease when there are no energy services such as heating or hot water maintained at a safe temperature.

As a house progressively more criteria are failed the house is more likely to use less energy as it loses multiple energy services. 


\section{Energy Savings from WoF level Insulation}

The models show that by upgrading from no insulation to GH WoF compliant insulation in the ceiling and subfloor, moderate energy savings can be obtained. With the minimum compliant insulation options (foil insulation and R-1.43 insulation), energy savings can be between $10 \%$ and $33 \%$, as set out in table 23 .

Heating with 'economic' heaters does not have savings as high as the other heating options because these heaters were not large enough to consistently maintain comfort temperatures without insulation. Some of the energy efficiency is seen as warmer temperatures with this heating option. Single room heating sees fewer benefits from the insulation because heat is lost from the living room into the rest of the house.

Single room heating can see savings of up to $13 \%$ while whole house heating can see savings of up to $33 \%$. However, the 'take-back' effect of achieving warmer temperatures can reduce these savings.

TABLE 23: HEAT CONSUMPTION WITH DIFFERENT HEATERS AND INSULATION LEVELS

\begin{tabular}{|c|c|c|c|c|}
\hline & Central heating & $\begin{array}{l}\text { 'Economic' } \\
\text { heaters }\end{array}$ & $\begin{array}{l}2 \mathrm{~kW} \text { electric } \\
\text { heaters }\end{array}$ & $\begin{array}{l}\text { Fireplace/heat- } \\
\text { pump in living } \mathrm{rm} \text {. }\end{array}$ \\
\hline No insulation & 26,933 & 15,983 & 26,113 & 12,828 \\
\hline Insulated & 20,254 & 14,594 & 20,163 & 11,327 \\
\hline Savings & $33 \%$ & $10 \%$ & $30 \%$ & $13 \%$ \\
\hline
\end{tabular}

Reducing heating use can equally offer substantial energy savings, although less desirable from a health and comfort perspective.

Moving from central heating to living room heating only can reduce energy requirements by $52 \%$ in a house without insulation while in the insulated house energy requirements are reduced by $44 \%$.

Moving from a collection of $2 \mathrm{~kW}$ heaters to living room heating only can save $20 \%$ of the energy requirements without insulation and $22 \%$ in a house with insulation. 


\section{How Does a WoF Compliant House Compare to a New House}

Figure 41 shows the difference in thermal performance between insulation levels which fail the WoF (the red points), insulation levels which just pass the WoF (orange points) and insulation levels which meet the current building code (green points). The clusters of performance for the options which pass the WoF are linked to climate (Auckland requires about half the heating of Dunedin) and heating type. Both a warmer climate and increasing levels of insulation cause the performance of the house to move closer to no heating and no discomfort $(0,0)$. The type of

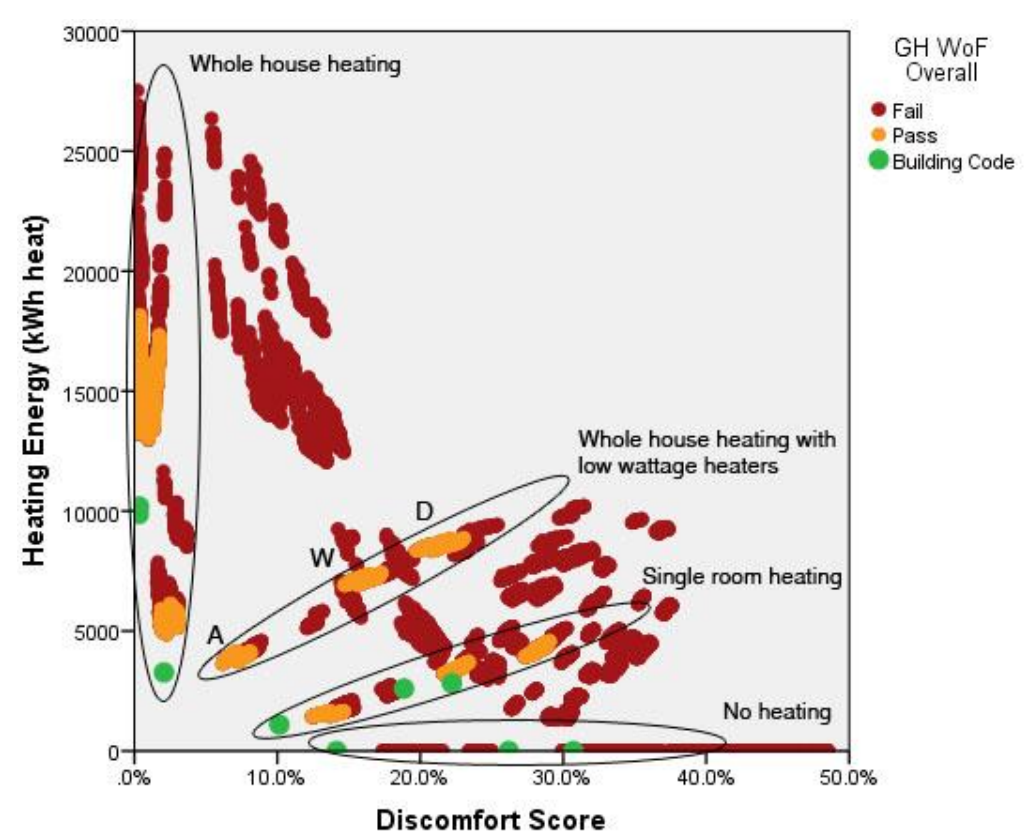

FiguRE 41: SCATTER PLOT OF WOF AND CODE THERMAL PERFORMANCE heating available influences the trade-off between high heating requirements or high discomfort. A passive house or high Homestar rating would be aiming for $(0,0)$ on this graph.

\section{Energy Use}

The WoF insulation standards are still below the requirements for new houses. By meeting the NZBC Acceptable Solution for thermal performance (roof, floor, walls and windows) $36 \%$ to $42 \%$ of heating requirements could be saved compared to the 13 to $33 \%$ achievable with the lower WoF insulation.

\section{Discomfort}

Discomfort is also reduced when the whole thermal envelope is insulated to the current NZBC requirements.

TABLE 24: DISCOMFORT SCORE IMPROVEMENTS BY MEETING NZBC REQUIREMENTS IN DIFFERENT CLIMATES

\begin{tabular}{|c|c|c|c|}
\hline & $\begin{array}{l}\text { Fails WoF with no } \\
\text { Insulation }\end{array}$ & Passes WoF & $\begin{array}{l}\text { Meets NZBC } \\
\text { requirements }\end{array}$ \\
\hline Auckland & $28.7 \%$ & $18.6 \%$ & $14.2 \%$ \\
\hline Wellington & $37.5 \%$ & $30.8 \%$ & $26.2 \%$ \\
\hline Dunedin & $43.1 \%$ & $38.5 \%$ & $30.7 \%$ \\
\hline
\end{tabular}

Auckland sees the largest comfort improvements when meeting the WoF requirements, but this is partially influenced by the criteria facilitating both retaining warmth through insulation and reducing overheating through ventilation. For a house in Dunedin to be comparably comfortable to a WoF compliant house in Wellington NZBC level insulation is required. 


\section{Which WoF Criteria Have the Largest Impact?}

The following sections examine each of the thermal criteria addressed by either of the WoFs and the impact these have on discomfort and/or energy consumption. Following these sections all of the criteria modelled are presented alongside each other to compare their impact on discomfort.

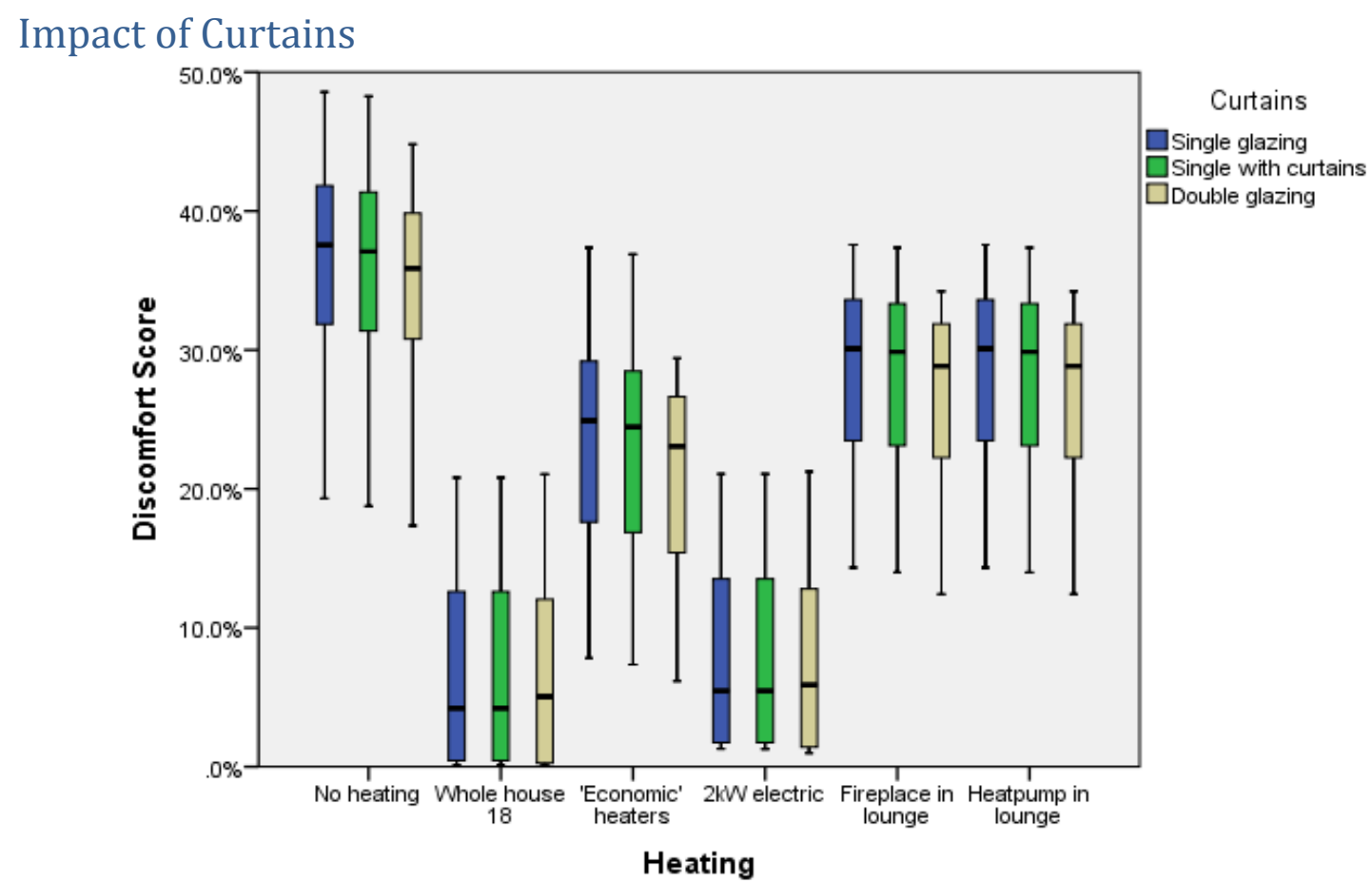

FIGURE 42: IMPACT OF WINDOW TREATMENT ON DISCOMFORT WITH DIFFERENT HEATING OPTIONS

The curtains have a minimal impact on the discomfort score (figure 42) because it is calculated from the air temperature whereas curtains raise the mean radiant temperature.

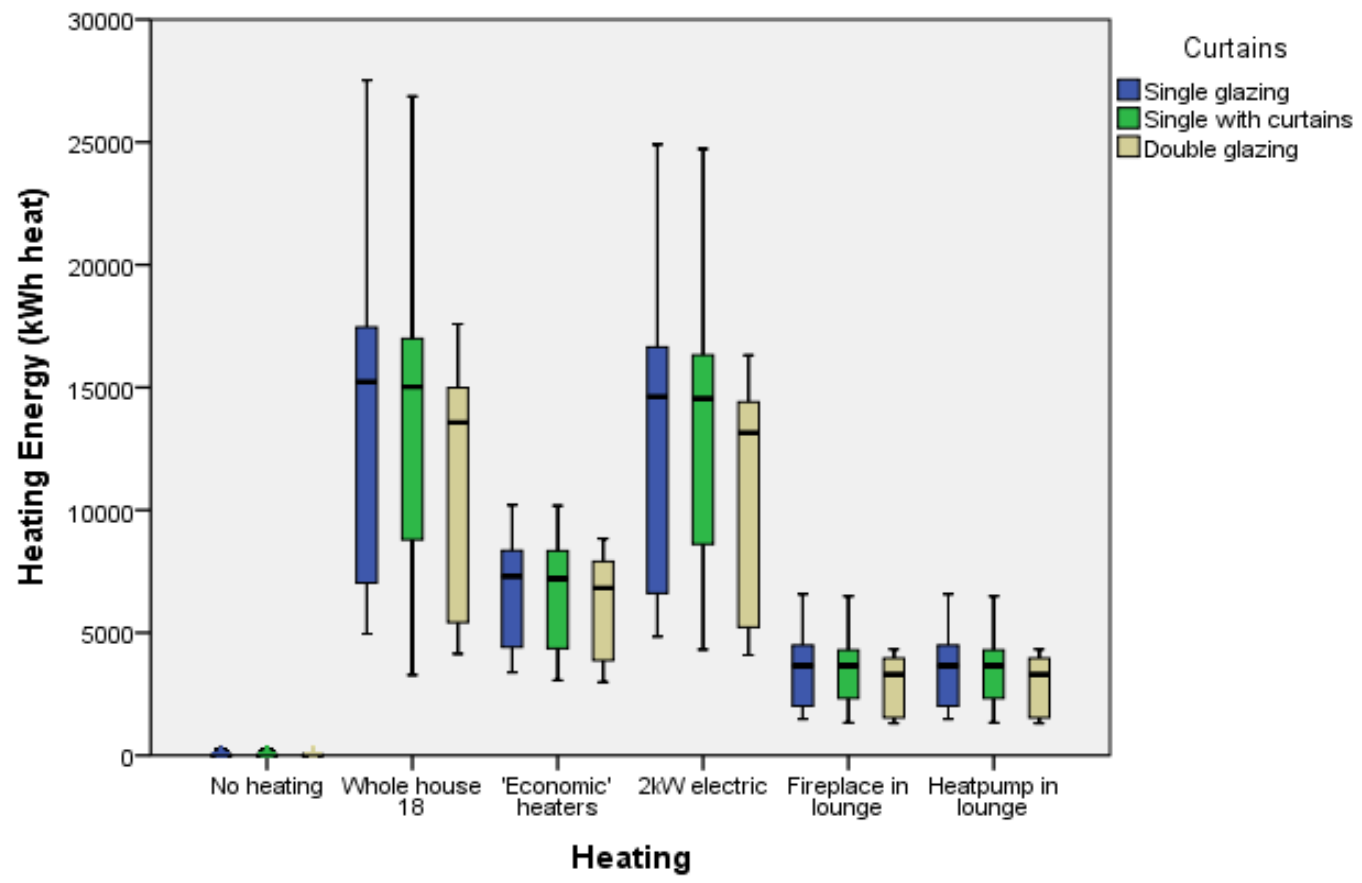

FIGURE 43: IMPACT OF WINDOW TREATMENT ON HEATING ENERGY WITH DIFFERENT HEATING OPTIONS 
The curtains also don't noticeably reduce the heating required because there is still heat loss through convection around the edges of the curtain (figure 43). The apparent benefits of double glazing in these graphs are amplified by the fact double glazing was only added to models which already had insulation - a simplification to reduce calculation times.

This analysis does not show the benefits of curtains where an occupant is sitting near a window and feels cold due to the cold glass. Drawing a curtain in this situation would provide increased thermal comfort. There is also the benefit of privacy no matter the thermal performance of the window coverings.

The test villa is an older style of housing which was originally constructed with single glazing, but the window-to-wall ratio is at $14 \%$ is lower than in many newer buildings. Increased glazing and an increased window-to-wall ratio is common in newer buildings, with the NZBC Clause H1 permitting up to $30 \%$ before the windows must be specifically considered. Double glazing however has only required in the Acceptable Solution for new buildings since 2007. Houses constructed prior to this can have larger single glazed areas than the test villa. These houses would have greater benefits from reducing heat loss through large areas of single glazing.

\section{Impact of Insulation}

The graphs below present the results from various combinations of sub-floor and ceiling insulation upgrades. Only Wellington results (falling between those of Auckland and Dunedin) with ventilation available are graphed to highlight changes caused by the insulation upgrades. Note the vertical scale in figure 44 is from $30 \%$ to $36 \%$, showing in all cases similar consequences, although some combinations have greater impact than others. 
Subfloor Insulation

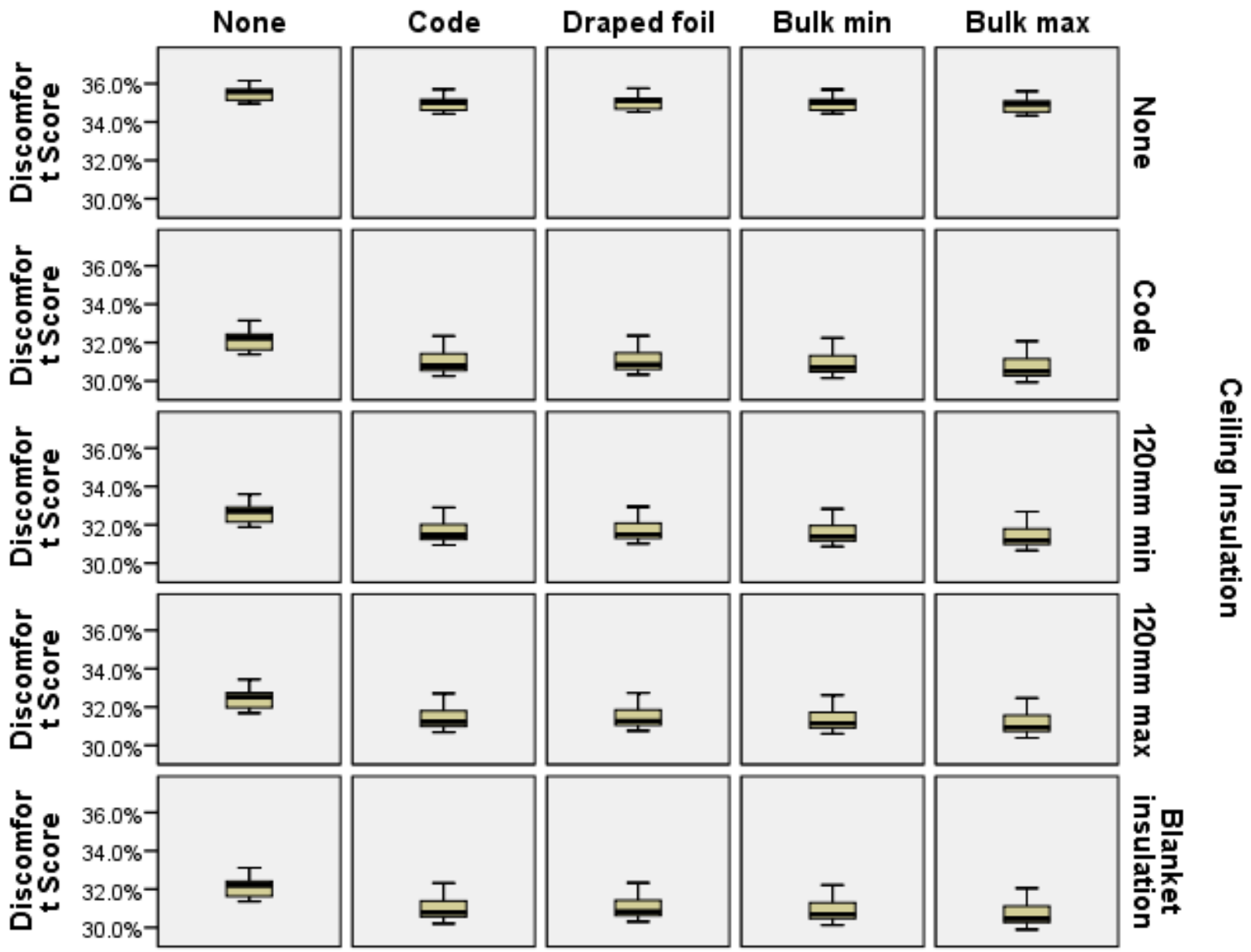

FIGURE 44: COMBINATIONS OF CEILING AND UNDERFLOOR INSULATION IN WELLINGTON WITH NO HEATING

Figure 44 and figure 45 show ceiling insulation provides a greater benefit than subfloor insulation. Having $120 \mathrm{~mm}$ of insulation in the ceiling, even with the minimum possible R-value has a greater impact on reducing discomfort than underfloor insulation. 
Subfloor Insulation

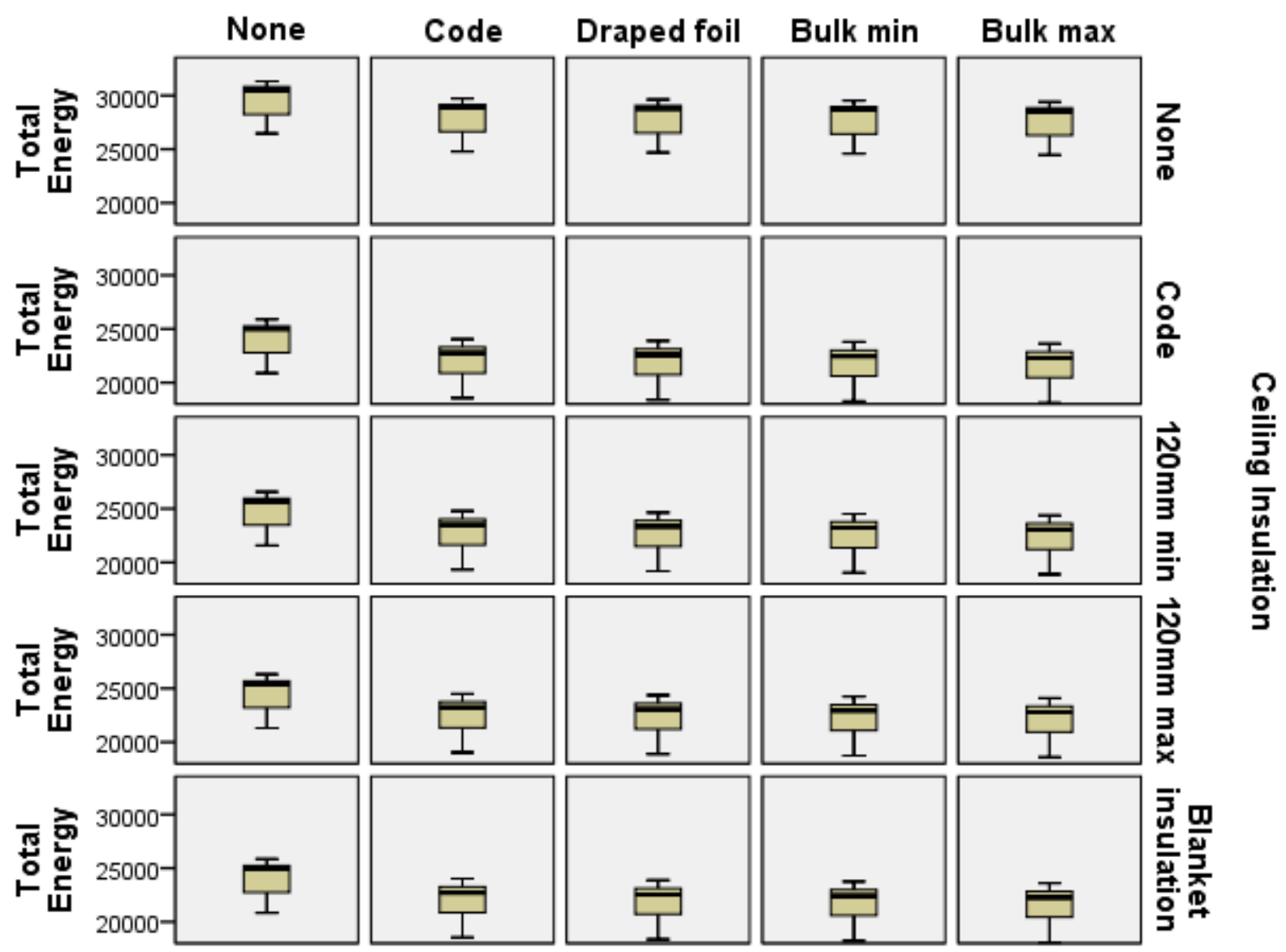

FIGURE 45: COMBINATIONS OF CEILING AND UNDERFLOOR INSULATION IN WELLINGTON WITH CENTRAL HEATING

Ceiling insulation also provides a reduction in heating requirements (central heating in figure 45 shows the largest benefit). All the subfloor insulation options appear to provide an equal benefit.

Insulation measured by depth rather than thermal performance

The insulation options tested included a $195 \mathrm{~mm}$ thick blanket insulation which technically does not pass the GH WoF because it is less than $200 \mathrm{~mm}$ thick. However, the installation method (over the rafters minimising thermal bridging) achieves R-3.0 which is above the NZBC Clause H1 Acceptable Solution requirement of R-2.9 for zones 1 and 2.

The models with ceiling blanket insulation had an average discomfort score of $20.9 \%$ and an average energy consumption of $13,939 \mathrm{kWh}$. This is comparable to the R-2.9 NZBC requirement which had the same average discomfort score but slightly less energy consumption of $13,955 \mathrm{kWh}$.

Omitting the blanket insulation from box plots did not show a visible difference to the range, median or quartiles, however it did impact numeric analysis. Models which failed the ceiling insulation requirements of the GH WoF used on average 15,049kWh of energy when the blanket insulation was included in this category. When it was excluded, the models which failed used on average $16,621 \mathrm{kWh}$. Classifying $195 \mathrm{~mm}$ of insulation as failing the WoF, the same as no insulation, resulted in the models which failed appearing on average more energy efficient. 
Because the $195 \mathrm{~mm}$ of insulation meets the intent and the owner could presumably provide evidence to indicate it should comply, this type of insulation was excluded from the GH WoF fail category.

For the HNZ WoF, any level of insulation is deemed to pass. There are no situations where comparatively high levels of thermal performance can be failed, but it is also possible to pass with comparatively low levels of insulation.

\section{Impact of Ventilation}

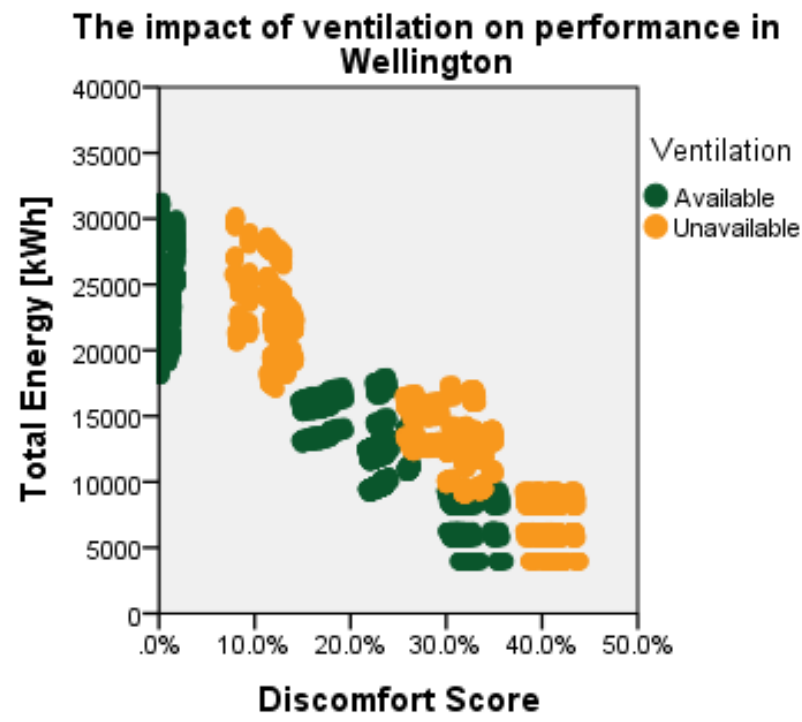

FIGURE 46: IMPACT OF VENTILATION ON ENERGY AND DISCOMFORT
Figure 46 shows that ventilation has a large impact on the thermal performance of the test villa. The green dots show the performance of fully ventilated models and the tan dots show models with no ventilation available. Auckland and Dunedin see a similar decrease in discomfort to Wellington. This decrease in discomfort is because ventilation is able to reduce the instances of hot temperatures (over $25^{\circ} \mathrm{C}$ ).

The test villa has reasonably high levels of infiltration before ventilation is added. The average infiltration rate in Wellington for the zones in the model ranges between $0.11 \mathrm{ACH}$ for the hall and 3.2ACH for the kitchen (see "Infiltration Modelling" p.51). The results in

figure 46 illustrate the benefits of both WoFs in reducing overheating discomfort in addition to the intended reduction of internal moisture and "maintaining healthy internal conditions" [6, p. 91]. The description of desired ventilation in the Housing Warrant of Fitness Assessment Manual [6] is very strongly targeted towards pollutant removal. The HNZ WoF criteria also link ventilation to the house being dry rather than adequately cooled [71].

The ventilation section of the GH WoF could be expanded to emphasise the increased comfort available to occupants by having openable windows of a suitable area. (The HNZ WoF does not provide detailed discussion of the benefits of any criteria.) This would also provide a reason for keeping window stays in the warrant criteria, as landlord feedback has been that it is excessive to require these. Window stays permit secure ventilating to reduce overheating, an issue which can occur while the occupants are not at home, as opposed to pollutant removal which is usually necessitated by occupant activities while they are at home (e.g. cooking, showering, breathing). 
Hot Water temp

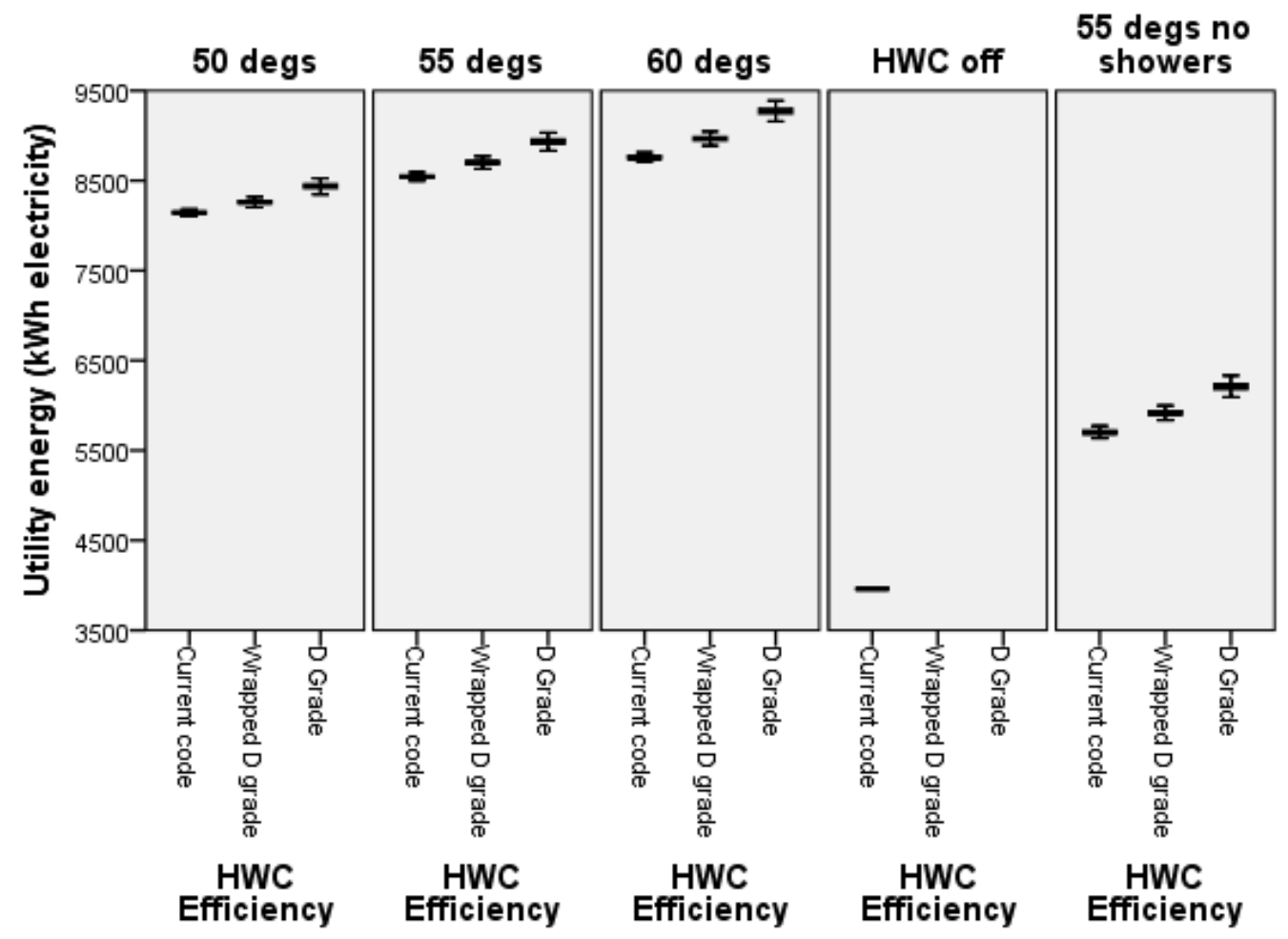

FIGURE 47: IMPACT OF HWC MEASURES ON UTILITY ENERGY USE

Figure 47 shows the efficiency and setpoint of the HWC has a small impact on energy use. Providing a $\mathrm{HWC}$ wrap gives about the same reduction in electricity as a $5^{\circ} \mathrm{C}$ reduction in the setpoint. The difference between the D-grade $\mathrm{HWC}$ at $60^{\circ} \mathrm{C}$ and the code $\mathrm{HWC}$ at $50^{\circ} \mathrm{C}$ is a $12 \%$ reduction in utility energy requirements. The small ranges in energy consumption (shown by the box whiskers) for each combination of efficiency and setpoint are due to the indoor temperatures. A warm house requires marginally less energy to keep the water hot than a cold one. 


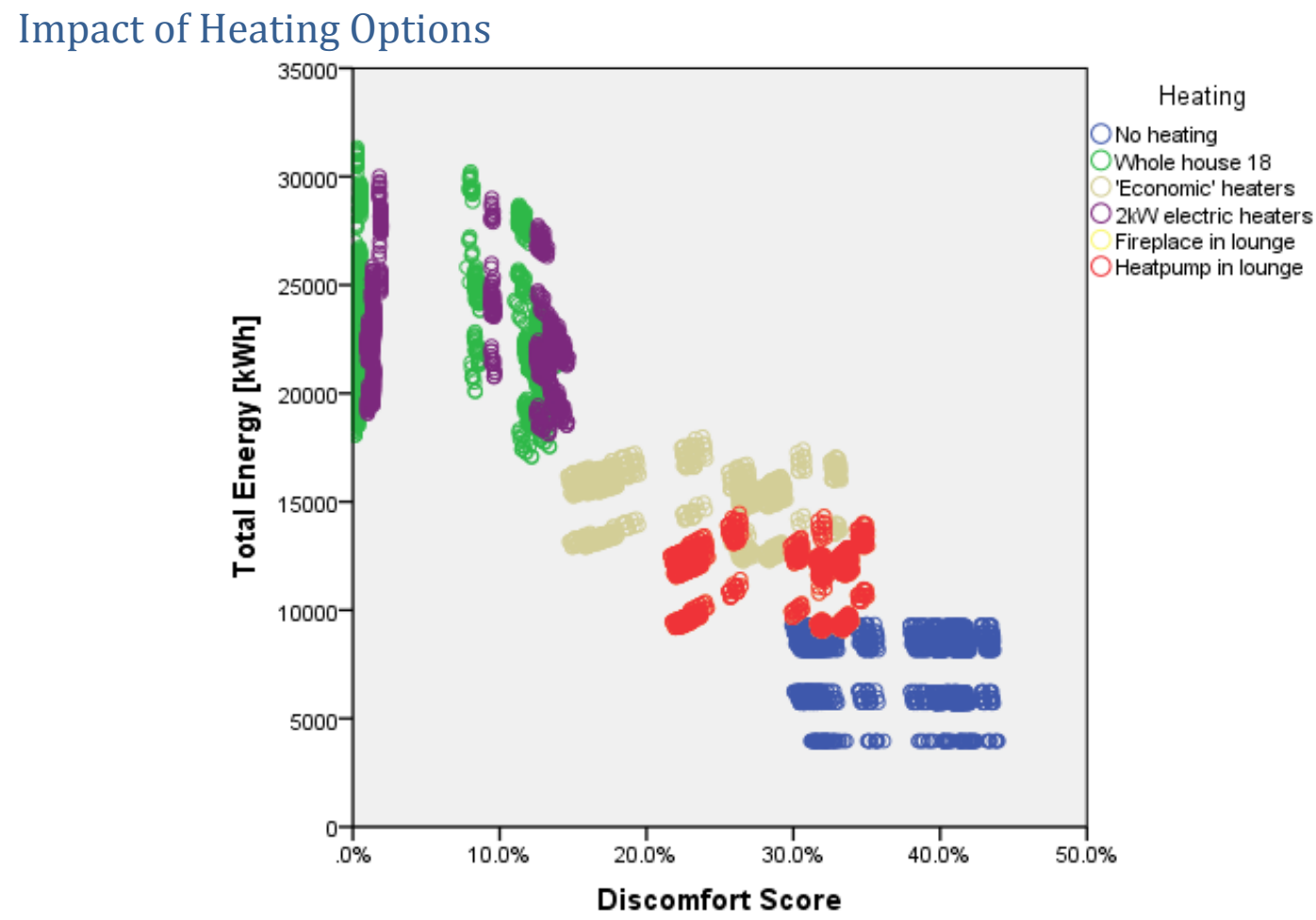

FIGURE 48: HEATING TYPE IMPACT ON ENERGY USE AND DISCOMFORT

Figure 48 summarises the heating type and house performance in Wellington. The performance of the fireplace and the heat-pump are identical in these models. The fireplace at $15 \mathrm{~kW}$ is evidently oversized for the heating requirements of the living room while the heat-pump is adequately sized, so both are always able to keep the room warm.

Surprisingly, the performance of the six electric heaters and the infinite capacity central heating system appear comparable. It appears that a $2 \mathrm{kw}$ portable heater in each room except the hall and the bathroom is adequate to keep the house warm. A drawback here is that electric circuits may not be designed to handle many plug-in electric heaters at one time [82]. Another issue is the cost of the electricity. Central heating systems are rarely electric; they are generally supplied by a boiler using more economic wood pellets, gas or other combustible fuels.

The 'economic' (electric) heaters initially appear to represent a good solution for this style of house (figure 48), providing a balance between excessive energy consumption and discomfort. Small heaters in 6 rooms have a benefit across the whole house, but the energy consumption is limited due to the low output of each individual heater. However, the cost of running these heaters is high, adding around $\$ 1,800$ to the annual power bill or $\$ 225$ per month for an 8 month winter. If an average household used this heating type they would have to reduce their heating hours by about $3 / 4$ to make it affordable. 


\section{Overall Comparison of WoF Criteria}

\section{Discomfort Score}

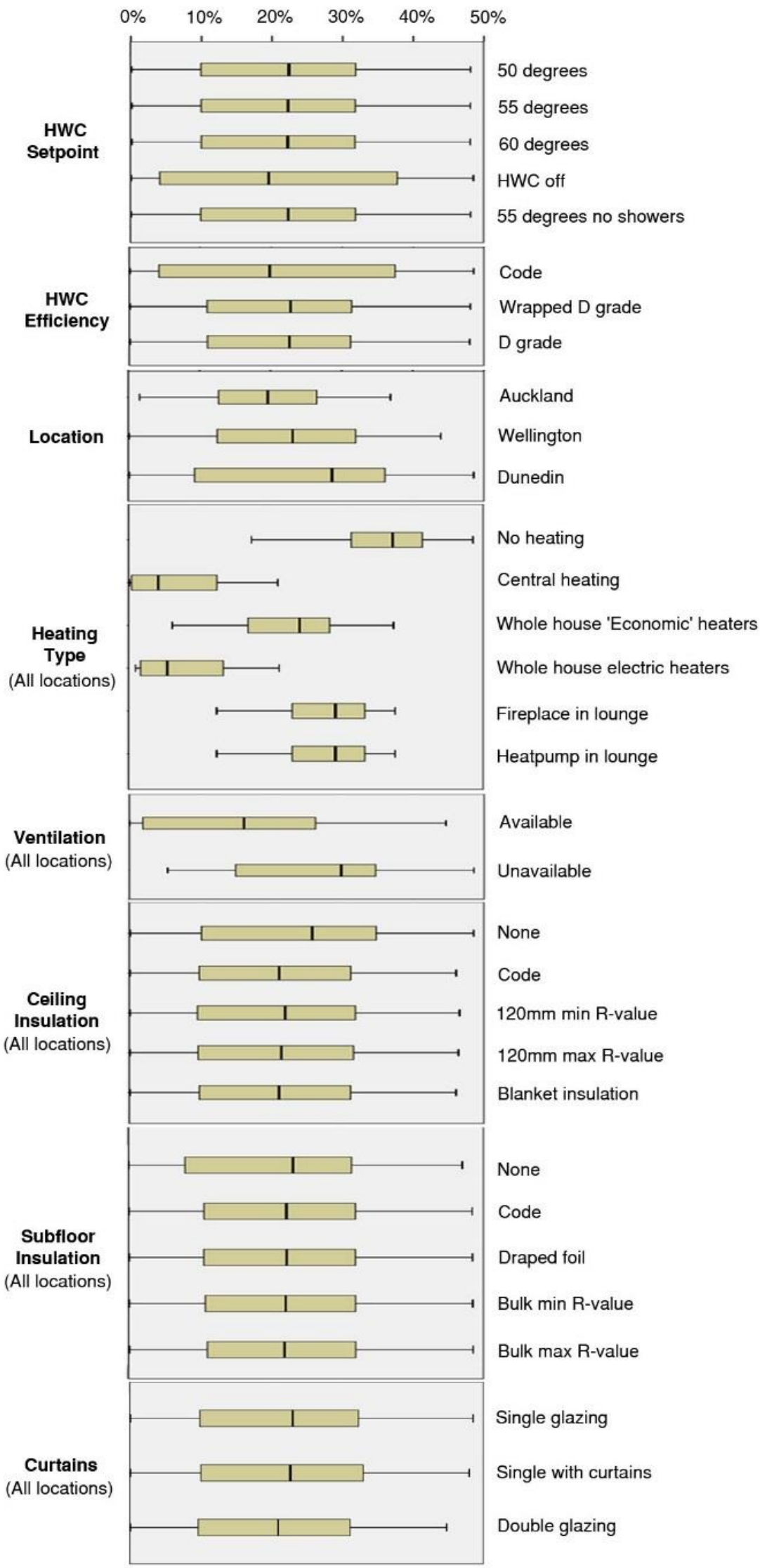

FIGURE 49: A COMPARISON OF THE IMPACT OF THE WOF CRITERIA ACROSS ALL SCENARIOS 
Figure 49 provides a graphical summary of the impact of each of the changes tested on occupant discomfort, allowing cross comparisons. A written summary is provided below.

Having a suitably sized and distributed heating system is the single best indicator of low levels of discomfort. The provision of ventilation in every room, providing pollutant removal and summer cooling, also leads to lower levels of discomfort. This is the case in every climate, not just Auckland, where cooling is perceived as more of an issue.

Climate (i.e. location) has a large impact on the expected levels of discomfort in a dwelling, greater than (for example) meeting the GH WoF requirements for insulation, although a WoF is unable to control location.

Having ceiling insulation reduces discomfort, however the R-values tested did not have a large impact on discomfort. Insulation options ranging from R-1.43 to R-3.01 only varied the average discomfort score by $0.3 \%$.

Subfloor insulation only provided an apparent benefit when there was adequate cooling ventilation otherwise it increased discomfort by increasing the instances of overheating. With adequate ventilation available, the overheating the subfloor insulation adds is outweighed by the reduction in time when it is too cold.

Curtains and double glazing provide small benefits in this house, partly due to the low window-towall ratio.

Turning the HWC off in Auckland provides an apparent benefit because it reduces internal heat gains which lead to overheating. However in Dunedin it is detrimental because these internal heat gains contribute to keeping the house adequately warm. Increasing the efficiency of the HWC has similar apparent benefits and costs.

The following is the suggested order of importance for the various components of the WoF:

1. Heating

2. Ventilation for cooling

3. Ceiling insulation

4. Subfloor insulation

5. Curtains 


\section{Location}

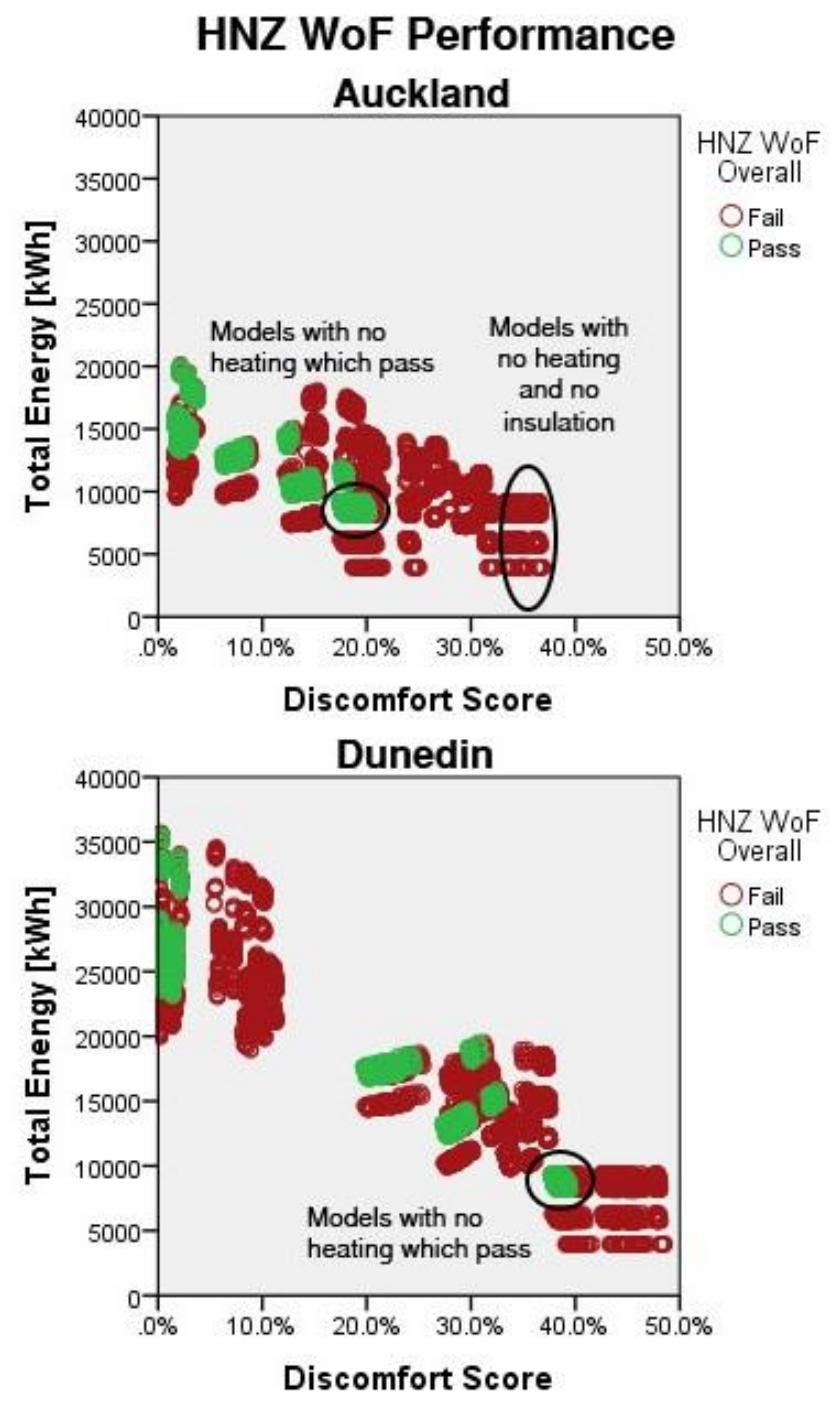

FIGURE 50: A COMPARISON OF THERMAL PERFORMANCE IN AUCKLAND AND DUNEDIN
The climate has a strong impact on how well the test villa performs, even when it passes the WoF. Figure 51 and figure 52 show a building in Auckland which passes would have a narrower range of expected performance (both in terms of discomfort and energy use) than one which passed in Dunedin. Interestingly the Auckland house has a higher minimum level of discomfort (figure 51), due to overheating and not cold temperatures. This finding would further support aligning the WoF ventilation criteria with cooling as well as fresh air supply. In general, the colder the climate the higher the potential levels of discomfort. Passing the WoF somewhat reduces the magnitude of this effect. Presumably an even larger reduction would be seen if the WoF also required wall insulation.

The dotted vertical line and circles in figure 50 show the test villa with ceiling and subfloor insulation to WoF standards in Dunedin would still be less comfortable than an uninsulated house in Auckland.

Graphs of the performance of both WoFs and heating types across the three climates are provided in the appendix. 


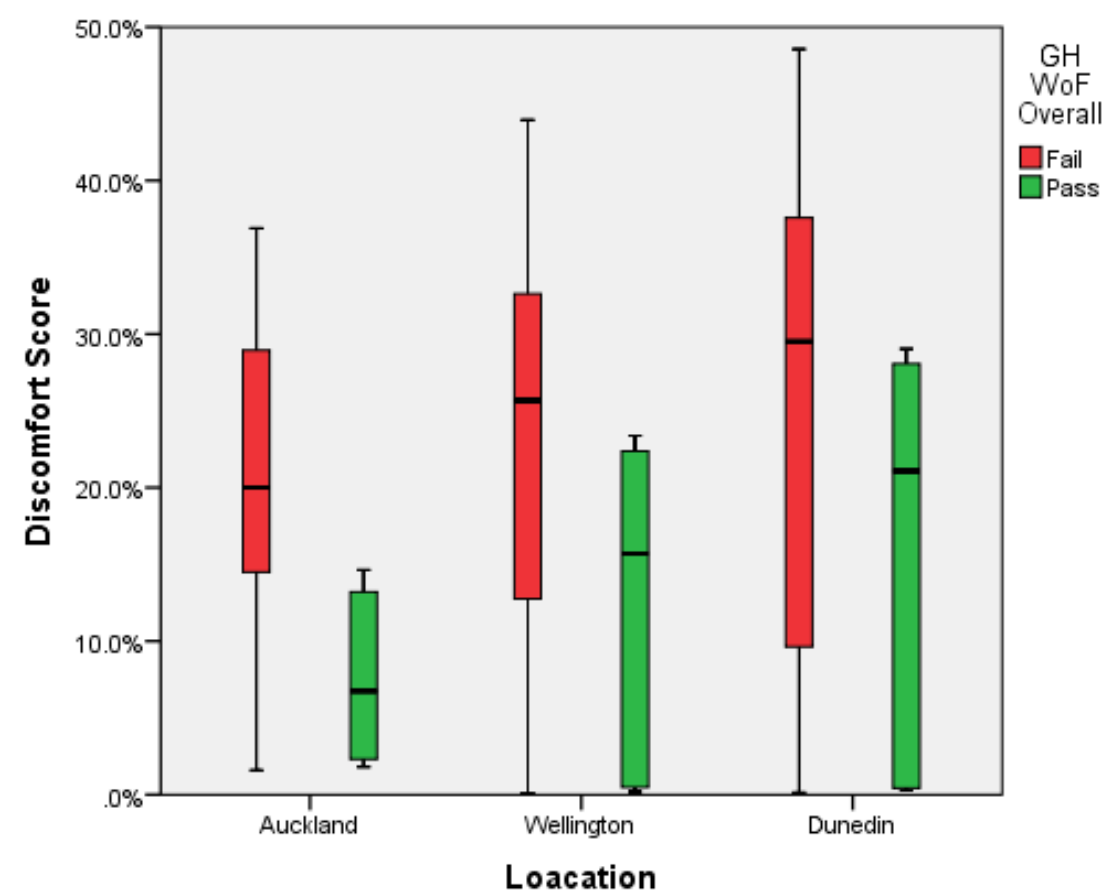

FIGURE 51: IMPACT OF CLIMATE VS PASSING THE GH WOF ON DISCOMFORT

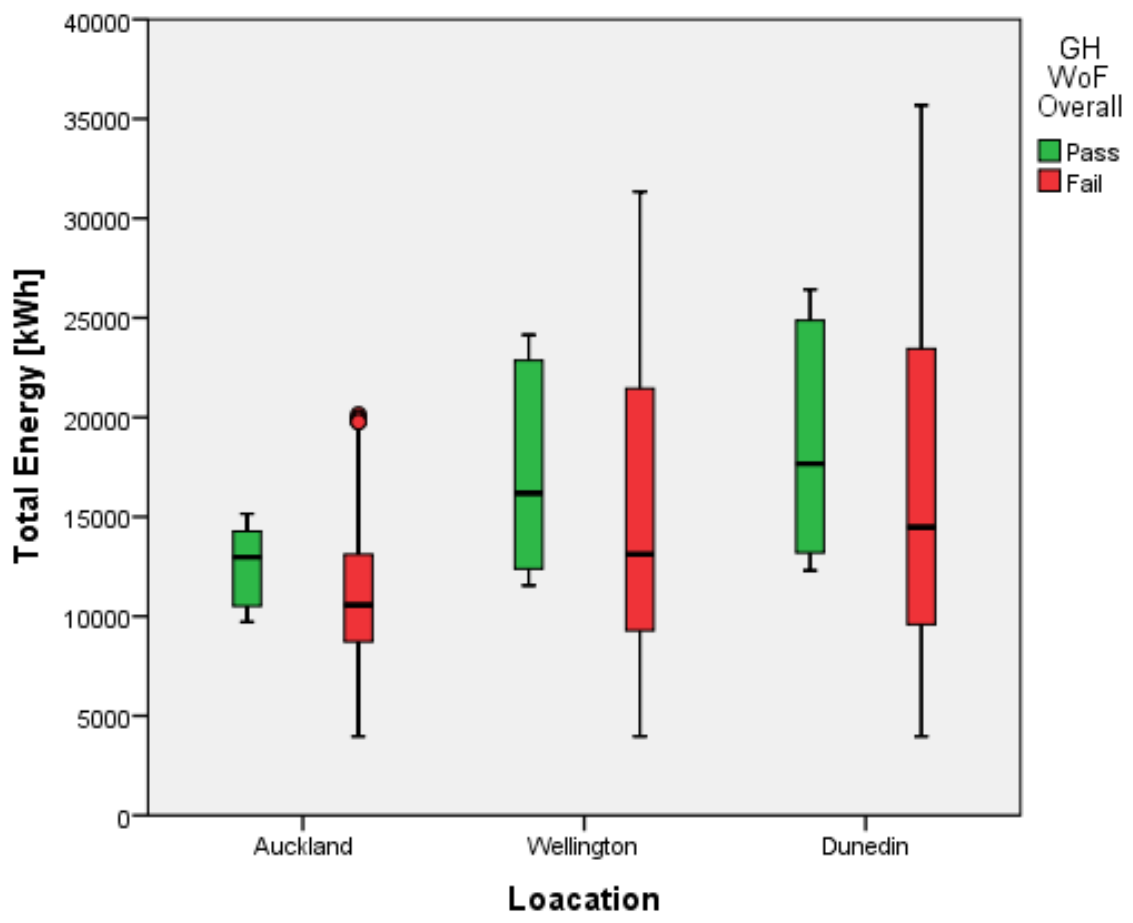

FIGURE 52: IMPACT OF CLIMATE VS PASSING THE GH WOF ON ENERGY USE 


\section{Fixed Heating}

The GH WoF requires "a fixed form of safe and effective heating" [6, p. 89], but the only limitation is that it is firstly fixed and located within the main living area and secondly it is not an unflued gas heater. The HNZ WoF requires appropriate heating to be installed only when either ceiling or underfloor insulation is not practicable [71].

HEEP found that houses with fixed heaters had higher evening temperatures in the living room than those with portable heaters. It is not possible to determine if the HEEP results are due to the size of the heater relative to the room being heated or the cost of the fuel. This may indicates that if the WoF required fixed heating in rental properties then living room temperatures, and hence energy use, may rise provided the occupants could afford the cost.

Most houses have the ability to use portable electric heaters already. The simulations indicated that portable electric heaters can physically keep the house warm the majority of the time.

Perhaps most of the benefit of a fixed (solid fuel) heating system is that it allows people to make use of more economic fuels for heating, and achieve greater comfort at lower cost.

\section{Fixed Electric Heating}

It appears likely that in many cases fixing an electric heater to the wall would be a landlord's preferred approach to meeting the GH WoF requirement for fixed heating. It doesn't require any new fuel to be delivered to the property, it can be a DIY installation and requires minimal upfront investment (around \$200). Installing a heat-pump, flued gas heater or solid fuel burner requires a higher investment, a tradesperson to do the installation, in some cases a building consent, and generally more input from the landlord.

There are around 480,000 rental properties in New Zealand [33]. Adding around this number of electric heaters, and following the WoF assumption that they are used, could have a large impact on national electricity use and peak electric demand.

What are the savings available if a landlord upgrades the house to meet a WoF using electric heaters fixed to the wall as well as insulation upgrades? How much could the tenant save in this case? Theoretically they could be running portable heaters already which would provide the same amount of heat output. The mean heating energy required by the house with $2 \mathrm{~kW}$ electric heaters is set out in table 25 for both WoFs. 
TABLE 25: HEATING WITH 2KW ELECTRIC HEATERS WHEN PASSING AND FAILING BOTH WOFS

\begin{tabular}{|l|l|l|}
\hline HNZ WoF & Pass & Fail \\
\hline Heating required $[\mathrm{kWh}]$ & 12,651 & 12,693 \\
\hline Cost of heating & $\$ 3,464$ & $\$ 3,475$ \\
\hline Savings & $\$ 20$ & \\
\hline & & \multicolumn{1}{|l|}{} \\
\hline GH WoF & Pass & Fail \\
\hline Heating required $[\mathrm{kWh}]$ & 11,929 & 13,155 \\
\hline Cost of heating & $\$ 3,266$ & $\$ 3,602$ \\
\hline Savings & $\$ 336$ & \\
\hline
\end{tabular}

The savings are for running a heater year round whenever the temperature drops below $18^{\circ} \mathrm{C}$, which is not usual heating behaviour, making \$336 energy savings a high estimate. For tenants to see these heating cost savings they would need to spend more than high-income households spend on average on all energy uses. It is uncertain what changes landlords may make to rents as a result of meeting the WoF, but one property manager has indicated that it may be in the region of $\$ 500-\$ 750$ a year [81]. This suggests that with electric heating, tenants may not see financial savings to make the increase in rent worthwhile.

\section{Sources of Fuel}

Figure 53 provides home heating energy costs from the magazine "Consumer" for 2014, the latest available [140].

\begin{tabular}{l}
\hline HOME HEATING COSTS2014 (cents per kWh) \\
\hline HEATERS \\
\hline Electricity (heat pump) \\
\hline Natural gas (flued heater) \\
\hline Electricity (nightstore/underfloor) \\
\hline Firewood (woodburner) \\
\hline Wood pellets (pellet burner) \\
\hline Electricity (plug-in) \\
\hline Diesel \\
\hline LPG (flued heater) \\
\hline LPG (unflued heater) \\
\hline CENTRAL HEATING \\
\hline Natural gas \\
\hline Wood pellets \\
\hline Diesel \\
\hline LPG
\end{tabular}

FIgURE 53: CONSUMER 2014 COMPARISON OF THE COST OF HEATING USING DIFFERENT HEATING SOURCES 


\section{Affordable Heat}

It appears that even if a house has insulation installed which meets the GH WoF requirements and a heat source fitted, targeted room heating is still the only affordable option. The graphs below illustrate the ranges of costs likely for a house which passes or fails the WoF, using a range of different heating types. The heating consumption is for maintaining $18^{\circ} \mathrm{C}$ in any room that is heated. The horizontal lines indicate the average actual expenditure on energy (for heating and all other uses) by New Zealand households. The dashed horizontal line indicates $\$ 410$, the likely expenditure on heating by 'average households'. The solid line indicates the possible heating expenditure by high-income households. Green bars are for houses which pass either WoF and red bars are for houses which fail.

The range in costs is partly because of fuel costs, and partly because of differing thermal performance.

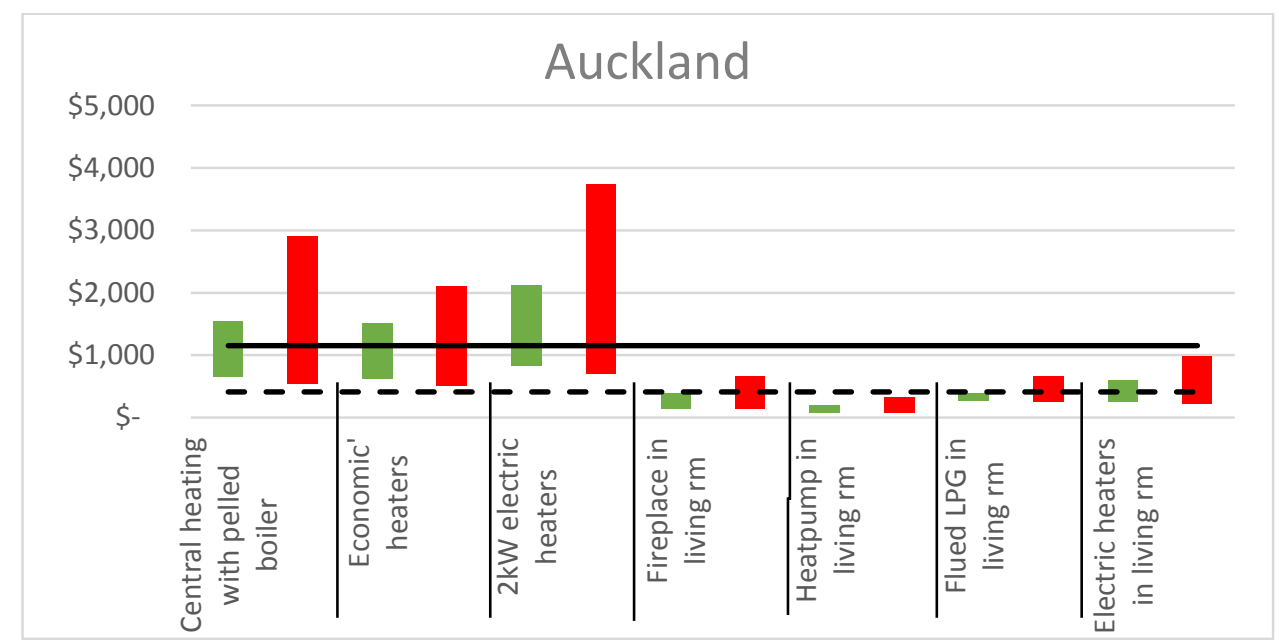

FIGURE 54: COST OF HEATING WITH DIFFERENT HEATING TYPES IN AUCKLAND, PASSING OR FAILING THE GH WOF

In Auckland (figure 54) when the house is insulated, maintaining the living room at comfortable temperatures consistently appears affordable with most heating types. Tenants may make tradeoffs by keeping multiple rooms warm for only some of the time.

The whole house heating options (central heating with a pellet boiler, multiple 'economic' heaters or multiple $2 \mathrm{~kW}$ heaters) appear unlikely to be possible in average income households, with or without insulation. They may still be possible for households with higher incomes. 


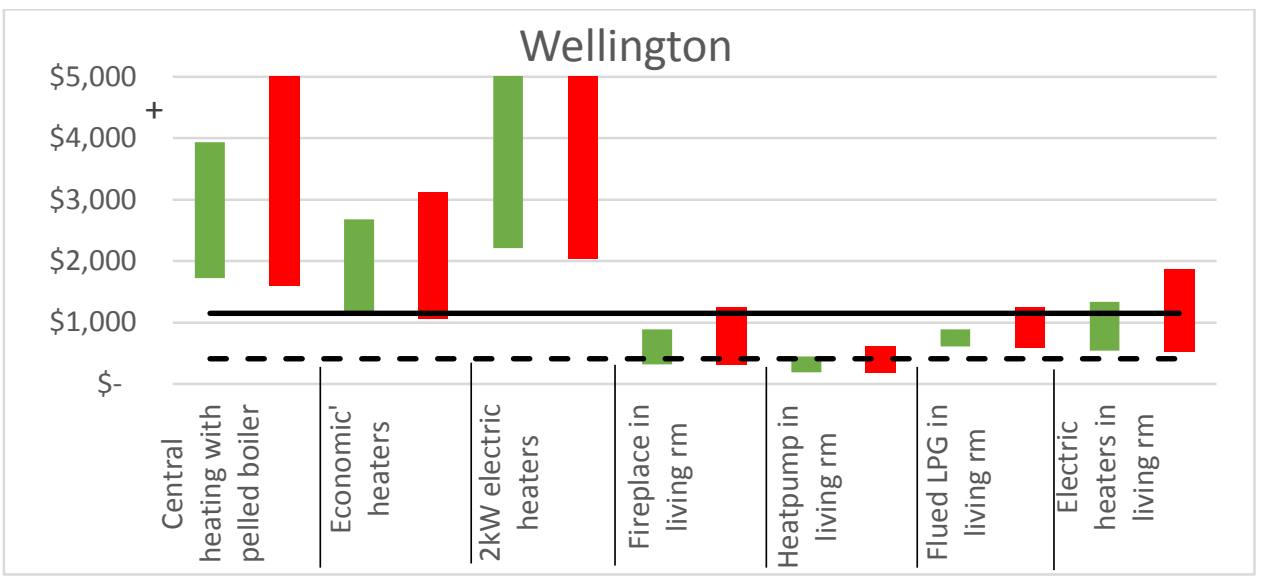

FiguRE 55: COST OF HEATING WITH DIFFERENT HEATING TYPES IN WELLINGTON, PASSING OR FAILING THE GH WoF

In Wellington (figure 55) using a heat-pump to maintain temperatures of $18^{\circ} \mathrm{C}$ appears affordable and a fireplace may be affordable depending on the cost of firewood. Flued LPG and electric heaters may be affordable when only used for select hours of the day. Whole house heating options appear unaffordable even for high-income tenants with WoF level thermal insulation in Wellington. Single room heating appears the most likely approach due to the cost.

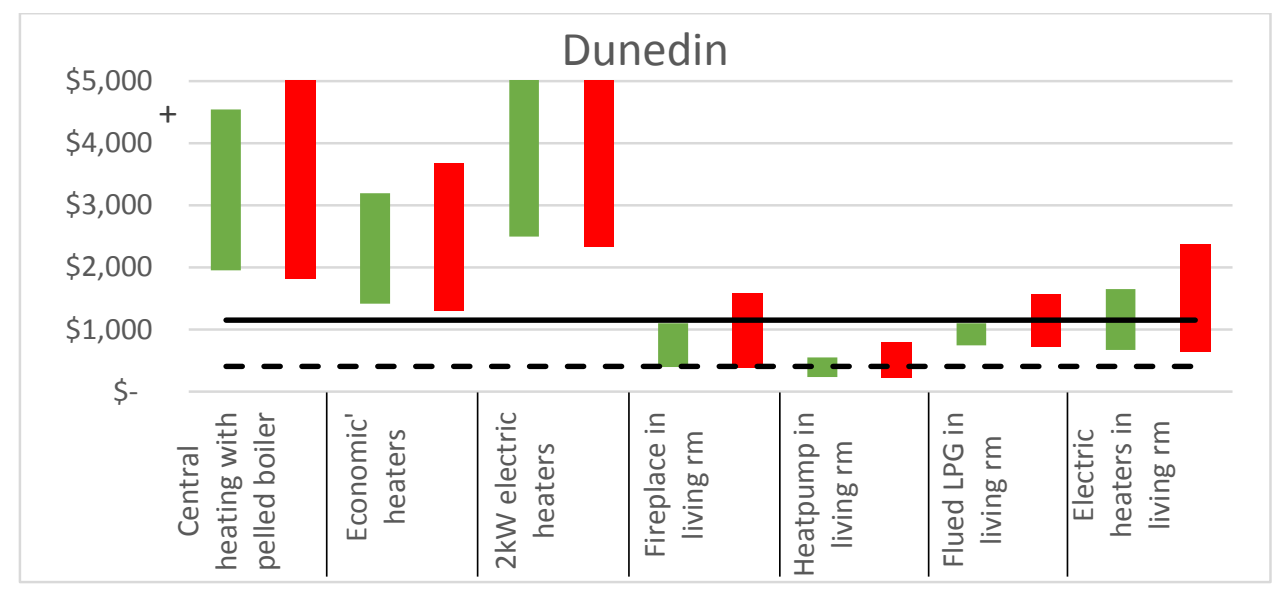

FIGURE 56: COST OF HEATING WITH DIFFERENT HEATING TYPES IN DUNEDIN PASSING OR FAILING THE GH WOF

In Dunedin (figure 56) maintaining consistent warmth with a heat-pump may not be affordable for average households, depending on the performance of the heat-pump. All other heating types are not affordable for consistent warmth. Even for the highest income households keeping the living room consistently warm without insulation may be unaffordable.

It does not appear possible for an average household to constantly maintain healthy temperatures across all of the house even when it meets the thermal requirements of the $\mathrm{GH}$ WoF. High-income households may be able to afford to keep the whole house warm in Auckland only. The test villa is moderately sized $\left(110 \mathrm{~m}^{2}\right)$ but many houses are larger and would require more heating. It would seem that the only possible option to enable average households to keep the living room affordably warm using electricity is a heat-pump.

Moving from portable electric heating to using a heat-pump offers noticeable savings, even without insulation. The average cost for insulation provided under the Warm up NZ Heat Smart programme was around $\$ 2,500$. The average cost for clean heat heater (often a heat-pump) was 
around $\$ 3,000$. It could make more sense financially to choose a heat-pump over insulation, as greater savings on running costs can be obtained for moderate additional cost. This may help explain the popularity of heat-pumps in owner occupied houses.

Running the $6 \times 2 \mathrm{~kW}$ 'economic' electric heaters to try and maintain the house at comfort temperatures where high levels of insulation have been retrofitted to a house, would cost more than a high-income household spends on energy in colder climates and prohibitively expensive without ceiling and subfloor insulation.

These figures illustrate a good reason for the HEEP heating patterns (predominantly only heating only the living room in the evening). Even with ceiling and subfloor insulation, heating the whole house all of the time is prohibitively expensive. If there is only plug-in electric heating and inadequate insulation then it can be very costly to heat multiple rooms. Financial constraints limit how much households can spend on utility bills, supporting a tendency to heat one room to be 'warm' rather than multiple rooms to be 'not quite as cold'.

\section{Future Electricity Prices}

Electricity prices have been rising on average $2.9 \%$ a year over the last 12 years [144]. WoF level insulation could reduce single room heating requirements by up to $12 \%$ if no 'take-back' is observed. (Take-back is when households gain warmer temperatures rather than lower heating costs and is common when occupants don't already heat to temperatures they find warm [22, p. 4].) In a little over 4 years the cost of heating a dwelling is likely going to be back to pre-WoF levels if electricity is used and prices continue to rise as per historical trends.

\section{Fixed Heating Summary}

Being able to use a less expensive fuel for heating would be the main opportunity for low-income (indeed all) tenants, but it appears unlikely that this will be the case. The HNZ WoF requires either heating or insulation while the GH WoF only requires safe heating (anything other than an unflued gas heater). The low cost landlord response to either WoF would seem to be electric panel heaters fixed to the wall.

There is no evidence to suggest that fixed electric resistance heating would help bring about improved health outcomes. The clean heating analysed in the Warm Up NZ: Heat Smart costbenefit analysis was heat-pumps or flued gas heaters [22].

Occupants of a household with power points intended to be the source of heating even with insulation are at a disadvantage. They are reliant on only one fuel and are vulnerable to fluctuations in cost. Their options are to pay more or use less. Fixing an electric heater to the wall would not alter this situation.

Other questions remain about the impacts of requiring fixed heating in rental properties, beyond the conditions in these properties. If the idea that a fixed heater and insulation are a bare minimum for rental houses becomes established, will this have an impact on owner occupied houses and the middle and upper ends of the housing market? Will owner occupiers begin to install heating because they don't want their housing to be considered 'worse' than a rental property or to allow for the possibility or renting it later? Will new houses start installing fixed heating in the living room as standard? Will middle and upper income houses install more sources of heating to make their house comparatively better? 


\section{0,000 Un-Rentable Houses?}

The housing minister has expressed concern of the consequences of introducing a WoF: "There's about 60,000 houses in New Zealand that you can't get under the floor or into the ceiling cavity to put insulation. What would it do for New Zealand right now to take 60,000 houses and by law banning them from being tenanted? That would cause substantial increases in rents." [145]

The GH WoF makes no allowance for trade-offs between heating and insulation, however the HNZ WoF considers it acceptable to install appropriate heating when it is not possible to insulate because of lack of access.

Houses which are unable to have insulation retrofitted for some reason should not automatically be considered un-rentable. This is because some construction methods have adequate thermal performance without insulation, and a house can be made economical to heat by the choice of heater rather than reducing the heating needs through insulation.

If the reason for being unable to retrofit insulation is a concrete floor then this is not problematic. An average size concrete floor has comparable thermal performance to a timber floor with foil insulation.

The cost savings achieved by installing insulation to GH WoF standards can also be achieved by installing more economic heating systems. WoF level insulation can save $13 \%$ on energy costs if only the living room was heated and $33 \%$ if the whole house had been heated. EECA has identified that the cost of safe heating options can range between 5 and 26 cents/kilowatt-hour of useful heat Moving from an electric plug-in heather with an average effective running cost of $26 \mathrm{c} / \mathrm{kWh}$ to a heat-pump costing $9 \mathrm{c} / \mathrm{kWh}$ would mean savings of $35 \%$. The financial savings gained by having insulation to the GH WoF standards can be matched by changing to high efficiency heat-pumps or solid fuel burners.

This suggests that for middle income tenants (who can afford to run some heating) living in a dwelling which cannot be retrofitted with insulation, addressing the heating systems could be a alternative way to make the dwelling affordably warm.

For very low-income tenants (who cannot afford to run heating to achieve acceptable temperatures) living in a house which met the $\mathrm{GH}-\mathrm{WoF}$ requirements would provide approximately 280 hours less time below $16^{\circ} \mathrm{C}$. These tenants would benefit more from insulation than efficient heating if they do not have the confidence or income to run the heating system. They may not be helped by substituting efficient heating for insulation. It has been proposed that subsidies and other financial strategies could also be used to reduce the unequal cost of running dwellings like these [146].

This approach would presumably provide tenants with one room which is able to be kept warm. If a heat distribution system or multiple heat sources were required it may become less costly for a landlord to alter the building's envelope to enable insulation (e.g. re-lining ceilings) rather than provide a heating system. 


\section{Financial savings from the WoF improvements}

The analysis has shown that the test villa can use anywhere between 3,962 and 35,684 kWh a year, giving running costs of between $\$ 1,080$ and $\$ 9,770$ if electricity was the only fuel used. Depending how this house is used, it could be affordable for even low-income tenants or it could be unaffordable for even high-income tenants. Not using energy services (heating or hot water) is the easiest way for a tenant to make a house cheaper to live in and match energyexpenditure to income.

The literature suggests that there are minimum temperatures which should be maintained for health $\left(16^{\circ} \mathrm{C}\right.$ minimum, $18^{\circ} \mathrm{C}$ for living rooms). Not using energy services means that tenants will be unable to maintain these temperatures in winter. From these costs it would appear difficult for a tenant in an uninsulated house, in a cold climate, without a large fixed heater to maintain these comfort temperatures. Single room heating becomes the only affordable option.

The models show that reducing the consumption of energy services can save more money than WoF level energy efficiency measures.

Turning off the HWC (as has been observed in some low-income households) can save up to \$997 per year depending on the temperature of the water and how much hot water is used. Reducing the HWC setpoint from $60^{\circ} \mathrm{C}$ to $50^{\circ} \mathrm{C}$ can save $\$ 142$. In comparison installing a HWC wrap on a Dgrade cylinder can save $\$ 49$ a year. Upgrading from a $\mathrm{D}$-grade cylinder to a modern cylinder could save $\$ 237$ a year.

While installing a HWC wrap has a payback period of 1 year (longer if installed on newer models) the financial savings appear small in comparison to household utility costs (lighting, appliances and hot water) which can range between $\$ 1,400$ and $\$ 1,660$. A $\$ 50$ saving is at most $3.5 \%$ of this bill. (For comparison the average HEEP house would have utility costs of around $\$ 2,300$ on this pricing plan). Upgrading an otherwise acceptable HWC could save proportionally more on the utility bills (up to $17 \%$ ), but it has a much longer payback period (over 11 years), with a new cylinder costing $\$ 1,600-\$ 1,800$ before installation.

By upgrading from no insulation to GH WoF compliant insulation in the ceiling and subfloor moderate energy savings can be obtained. With the minimum compliant insulation options, energy savings can be between $10 \%$ and $33 \%$ (see table 23 ).

When adequate capacity heating is available and WoF level insulation installed, single room heating can see savings of up to $13 \%$ while whole house heating can see savings of up to $33 \%$. In comparison moving from central heating to living room heating only can reduce energy requirements by $52 \%$ in an uninsulated house and in an insulated house, by $44 \%$. Changing from $2 \mathrm{~kW}$ heaters throughout the house to living room heating only can save $20 \%$ of the energy requirements without insulation and $22 \%$ with insulation.

With both the hot water and insulation, providing WoF energy efficiency measures will still not make the house inexpensive to run when compared to reduced hot water or heat consumption. This indicates that there may need to be education about what a WoF compliant house actually is. Just because it may be more thermally efficient does not necessarily mean it is inexpensive to run or that heaters are not required in winter. As has been commented by assessors who trialled the GH WoF, the WoF is a measure of adequacy not quality [6, p. 24]. 



\section{SUMMARY AND CONCLUSIONS}

This section brings together the many issues which have been explored in this thesis, and provides guidance to the use and future development of housing Warrant of Fitness for New Zealand.

\section{Process Summary}

The following sections are a summary of the results from the process of researching thermal rating tools, describing an appropriate model, and running simulations to evaluate the impact of WoF tools on thermal performance.

\section{Literature}

Many building rating tools have been trialled in New Zealand in recent years. These have been targeted at improving the quality and in some cases sustainability of housing. A number of these tools have been retired and others have been recently developed aiming to tackle this problem in different ways. A common issue with voluntary rating tools is their low uptake. A Warrant of Fitness tool would have to be mandatory to have any chance of improving our housing stock. If it is not made mandatory anyone who even suspects their house may fail will simply not participate in the scheme.

The two proposed Warrant of Fitness tools are broadly similar, their main differences are in heating and insulation. The Housing New Zealand WoF accepts heating OR insulation of any kind, while the Green Building Council and the Housing and Health Research Programme WoF requires heating AND insulation which meets minimum thickness requirements.

\section{Moisture Modelling}

Initially it was intended to investigate both moisture and thermal performance. It was found that moisture analysis (or analysis of hygrothermal performance) was not practical with the energy analysis software and the input data currently available. Even so, the brief investigation into moisture analysis supports the finding that moisture can have significant impacts on a dwelling's performance. Criteria in both WoFs aim to improve moisture issues as well as thermal performance, but without up to date information on New Zealand relevant moisture loads it is difficult to tell if the WoFs measures will be effective.

\section{Thermal Modelling}

All the desired features of a domestic house were able to be modelled; including plumbing systems, natural ventilation and curtains. Modelling timber framing and insulation separately was possible but not practical. The main challenge with adding each of these different features into a model is finding suitable input values.

\section{Modelling Process}

It is possible to use Microsoft Excel as a tool to write out EnergyPlus files. This opens up many possibilities of automatically generating files using Excel's VBA programming language.

EnergyPlus can simulate many files at one time, depending on the capabilities of the computer being used. 24 (instead of the suggested 4) simultaneous processes (simulations) were able to be run on a computer with 8 processors. Simulation times have ranged from $\sim 5$ hours to $\sim 30$ hours for 1,914 houses in three locations each. 


\section{Conclusions}

\section{Warrant of Fitness Analysis}

The aim was to determine whether the housing WoF tools able to measure and improve thermal performance. The results show:

Both WoFs are able to make houses perform better thermally. By upgrading features of a house to meet WoF requirements, thermal performance should improve.

Both WoFs are able to identify very substandard thermal performance. Houses without heating, insulation and energy services will perform badly in either.

Neither WoF is able to provide a guarantee of good thermal performance, low heating cost or thermal comfort. A house with ceiling and subfloor insulation but heated with a portable electric heater may not be as affordably warm as a house with no insulation but a heat-pump installed.

Both WoFs fail to make allowances for New Zealand's range of climatic conditions, which have more impact on thermal performance than passing or failing either of the WoFs.

Passing the GH WoF would be a better predictor of better thermal performance than the HNZ WoF. However the HNZ WoF has the ability to substitute thermal performance for economic performance, which may be more meaningful to a tenant.

As discussed (on page 19), the public perception of a WoF appears to be that a house which passes is better than a house which fails. This is not a guaranteed or meaningful result. There are many ways a house can fail a WoF, some more concerning than others.

The fact that a house fails the WoF is not as important as why it fails the WoF.

Houses which fail some thermal criteria but have adequate heating available are able to make energy-comfort trade-offs. Depending on the fuel sources available these trade-offs may or may not be economical for the tenants.

Passing the GH WoF reduces the need to make energy-comfort trade-offs. Failing all of the GH WoF criteria means it is not possible to make these trade-offs. A simple pass/fail WoF result disguises whether houses have the physical and economic possibility of substituting comfort with energy consumption.

Both WoFs appear able to improve thermal performance. However they both have a limited ability to communicate thermal performance because of their pass/fail nature. The vehicle WoF inspiration for these tools, which makes them easy to understand, is also their main limitation. Having only two possible outcomes makes it difficult to communicate nuanced aspects of thermal performance and ignores overlapping performance between situations which pass and fail.

\section{Will a Warrant of Fitness help thermal performance?}

Meeting the requirements of the GH WoF (heating AND insulation) or the HNZ WoF (heating OR insulation) should help reduce poor thermal performance in rental properties.

- By providing both a source of heat and insulation a house can be kept warm at lower cost.

- If only insulation is provided the house will be slightly warmer than without insulation. 
- If only heating is provided it will cost more to be comfortable in the house. This can become very expensive if the tenant tries to achieve thermal comfort in multiple rooms of a house throughout the day.

However, a wide range of thermal performance is still possible from a house which passes the $\mathrm{GH}$ WoF. An even wider range of thermal performance is possible from a house which passes the HNZ WoF (requiring insulation or heating when this cannot be installed).

Because of the requirement to have both heating and insulation, houses meeting the GH WoF standards can be expected to have lower levels of discomfort and lower levels of required heating. Meeting the HNZ WoF thermal requirements still helps reduce discomfort, although not as much as meeting the $\mathrm{GH}$ WoF requirements. Meeting the HNZ WoF requirements would not necessarily encourage lower energy consumption, but depending on the type of heating installed this heating could be more affordable.

A house with the level of insulation required by the GH WoF would not be expected to perform as well as a house which has been built to the thermal requirements of the current NZBC. Code compliant houses will have floor and ceiling insulation along with wall insulation and double glazing. By addressing the entire thermal envelope these houses will have adequate thermal performance even if the ceiling insulation does not meet a specific depth requirement. In terms of thermal performance, a house built to the current building code should meet the requirements of a WoF no matter the measured depth of ceiling insulation.

Will a Warrant of Fitness help tenants know how their house will perform?

Knowing a house has passed either of the WoFs will not necessarily tell a prospective tenant how warm and economic to heat a house will be. There is considerable overlap in discomfort and energy consumption between circumstances which pass and fail the WoFs for the same house design. With different house designs, constructions and local climates, the range of possible performance will only increase.

If prospective tenants are looking to rent a house and are trying to decide between an option which passes and an option which fails the thermal requirements of the GH WoF, the house which passes is not guaranteed to perform better than the house which fails.

If tenants are already living in a house and it is being upgraded to meet WoF requirements, then the house will have better thermal performance with the upgrades than without them.

What role does climate play?

Climate has a significant impact on the thermal performance of a house fitted with insulation to the GH WoF standards. A house which has ceiling and underfloor insulation in Dunedin can still be less comfortable than a house which does not have any insulation in Auckland.

The Housing and Health Research Programme and Housing New Zealand say they are aiming for "improved health outcomes" and "healthier and safer living environments" [6, p. 9], [73, p. 1]. The implied link between these statements and requiring insulation is indoor temperatures. How much do indoor temperatures need to be raised to bring about these benefits? The current identical requirements for insulation without regard for the climate may see uneven benefits for people in different parts of New Zealand. 
What will tell tenants how comfortable and economic their rental will be?

The feature of the GH WoF which will provide the best indicator of comfort levels is the heating system. Climate and the presence of ventilation also provide an indication of likely performance. In the graph on p.91 only changes in the heating type, ventilation and location have obvious differences in discomfort levels.

The size, placement, fuel source and type of a heating system have a very significant impact on the tenant's ability to keep the house warm at reasonable cost.

The level of comfort attainable with different heating types is matched by the amount of energy required to run them. Investigations into the cost of heat provided by different heating systems carried out by EECA show that the cost of heat can vary between 4 and $25 \mathrm{c} / \mathrm{kWh}$ [139]. This can make the difference between each of these heating approaches being possible or prohibitively expensive.

\section{What about a scale rating?}

There is a trend of decreasing thermal performance if a house has fewer of the required WoF thermal criteria features, however the first criteria failed seems to have the largest impact. The range of likely performance for both energy consumption and discomfort becomes much wider when any one criteria fails. The range increases somewhat when more criteria are failed then decreases significantly when there are no energy services available for the house. Discomfort rises as soon as one criteria is failed. Energy consumption is more complex as it can increase or decrease depending on which services are provided.

A house which fails only a couple of thermal criteria in either of the WoFs may be just as comfortable (or cold) as one which passes all the criteria. This is primarily dependent on the tenants having access to a heating system they can afford to run. A house which fails all of the thermal criteria in the WoF will perform worse than one which passes. The range of expected performance for this type of house is very narrow when compared to a house which passes at least some of the WoF criteria. These are the houses will have a noticeable increase in performance through meeting the WoF standards.

\section{Are there any drawbacks?}

Electric heaters fixed to the wall in the living room of every rental property in New Zealand appear to be the cheapest and therefore most likely outcome of the current wording of the GH WoF.

Electricity prices have been increasing every year, above the rate of inflation [144]. Providing and WoF level insulation will initially make electric resistive heating more affordable. However, if electricity prices continue to rise at the same rate as they have historically, then the houses will be back to being unaffordable to heat in a little over 4 years if the tenants heat one room.

Most tenants can already afford to buy a portable electric heater, they retail for as little as $\$ 18$. Simulation results indicate that six of these heaters could provide comfort levels comparable to central heating. A $\$ 108$ one-off cost does not appear to be what prohibits tenants from keeping the whole house warm, it is the cost of the electricity to run the heaters that is much larger (this heating would cost around $\$ 2,700$ to maintain comfort temperatures year round). Providing fixed electric resistive heating would do little to solve the need for affordable heat. 
How can 'un-rentable' houses be addressed?

The housing minister Nick Smith has expressed concern that New Zealand may have 60,000 unrentable houses if a Warrant of Fitness is introduced [145]. These need not automatically be considered un-rentable. Some construction types have adequate thermal performance without additional insulation. Otherwise economic heating options able to keep an uninsulated house warm at a comparable cost to electric resistive heating in a house insulated to the GH WoF requirements.

The cost savings achieved by installing insulation to GH WoF standards can also be achieved by installing more economic heating systems. WoF level insulation can save between $13 \%$ and $33 \%$ of heating requirements. Moving from an electric plug-in heather with an average running cost of $26 \mathrm{c} / \mathrm{kWh}$ to a heat-pump with an average running cost of $9 \mathrm{c} / \mathrm{kWh}$ would mean savings of $35 \%$. The financial savings gained by having insulation to the GH WoF standards can be matched by changing to high efficiency heat-pumps or solid fuel burners.

For middle income tenants (who can afford to run some heating) living in a dwelling which cannot be retrofitted with insulation, addressing the heating systems could be a viable way of making the dwelling economically comfortable. For very low-income tenants (who cannot afford to run heating) living in a house with ceiling and under floor insulation would provide approximately $3.8 \%$ less exposure to temperatures below $16^{\circ} \mathrm{C}$. These tenants would benefit more from insulation than efficient heating only if they do not have the income to run the heating system.

\section{Recommendations}

Based on the research discussed in this thesis, some guidance for the use of a WoF for achieving affordably warm homes can be offered.

Good thermal performance cannot be attained for any house until the entire thermal envelope is addressed (roof, walls, floor and windows) as heat takes the path of lowest resistance. Both WoFs only begin to acknowledge this.

The intent behind these WoFs seems to be that all tenants are able to have an affordably warm home. Even houses insulated to the current building code will not always remain above $16^{\circ} \mathrm{C}$ without heating (in any climate zone). Therefore some heating must always be used and consequently there are trade-offs between insulation levels, heating placement, heating efficiency and fuel source. This should be acknowledged within any thermal performance assessment and owners permitted to combine solutions to make their houses affordably warm rather than meet a tick box requirement.

Due to high running costs, fixed electric resistive heaters should not comply with a WoF requirement for 'fixed heating' unless the house is has insulated walls, ceilings and floors. There is no material difference in the comfort attainable or running costs of an electric resistive heater bought by the owner rather than the tenant.

The ability of different tenant types to pay for space heating will differ. Owners of houses for market rate tenants should be permitted to make trade-offs between providing an economic form of heating and subfloor insulation. An economic heat source and ceiling insulation will work together to help provide affordable warmth; sub-floor insulation has a smaller impact on energy use and comfort than ceiling insulation. 
Landlords for low income (social housing) tenants should not be permitted to make any trade-offs between insulating and providing economic heating (such as HNZ suggest in their WoF). These tenants are not always able to afford to run heating and so would not see the same benefit from an efficient heater/cheaper fuel source.

Any WoF should provide a scale rating (whether it be a percentage, score or stars) alongside or instead of a pass/fail. Having only two possible outcomes does not reflect the range of attributes a WoF (tries to) assess and can be misleadingly interpreted as good/bad. Houses are complex constructions with less standardised designs than cars, so an assessment tool should reflect this.

\section{What Still Needs to be Investigated?}

The impact of moisture loads and control strategies (natural ventilation or mechanical extract systems) deserves a more thorough analysis. These are also expected to have a strong impact on the ability of tenants to live healthy and safe lifestyles in their homes. In particular it appears it is necessary to collect information on how much moisture would be expected to be released from different indoor activities which are relevant to New Zealand conditions and current technologies. Such information would help to prioritise moisture control and mitigation measures.

Tenants must have both the income and the confidence to run the heating provided. An efficient heat-pump will not be useful if a low-income tenant does not turn it on because they don't know if they will be able to afford the electricity bill at the end of the month. The heating type benefiting these tenants the most (balancing running cost and budgeting ability) should be investigated.

Houses with high thermal mass (concrete, stone and brick constructions) and apartments have not been investigated in this thesis. These types of constructions may be more difficult to insulate and will have differing thermal performance to low mass constructions. It should be investigated whether there are types of high-mass constructions which can be permitted to pass a WoF without added insulation.

There is the possibility of quantifying the reduced heating costs or discomfort hours experienced by a house with low levels of insulation upgrading to WF level insulation. The 2010 BRANZ 2005 House Condition Survey found that the majority of households had ceiling insulation of between $51 \mathrm{~mm}$ and $100 \mathrm{~mm}$. It is unknown how close in thermal performance these houses with low levels of insulation are to houses with WoF level insulation.

Other house types built after the villa included increasing levels of insulation, larger floor areas and more open plan style layouts. All of these aspects will have an impact on thermal performance. Roof, wall and floor insulation was made mandatory from 1978. Investigating the thermal performance of house styles common before then would provide a more comprehensive picture of the benefits to New Zealand's building stock of upgrading to WoF level insulation and how different heat sources help different housing plans.

Hot water costs may be anywhere from a third to over half a households power bill and can be comparable to space heating costs. With a few minor adjustments the test villa model could be 
used to assess the impact of energy efficiency upgrades for hot water systems and whether these measures could also help address affordability issues for very low-income households.

Ideally these simulated results would be validated against measurements from a constructed house. This could be tested by retrofitting different insulation options to an uninsulated villa style house and measuring the passive indoor temperatures (without heating). However, as such an exercise is costly, efforts may be better directed to simply providing insulation for houses with none. 


\section{WORKS CITED}

[1] "BRANZ 2010 House Condition Survey - Condition Comparison by Tenure," BRANZ, Judgeford, SR 264 (2012).

[2] K. Saville-Smith, "It's Our Future \& It's Not OK," presented at the 2010 Australasian Housing Researchers' Conference, Auckland, 2010.

[3] S. Rotmann, "Warm Up New Zealand Heat Smart: Lessons in large scale implementation of a residential energy efficiency grant programme."

[4] V. Cowan, L. Burrough, and L. Easton, "Beacon resource: Performance of rental housing v3," health, vol. 66, no. 4, pp. 379-384, 2014.

[5] New Zealand Green Building Council, "Housing WOFs - field tests to start in five cities," 16Dec-2013. [Online]. Available:

http://www.nzgbc.org.nz/images/stories/Rental_WoF_joint_release.pdf. [Accessed: 14Apr-2015].

[6] J. M. Bennett, E. Chisholm, R. Hansen, and P. Howden-Chapman, "Results from a Rental Housing Warrant of Fitness Pre-Test," University of Otago, Wellington, May 2014.

[7] Children's Commissioner's Expert Advisory Group, Solutions to Child Poverty in New Zealand: Issues and Options for Consideration. Wellington [N.Z.]: Office of the Childrens' Commissioner, 2012.

[8] New Zealand College of Public Health Medicine, "Housing: New Zealand College of Public Health Medicine Policy Statement." Aug-2013.

[9] Canterbury District Health Board, "Housing, home heating and air quality: a public health perspective." Apr-2012.

[10] Auckland Regional Public Health Service, "Chapter 5: Substandard Housing," in Housing and Health in Auckland, 2004, pp. 21-24.

[11] World Health Organisation, Guidelines for Healthy Housing. Copenhagen, 1988.

[12] N. Isaacs and M. Donn, "Health and housing-seasonality in New Zealand mortality," Australian Journal of Public Health, vol. 17, no. 1, pp. 68-70, Mar. 1993.

[13] Electricity Authority, "Historical analysis of electricity costs." [Online]. Available: https://www.ea.govt.nz/monitoring/enquiries-reviews-and-investigations/2013/historicalanalysis-of-electricity-costs/. [Accessed: 22-Apr-2015].

[14] Statistics New Zealand, "Housing Profiles: Renting Households," Feb-2002. [Online]. Available:

http://www.stats.govt.nz/browse_for_stats/people_and_communities/Households/housin g-profiles-renting.aspx. [Accessed: 01-Jul-2014].

[15] B. Barton, "A warm and dry Place to live: Energy efficiency and rental accommodation," Canterbury Law Review, vol. 19, pp. 1-25, 2013.

[16] I. McChesney, I. Cox-Smith, and L. Amitrano, "Thermal insulation in New Zealand homes: A Status Report." Beacon Pathway Limited, Mar-2008.

[17] L. Schipper, F. Unander, C. Marie-Lilliu, I. Walker, and S. Murtishaw, "Indicators of energy use and efficiency in New Zealand in an international perspective," International Energy Agency and Lawrence Berkeley National Laboratory, Paris and Berkeley, p. 79, 2000.

[18] N. Isaacs, M. Camilleri, L. French, A. Pollard, K. Saville-Smith, P. Rossouw, and J. Jowett, "Energy Use in New Zealand Households: Report on the Year 10 Analysis for the Household Energy End-use Project (HEEP)," BRANZ, Judgeford, SR 155 (2006), 2006.

[19] R. Jaques, "Review of the BRANZ Green Home Scheme," 134, 2004.

[20] New Zealand Green Building Council, "Homestar Ratings Guide," 2013-2010. [Online]. Available: http://www.homestar.org.nz/homestar-ratings-guide. [Accessed: 18-Jun-2014].

[21] Centre for Research, Evaluation and Social Assessment (CRESA) and East Harbour Management Services (EHMS), "The Energy Efficiency Characteristics Of NZ Houses and Householder Receptivity to a Rating Scheme (HERS)," The Energy Efficiency and Conservation Authority (EECA), Jul. 2007. 
[22] A. Grimes, T. Denne, P. Howden-Chapman, R. Arnold, L. Telfar-Barnard, N. Preval, and C. Young, "Cost Benefit Analysis of the Warm Up New Zealand: Heat Smart Programme," Report to the Ministry of Economic Development, 2012.

[23] "Healthy Homes Guarantee - Ministry of Justice, New Zealand," 07-Nov-2013. [Online]. Available: http://www.justice.govt.nz/policy/constitutional-law-and-human-rights/humanrights/bill-of-rights/healthy-homes-guarantee. [Accessed: 17-Jun-2014].

[24] Ministry of Health NZ, "Publicly funded health and disability services," Ministry of Health NZ, 15-Apr-2011. [Online]. Available: http://www.health.govt.nz/new-zealand-healthsystem/publicly-funded-health-and-disability-services. [Accessed: 30-Jun-2014].

[25] N. Smith, "Housing WoF to be developed and trialled," 16-May-2013. [Online]. Available: https://www.national.org.nz/news/news/media-releases/detail/2013/05/16/housing-wofto-be-developed-and-trialled. [Accessed: 06-Jun-2014].

[26] "Bennett: 'I'm an advocate' for Warrant of Fitness on private rental housing.," The National Business Review, Dec-2013. [Online]. Available: http://www.nbr.co.nz/article/bennett\%E2\%80\%98im-advocate-warrant-fitness-private-rental-housing-dc-148051. [Accessed: 20May-2014].

[27] M. Turei, Energy Efficiency and Conservation (Warm Healthy Rentals Warrant of Fitness) Amendment Bill. 2012.

[28] "WOF checks for rental housing," Stuff.co.nz, 30-Dec-2013.

[29] A. FENSOME, "Push for rental home WOFs," Stuff.co.nz, New Zealand, 11-Sep-2013.

[30] "FAQ | Improve the performance of your home with Homestar ${ }^{\mathrm{TM},}$," 2013. [Online]. Available: http://www.homestar.org.nz/faq. [Accessed: 12-May-2014].

[31] "Healthy Housing - He Kainga Oranga." [Online]. Available: http://www.healthyhousing.org.nz/. [Accessed: 24-Jun-2014].

[32] Ministry of Business, Innovation and Employment, "File No. OIA 1121," 04-May-2015.

[33] Office of the Minister of Housing, "Cabinet Social Policy Committee Paper - Warrant of Fitness for Rental Housing." Obtained under an Official Information Act request, OIA 1211, 02-May-2013.

[34] C. HARRIS, "Landlords bag housing WOF," Stuff.co.nz, New Zealand, 16-May-2014.

[35] NZ Transport Agency, "Getting a warrant of fitness." [Online]. Available: http://nzta.govt.nz/vehicle/warrants-certifications/getting-wof/. [Accessed: 09-Jul-2014].

[36] N. Isaacs, A. Pollard, K. Saville-Smith, P. Rossouw, and J. Jowett, "Energy Use in New Zealand Households Final Report on the Household Energy End-use Project (HEEP)," BRANZ, Judgeford, Study Report SR 221, 2010.

[37] R. H. Socolow, "The twin rivers program on energy conservation in housing: Highlights and conclusions," Energy and Buildings, vol. 1, no. 78, pp. 207-242, 1977.

[38] Building Act 2004 No 72 (as at 01 January 2015), . 2015.

[39] L. J. Armitrano, N. R. Kirk, and I. C. Page, "Market Segmentation of New Zealand's Housing Stock," Beacon Pathway, PR106, Oct. 2006.

[40] Statistics New Zealand, "2013 Census QuickStats about housing," 18-Mar-2014. [Online]. Available: http://www.stats.govt.nz/Census/2013-census/profile-and-summaryreports/quickstats-about-housing/households-who-rent.aspx. [Accessed: 01-Jul-2014].

[41] B. Perry, "Household Incomes in New Zealand: trends in indicators of inequality and hardship 1982 to 2012," Ministry of Social Development, Wellington, Feb. 2014.

[42] L. Telfar-Barnard, N. Preval, P. Howden-Chapman, R. Arnold, C. Young, A. Grimes, and T. Denne, "The impact of retrofitted insulation and new heaters on health services utilisation and costs, pharmaceutical costs and mortality," MED1358321, Oct. 2011.

[43] B. White, "A Warrant of Fitness to Improve Housing Quality for Child Safety," Mar. 2013.

[44] "Rental Property Warrant of Fitness :: NZPIF." [Online]. Available: http://www.nzpif.org.nz/projects/view/55938. [Accessed: 20-May-2014]. 
[45] "Warrants of fitness not the solution: NZPIF - Landlords.co.nz," 06-Sep-2012. [Online]. Available: http://www.landlords.co.nz/article/4472/warrants-of-fitness-not-the-solutionnzpif. [Accessed: 30-May-2014].

[46] G. Vaughan, "'Warrant of fitness' rental housing tests aiming to tackle 'cold and damp' housing coming to five NZ cities," Interest.co.nz, 17-Dec-2013. [Online]. Available: http://www.interest.co.nz/property/67862/warrant-fitness-rental-housing-tests-aimingtackle-cold-and-damp-housing-coming-five-. [Accessed: 29-May-2014].

[47] S. Nicol, M. Roys, M. Davidson, C. Summers, D. Ormandy, and P. Ambrose, Quantifying the Cost of Poor Housing. Bracknell: IHS BRE Press, 2010.

[48] J. Nriagu, P. Smith, and D. Socier, "A rating scale for housing-based health hazards," Science of The Total Environment, vol. 409, no. 24, pp. 5423-5431, Nov. 2011.

[49] Great Britain and Department for Communities and Local Government, Housing health and safety rating system: guidance for landlords and property related professionals. London: Dept. for Communities and Local Government, 2006.

[50] M. Keall, V. Kamalesh, M. G. Baker, and P. Howden-Chapman, "Taranaki Home Injury Study," BUILD, no. 112, pp. 52-53, Jul-2009.

[51] BRANZ, "Green Home Scheme FAQs," 27-May-2010. .

[52] International Energy Agency - Australia, "Performance Standards and 5-Star Rating for Buildings: MEPS and NatHERs," 12-May-2014. [Online]. Available:

http://www.iea.org/policiesandmeasures/pams/australia/name,23022,en.php. [Accessed: 01-Jul-2014].

[53] ABSA, "ABSA (Association of Building Sustainability Assessors)," 17-Feb-2011. .

[54] "Energy Efficiency: Industry and NGO To Deliver Home Energy Rating Scheme," NZ Energy and Environment Business Alert, 10-Nov-2010. .

[55] Australian Government Department of Industry, "NatHERS." [Online]. Available: http://www.nathers.gov.au/. [Accessed: 08-May-2014].

[56] EECA, "How home energy ratings are calculated," 03-Jun-2010. .

[57] M. Keall, M. G. Baker, P. Howden-Chapman, M. Cunningham, and C. Cunningham, "Healthy Housing Index Pilot Study Final Report," He Kainga Oranga / Housing and Health Research Programme, Mar. 2007.

[58] J. Gillespie-Bennett, M. Keall, P. Howden-Chapman, and M. G. Baker, "Improving health, safety and energy efficiency in New Zealand through measuring and applying basic housing standards," The New Zealand Medical Journal (Online), vol. 126, no. 1379, pp. 74-85, Aug. 2013.

[59] New Zealand Green Building Council, "BASE Handbook V2." [Online]. Available: http://www.nzgbc.org.nz/images/stories/BASE_Handbook-V2.pdf. [Accessed: 06-May2014].

[60] J. Bennett, "How do apartments measure up?," BUILD, no. 177, pp. 72-73, May-2010.

[61] J. M. Bennett and I. P. Isaacs, "New Zealand Apartment Living: Developing a Liveability Index," The Built \& Human Environment Review, vol. 2, no. 1, 2011.

[62] "Dunedin Student Housing STARS." [Online]. Available: http://www.housingstars.co.nz/. [Accessed: 25-May-2014].

[63] "Rate My Flat," 2015. [Online]. Available: http://www.ratemyflat.org.nz/about. [Accessed: 17-Apr-2015].

[64] D. Utting, "A Web Based Sustainability Assessment Tool Streamlining Local Government Practice: TUSC," 2007. [Online]. Available: http://www.thesustainabilitysociety.org.nz/conference/2007/papers/UTTING-TUSC.pdf. [Accessed: 21-May-2014].

[65] "TUSC - Home," 2014. [Online]. Available: http://tusc.synergine.com/. [Accessed: 30-Jun2014].

[66] BRANZ, "Branz ALF (Annual Loss Factor) 3.2." [Online]. Available: http://alf.branz.co.nz/. [Accessed: 31-Oct-2014]. 
[67] M. Cutler-Welsh, "Homestar - A WoF for Rentals," presented at the "Achieving Affordable Warmth for all NZ Families," Wellington, N.Z., 26-Sep-2013.

[68] "Proposed Housing Warrant of Fitness." [Online]. Available: http://www.healthyhousing.org.nz/wp-content/uploads/2013/08/Proposed-HousingWarrant-of-Fitness.docx. [Accessed: 30-May-2014].

[69] "Fit to rent? Housing WOF trial results released | Homestar." [Online]. Available: http://www.homestar.org.nz/newsroom/fit-rent-housing-wof-trial-results-released. [Accessed: 15-May-2014].

[70] N. Smith, "Housing WOF trial gets underway," 19-Feb-2014. [Online]. Available: http://www.beehive.govt.nz/release/housing-wof-trial-gets-underway. [Accessed: 14-Apr2015].

[71] Housing New Zealand, "Draft housing Warrant of Fitness checklist." [Online]. Available: http://www.beehive.govt.nz/sites/all/files/Draft_housing_Warrant_of_Fitness_checklist.p df. [Accessed: 05-Jun-2014].

[72] Ministry of Business, Innovation and Employment, "Building warrants of fitness (BWoFs)," Building and Housing Information, 31-Mar-2005. [Online]. Available:

http://www.dbh.govt.nz/bofficials-building-warrants-of-fitness. [Accessed: 07-Jul-2014].

[73] Housing New Zealand, "Warrant of Fitness - Frequently asked questions." [Online]. Available: http://www.beehive.govt.nz/sites/all/files/Frequently_asked_questions.pdf. [Accessed: 06-Jun-2014].

[74] "Solutions to Child Poverty - Initial Priority 2 - Housing WOF.pdf." [Online]. Available: https://cdn.auckland.ac.nz/assets/education/about/schools/crstie/docs/2013/Solutions\%2 0to\%20Child\%20Poverty\%20-\%20Initial\%20Priority\%202\%20-\%20Housing\%20WOF.pdf. [Accessed: 20-May-2014].

[75] P. Howden-Chapman, A. Matheson, J. Crane, H. Viggers, M. Cunningham, T. Blakely, C. Cunningham, A. Woodward, K. Saville-Smith, and D. O'Dea, "Effect of insulating existing houses on health inequality: cluster randomised study in the community," Bmj, vol. 334, no. 7591, p. 460, 2007.

[76] P. Howden-Chapman, N. Pierse, S. Nicholls, J. Gillespie-Bennett, H. Viggers, M. Cunningham, R. Phipps, M. Boulic, P. Fjällström, S. Free, R. Chapman, B. Lloyd, K. Wickens, D. Shields, M. Baker, C. Cunningham, A. Woodward, C. Bullen, and J. Crane, "Effects of Improved Home Heating on Asthma in Community Dwelling Children: Randomised Controlled Trial," BMJ: British Medical Journal, vol. 337, no. 7674, pp. 852-855, Oct. 2008.

[77] M. Camilleri, L. French, and N. Isaacs, "The Effect of Mandatory Insulation on Household Energy Consumption," presented at the The XXXVth International Association of Housing Science (IAHS) World Congress on Housing Science, Melbourne, 2007.

[78] K. Saville-Smith and R. Fraser, "National Landlords Survey: Preliminary Analysis of the Data." 2004.

[79] "Editorial: Warrants of fitness a must for all rental homes - National - NZ Herald News." [Online]. Available:

http://www.nzherald.co.nz/nz/news/article.cfm?c_id=1\&objectid=11208546. [Accessed: 13-Apr-2015].

[80] A. PEARSON, "Rentals across NZ fail warrant of fitness," Stuff.co.nz, 15-May-2014.

[81] M. Butler, "NZCPR-Housing-Warrant-of-Fitness-Report.pdf." [Online]. Available: http://www.nzcpr.com/wp-content/uploads/2014/07/NZCPR-Housing-Warrant-of-FitnessReport.pdf. [Accessed: 06-Apr-2015].

[82] J. Gray, "Managing a cold, damp house," in Contexts of Architecture, Launceston, Tasmania, 2004.

[83] Statistics New Zealand, "Housing indicators 2008: Indicator 11 Dwelling Type," Statistics New Zealand Website, 2008. [Online]. Available: http://www.stats.govt.nz/browse_for_stats/people_and_communities/housing/housingindicators/11-dwelling-type.aspx. [Accessed: 22-Apr-2015]. 
[84] N. P. Isaacs, "What's Holding The Roof Up - Using Census Data To Explore Dwelling Construction And Structure Changes," in Proceedings of the 5th International Congress on Construction History (in press), Chicago, 2015.

[85] Community Energy Action Charitable Trust (CEN), "Fuel Poverty Workshop Proceedings June 2008." Community Energy Action Charitable Trust, 04-Jun-2008.

[86] "EnergyPlus Energy Simulation Software: Testing and Validation." [Online]. Available: http://apps1.eere.energy.gov/buildings/energyplus/energyplus_testing.cfm. [Accessed: 22-Apr-2015].

[87] BRANZ, "Villa | BRANZ Renovate." [Online]. Available: http://www.renovate.org.nz/villa/. [Accessed: 08-Dec-2014].

[88] T. Pringle, Renovate Villas. Porirua, NZ: BRANZ, 2010.

[89] J. Salmond, Old New Zealand Houses 1800-1940. Auckland: Reed Methuen, 1986.

[90] G. J. Raw, C. Aizlewood, and R. M. Hamilton, Eds., Building regulation, health and safety: a report concerning the influence on the health and safety of building users of fabric and services controlled or controllable by regulation of buildings. London: BRE Centre for Safety, Health \& Environment, 2001.

[91] M. Cunningham, "Moisture as a Pollutant," BUILD, no. April/May, pp. 30-31, 1996.

[92] BRANZ, "Internal Moisture Control," Bulletin, no. 460, Apr-2005.

[93] British Standards Institution, British Standard 5250: Code of practice for control of condensation in buildings. [S.I.]: BSI, 2002.

[94] Consumer Build, "Interior maintenance : Combating dampness." [Online]. Available: http://www.consumerbuild.org.nz/publish/maintenance/interior-dampness.php. [Accessed: 30-Oct-2014].

[95] Eco Design Advisor, "Popenhagen Moisture and Ventilation 8 Aug 2014.pptx - PopenhagenMoisture-and-Ventilation-8-Aug-2014.pdf." [Online]. Available:

http://www.ecodesignadvisor.org.nz/assets/Uploads/Popenhagen-Moisture-andVentilation-8-Aug-2014.pdf. [Accessed: 30-Oct-2014].

[96] N. P. Isaacs, Building Science, Regulations and Health. BRANZ, 1999.

[97] SmarterHomes.org.nz, "SmarterHomes.org.nz : Moisture," 02-Jul-2013. [Online]. Available: http://www.smarterhomes.org.nz/design/moisture/. [Accessed: 30-Oct-2014].

[98] World Health Organisation, "Health Impact of Low Indoor Temperatures," Copenhagen, Report on A WHO Meeting 16, 1987.

[99] H. A. Trenthowen, "A Survey of Subfloor Ground Evaporation Rates," BRANZ, Judgeford, SR13, 1988.

[100] H. A. Trenthowen, "Three Surveys of Subfloor Moisture in NewZealand," Symposium on Recommended Practices for Controlling Moisture in Crawl Spaces, vol. Part I, no. 14271438, 1994.

[101] BRANZ, BRANZVENT: A guide to passively ventilating houses. .

[102] J. Burgess and I. Cox-Smith, "Accurate modification for New Zealand," BRANZ, Judgeford, EC1353, Sep. 2007.

[103] US Department of Energy, "EnergyPlus Input Output Reference," 29-Sep-2014. [Online]. Available:

http://apps1.eere.energy.gov/buildings/energyplus/pdfs/inputoutputreference.pdf. [Accessed: 26-Oct-2014].

[104] J. Woods, J. Winkler, and D. Christensen, "Evaluation of the Effective Moisture Penetration Depth Model for Estimating Moisture Buffering in Buildings," National Renewable Energy Laboratory, NREL/TP -5500-57441, Jan. 2013.

[105] J. Woods, J. Winkler, and D. Christensen, "Moisture modeling: Effective moisture penetration depth versus effective capacitance," in Proceeding of Thermal Performance of the Exterior Envelopes of Whole Buildings XII International Conference, 2013.

[106] US Department of Energy, "EnergyPlus Engineering Reference," 25-Sep-2014. [Online]. Available: 
http://apps1.eere.energy.gov/buildings/energyplus/pdfs/engineeringreference.pdf. [Accessed: 26-Oct-2014].

[107] E. Stephan, A. Caucheteux, R. Cantin, S. Tasca-Guernouti, and P. Michel, "Sensitivity Analysis of an EnergyPlus Simulation Model of the Ambient Humidity in an Old Building," in Proceedings of BS2013, Chambéry, France, August 26-28, pp. 2890-2897.

[108] Ministry of Business, Innovation and Employment, "Compliance Document for New Zealand Building Code Clause H1 Energy Efficiency - Third Edition." New Zealand Government, 2011.

[109] M. R. Donn, G. Thomas, Cement \& Concrete Association of New Zealand, New Zealand, and Energy Efficiency and Conservation Authority, Designing comfortable homes: guidelines on the use of glass, mass and insulation for energy efficiency. Wellington [N.Z.]: Cement \& Concrete Association of New Zealand, 2010.

[110] P. Baker, "Technical Paper 1: Thermal performance of traditional windows," 2008.

[111] R. Hendron, C. Engebrecht, and National Renewable Energy Laboratory, "Building America House Simulation Protocols." US Department of Energy, Sep-2010.

[112] US Department of Energy, "Building America Analysis Spreadsheets," Energy.gov, 26-Jan2011. [Online]. Available: http://energy.gov/eere/buildings/building-america-analysisspreadsheets. [Accessed: 17-Sep-2014].

[113] EECA Energywise, "Running Cost Calculator | EECA Energywise," 2014. [Online]. Available: http://www.energywise.govt.nz/ratings-and-labels/running-costs-calculator. [Accessed: 14-Nov-2014].

[114] Rheem, "Electric Water Heaters (Hot Water Cylinders) - Model: 312250," 2014. [Online]. Available: http://www.rheem.co.nz/hot-water-cylinders/product/312250/. [Accessed: 11Nov-2014].

[115] M. Heinrich, "Getting a handle on water use in Auckland homes," BUILD, no. 110, pp. 6667, Mar-2009.

[116] Whirlpool, "Average hot water temp - Home," Whirlpool, Jul-2012. [Online]. Available: http://forums.whirlpool.net.au/archive/1952143. [Accessed: 11-Nov-2014].

[117] S. Cory, "An Exploration of the Feasibility of Converting the New Zealand Commercial Building Stock to be Net Zero Energy," Victoria University of Wellington, Wellington, 2015.

[118] S. McNeil, L. Quaglia, M. Bassett, G. Overton, M. Plagmann, M. Cunningham, S. Upton, M. Boulic, I. Smith, T. Bishop, and others, "A survey of airtightness and ventilation rates in post 1994 NZ homes," in AIVC 33rd conference: optimising ventilative cooling and airtightness for [nearly] zero-energy buildings, IAQ and comfort, 2012.

[119] J. Kneifel, "Prototype Residential Building Designs for Energy and Sustainability Assessment," National Institute of Standards and Technology, Gaithersburg, MD, NIST TN 1765, Oct. 2012.

[120] M. Bassett, Infiltration and leakage paths in single family houses: A multizone infiltration case study. Coventry (GB): Air Infiltration and Ventilation Centre, 1990.

[121] L. Quaglia and S. McNeil, "Changing The Air Indoors," BUILD, no. 127, pp. 48-49, Dec-2011.

[122] A. Stoecklein, "Construction R-value Calculator," Design Navigator. [Online]. Available: http://www.designnavigator.co.nz/CRC.php. [Accessed: 02-Feb-2015].

[123] F. Nicol, M. Humphreys, and S. Roaf, Adaptive Thermal Comfort: Principles and Practice. Routledge, 2012.

[124] J. L. M. Hensen, "Literature review on thermal comfort in transient conditions," Building and Environment, vol. 25, no. 4, pp. 309-316, 1990.

[125] "Alpha 134: The Energy we Use in New Zealand Homes," The Royal Society of New Zealand. [Online]. Available: http://assets.royalsociety.org.nz/media/publications-teaching-alpha134.pdf. [Accessed: 04-Dec-2014].

[126] L. Easton, "Papakowhai renovations offer insights," BUILD, no. 141, pp. 64-65, May 2009.

[127] "Products | Econo-Heat New Zealand | English." [Online]. Available: http://econoheat.com/nz/products-2/. [Accessed: 01-Mar-2015]. 
[128] "Energy Star Heat pump | EECA Energywise." [Online]. Available:

http://www.energywise.govt.nz/energy-star/heat-pump. [Accessed: 01-Mar-2015].

[129] G. Tims, D. Molloy, and Building Research Association of New Zealand, House insulation guide. Porirua, N.Z.: BRANZ, 2007.

[130] Centre for Advanced Engineering, Energy efficiency: a guide to current and emerging technologies. Christchurch, N.Z.: Centre for Advanced Engineering, University of Canterbury, 1996.

[131] I. Page and BRANZ, "Energy Saver Fund Second Stage - Details of Energy Savings." EECA, Apr-1996.

[132] PinkBatts, "Hot-water-cylinder-wrap.pdf." [Online]. Available: http://www.pinkbatts.co.nz/assets/DataSheets/Hot-water-cylinder-wrap.pdf. [Accessed: 19-Mar-2015].

[133] BRANZ, "How space heating improves energy efficiency in New Zealand homes," 13-Apr2015. [Online]. Available: http://www.level.org.nz/energy/space-heating/. [Accessed: 14Apr-2015].

[134] Beacon, K. Saville-Smith, R. Fraser, N. Buckett, and M. Camilleri, "HomeSmart Renovations: Householder Actions and Responses to Dwelling Performance," HR2420/13, Jun. 2010.

[135] World Health Organisation, "DAMP AND MOULD: Health risks, prevention and remedial actions," 2009. [Online]. Available:

http://www.euro.who.int/_data/assets/pdf_file/0003/78636/Damp_Mould_Brochure.pd f. [Accessed: 14-Apr-2015].

[136] D. Ormandy and V. Ezratty, "Health and thermal comfort: From WHO guidance to housing strategies," Energy Policy, vol. 49, pp. 116-121, Oct. 2012.

[137] World Health Organisation, "Public health advice on preventing the effects of heat," 2011. [Online]. Available:

http://www.euro.who.int/_data/assets/pdf_file/0007/147265/Heat_information_sheet.p df. [Accessed: 15-Apr-2015].

[138] L. French, "Design and Construction Features which cause New Houses in New Zealand to Overheat: A thesis submitted to Victoria University of Wellington," Victoria University of Wellington, 2008.

[139] EECA, "Heating your home | EECA Energywise." [Online]. Available: http://www.energywise.govt.nz/your-home/heating-and-cooling/heating. [Accessed: 02May-2015].

[140] Consumer, "Home energy costs," Consumer NZ. [Online]. Available: http://www.consumer.org.nz/topics/home-energy-costs. [Accessed: 06-Apr-2015].

[141] Statistics New Zealand, "Household economic tables," 18-May-2015. [Online]. Available: http://www.stats.govt.nz/tools_and_services/nzdotstat/tables-by-subject/householdeconomic-tables.aspx. [Accessed: 18-May-2015].

[142] MSD, "Community Services Card." MSD.

[143] Ministry of Business, Innovation and Employment, "Sales-based Electricity Costs," Dec2014. [Online]. Available: http://www.med.govt.nz/sectors-industries/energy/energymodelling/data/prices/electricity-prices/sales-based-residential-prices.pdf. [Accessed: 07Apr-2015].

[144] Ministry of Economic Development, "Electricity cost and price monitoring | Ministry of Economic Development." [Online]. Available: http://www.med.govt.nz/sectorsindustries/energy/energy-modelling/data/prices/electricity-prices. [Accessed: 02-May2015].

[145] "Call for action on squalid houses | Radio New Zealand News." [Online]. Available: http://www.radionz.co.nz/news/top/271979/call-for-action-on-squalid-houses. [Accessed: 17-May-2015].

[146] Ministry of Social Development, "Fuel Poverty in New Zealand." MSD, Mar-2006. 


\section{APPENDIX}

\section{Auckland Graphs}

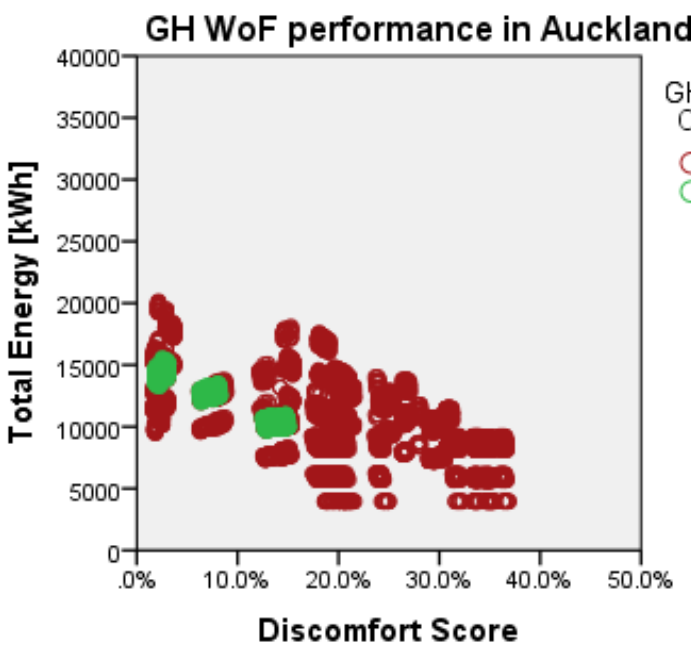

FIGURE 57: GH WOF PERFORMANCE IN AUCKLAND

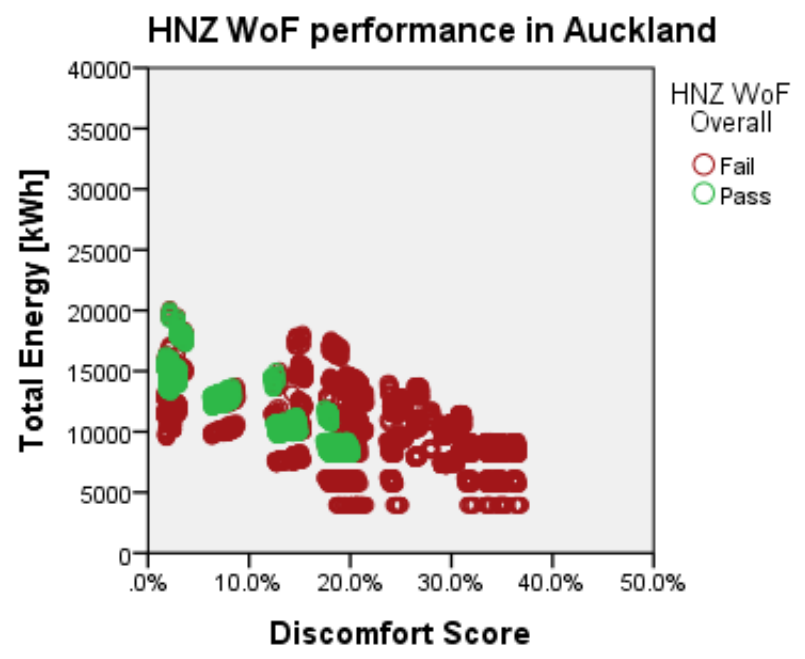

FIGURE 58: HNZ WOF PERFORMANCE IN AUCKLAND

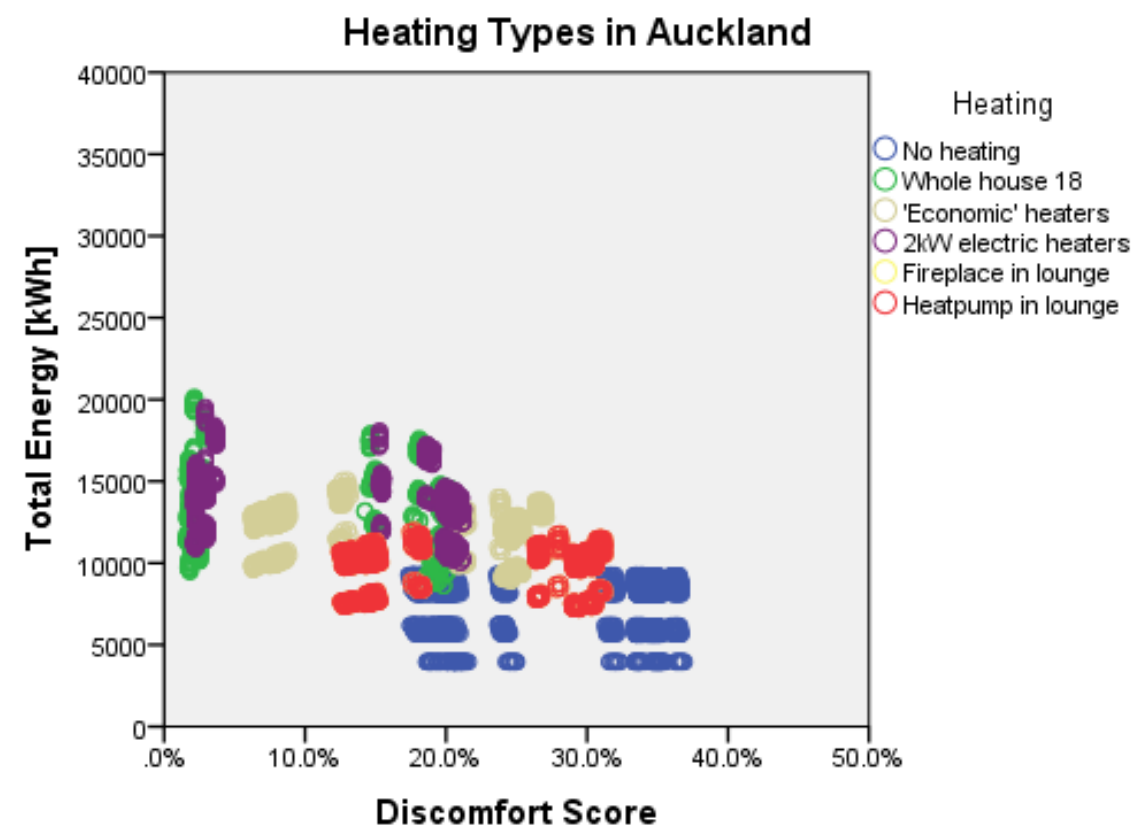

Figure 59: HeAting Types In AuCKLAND 


\section{Wellington Graphs}

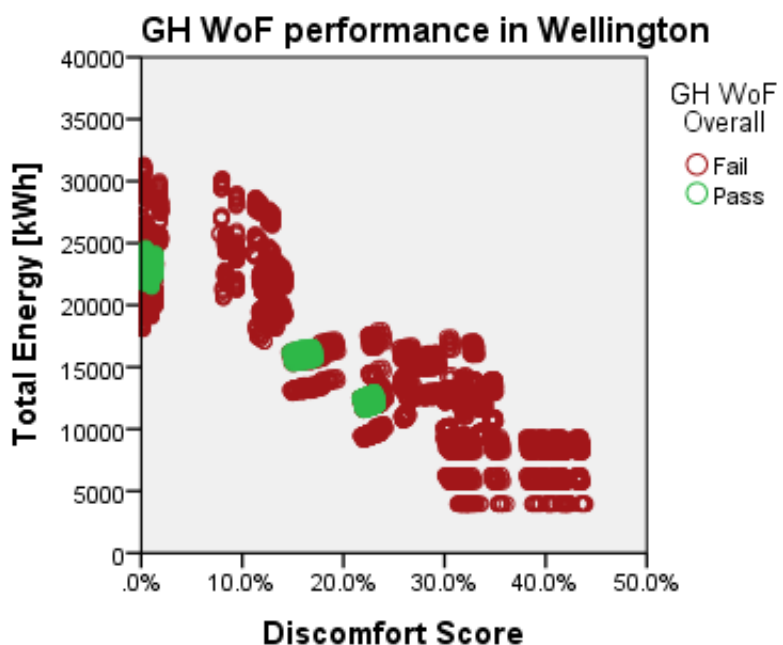

FIGURE 60: GH WOF PERFORMANCE IN WELLINGTON

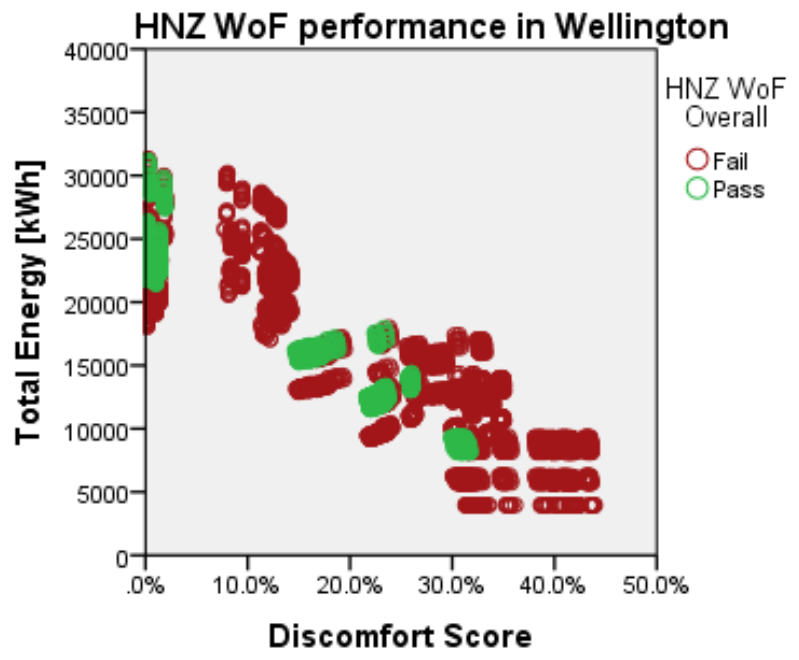

FIgURE 61: HNZ WOF PERFORMANCE IN WELLINGTON

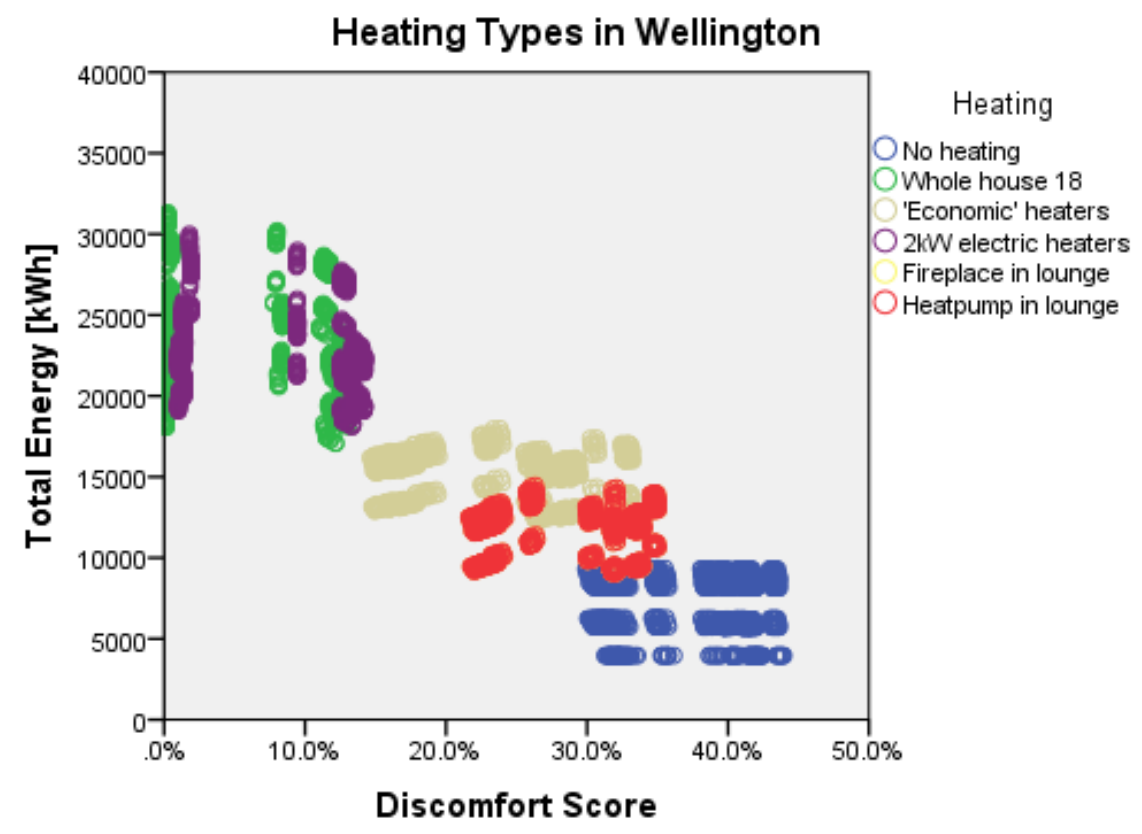

Figure 62: HEATING TYPES IN WELLINGTON 


\section{Dunedin Graphs}

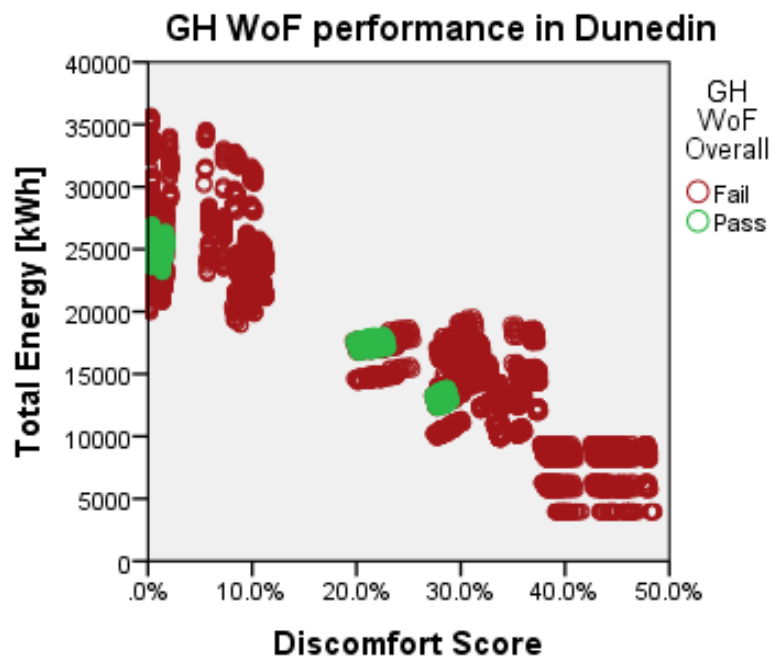

FIGURE 63: GH WOF PERFORMANCE IN DUNEDIN

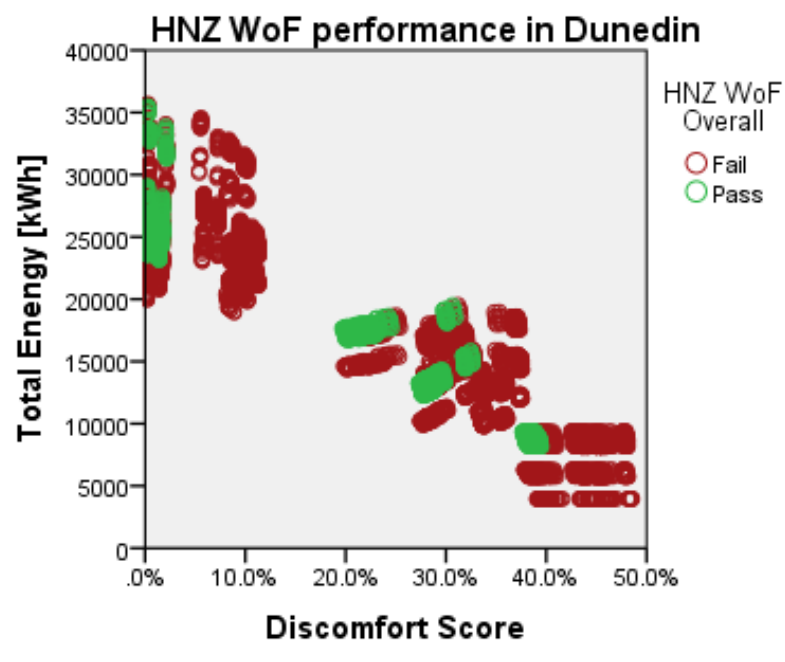

FIGURE 64: HNZ WOF PERFORMANCE IN DUNEDIN

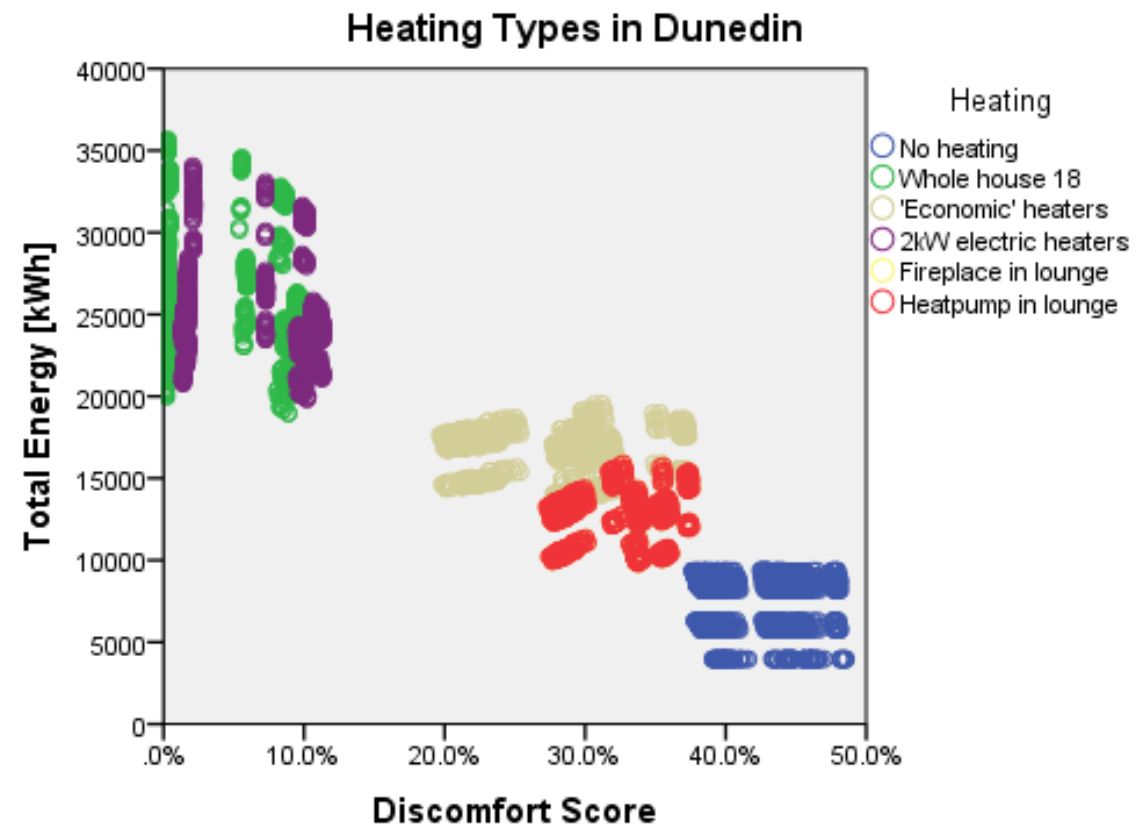

FigURE 65: HEATING TYPES IN DUNEDIN 


\section{Endnotes}

Lessons from using EnergyPlus that may be of interest to other researchers.

\footnotetext{
'The file name is MoistureMaterials.idf

ii The thermal performance of timber framing (joists, rafters and studs and dwangs) has been assumed to be negligible when not accompanied by insulation. This is because $80 \%$ of the surface is only insulated by a still air layer (which EnergyPlus accounts for when not inside a cavity) so thermal bridging will render the insulating effect of timber framing insignificant. Thermal bridging through the timber framing is accounted for in the composite R-value for insulated floors and ceilings.

iii Initially the EnergyPlus model produced inaccurate results for the water consumption. The problem was that for schedules at a finer resolution than the overall time step specified in EnergyPlus (for example accurate to the nearest minute), the command "Interpolate: Yes" must be entered before a compact schedule to ensure EnergyPlus calculates consumption correctly.

iv The option to set the number of files being simulated at one time is hidden in the EP-Launch window.

It can be found under View-Options-Command window-Number of simultaneous processes.

Significantly reduced calculation times were gained by going above the suggested maximum of 4 simultaneous files with no evident drawbacks. However the computers were only being used to run EnergyPlus simulations, this may not be a viable strategy if the computer is being used for multiple tasks

${ }^{\vee}$ This option can be found under OutputControl:Table:Style Column Separator (comma) in the IDF Editor. The default here is HTML

vi Analysing such a large number of files provided unique opportunities for trouble-shooting. Small errors which could be missed in one or two files became apparent when the issue occurred hundreds or thousands of times.
} 